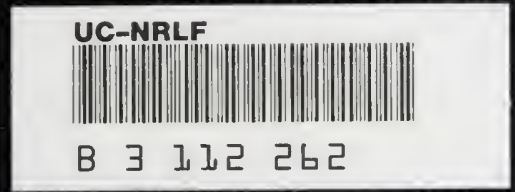


WIVEREITY OF CA _IF ORINIA

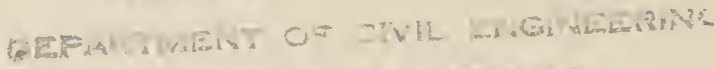
FEA

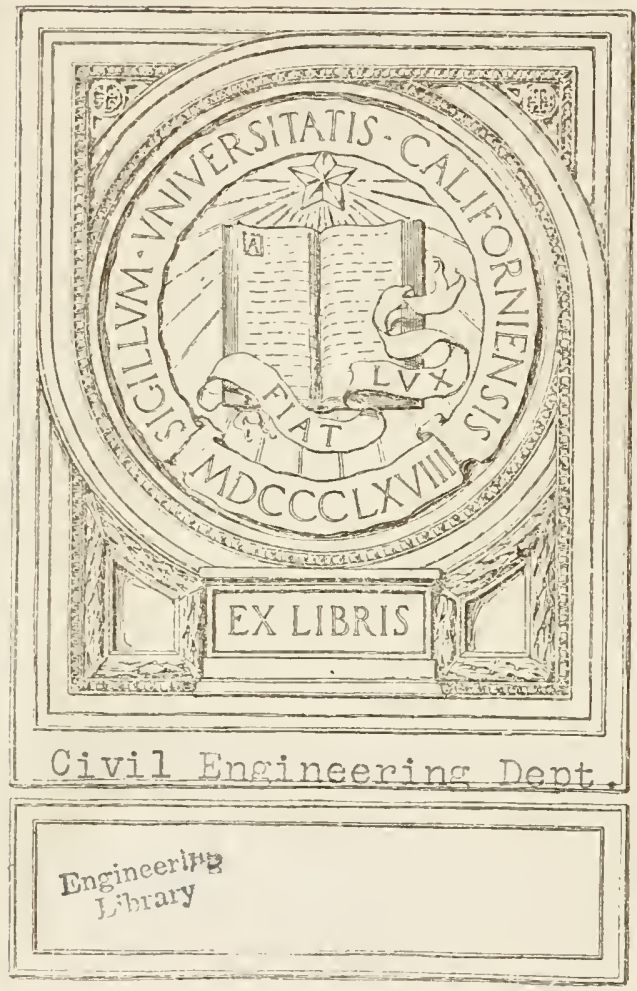




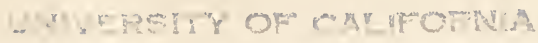

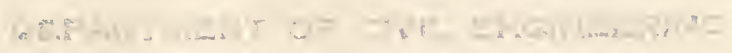

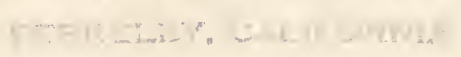




Digitized by the Internet Archive in 2008 with funding from Microsoft Corporation 
MOSQUITO ERADICATION 


\section{Me Grawe- Fill Book Co, The}

Electrical World $\nabla$ Engineering News-Record Power $\nabla$ Engineering and Mining Journal-Press Chemical and Metallurgical Engineering Electric Railway Journal $\nabla$ Coal Age American Machinist $\nabla$ Ingenieria Internacional Electrical Merchandising $\nabla$ BusTransportation Journal of Electricity and Western Industry Industrial Engineer 


\title{
MOSQUITO ERADICATION
}

\author{
$\mathrm{BY}$ \\ W. E. HARDENBURG \\ SaNitaRY ENGINEER \\ CERTIFIED MEMBER, AMERICAN Association OF ENGINEERS
}

First Edition

MCGRAW-HILL BOOK COMPANY, INC. NEW YORK: 370 SEVENTH AVENUE LONDON: $6 \& 8$ BOUVERIE ST., E. C. 4 1922 
Engineering Library

Copyright, 1922, by the

McGraw-Hill Book Company, Inc.

Civil Engineering Dept.

THE MAPLE PRESS - YORK PA 


\section{PREFACE}

Along with the marked increase in public appreciation of preventive medicine, that has developed in recent years in the United States, has come a recognition of the great importance of mosquito eradication, particularly in the South. This has manifested itself in the launching of anti-mosquito campaigns in cities, towns and villages in every Southern State, and it is a foregone conclusion that the success of these will spur other communities on to action.

Abroad, too, the menace of the mosquito-borne diseases is being recognized. In the tropical and sub-tropical areas of Latin-America, the International Health Board of the Rockefeller Foundation has done, and is doing, very valuable work. Many American corporations employing labor in those regions have found that it pays to protect their labor, and are doing so. Furthermore, the governments of many of the Latin-American countries are awakening to the heavy toll of the mosquitoborne discases, and are taking steps to eradicate them.

The same may be said of many regions in Europe, Asia and Africa. Anti-mosquito work now is being carried on to a greater or lesser extent in Italy, Spain and several of the Balkan countries; in Mesopotamia, India, Ceylon, the Malay Peninsula and many Pacific islands; in East and West Africa, Madagasear and various other political subdivisions.

This means that, in the aggregate, an enormous volume of anti-mosquito work is being done today. And, as the fruits of this work become better known and appreciated, it will increase many fold in all the above-mentioned countries. Furthermore, as other territories, that are today undeveloped, awake, more anti-mosquito work will have to be done, if man is to exploit their resources efficiently.

This vast volume of work, both present and prospective, renders it incumbent that only the best methods should be employed. While many persons may have a general idea as to the procedure in mosquito eradication, this is not sufficient for the 
men in charge of the work. They must know what methods are best adapted to the particular problem they have in hand, or, in other words, what is the cheapest way of accomplishing the desired result. In anti-mosquito work, as in other branches of engineering, the goal should be to get the best results for the money available. If the cost of eradicating mosquitoes is to amount to as much as the toll of the mosquito-borne diseases, but little is gained.

Although the importance of this matter is self-evident, there seems to be an amazing paucity of books on mosquito control. When the writer started in at anti-mosquito work, about the only material he could find on the subject was stray references to it in medical works, various pamphlets published by Federal and State health and agricultural organizations and LePrince and Orenstein's valuable volume. "Mosquito Control in Panama," which, however, deals with work under somewhat exceptional conditions.

So far as the writer knows, this situation still obtains. Asked repeatedly for the name of some text-book on mosquito control, he has been unable to mention any one book, with the exception of LePrince and Orenstein's, that deals adequately with the subject. It is with a view to supply this deficiency that he has prepared the present volume.

A conscientious effort has been made to outline the best practice, both in the United States and abroad. It has been the special aim of the writer to be concise, so as to avoid making the volume too bulky, but to omit nothing of value.

The writer takes pleasure in acknowledging here the kindness of Dr. Harrison G. Dyar, Director of the U. S. National Muscum, in revising part of the chapter on mosquitoes; of S. F. Hildebrand, Ichthyologist, in revising the chapter on fish control; and of W. A. Hardenbergh, Sanitary Engineer, in making many valuable suggestions regarding the book. Credit is given writers, from whose works extracts have been used, throughout the volume.

W. E. Hardenburg.

San Diego, Calif., June, 1922. 


\section{CONTENTS}

Preface

CHAPTER 1.-The Toll of the Mosquito

Discases spread by the mosquito-Transmission of malariaCharacteristies of malaria-Distribution of malaria-Mortality and morbidity of malaria-Economic significance of malariaMalaria as a labor problem-Transmission of yellow feverMortality and morbidity-Yellow fever versus malaria controlDengue-Filariasis-Economic significance of yellow fever, dengue and filariasis-The mosquito as an annoyance; effects upon heatth - The mosquito as an annoyance; economic significance-Increasing property values.

CHAPTER 2. - Some Disease-bearing American Mosquitoes

The mosquito in general-Life-history of the mosquito-Variations in eggs, larvae and pupae-Why mosquitoes bite-Identifica-

$L$ tion of mosquitoes-Anatomy of the mosquito-Anatomy of the larvae-The Anophelinao-Identification of the AnophelinaeA. quadrimaculatus say-A. crucians Wied.-A. punctipennis Say-A. occilentalis D. \& K.-The Culicinae-Aedes calopus Neig -Culex fatigans Wied..--Some common troublesome mosquitoesHouse group-Fresh-water sylvan group_- Salt marsh group.

CHAPTER 3.-Development of Control Meastres

Historical aspects-Beginning of mosquito control-Sanitury conquest of the Canal Zone-Anti-mosquito work elsewhereMalaria control in U.S.--Interpreting results-Early U. S. malaria control demonstrations-Demonstration at Electric Mills, Miss.Co-operative demonstration at Crossett, Ark.-Work of st. Louis \& Southwestern Railroad-U. S. Anti-mosquito work during world war-13 war-project areas protected-Post-war mosquito control-The situation today-Change in public viewpoint-Growth of appreciation-Eradication cheaper than enduring malaria-Some typical campaign costs.

CHAPTER 4.-Initiating the Campaign.

Need for statistics-Collection of statisties-The survey- What to observe-The estimate of cost-Questions of policy-suggested policy toward property-owners-Raising funds-Handling the funds-Obtaining co-operation-Other possible sources of aidPlanning the work-Personnel-Naterials and equipment.

CHAPTER 5.-Adinsistratrye Aspects of the Campaign. . . .

Mosquito-breeding about homes-Planning the inspection system -Handling the negligent citizen-Complaint bureau-Publicityvii 
Texts for articles-Other methods of obtaining co-operationDaily reports-Records-Maps.

CHAPTER 6.-Inland Drainage

Importance of drainage as an anti-mosquito measure-Limitations of drainage-Preliminary work-Types of inland drainage problems-Problem of pond, lake and swamp drainage-Treatment of seepage outcrops-Drying up a swamp-Ditch construction in general-Hand ditching on firm ground-Cost of ordinary hand ditehing-Hand ditching in swamps-Blasting ditches in swamps-Making trial shots-Cleaning out the ditch-Ad-

- vantages of blasting ditches-Machine ditching-Some typical open-ditehing machines-Maintenance of open ditches-The weed burner-Maintenance costs-Permanent lining of anti-mosquito ditches-Sub-surface tile drains-Tile drains versus open ditehes -Laying out a tile drainage system-Placing the tile-Tile drainage costs-Vertical drainage-Typieal vertical drainage operation-Vertical drainage for large areas-Stream re-chaneling-Blasting new channels-Clearing streams of logs, etc.Filling.

Chapter 7. - Salt Marsh Drainage.

The salt marsh problem in general-Agricultural versus anti-mosquito drainage of salt marshes-Design of salt marsh ditehes-Salt marsh ditching by hand-Machine ditching-Filling-Diking and tide-gating in general-Constructing the dike-The tide-gate and sluice-box-Construction of sluices-Gate construction-specifications for large sluiees-Installation-Other types of tide-gates - The Calco gate-Operation of tide-gates-Salt marsh shrinkage -Pumping.

CHAPTER 8.-OILING .

Place of oiling in anti-mosquito work-Where oiling is applicableApplying the oil-Kind of oil required-Larvieides-The Panama larvicide-Other larvicidal substances - The sprayer-Drip-cansUse of drip-cans-Other methods of applying oil-Frequency of oiling-Distribution of oil-Storage of oil-Costs of oiling.

CHAPTER 9,-Fish Control.

Advantages and limitations-How fish destroy larvae-The top minnow (Gambusia affinis) - The barred killifish (Fundulus heteroclitus)-The striped killifish (Fundulus majalis)-The fresh-water killy (Fundulus diaphanous) - The variegated minnow (Cyprinodon variegatus) - The rain-water fish (Lucania parvia)-The spotted top minnow (Fundulus notatus) - The star-headed minnow (Fundulus notii)-Other fishes-Procedure in fish control-Number of fish required-Distributing the fish-Necessity of aiding the fish-Plants in relation to fish control-Eliminating larva-protecting plants-The sub-aqueous saw-Using the saw.

CHAPTER 10.-SCREENING.

Place of sereening in anti-mosquito work-Rarity of good sereen- 
ing-Essentials of good screening-screening of doors-Fome general rules-Screening of windows-screening of porchesScreening of chimneys and fire-places-The life of a screenScreening near the sea-side-Conducting a screening campaignValue of screening-Cost of sereening-Does screening pay?

CHAPter 11.-Other Measures axd Expedients axd Points

Requiring INTESTIGation. . . . . . . . . . . . . . . Scope of this chapter-Auxiliary methods and expedients in general-Direct exterminative measures-The bat as a destroyer of adult mosquitoes-Other animal foes of the mosquitoDestruction of mosquitoes in dwellings-Harassing the mosquito -Further protective measures-Lise of animals as a protection against mosquitoes-Application of substances repellent to mosquitoes-Use of quinine for malaria-Demonstrations of the value of mass treatment by quinine-Quinine rersus anti-mosquito measures-Points that require further investigation.

CHAPTER 12.-Rural Mosevito axd Malaria Control

Unfavorable factors in rural control-Favorable factors in rural control-Need for a survey-Control measures ahout the arerage home-Further measures-Protecting homes in swamps, etc.The rice-field problem-The rice-field problem abroad-Community measures in rural areas-Rural community protective demonstrations.

appendix A.-Table to Determine Species of Certain Commox Anericax Mosquitoes . . . . . . . . . . . . 228

APPENDiX B.-Approned Anti-mosquito Ordinance. . . . . . 233 APPENDIX C.-Sicgaested ANTI-Mosqeito Leaflet for CAMPAigN Educatioxal Work . . . . . . . . . . . 235 APPENDIX D.-BibllograPhY. . . . . . . . . . . . 235 INDEX. . . . . . . . . . . . . 241 



\title{
MOSQUITO ERADICATION
}

\author{
CHAPTER I \\ THE TOLL OF THE MOSQUITO
}

\section{DISEASES SPREAD BY THE MOSQUITO}

While much has been accomplished in recent years in diffusing information as to the preventability of the mosquito-borne diseases, it is very doubtful if the public yet has an adequate idea of the mortality, suffering and loss they occasion and of the general feasibility and direct ceonomic advantage of mosquito eradication.

The toll of the mosquito may be regarded from three aspectsfirst, the annoyance, suffering and death caused by the diseases it transmits; second, the economic loss resulting from these diseases in expenditures for medieal aid, nursing and medicines and in loss of time and productive energy; and, third, the eeonomic loss it oceasions by holding back development of, and depressing property values in, seetions where it abounds.

Apart from the discomfort and vexation it causes, the mosquito is the transmitting agent of no fewer than four distinct diseasesmalaria, yellow fever, dengue and filariasis. Of these, malaria and yellow fever are of the very first importance.

\section{TRANSMISSION OF MALARIA}

Malaria is caused by three separate blood parasites or hematocytozoa, Plasmodium malariae (Laveran), Plasmodium vivax. (Grassi and Filetti) and Plasmodium falciparum (Weleh). These produce respectively quartan, tertian and estivo-autumual or tropical malaria, all having the same ctiology and mode of transference, despite well-defined clinical differences.

It is now well established that malaria is transmitted in mature only by the bite of the Anopheles mosquito, this mosquito being the only animal, other than man, which earries the malaria parasites. The mosquito is the definitive host and man the intermediary host, both being necessary to complete the life cycle of the parasite, which is as follows. 
When man is infected, a non-sexual cycle, known as schizogony, begins, which takes from 48 to 72 hours. The sporozoite bores into a red cell, becomes round, increases in size and finally divides into a number of sporozoites, each of which repeats this process.

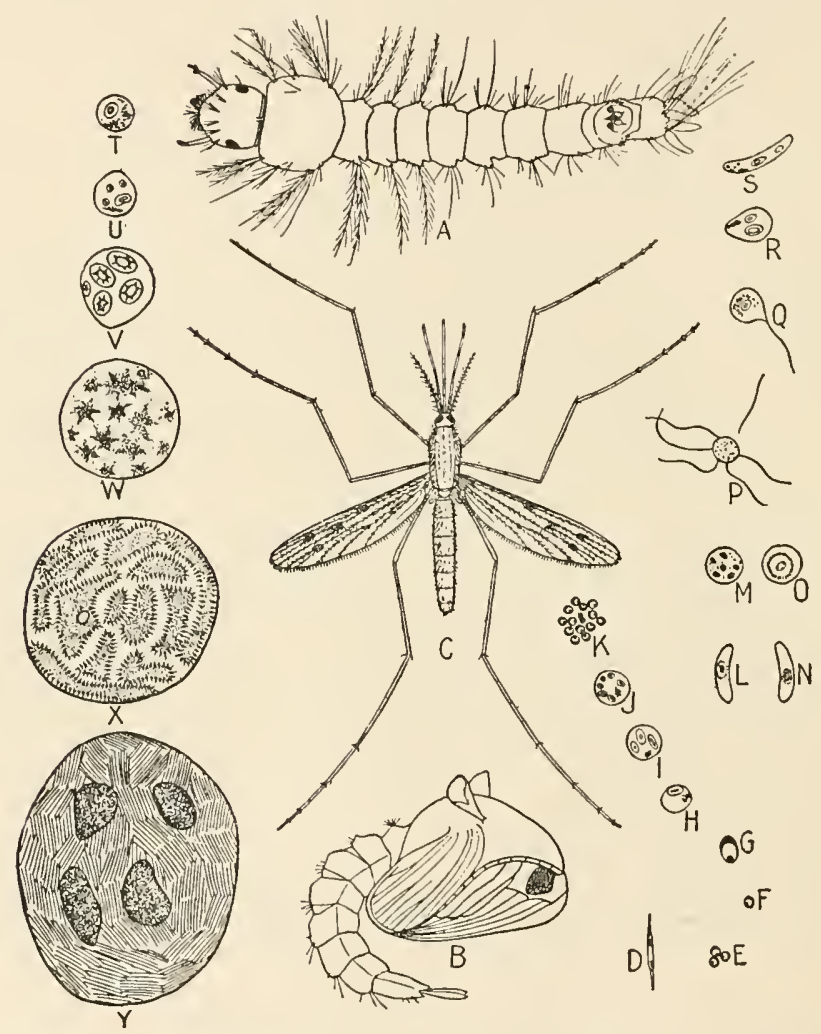

FIG, 1. - The malaria parasite and its life cycle. (After John B. Smith, New Jersey Agricultural Experiment Stations.)

Anopheles Mosquito and Malaria: A, larva; B, pupa; C, adult; D, the blast introduced into the blood by the mosquito; $\mathrm{E}$ to $\mathrm{J}$, stages through which the plasmodium passes in the red blood corpuseles; $K$, the spores, which enter new blood eorpuscles; $\mathrm{L}, \mathrm{M}$, the microgamete; $\mathrm{N}$, $\mathrm{O}$, the maerogamete; $\mathrm{P}$, fiagellae forming; $\mathrm{V}$, union of a flagellum with a maerogamete; $\mathrm{R}$, fusion of nuclei; $\mathrm{S}$, the vermicule; T to Y, furmation of the zygote in the stomach of the mosquito, the fully developerl zygote, Y, rupturing to produce blasts.

In about 2 weeks, the sporozoites become so numerous that the toxin liberated at each division is sufficient to cause chills. Eventually, sexual forms appear, the females being known as macrogametes and the males as microgametocytes. When the 


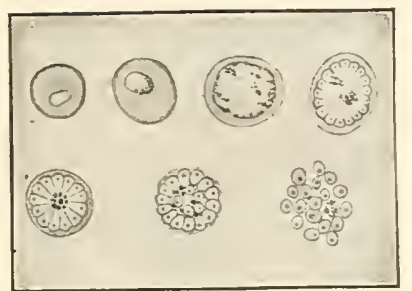

Fig. 2.- Parasites of tertian malaria. (After Thayer and Hevetson.)

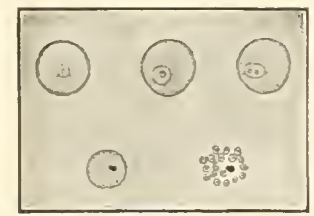

Fig. 3.-Parasites of estivoautumnal malaria. (After Thayer and Hewetson.)

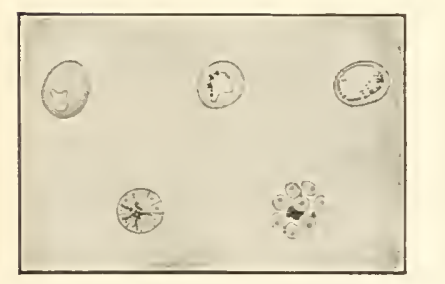

Fig. 4.- Parasites of quartan malaria. (After Thayer and Hewetson).

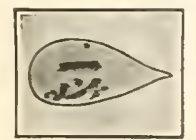

FIG. 5.-Fertilized female mal a ria parasite (zygote). (After Craig.)

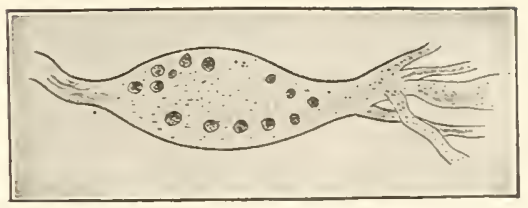

Fig. 6. - Stomach of mosquito with oöcysts. (After Craig.)

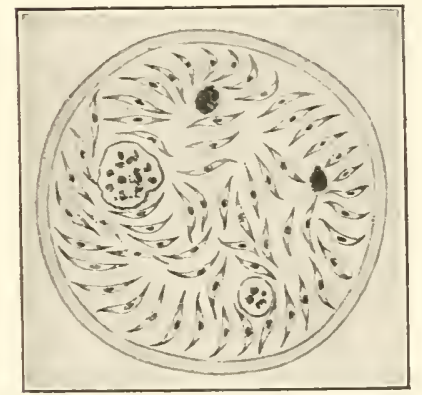

Fig. 7.-Sporozoites in oöcyst. (After Craig.)

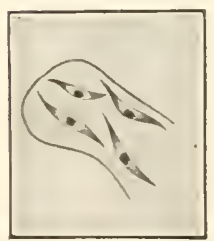

FIG. S.-Sporozoites (After Craig.) 
mosquito bites a person, these forms enter its stomach, where they combine to form zygotes. The zygotes divide into sporozoites, which finally appear in the salivary glands of the Anopheles. From here they enter the blood of the person bitten by the mosquito and start again on the non-sexual cycle.

\section{CHARACTERISTICS OF MALARIA}

It is noteworthy that it requires about 12 days after entering the body of the mosquito before the sporozoites appear in its salivary glands. This means that the mosquito cannot transmit malaria until 12 days after it has bitten a malaria patient. The parasite does not seem to injure the mosquito, which may live many weeks and infect several persons successively. A mean temperature of less than $60^{\circ} \mathrm{F}$. inhibits development of the parasite in the mosquito.

"A person who once has had malaria," says Rosenau, " is more apt to have subsequent attacks. Ordinarily there is an increased susceptibility rather than an immunity. However, repeated infections, especially during early life, leave a very pronounced resistance. In malarious regions many children carry the parasites in their circulating blood without any manifestations of the disease. These carriers are important factors.in spreading the infection in endemic areas, and must be taken into account in preventive measures.

"There is no true racial immunity in this disease. Occasionally a congenital immunity seems to be transmitted; this must be rare. Practically all persons who receive the infection for the first time are susceptible. The freedom from malaria which some persons seem to enjoy may be accounted for partly by the fact that mosquitoes seldom bite such persons. It is well known that on account of the odors, or what not, mosquitoes do not bother certain individuals. No doubt the infection of a small number of parasites is of ten overcome largely through a vigorous phagocytosis.

"Individual resistance varies in different individuals and in the same individual at different times. The parasite may remain latent in the spleen and other organs for years. Exposure, over-eating, fasting, overwork, or worry, or anything that lowers the vitality of such individuals predisposes to an attack of malaria. The disease often breaks out in persons in good health leaving a malarial region for a health resort, whether mountain or seashore."

1 "Preventive Medicine and Hygiene," New York and London, 1918. 


\section{DISTRIBUTION OF MALARIA}

Trask $^{1}$ sums up the distribution of malaria in the United States as follows:

"In the territory extending from the Culf of Mexico to a line north of the Ohio River and from the Atlantic seaboard to and into the eastern part of Kansas, Oklahoma and Texas, few, if any, localities are entirely free from malaria. In most of the lowlands it is very prevalent; in the mountains and better drained areas less prevalent.

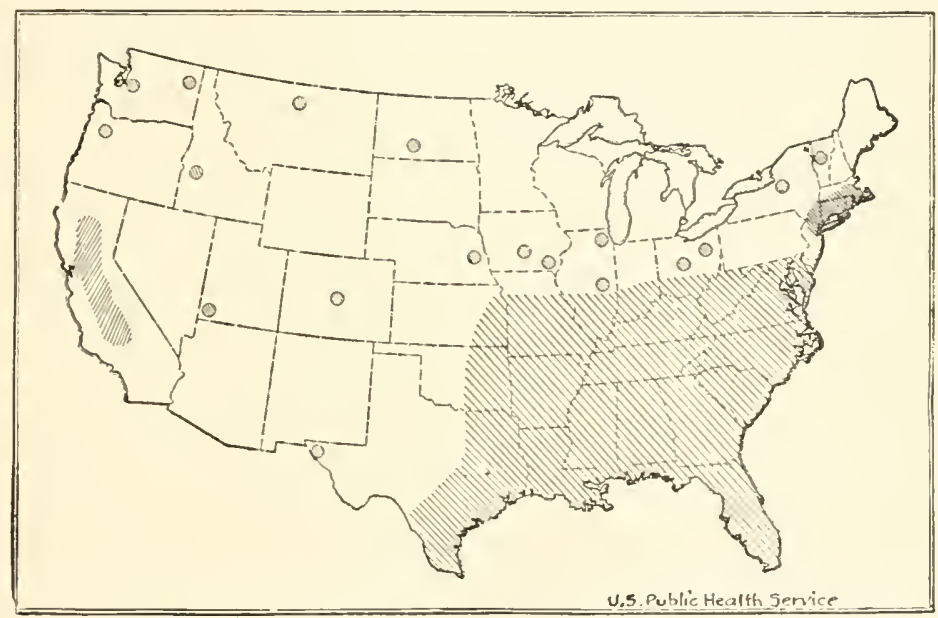

Fig. 9.-Endemic areas of malaria in the United States. Shaded portions of map show endemic areas. Shaded circles represent localities in which cases of malaria occur and in which the disease is probably endemic. (After Trask.)

"The disease is also endemic in southeastern New York and parts of Connecticut, Rhode Island and Massachusetts, and in California in the Sacramento and San Joaquin valleys.

"There is probably no state in the Union in which the disease is not $c$ present and in which it is not spread by mosquitoes grown locally.

"The disease constitutes one of the big national health probtems. It is also an economic problem of importance."

Elsewhere, malaria is found in nearly every country, its incidence increasing, as a rule, with proximity to the Equator.

1 "Malaria, A Public Health and Ecoromic Problem in the United States," U. S. Public Health service, 1917. 


\section{MORTALITY AND MORBIDITY OF MALARIA}

Sir Ronald Ross, discoverer of the transmission of malaria by the mosquito, says:

"Malarial fever is perhaps the most important of human diseases, and, though it is not often directly fatal, its wide prevalence in almost all warm climates produces in the aggregate an enormous amount of sickness and mortality."

"Malaria," says Leathers," "is the most prevalent disease in all semi-tropical and tropical countries. It is the most frequent cause of sickness and death in those parts of the world that are most densely populated. It is also the most prevalent disease in the United States, and at least two-thirds of the cases found in this country occur in the Southern States.

"Malaria is one of the greatest scourges inflicted upon humanity. It's a menace to any people or country in which it has a decided incirence. In the number of deaths caused either directly or indirectly the sickness and suffering, the loss of time and efficiency, the expense, the lowered vitality of those afflicted and in the reduction of the valuation of property, malaria is without a rival among the diseases afflicting mankind.

"A careful investigation shows that about 15,000 people die directly from malaria each year in the United States. This does not take into consideration the indirect effects of the disease and the consequent mortality assigned to other causes, which, in reality, malaria is responsible for in large measure. In addition to the mortality accruing from malaria, there are from $1,500,000$ to $3,000,000$ people in the United States sick from this disease annually."

Carter ${ }^{2}$ estimates the annual morbidity from malaria in the United States at 6,000,000 to 7,000,000.

Rose $^{3}$ estimates that in India malaria causes on the average each year about $1,130,000$ deaths and more than $100,000,000$ cases of illness.

Hoffman ${ }^{4}$ gives the mortality from malaria in certain other countries during designated periods as follows:

1 The Importance of Malaria from a Public Health and Economic Standpoint, Southern Medical Journal, August, 1918.

2 "The Malaria Problem of the South," U. S. Public Health Service, 1919.

${ }^{3}$ Field Experiments in Malaria Control, Journal, American Medical Association, Nov. 8, 1919.

" "A Plea and A Plan for The Eradication of Malaria," Prudential Insurance Company of America, 1917. 


\begin{tabular}{|c|c|c|c|c|}
\hline Country & Period & $\begin{array}{l}\text { Aggregate } \\
\text { population }\end{array}$ & Deaths & $\begin{array}{l}\text { Rate per } \\
100,000\end{array}$ \\
\hline Mauritius. & $1910-14$ & $1, \$ 42,561$ & 21,686 & $1,176.9$ \\
\hline Nicaragua....... & $190 s-11$ & $2,180,000$ & 15,859 & 727.5 \\
\hline British Honduras. . & $1914-15$ & $\$ 3,268$ & 491 & 589.7 \\
\hline Straits Settlements. & $1910-14$ & $3,596,554$ & $19, \mathrm{~S} 1 \mathrm{~S}$ & 551.0 \\
\hline British Guiana..... & $1911-15$ & $1,516,710$ & 6,385 & 421.0 \\
\hline Philippine Islands .... & $1909-13$ & $29,472,283$ & 117,139 & 397.5 \\
\hline Venezuela........... & $1908-12$ & $13,525,191$ & 41,331 & 305.6 \\
\hline Panama Canal Zone... & $1911-15$ & 677,792 & 949 & 140.0 \\
\hline Porto Rico........... & $1911-15$ & $4,675,044$ & 3,793 & $\$ 1.1$ \\
\hline Costa Rica......... & $1911-15$ & $1,999,545$ & 1,251 & 62.6 \\
\hline Ceylon............ & $1910-14$ & $20,817,228$ & 11,304 & 54.3 \\
\hline Cuba....... & $1910-14$ & $11,561,416$ & 2,535 & 21.9 \\
\hline Spain............ & $1906-10$ & $96,717,000$ & 10,930 & 11.3 \\
\hline Italy . . . . . . . . . & $1909-13$ & $173,356, \$ 85$ & 17,399 & 10.0 \\
\hline
\end{tabular}

\section{ECONOMIC SIGNIFICANCE OF MALARIA}

"It is not in the death-rate, however, that the gravest injury of malaria lies," declares Carter. ${ }^{1}$

"It is in its sick-rate; in the loss of efficiency it causes, rather than in the loss of life. One death from pneumonia should eorrespond to about 125 sick-days - work-days lost; one from typhoid fever to 400 to 500 sick-days; one from tuberculosis to somewhat more than this among whites, decidedly less among negroes. A death from malaria, however, corresponds to from 2,000 to 4,000 sick-days. This loss of efficiency may really be doubled or trebled, for the man infected with malaria is frequently half sick all the time.

"And it is the amount of malaria, when it is bad, which appalls. If 1 per cent of the population is stricken with typhoid fever, it is an epidemic, and a bad one. Contrast this with 40 per cent to 60 per cent of a population per annum affected with malaria, and I have seen outbreaks with 90 per cent, and you gain some idea of the importance of this disease. The loss of efficiency caused by malaria in the malarious section of the South is beyond comparison greater than that caused by any other disease, or even by any two or three diseases combined, including typhoid fever and tuberculosis.

"I am not speaking at random. You have never heard of the prevalence of typhoid determining the failure to locate industrial plants. Yet, at one place where power was abundant and very cheap, the manager told me that a number of options for cotton mills, wagon factories, etc.--options which had been taken because of the cheapness of the power-had been abandoned because of the prevalence of malaria.

${ }^{1}$ The Malaria Problem of the South," U. S. Public Health Service, 1919. 
Has the presence of tuberculosis ever prevented a real estate transaction? I know of a deal involving the purchase of large tract of land for colonization - a tract valued at about half a million dollars - not consummated on account of the prevalence of malaria in that section, and there was not much malaria either. You have not seen homes abandoned becanse of either tuberculosis or typhoid fever. I can assure you that I have seen them abandoned on account of malaria."

\section{MALARIA AS A LABOR PROBLEM}

"It is not going too far," says Hoffman, ${ }^{1}$ "to say that malaria - eradication is essentially a labor problem of the first importance; that an enormous amount of labor inefficiency due to malaria continues to hinder the progress of semi-tropical and tropical countries, which, if brought under control and completely done away with, must needs assist profoundly in the reclamation of the tropical regions for the practical needs of the world at large."

An interesting investigation of the losses occasioned by malaria in the cotton-growing section of Louisiana was made by Van Dine of the U.S. Department of Agriculture. The work involved a detailed study of the malaria morbidity among 74 tenant families, comprising 299 persons, men, women and children, on a typical plantation. There developed from May to October inclusive 166 cases of malaria in 138 persons, causing a total loss of time of 1,066 adult days or 6.42 adult days per case. This was equivalent to loss of the entire working time of 5.54 families. Reduetion of efficieney of the workers amounted to a loss of time of 9.25 families, making a total loss of time of 14.79 families. In other words, 60 families would have done the same amount of work, had there been no malaria, as 74 families did with malaria. Reduced to money, it was found that the actual loss of time amounted to $\$ 2,200$ and loss of efficiency to $\$ 4,300$, making a total financial loss due to malaria of $\$ 6,500$.

From these figures, it will be noted that a community of less than 300 persons could well have afforded to spend up to $\$ 5,000$ to $\$ 6,000$ in anti-mosquito work, while an investment of less than $\$ 3,500$ would have returned a dividend of 100 per cent.

\section{TRANSMISSION OF YELLOW FEVER}

Although the cause of yellow fever is not definitely known, the infective agent being apparently ultramicroscopic, the manner

1 "A Plea and A Plan for The Eradication of Malaria," Prudential Insurance Company of America, 1917. 
of transmission is well understood. It is now definitely established that the disease is conveyed in nature only through the bite of an infected female Aedes calopus mosquito.

It is believed that the mosquito becomes infected by biting persons suffering from yellow fever during the first 3 days of the fever, experiments indicating that the infective principle disappears from the blood after that period. The mosquito, however, is unable to transmit the discase until about 12 days after it has sucked the blood; from then on, it remains infected all its life and may communicate the disease to several persons successively.

So far as is known, man is the only animal subject to yellow fever, attempts to infect other animals having failed.

The fact that the mosquito can be infected only during the first 3 days of the discase is an important factor in prevention of yellow fever, since if the patient can be isolated from mosquitoes during this period, no mosquitoes will be infected and, hence, the disease cannot spread. Difficulty in cliagnosing yellow fever sometimes renders this impossible.

Although yellow fever has been a scourge for centuries, it was not until 1900 that the role of the mosquito in transmitting this dread plague was ascertained and the preventive measures, based thereon, developed. This epoch-making discovery was made by a board of American army medical officers. Previously, it had been believed that the infection was carried in clothing, by the air, ete.

\section{MORTALITY AND MORBIDITY}

Although yellow fever in the United States today is virtually eliminated, the terrible epidemies of former years in which panic reigned throughout the South are not yet forgotten. In South and Central America, the disease is still epidenic in many places, as well as in other parts of the world. But modern medical and engineering science is routing it all along the line.

The following compilation from the U.S. Public Health Service ${ }^{1}$ reports of cases occurring in various North, South and Central American countries during the fiscal years indicated, is admittedly incomplete and should be considered only as an indication of the areas in which the disease is more or less endemic:

${ }^{1}$ Annual Reports, U. S. Public Health Service, 1918, 1919, 1920 and 1921. 


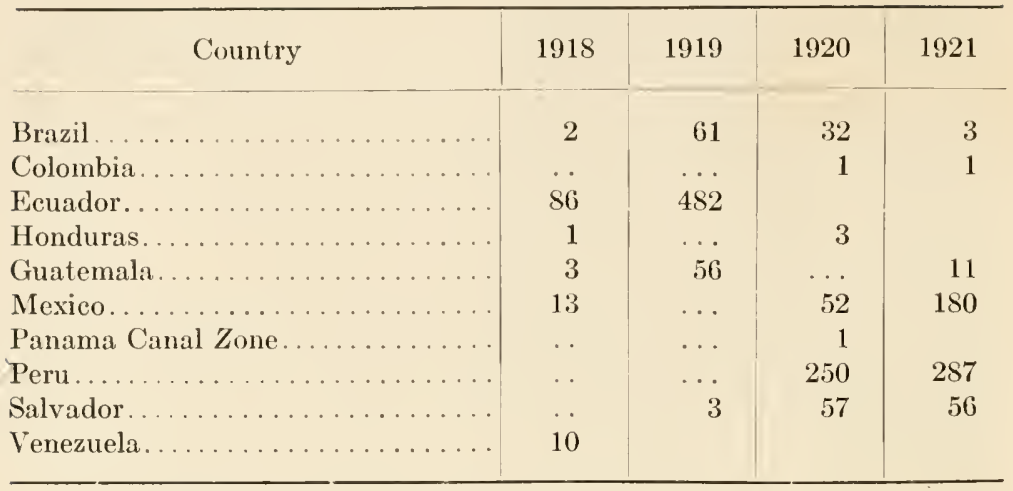

YELLOW FEVER VERSUS MALARIA CONTROL

While the same principles that apply to the prevention of malaria apply to the prevention of yellow fever, prevention of the latter is by far the easier. In the first place, the range of breeding places of Aedes calopus is much more restricted than that of the Anopheles. Again, the Anopheles mosquito flies much further than cloes Aedes calopus. Finally, yellow fever patients remain infective for only 3 days, while malaria patients earry the parasites sometimes for years.

It is due for the most part, probably, to the last factor mentioned that yellow fever has been so largely eradicated throughout the United States today, despite the fact that Aedes calopus is still one of the most widely distributed of the Southern mosquitoes. In other words, the chief reason why yellow fever is not still as prevalent in the South today as malaria is because there are no human earriers. When an infeeted person does enter the territory of Aedes calopus it is neeessary only to protect him from the mosquito for 3 days, and nobody else will be infeeted. With malaria, the case is far different; in almost every community there are human carriers, who-unless preventive work is undertaken-are bound to be bitten some time during the summer by Anopheles mosquitoes, and the Anopheles, of course, pass on the infection to other persons.

\section{DENGUE}

This disease frequently resembles yellow fever in its epidemiology and symptomatology, and, although few persons have ever died of it, the victim often is left in a more or less disabled condition for months. 
Dengue is believed to be transmitted by Culex fatigans, although the causative factor is as yet unknown. Graham ${ }^{1}$ described a protozoon which he believed caused the disease, but Ashburn and Craig ${ }^{2}$ assert that a filterable virus is responsible for it. They placed the period of incubation at 3 days and 14 hours.

Dengue somewhat resembles yellow fever in its rapid communicability, sometimes spreading with marvelous rapidity and infecting virtually every person within its vicinity. Unlike vellow fever, however, there is no definite immunity.

The prevalence of dengue in the United States and territories during the fiseal years 1918 and 1919 is reported by the U.S. Public Health Service as follows:

\begin{tabular}{|c|c|c|c|c|}
\hline \multirow{2}{*}{ States and territories } & \multicolumn{2}{|c|}{$191 \mathrm{~S}$} & \multicolumn{2}{|c|}{1919} \\
\hline & Cases & Deaths & Cases & Deaths \\
\hline Texas ............ & 24 & 9 & 127 & 4 \\
\hline Louisiana. . . . . . . . & 4 & . & $7 t$ & \\
\hline Colorado........ & 1 & & & \\
\hline California ....... & . & . & 1 & \\
\hline Florida......... & . & & 12 & \\
\hline Porto Rico............ & . & & 345 & \\
\hline Hawaii. . . . . . . . . & 5 & 4 & & \\
\hline
\end{tabular}

While cases of dengue in the United States are comparatively few, as indicated by the above table, it is eertain that in South and Central America and other tropieal and sub-tropical countries the morbidity from this disease reaches a not inconsiderable figure.

\section{FILARIASIS}

This discase consists of the infestation of the connective tissues, lymphaties and body eavities of man with larvae or adults of filaria, a long, slender threadworm with a curved tail. According to Rosenau, ${ }^{3}$ none of the young worms do any appreciable injury to the blood, while of the adult worms only one, Filaria

1 Journal of Tropical Medicine, vol. 6, 1903; quoted by Rosenat.

${ }^{2}$ Philippine Journal of Science, May 1, 1907; quoted by Rosexat.

3 "Preventive Medicine and Hygiene," New York and London, 1918. 


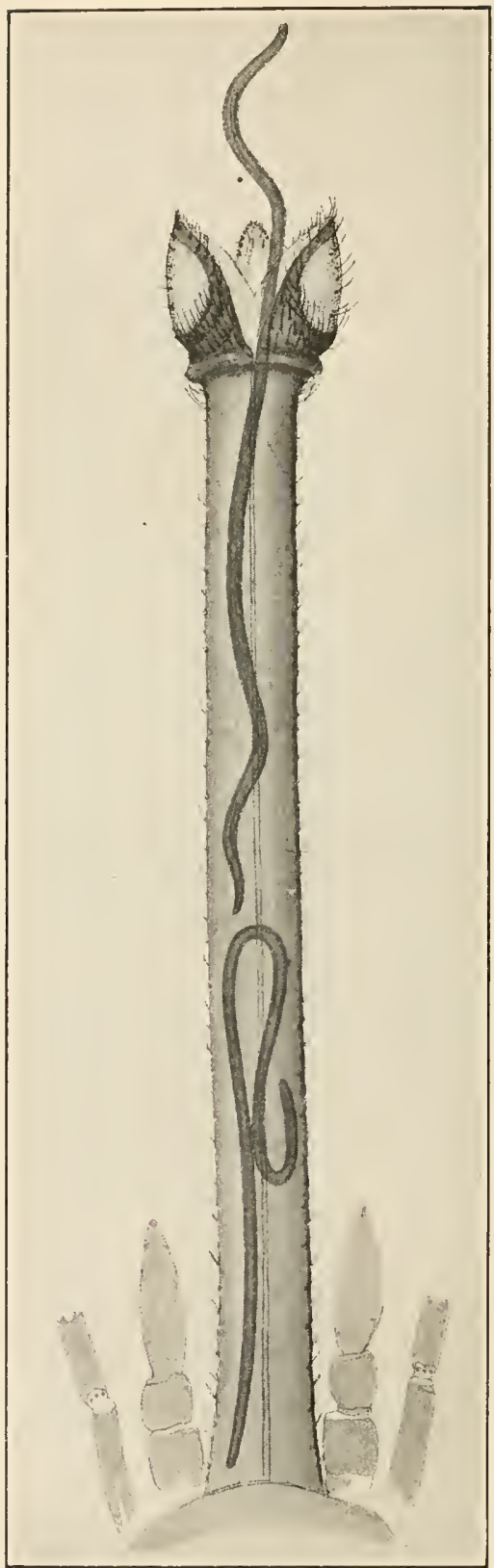

FIG. 10.-Mature larvæ escaping from proboscis of Culex fatigans; one mature larvæ coiled in base of proboscis. From mosquito dissected after being infected at Charleston, S. C. 
bancrofti, which causes elephantiasis, can be viewed as serious. These worms are transmitted to man by mosquitoes, Culex fatigans apparently being considered as the chief offender.

The most important filariae of man, according to Rosenau, ${ }^{1}$ are:

"(1) Filaria bancrofti, the larva of which is known as Filaria nocturna, appearing in the blood at night and occurring in all tropical lands, includ-

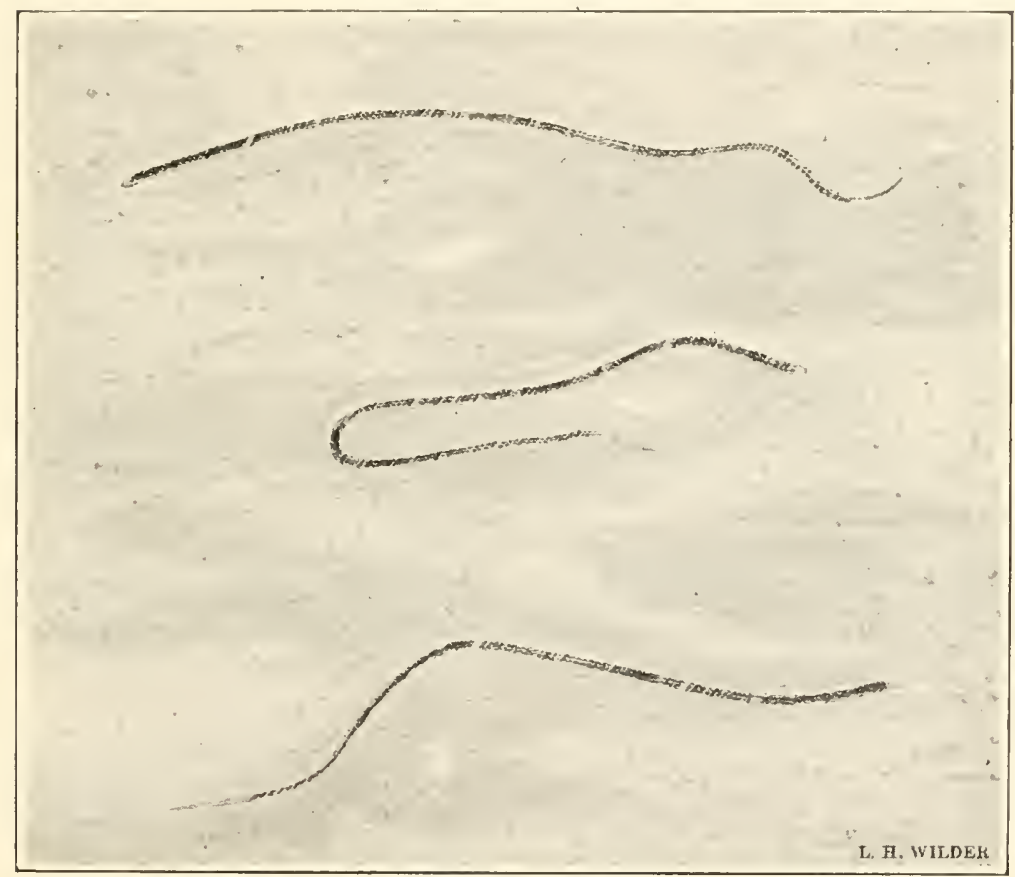

Fig. 11.-Filariæ (without sheath) in thoracic muscles of Culex fatigans, 9 hours after ingestion of filarial blood; infected at Charleston, S. C. Teased preparation.

ing America; (2) Filaria loa, the larva of which is known as Filaria diurna, occurring in the blood by day and prevalent in West Africa and India; (3) Filaria perstans, which persists in the blood both day and night, and occurs in West Africa and a number of other places."

Rosenau ${ }^{1}$ describes the movements of filariae in the body of mosquitoes fed on the blood of filarial-infested individuals as follows:

1 "Preventive Medicine and Hygiene," New York and London, 1918. 
"The filarial larvae soon escape from their sheaths in the thickened blood within the stomach of the mosquito. They pierce the stomach wall, enter the thoracic muscles of the insect, pass through a metamorphosis which takes from 16 to 20 days (longer or shorter, according to atmospheric temperature); they now quit the thorax and a few find their way to the abdomen; the vast majority, however, pass forward through the prothorax and neck and, en ering the head, coil themselves up close to the base of the proboscis and beneath the pharynx and under surface of the cephalic ganglia."

It is not yet definitely known whether Culex fatigans is the only species of mosquito which transmits filariasis; for this reason, anti-mosquito work for the prevention of filariasis should be directed against all the mosquitoes in the vicinity.

Filariasis occurs throughout the tropies and sub-tropies generally, and the total morbidity from this infection undoubtedly is large. In the United States, oceasional cases are reported in the Southeast, the endemic area reaching as far north as Charleston, S. C.

\section{ECONOMIC SIGNIFICANCE OF YELLOW FEVER, DENGUE AND FILARIASIS}

While none of these diseases are widely prevalent in the United States, the impairment of working eapacity which the last two entail-which probably corresponds in a large measure with that caused by malaria-no doubt amounts to a not inconsiderable sum annually.

In the tropical regions, however, where these diseases are much more common, it is elear that their economic significance must be very large. The inefficieney of tropical labor has been noted by virtually all persons who have visited those parts, and it is apparent that this inefficiency is due largely to malaria, yellow fever, dengue and filariasis - preventible, mosquito-borne diseases.

\section{THE MOSQUITO AS AN ANNOYANCE; EFFECTS UPON HEALTH}

Little need be said as to this phase of the mosquito's activities and its effeets upon the comfort and health of the eommunity, as anyone who has lived in vieinities that the mosquito frequents knows how much diseomfort it causes.

Not only do they make life miserable for their vietims, but, merely as an annoyance alone, they have a very pernieious effeet upon the health. The illness caused by loss of rest and sleep, by 
over-wrought nerves and temper and by poisonous swellings that sometimes follow the bites probably would reach an enormous figure, were such eases traced down and recorded.

Another aspect of the effect upon health of annoyance by mosquitoes is the possibility that they may have some connection with other diseases than the four hitherto discussed. There are still many diseases whose etiology is as yet comparatively unknown, and the possibility is by no means remote that further investigation may show that the mosquito is in some way connected with their transmission.

\section{THE MOSQUITO AS AN ANNOYANCE; ECONOMIC SIGNIFICANCE}

But the ecomomic significance of the mosquito as an annoyance is probably even more apparent than its significance as a menace to health. The mere fact that mosquitoes are abundant in a region holds back development of that region and keeps property values down to a very low figure.

Speaking of the economic benefits of eradicating mosquitoes along the New Jersey coast, Headlec ${ }^{l}$ says:

"Everywhere (that) the drainage has been completed and is maintained, the thoughtful residents speak of the great relief afforded. As the result of an investigation made during the season of 1912-13, shoreline property values between Jersey City and Rumson were found to have increased by $\$ 5,600,000$. It is significant of the influence of mosquito control on this increase to note that while the increase in the factory section was only 15 per cent, in the residential portions it ranged from 25 to 300 per cent. This tallies well with the observation that parts of the shore, formerly almost uninhabitable because of the mosquito pest, have now become delightful summer resorts.

"A rather unexpected, but very natural, benefit has appeared as a result incidental to that drainage necessary to eliminate salt marsh mosquito-breeding. An estimate, prepared during the year 1912-13, showed that the salt marshes which had been drained and kept drained 3 years or more were producing 2.6 tons of hay per acre, as compared with 0.7 ton produced by marshes that are undrained or only recently drained.

\section{INCREASING PROPERTY VALUES}

"It is well-nigh impossible to prepare reliable estimates of the value of ridding the rest of the salt marsh of mosquito-breeding. The carrying

${ }_{1}$ "The Mosquitoes of New Jersey and Their Control," New Jersey Agricultural Experiment Stations, Bull. 276, 1915. 
out of this work would remove the greatest bar which now exists to the proper urban and agricultural development of South Jersey. The complete occupation of the shore as a summer resort awaits the control of the mosquito. Across the marsh from this line of summer resorts is bound to appear the second line of summer residences. Eventually, the marsh itself will be filled and built up. The agricultural land lying back of this urban development will be called upon to produce truck and fruit to supply this national play-ground.

"The salt marsh mosquito stands in the way of this tremendous development. The marshes should be drained and the mosquito destroyed."

It is obvious that the same considerations that apply to mosquito eradication along the New Jersey coast apply in larger or lesser degree to mosquito eradication in similar coast areas. It is equally obvious that they also apply to many inland areas. There are probably millions of acres in the United States where eradication of mosquitoes as a mere annoyance alone would greatly increase, if not double or treble, property values. 


\section{CHAPTER II}

\section{SOME DISEASE-BEARING AMERICAN MOSQUITOES}

\section{THE MOSQUITO IN GENERAL}

While mosquitoes have a world-wide distribution, they differ very materially in their habitat, their appearance, their ability to transmit disease, the eharacter of their breeding-places and the mode of continuing their existence from one generation to another.

From the point of view of habitat, mosquitoes may conveniently be divided into three general classes: The domestic mosquito, which breeds largely about homes, as Aedes calopus, the yellow fever mosquito; the fresh-water sylvan mosquito, which breeds in pools, swamps, streams, ponds, ete., as the Anopheles, the malaria-carrying mosquito; and the salt-marsh mosquito, which breeds almost entirely in brackish marshes along the sea, as Culex sollicitans. It is the domestic and fresh-water sylvan mosquitoes which constitute the menace to health.

Of its own volition, the mosquito seldom travels far. Experiments indieate that, as a rule, the inland mosquito does not fly more than half a mile or so from its breeding-place and that the average flight is much less than this distance. They may, however, be wafted considerable distanees by the wind, and this fact should be borne in mind in planning anti-mosquito work; the control area should extend, say, a mile or more in the direetion of the prevailing wind, while the other side may be reduced in width to half a mile.

\section{LIFE HISTORY OF THE MOSQUITO}

Although the mosquito is a winged animal, no fewer than three of the four stages of its life are aquatic, and these are the first. The egg is laid in a quiet pool or other suitable breedingplace; if the weather is warm, in a couple of days the eggs hatch out into larvae (wiggletails or wrigglers); in 4 or 5 days more the larvae turn into pupae; this stage lasts 2 or 3 days, when the adult mosquito emerges from the pupal shell. Therefore, if 
conditions are favorable-that is, if the weather is warm, the water rich in food and other factors are right-the egg may develop into an adult mosquito in 8 to 10 days.

The length of life of the adult mosquito varies with conditions. The average mosquito probably lives several months under favorable circumstances. Guiteras kept one alive in Havana for 154 days, and it is frequent to keep them alive in laboratories for 70 to 90 days. Without water, however, the mosquito will perish in 4 or 5 days.

The character of the breeding-place varies with the species and with conditions. Thus, the domestic mosquitoes generally choose water impounded in artificial containers about homes, such as barrels and cisterns, tin cans and bottles, cesspools, shallow wells, etc. The fresh-water sylvan mosquitoes may be found occasionally in this elass of breeding-place, as well as in forest pools, swamps, ponds and streams, their usual breedingplaces. The character of breeding-place of any given group may be modified by conditions.

\section{VARIATIONS IN EGGS, LARVAE AND PUPAE}

The eggs, too, vary materially with the different species. The eggs of the Culex are deposited vertically in large, brownish rafts; those of the Aedes and Anopheles, on the other hand, are found isolated, one by one, on their sides.

The habits and appearance of the larvae also present noticeable differences. Although all larvae are aquatic animals, they are, nevertheless, nearly all air breathers, lying just under the surface of the water and connecting with the air supply from time to time by means of a breathing siphon. The Anopheles larvae recline under the surface of the water in a horizontal position, while the Culex, Aedes and others, on the contrary, hang with their heads down.

The pupae of all species do not eat, having no mouth. Like the larvae, however, they are air breathers, breathing through a pair of trumpet-shaped tubes which are connected with the thorax.

Some speeies pass the winter as adults hidden in natural shelters; others as larvae; and still others as eggs. The eggs of some mosquitoes will retain their vitality after having been perfectly" dry for months; exposure to water for a few hours will result in the hatching of larvae. These varied methods of survival render extinction of the race impossible. 


\section{WHY MOSQUITOES BITE}

Mosquitoes bite because blood is believed to be a biological necessity for full development of the eggs. As this necessity is only a feminine one, male mosquitoes are vegetarians, and never bite. They may be distinguished from the females by the fact that their antennae are more plumose-that is, more heavily haired.

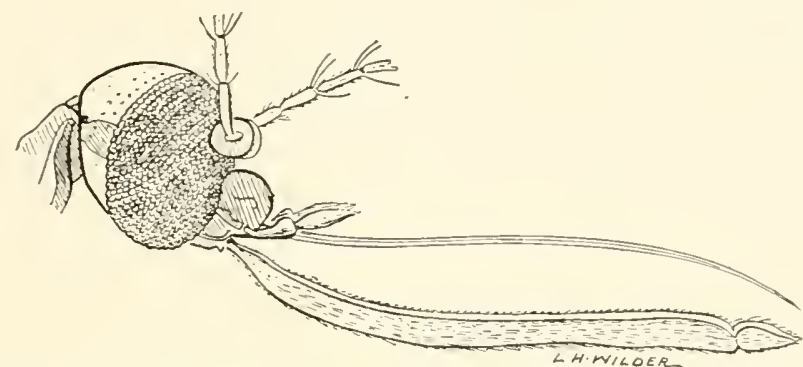

FIG. 12.-Proboscis of mosquito with lancets (stilette bundle) raised out of sheath. (After U. S. Public Health Service.)

While biting, the mosquito pierces the skin of its victim by means of a number of lancets which lie in the beak. As they enter the skin, the beak covering bends near the middle, thus

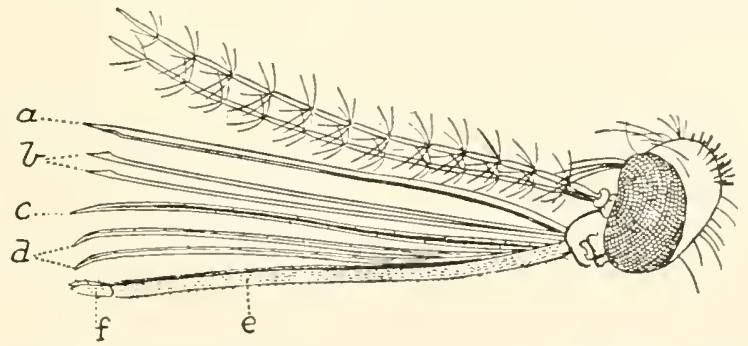

FIg. 13.-Proboscis resolved into stilette bundle. (After Daniels.) A, labrum; B, two mandibles; C, hypopharynx; D, two maxillae; E, sheath (labium). $F$, distal end of the sheath.

allowing the head of the mosquito to get up elose. The beak and lancets are described by Headlee' as follows:

"The beak covering, which is the only member of the mouth appendages seen by the ordinary observer, corresponds to the labium or lower lip of the chewing insect. It is grooved length-wise along its upper

I "The Mosquitoes of New Jersey and Their Control," New Jersey Agricultural Experiment Stations, Bull. 276, 1915. 
surface and forms a trough in which the delicate piercing lancets lie and by which they are protected from harm.

"The lancets consist of six parts. The upper is a compound structure, representing the labrum or upper lip and the epipharynx of the chewing insect. The epipharynx is grooved length-wise of its lower surface in such a fashion as to form a complete tube when the hypopharynx is laid against it from below. The hypopharynx is a slender, flattened piece that fits closely against the open groove of the epipharynx. Through the tube thus formed, the victim's blood is drawn into the mosquito's digestive tract. The next pair of lancets are slender sharppointed rods, which correspond to the mandibles or primary jaws of chewing insects. The next pair of lancets, which correspond to the maxillae or secondary jaws of chewing insects, are slender and pointed, but have slightly enlarged barbed ends.

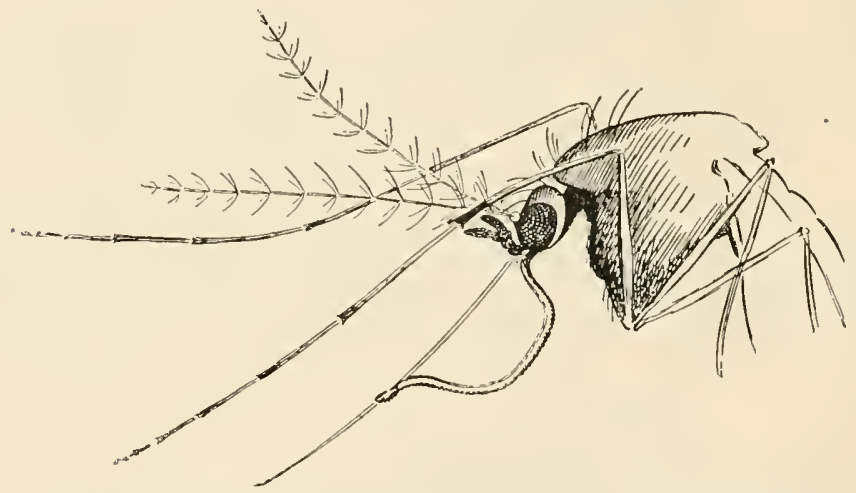

F1G. 14.-Mosquito in the act of sucking blood, the stilette bundle being free from the sheath, except at the distal end of the sheath. (After Bahr.)

"Almost, if not quite, coincidently with the moment that the skin is pierced, a small amount of saliva is injected through the epipharyngeal groove into the wound, and suction begins very soon after that. The pumping portion, the fore-intestine, regularly contracts and expands, drawing the blood from the victim into the mosquito's body. Unless disturbed, the creature will continue to feed until its abdomen is distended almost to bursting."

\section{IDENTIFICATION OF MOSQUITOES}

Ability promptly to identify the various kinds of mosquitoes is almost an absolute necessity for the director of an anti-mosquito campaign. Not only do the methods to be used for their eradication depend upon the species, but a knowledge of the particular 
species prevalent in a community may prevent the expenditure of large sums in measures direeted against species which are not troublesome there. Furthermore, if occasional mosquitoes are noted in a community where anti-mosquito work is being earried on, knowledge of their species will facilitate determination whether their presenee is due to failure of the work or whether they have blown in from the salt marshes or elsewhere. Again, determination of the species eausing trouble will make it possible for the director to loeate their breeding-places through knowledge of the habits of that particular species.

This necessary acquaintance with the more common species of mosquitoes ean be obtained only by familiarizing oneself with the characteristic outer anatomy of the adult and the larvae, so as to enable one readily to grasp the keys used in classification. Mere character of breeding-place is not a sufficient basis for identifieation.

Adults can only be positively identified if they are in good shape-not crushed or damaged and not so old that the characteristic markings have worn off. The most favorable age for identification is 1 or 2 days. As soon as caught, the specimen should be placed in a jar of cyanide or other toxic gas until dead, after which it may be pinned through the thorax. If it is desired to preserve the specimen, it should be earefully placed in a tightclosing box containing naphthalene, eare being taken to attach an identifying paper to it.

Larvae and pupae may be placed in bottles of 80 per cent aleohol, which will preserve them indefinitely, so that they will be available for mieroseopical examination at any time. They may, if desired, for permanent reference, be mounted on slides with Canada balsam.

\section{ANATOMY OF THE MOSQUITO}

"The mosquito's body," says Headlee, ${ }^{1}$

"like that of most other insects, is made up of three distinct regionsthe head, thorax and abdomen. The head is a globular object having (1) a pair of eyes, one on each side of the head; (2) a pair of more (male) or less (female) feathery feelers or antennae; (3) a pair of mouth feelers or palpi; (4) a long, prominent beak. The thorax is long, elliptical and

1 "The Mosquitoes of New Jersey and Their Control," New Jersey Agricultural Experiment Ntations, Bull. 276, 1916. 
bears three pairs of legs on its lower surface and one pair of more or less transparent wings on its upper surface. The abdomen is long and narrow and composed of many plainly defined segments. It bears no

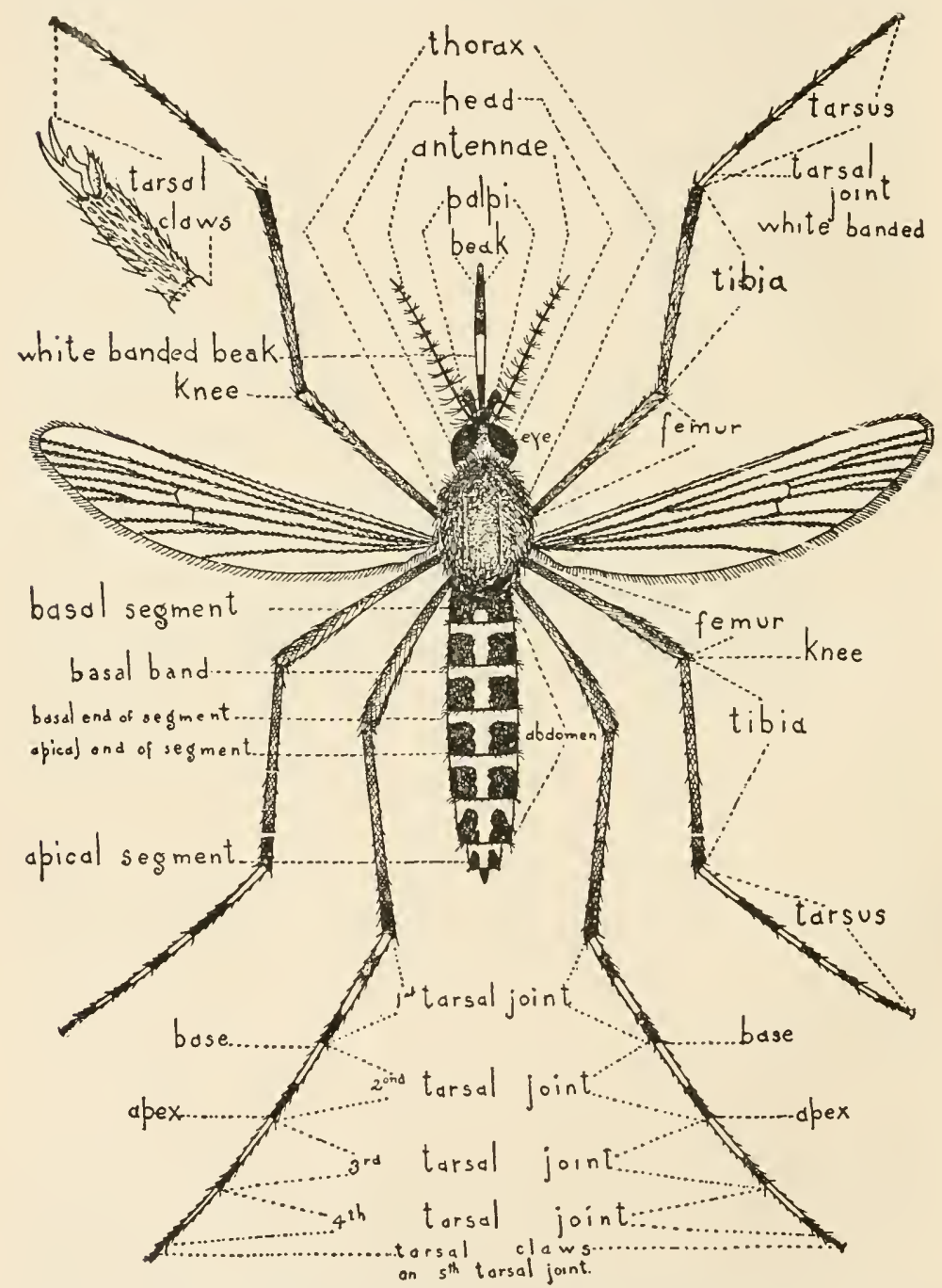

FIG. 15.-Adult mosquito, (Aedes sollicitans Wlk.) with parts named. (After John B. Smith, New Jersey Agricultural Experiment Stations.)

appendages other than certain ones connected with reproduction, and apparently they are not necessary in elementary classification.

"Each leg consists of a small coxa, a long femur, an equally long tibia 


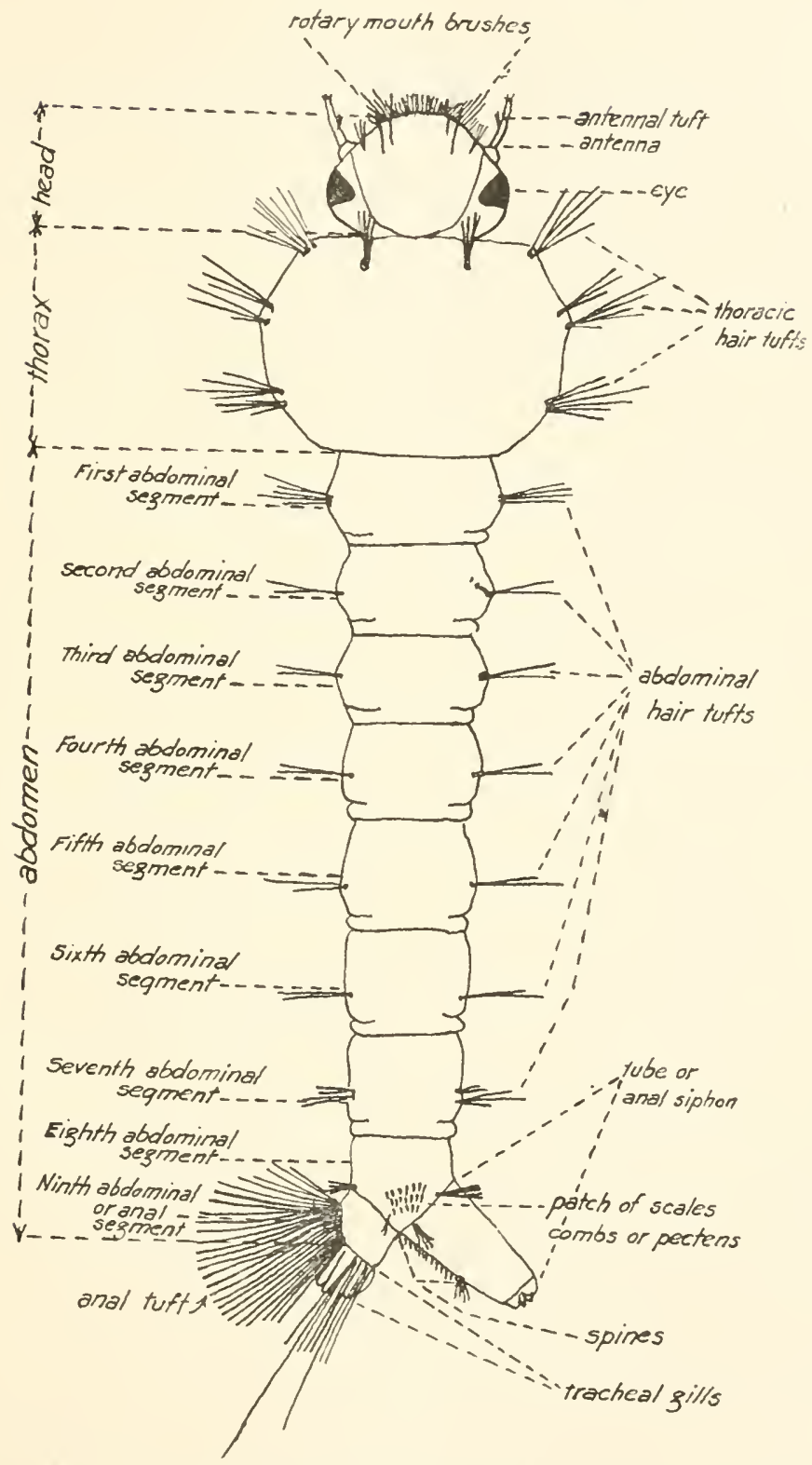

Fig. 16.-Mosquito larva with parts named. (After John B. Smith, New Jersey Agricultural Experiment Stations.) 
and a five-jointed foot or tarsus. The last tarsal joint is tipped with claws.

"The wings have scales, generally collected along the veins. The color and arrangement of the scales determine the uniformity or spotted appearance of the wings."

\section{ANATOMY OF THE LARVAE}

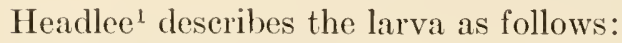

"Like the adult, the wriggler exhibits the three divisions of the body - head, thorax and abdomen. The head bears a pair of eyes, a pair of

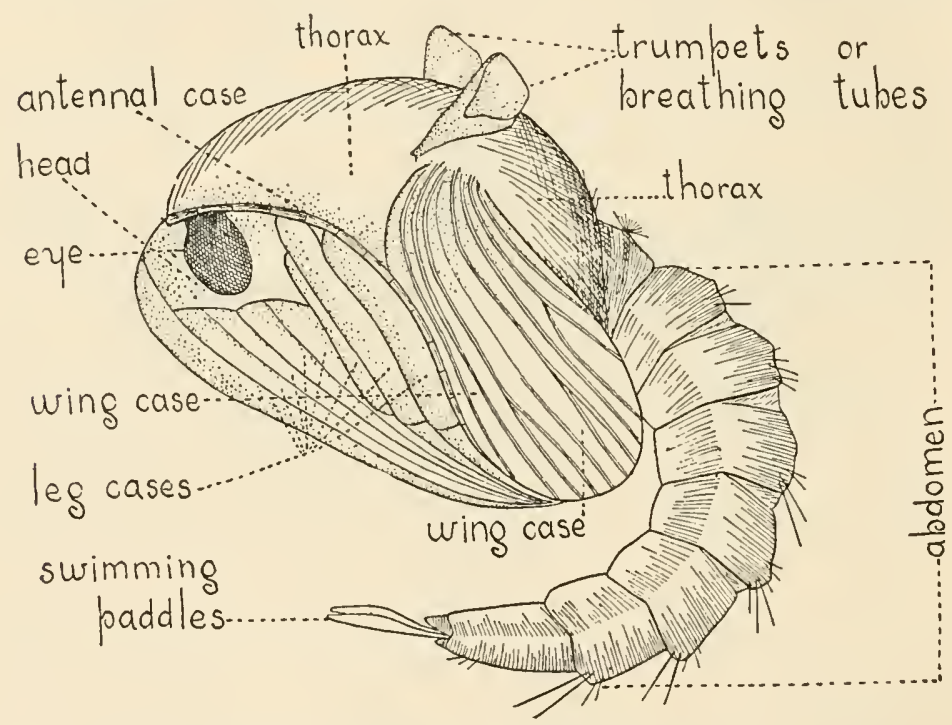

FIG. 17.- Mosquito pupa with parts named. (After John B. Smith, New Jersey Agricultural Experiment Stations.)

antennae and rotary mouth brushes. Each antemna exhibits a small bunch of hairs, which has been designated as the antennal tuft. The thorax has various tufts of bristles seattered over it, known as the thoracie tufts. The abdomen consists of eight well-developed segments, each of which bears some tufts of bristles, known as the abdominal hair tufts. The eighth segment has grown a process known as the anal tube or siphon, which bears a double row of spines on its posterior surface and has the opening of the breathing system at its tip. In nearly all species, this tube is used to penetrate the water surface film and to reach the atmospheric air. The ninth segment is small, bears a large group 1 "The Mosquitoes of New Jersey and Their Control," New Jersey Agricultural Experiment Stations, Bull. 276, 1915. 
of bristles, the anal tuft and some smaller tufts. The anal opening is situated at the outer end of this segment and the tracheal gills extend outward from this opening. On each side of the eighth segment, there is a little patch of scales that are much used in classification.'

The pupa has a small head attached to a very large thorax, with the abdomen eurled around under the latter. The breathing tubes or trumpets outerop from the top of the thorax, while underneath are the leg and wing cases. At the extreme end of the eurled abdomen are the swimming paddles by which this strangelooking creature moves about from place to place.

\section{THE ANOPHELINAE}

Of the sub-family Anophelinae, no fewer than 6 genera, eomprising at least 25 different species, are believed to transmit malaria. Knab gives a list of 34 species of American Aropheles, of which the following have been definitely shown to serve as hosts for the malaria parasite:
A. albimanus
A. argyritarsis
A. crucians
A. intermedium
A. quadrimaculatus
A. pscudomaculipes
A. tarsimaculata
A. pseudopunctipcrnis
A. occidentalis

In addition to these, $A$. punctipennis has been shown to transmit malaria under laboratory conditions, but whether or not it is an important veetor of malaria in nature is not yet entirely established.

The Anopheles of sanitary importance in the United States are: $A$. quadrimaculatus, $A$. crucians and $A$. punctipennis in the East and South, and $A$. occidentalis along the Pacific coast.

Known transmitters of malaria elsewhere include: $A$. sinensis in India; $A$. costalis in Afriea; $A$. clariger in Spain; and $A$. maculipennis, which is believed to be the sime as A. quadrimaculatus, in other parts of Europe.

\section{IDENTIFICATION OF THE ANOPHELINAE}

Adult Anopheline mosquitoes may readily be distinguished from all other genera by the fact that the wings are distinctiy spotted. Furthermore, in the female, the palpi (the slender rods found on either side of the beak or proboscis) are about threequarters as long as the beak itself, while the same organs in the females of other speeies (except one, which has a curved proboseis) are seldom one-quarter the length of the beak. 
Adult Anopheles also may be identified by their peculiar posture while resting or biting. On a vertical wall, the head, thorax

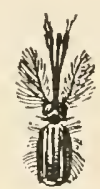

Fig. 18.- Head of Anopheles, male. (After U.S. Pub. lic Health Serviee.)

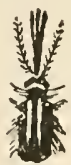

Fig. 19.-Head of Anopheles, female. (After U. S. Publie Health Serviee.)

and abdomen form one straight line, pointing downward at an angle of about 60 degrees from the horizontal; other common

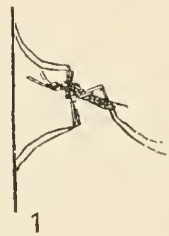

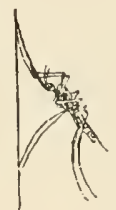

2

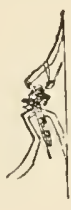

3

Fig. 20.-Resting posture of mosquitoes. (After Sambon.) 1 and 2, Anopheles; 3, Culex pipiens.

mosquitoes sit humped up, both head and abdomen being lower than the thorax.

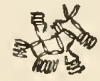

Fia. 21.-Ova of Anopheles. (After $U$. S. Public Hialth Service.)

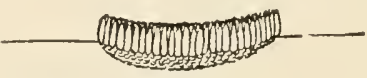

Fig. 22.-Culex eggraft. (.1fter U. S. Public Health Scrvice.)

Adult Anopheles also may be distinguished from other common mosquitoes by their actions. They seldom bite in the day-time

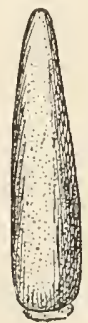

Fig. 23.--Greatly enlarged view of a Culex egg. (After U. S. Public Health Service.) and rarely bite a person moving about; the Culex, on the other hand, bites at all times. The Anopheles does not loum so loudly as other common mosquitoes.

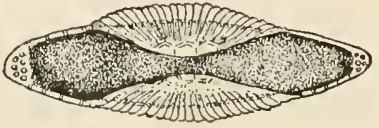

Fig. 24.-Greatly enlarged view of an Anophcles maculipennis egg. (After U.S.Public Health Serviee.) 
The eggs of Anopheles may be distinguished from those of C'ulex and some other common mosquitoes by the fact that the former are laid singly and are supported on the surface of the water by lateral air-spaces, while the latter stand vertically in closely-packed rafts.

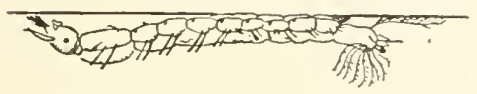

Fig. 25.- Larra of Anopheles. (After U. S. Public Health Serviee.)

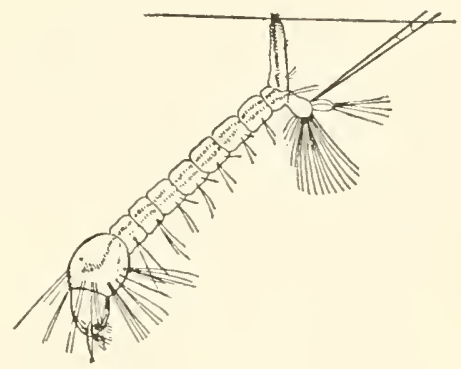

Fig. 26.-Larva of Culex. (After $L^{\top}$. S Public Health Service.)

Anopheline larvae may be distinguished from the larvae of all other genera by the faet that the head is much smaller than the thorax, that they have virtually no breathing tube and that they

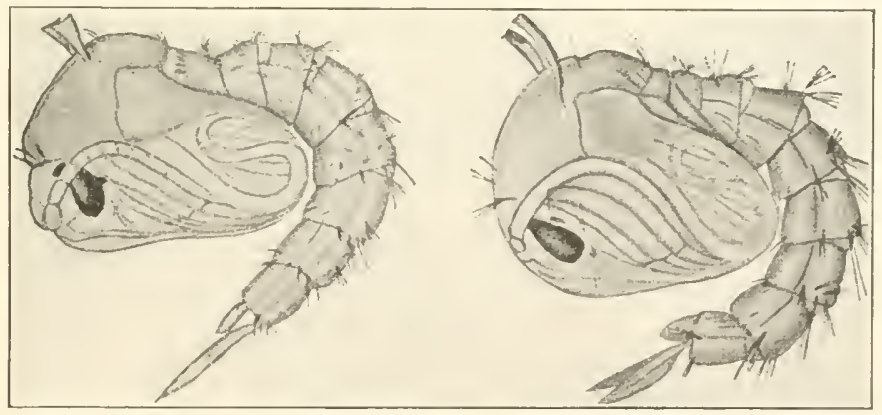

Fig. 27.-Pupa of Anopheles Frg. 28.-Pupa of Culex pipiens. punetipennis. (After Howard, (After Howard, Dyar and Knab.) Dyar and Knab.)

lie horizontally under, but close to the surface, of the water, very much like a basking pike. All other common Ameriean larvae, on the other hand, have the head larger than the thorax, have a long breathing tube and hang head down at an angle of about 60 degrees from the plane of the water surface. Upon being frightened, Anopheles larvae usually dart about parallel to the surface, while other larvae usually dart downward. 
Anopheles pupae are larger in the antero-posterior direction and narrow laterally, while $C$ ulex pupae are short and broad from side to side. The breathing siphons of Anopheles pupae are short and trumpet-like, while those of Culex larvae are long and narrow.

As a general rule, the Anophelinae prefer natural breeding places to artificial ones and manifest an aversion for sewagepolluted water and for brackish water, although they are occasionally found in such waters. Their food, in the larval state, consists mainly of algal spores, minute insects or erustaceans, etc. Some authorities state that they become cannibalistic when their usual food beeomes scarce.

\section{A. QUADRIMACULATUS SAY}

Of the three common American malaria-carrying mosquitoes it is believed that $A$. quadrimaculatus Say is probably responsible for more harm than either of the other two.

A. quadrimaculatus may be distinguished from the other Ameri-

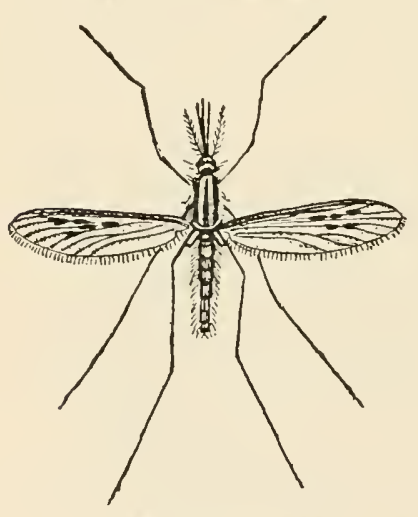

FIG. 29.-Anopheles quadrimacu. latus, female. can Anopheles by the fact that it is brownish in color and has from three to five-but generally four-blackish spots on the second and fourth wing veins, whence its name is derived. These spots are patches of black scales.

A. quadrimaculatus passes the winter as an adult female, in cellars, forests, barns and other sheltered places. When warm weather comes in the spring, these females emerge from their hiding places and deposit their eggs. From 50 to 75 are laid at a time. If the weather is favorable, the larvae emerge in 2 or 3 days and begin feeding. In from 4 to 6 days of warm weather-or much longer in cool-the wrigglers transform into pupae; 2 or 3 days more and the adult emerges. Breeding appears to be as continuous from spring to autumn as temperature and other conditions will allow.

While the favorite breeding-place of $A$. quadrimaculatus is grass-bordered pools, ponds, pot-holes, etc., it has been reported to breed in slowly moving streams. It will also, on occasions, 
breed in artificial containers. A. quadrimaculatus has also been known to breed in salt marshes and other brackish water and, rarely, in sewage-polluted water.

A. quadrimaculatus enters buildings very readily, and the slightest opening in the screening will be taken advantage of. If the size of mesh of the screen is less than No. 16 or No. 14, painted, small-sized individuals will be certain to get in. $A$. quadrimaculatus enters inhabited buildings at night and makes its exit carly in the morning, unless so gorged with blood as to be unable to pass through the sereen. In this case it may be observed resting on the sereen next day.

It has been found, by means of the recovery of stained specimens previously liberated, that $A$. quadrimaculatus sometimes will travel more than a mile, although it is not believed that, under average conditions, the usual flight is as much as that. It is believed that $A$. quadrimaculatus could become of sanitary importance more than a mile from its brecding-place only if the breeding-place were very extensive and production therein very heavy.

\section{A. CRUCIANS WIED}

As compared with the other Anopheles, the wing of the crucians is more dusky and the veins, thereof, more prominently marked. The characteristic marks are three small, blackish spotspatches of black scales-on the sixth wing vein, thoracic end, posterior margin. If the specimen be very old, the end spot may be indistinct.

The crucians has been ealled the "day-light Anopheles," owing to its habit-in contrast with that of A. quadrimaculatus and $A$. punctipennis-of biting during the day and early evening. A. crucians enters dwelling-places fully as readily as does $A$. quadrimaculatus; it may also frequent privies and be abundant underneath houses. Despite these circunstances, A. crucians is believed to be somewhat less efficient as a vector of malaria than $A$. quadrimaculatus.

A. crucians appears to be able to travel somewhat further than A. quadrimaculatus, recent tests indicating that this species can, on occasions, fly as far as 7.000 fect.

In its life-habits, A. crucians is similar to A. quadrimaculatus. It is not so fastidious as to character of breeding-place, however, and fairly frequently may be found breeding abundantly in 
brackish waters and waters contaminated with chemicals. Met $z^{7}$ reports that he has found crucians breeding freely in water so impregnated with noxious substances from the drain of a chemical factory that fish were unable to live in it.

A. crucians apparently is not quite so widely distributed as is A. quadrimaculatus, its habitat evidently being somewhat more

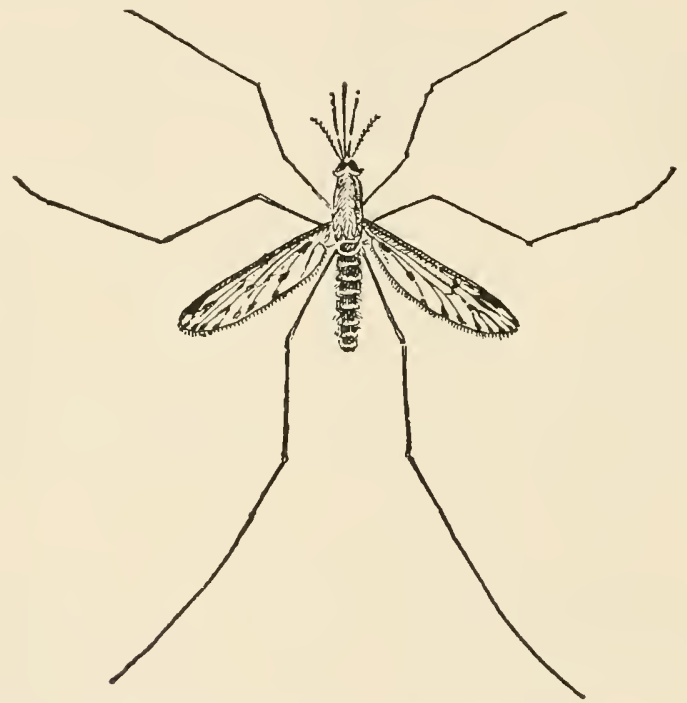

FIG. 30.-Anopheles crucians, female.

restricted. Often, where it is found at all, it is found in great abundance.

\section{A. PUNCTIPENNIS SAY}

This species may be distinguished from other common Anopheles by the fact that it carries a large square or oblong white or yellowish patch at the anterior margin of the wing, near the outer end. Sometimes, there is a blackish patch also noticeable. The white patch is readily visible to the naked eye, and is quite perceptible, even when the insect is in the resting position with the wings crossed. The anterior margin of the wing is dark, while the balance is lightly spotted with black, with an almost invisible white spot at the extreme apex.

The life-habits of $A$. punctipennis are similar to those of $A$.

" Some Aspects of Malaria Control Through Mosquito Eradication," U. S. Public Health Service, 1919. 

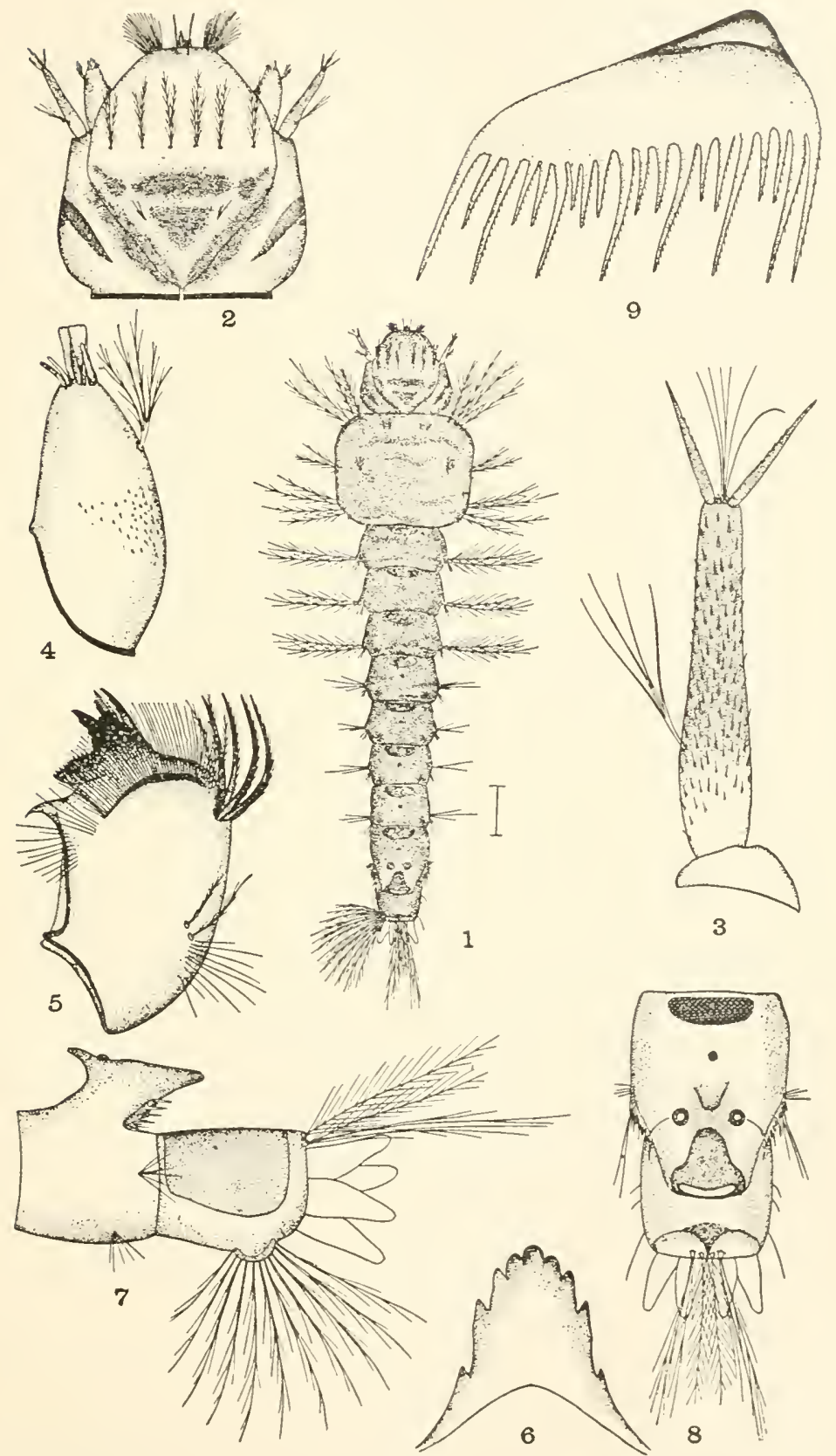

FIG. 31.-Larva of Anopheles crucians. (After John B. Smith, Neu Jersey Agricultural Experiment S'tations.)

1, larva; 2 head from above; 3 , antenna; 4 , palpus; 5 , manrlible; 6 , mentum; 7 , anal segments from side; 8 , anal segments from above, showing spiracles; 9 , one of the scales. All are greatly enlarged. 
quadrimaculatus, except that punctipennis appears to be somewhat less fastidious about the charaeter of the water in which it breeds.

A. punctipennis apparently does not enter houses so freely as $A$. quadrimaculatus and A. crucians. It is generally a porchbiter, and ordinarily will be found most abundantly in the early evening. It does not appear to fly so far as A.quadrimaculatus.

This species probably is the most common of the North American Anopheles.

\section{A. OCCIDENTALIS, D. AND K.}

This mosquito, the common malaria carrier of the Pacifie coast, has been considered by some authors to be identical with

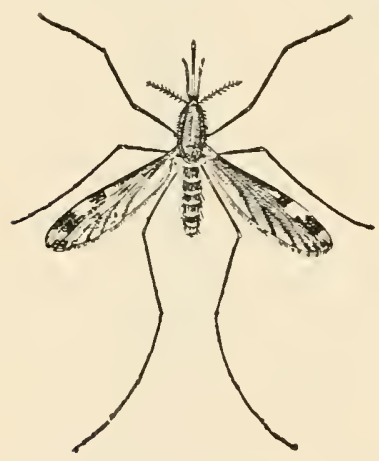

FIG. 32.-Anopheles punctipennis, female.

A. quadrimaculatus. While the general appearance is quite similar to that of $A$. quadrimaculatus, there are, aceording to Dyar, well-defined differences in the male genitalia.

It appears that this mosquito is of sanitary importance only west of the Rockies.

\section{THE CULICINAE}

The sub-family, Culicinae, is subdivided into two genera-the Culex and the Aedes. Species belonging to both of these genera transmit disease.

Adults of this sub-family may be distinguished from adult Anopheles by the fact that the palpi are long in the male and short in the female, while the Anopheles of both sexes have long palpi. Another differentiation is the fact that Culicines have flat abdominal seales, while Anopheles do not. As already intimated, the resting position of the Culicines is also very different from that of the Anopheles.

The difference between Anopheline and Culicine larvae has already been indicated.

The ehief differences between Culex and Aedes may be summed up as follows:

Adult Culex and Acdes are best distinguished by the shape of the abdomen; in the Culex, the abdomen is blunt, with short cerci; in the Aedes, it is tapered, and pointed, with distinct cerei. 

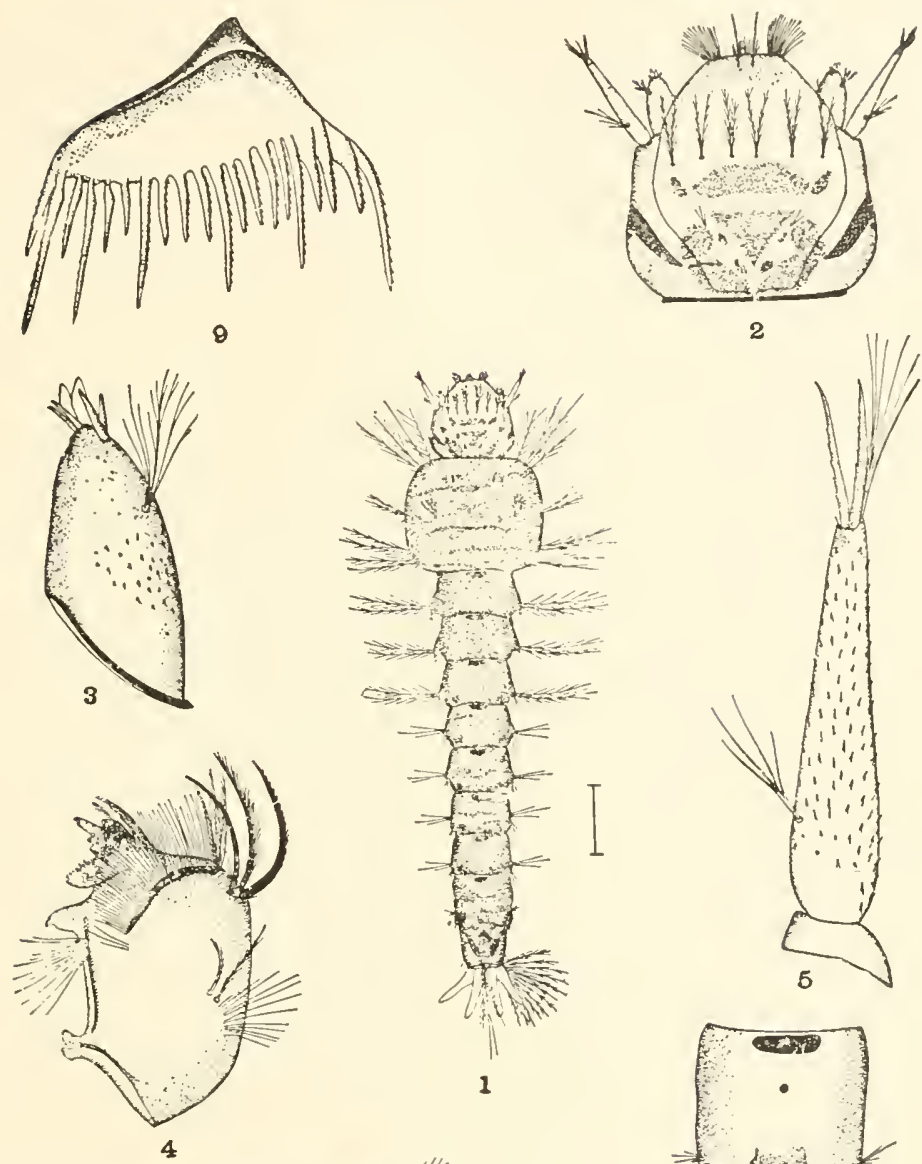

2
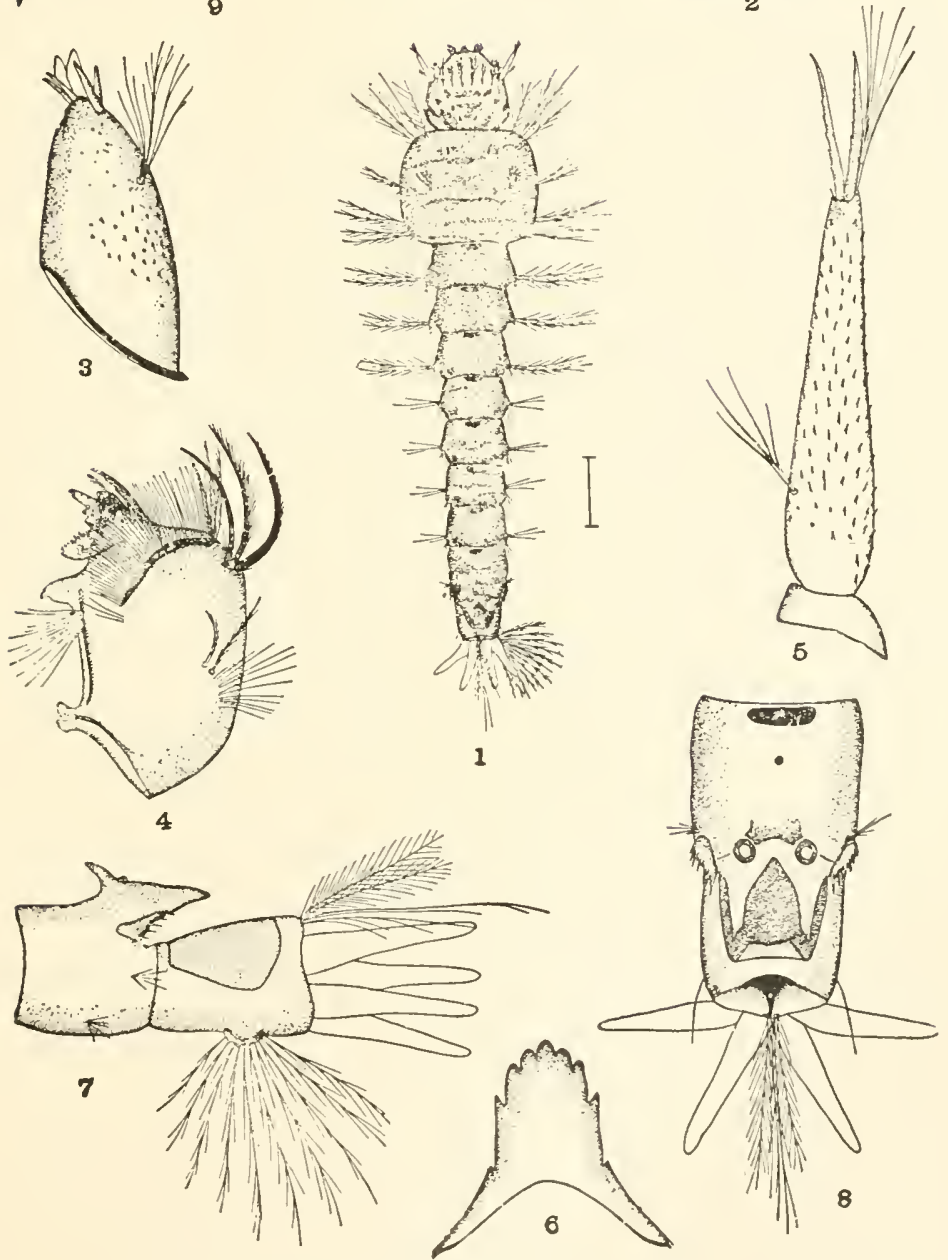

FIG. 33.- Larva of Anopheles punetipennis. (.1fter.John B. Smith, New Jersey Agricultural Experiment Stations.)

1, larva; 2, head above; 3 , palpus; 4 , mandible; 5 , anteuna; 6 , mentum; 7 , anal segments from the side; $s$, anal segments from above, showing the two spiracles; 9 , one of the scales. All are greatly enlarged. 
Eggs of the Culex are laid vertically in rafts and are generally of a brownish color, while eggs of the Aedes are laid in clusters and gradually turn black.

The larvae of Culex are easily distinguished from those of Aedes by the air-tube; in the Culex, there are many hairs along its posterior aspect, while in the Aedes, there is but a single tuft near the end of the pecten.

The pupae manifest few differences.

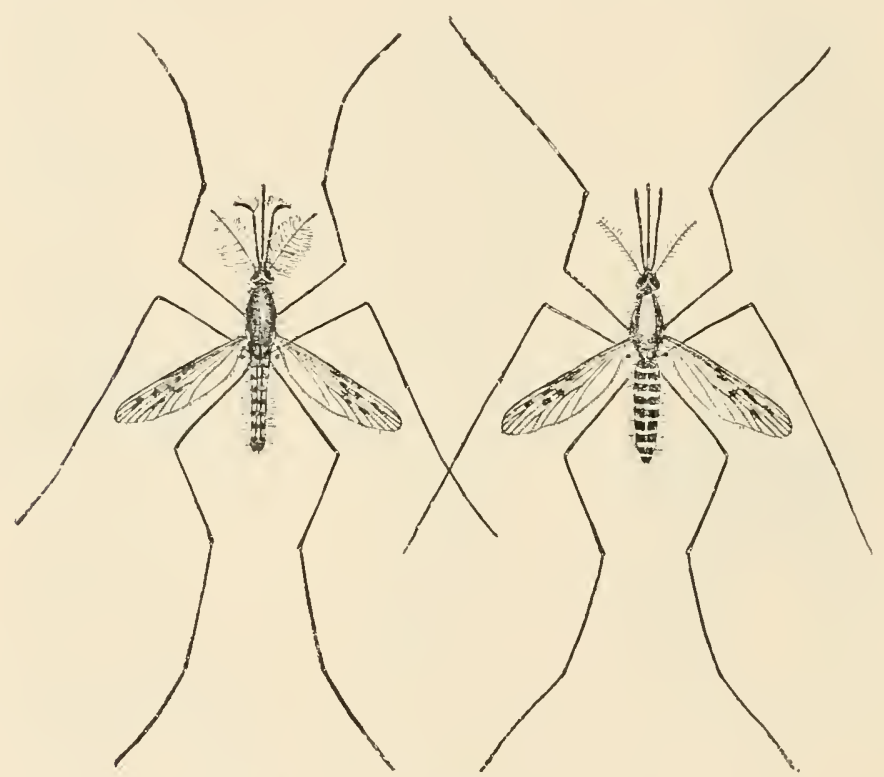

FIG. 34.-Anopheles occidentalis, male and female.

\section{AEDES CALOPUS MEIG (STEGOMYIA FASCIATUS FAB.)}

Acdes calopus, the yellow fever mosquito, is very widely distributed, it being found from $38^{\circ}$ South to $38^{\circ}$ North latitude. As a rule, Aedes calopus prefers the lowlands, and is rarely found in the higher parts of the South.

The yellow fever mosquito is essentially a domestic mosquito, breeding by preference in standing water about houses, such as that in eisterns, barrels, tin cans, bottles, etc. Rarely, if ever, is this mosquito found breeding in swamps, pools and streams, the favorite haunts of the malaria mosquito.

Although Aedes calopus may, as an adult, survive a brief 
winter, this mosquito generally passes the winter in the egg stage. The eggs, which are shaped something like a eigar and measure about half a millimeter in length, are laid on the surface of the water or just above the water-line. They can withstand freezing and may be kept dry for 6 months without losing their vitality. They do not form rafts, as do the Culex, but lie singly or in isolated groups.

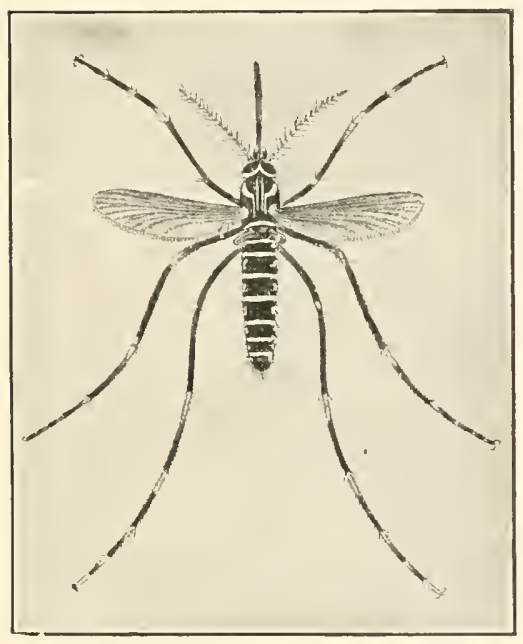

Fig. 35.-Aëdes calopus, female.

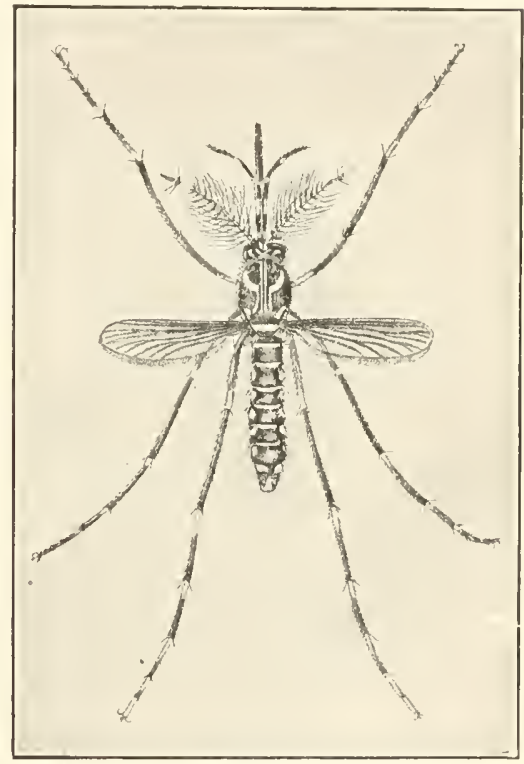

FIg. 36.-1ëdes calopus, male.

In about 36 to 48 hours, if the weather is warm, the egg develops into the larva, which also is very resistant, it being apparently able to stand freezing for a brief period. A distinguishing feature of this larva is the fact that it has a black, barrel-shaped breathing siphon. This larva is easily scared and stays at the bottom of the water a good share of the time.

If the weather is warm, the larva turns into a pupa in 5 to 8 days. The pupa stays near the surface of the water most of the time. In 36 to 48 hours the adult mosquito emerges.

Acdes calopus is of a grayish color and average to smallish size. It has glistening whitish lyre-shaped marks on the batek of the thorax, with silver-white dots on the sides. There are white limes at each tarsal joint and on the palpi,. while the scutellum also is white. Outside of the markings, the female is 
distinguished from Anopheles mosquitoes by the fact that the palpi are rudimentary.

Being smallish, A. calopus can pass through a screen composed of 16 strands or 15 meshes to the inch. To be effectual, therefore, screens should have more than 15 meshes to the inch.

As a rule, A. calopus does not fly nearly so far as the malariacarrying mosquitoes, manifesting an apparent desire to remain about the environment that gave it birth. It is active chiefly during the day-time, resting at night, unless attracted by bright lights. During the day-time it seeks shade, since it cannot survive long in the direct sunlight. It is, therefore, chiefly dangerous in houses or in brush, etc.

Rosenaul says: "It may possibly at times fly across the street, but it is evident that it neither flies far nor is it ordinarily transported to any great distance on railroad cars, although it may be carried over seas in ships."

\section{CULEX FATIGANS WIED. (C. QUINQUEFASCIATUS SAY)}

This mosquito is believed to transmit both dengue and filariasis to man. It is very widely distributed over the tropies and subtropies. C. fatigans and A. calopus are two of the commonest house mosquitoes in the Southern States.

While these two species are constantly associated in that section, breeding together in house-yards in the same water and in the same containers, $A$. calopus has been exonerated as a disseminator of dengue and filariasis, while $C$. fatigans has been found to be almost wholly responsible for the spread of these diseases.

C. fatigans, like A. calopus, is essentially a domestic mosquito, breeding in fresh water in back-yards, in eisterns, rain-water barrels, tin cans and other miscellaneous artificial containers.

C. fatigans is a smallish to medium-sized mosquito, ranging in color from yellow to dark-brown, with light bands at the base of each segment. Its legs and proboscis are not banded.

Probably the quickest way of distinguishing $C$. fatigans from A. calopus is by the fact that the former is essentially a nightbiter, while the latter is a day-biter. This is rery perceptible, wherever the two occur together.

The larva of this species may be distinguished from that of $A$. calopus by the fact that its respiratory siphon is brownish and nearly three times as long as it is broad.

1 "Preventive Medicine and Hygiene," New York and London, 1918. 
C. fatigans passes the winter as an adult female. She hides away in protected places and, when warm weather comes, lays her eggs in dark-brown rafts of from 50 to 400 eggs. In about 8 or 9 days, if the weather is favorable, the adult of the new brood emerges. Breeding is more or less continuous up to cold weather in the autumn.

C. fatigans ordinarily does not fly far. However, where produetion is heavy, it may travel 2 or 3 miles.

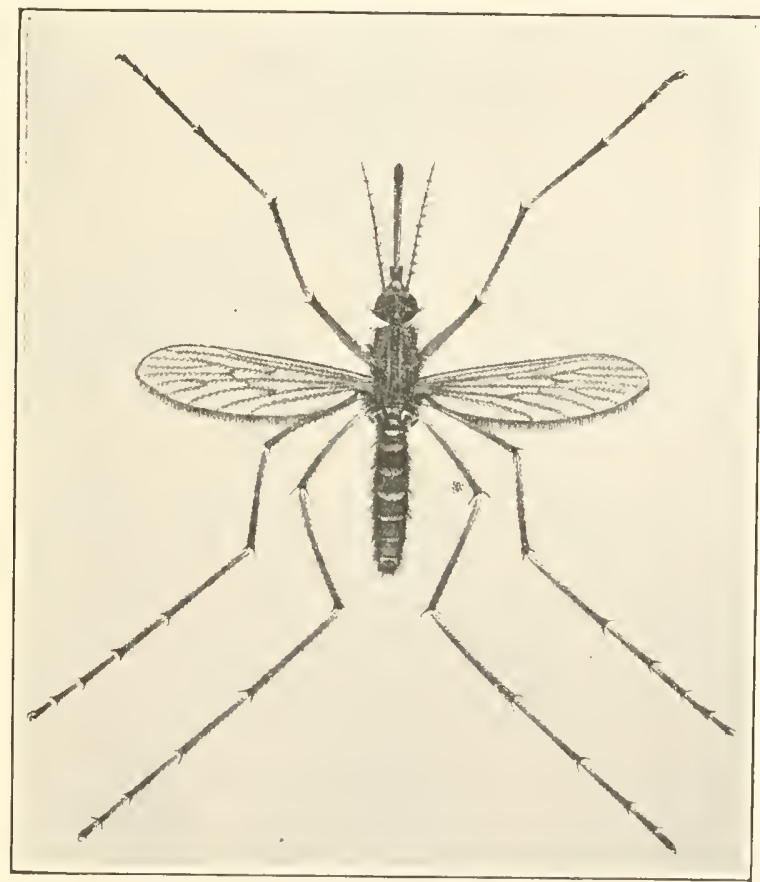

Fig. 37.-Adult female Culex fatigans.

\section{SOME COMMON TROUBLESOME MOSQUITOES}

In the next few pages, several of the more common annoying mosquitoes prevalent in the United States will be diseussed briefly. So far as is known, none of these transmit disease, but all are more or less troublesome in mosquito eradication work.

For the purposes of this diseussion, it may be convenient, perhaps, to divide these mosquitoes into rough groups as follows: 


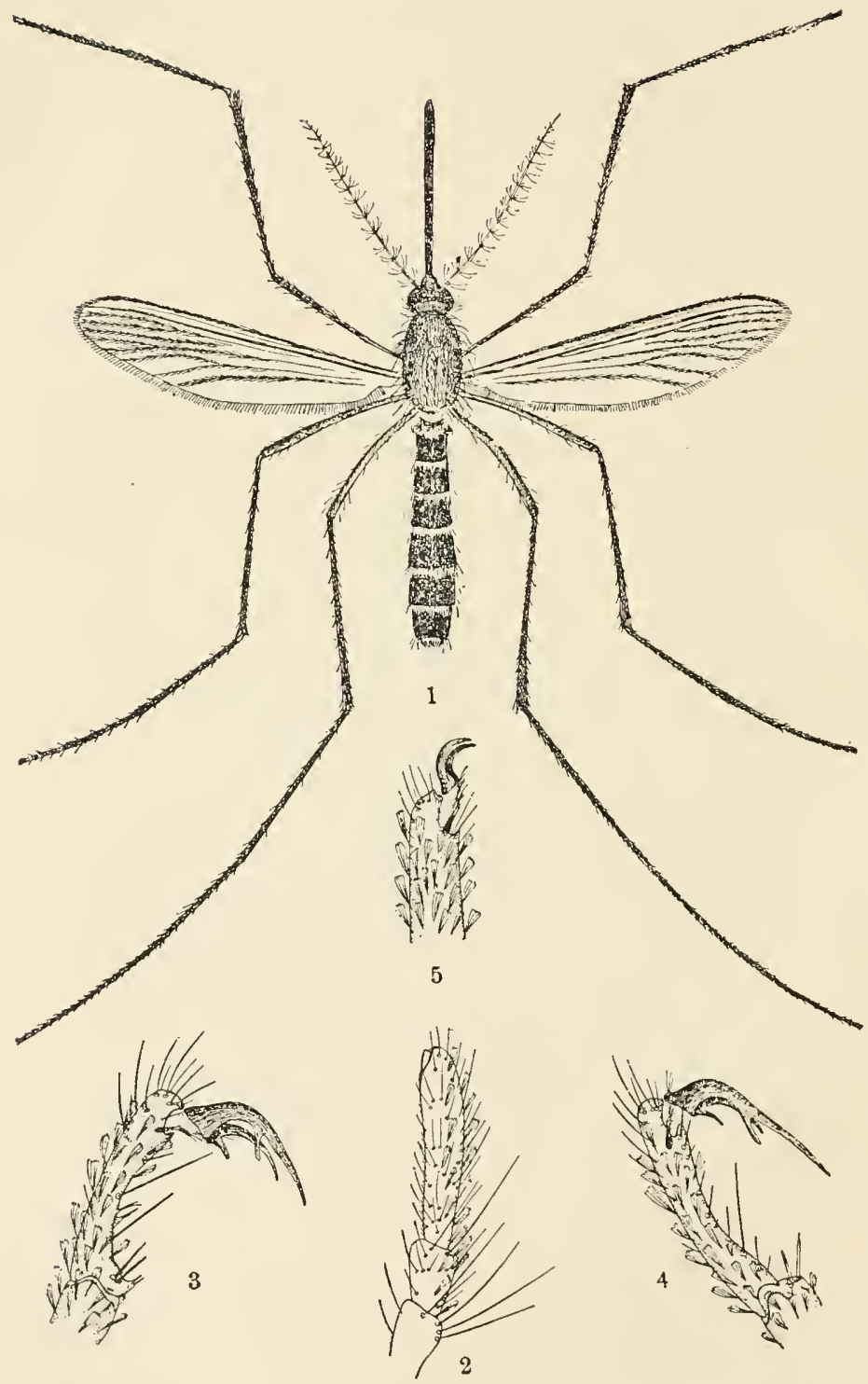

FIG. 38.-Adult Culex pipiens. (After John B. Smith, New Jersey Agrieultural Experiment Stations.)

1 adult female; 2 , palpus of same; 3 , anterior; 4 , middle, and 5 , posterior claws of male. All are greatly enlarged. 
house mosquitoes, fresh-water sylvan mosquitoes and saltmarsh mosquitoes.

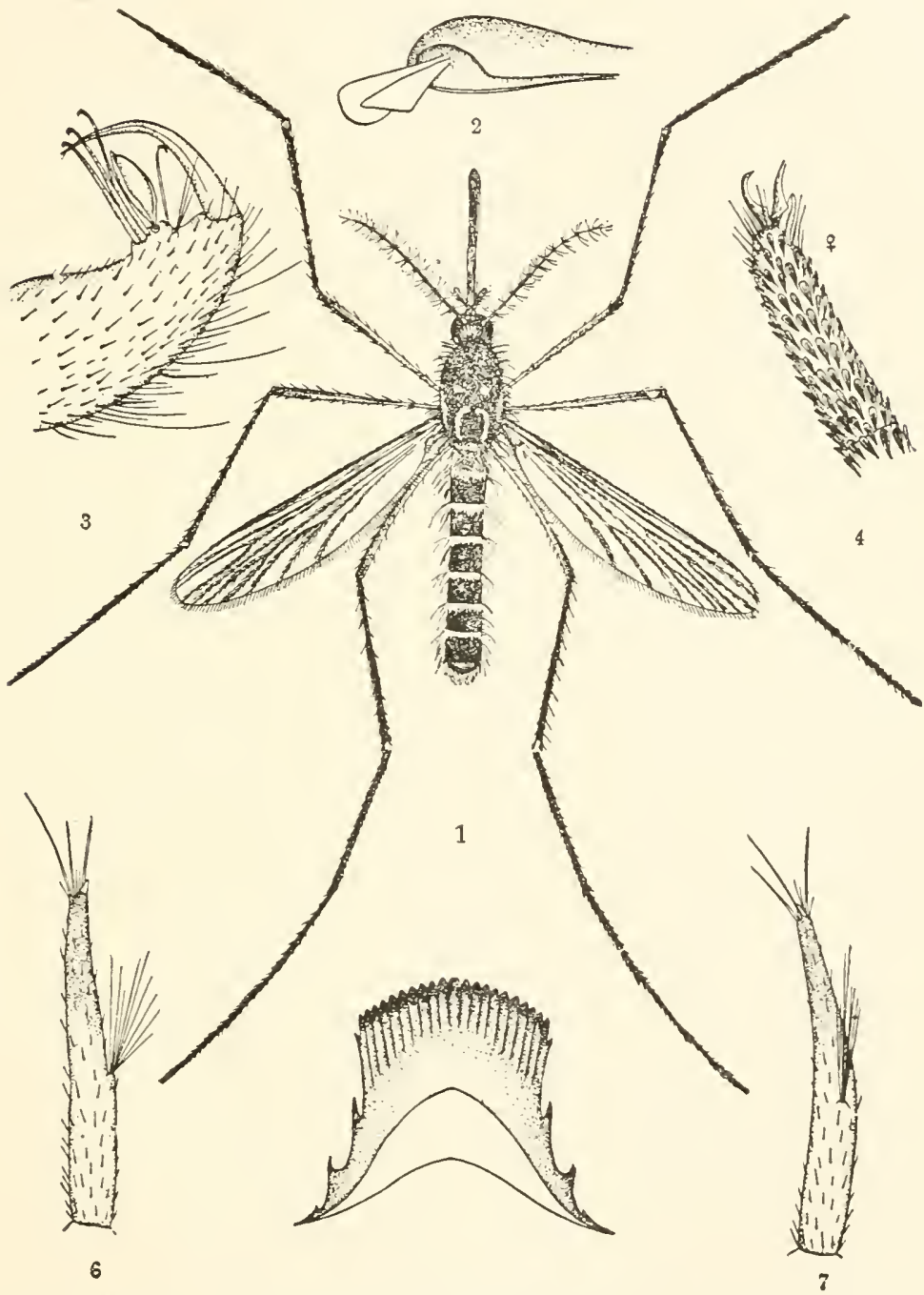

Fig. 39.-Adult of Culex restuans. (After John B. Smith, New Jersey Agricultural Experiment Stations.)

1 , adult female; 2, appendage to tip of clasper; 3 , clasper of male genitalia: 4 , anterior claws of female; 5 , mentum of larva; 6 and $\overline{7}$, antennae of same. All are greatly enlarged.

\section{HOUSE GROUP}

Probably one of the most annoying mosquitoes of this group is Culex pipiens, Linn., a close relative of $C$. fatigans. This 
speeies is very widely distributed and breeds in almost any kind of water, apparently preferring water that eontains sewage. It will, on occasions, breed in salt water, but it is preferentially a domestic inseet. It enters inhabited houses freely and bites all night. The adults resemble $C$. fatigans so elosely that it is difficult to distinguish them. The males differ most in the

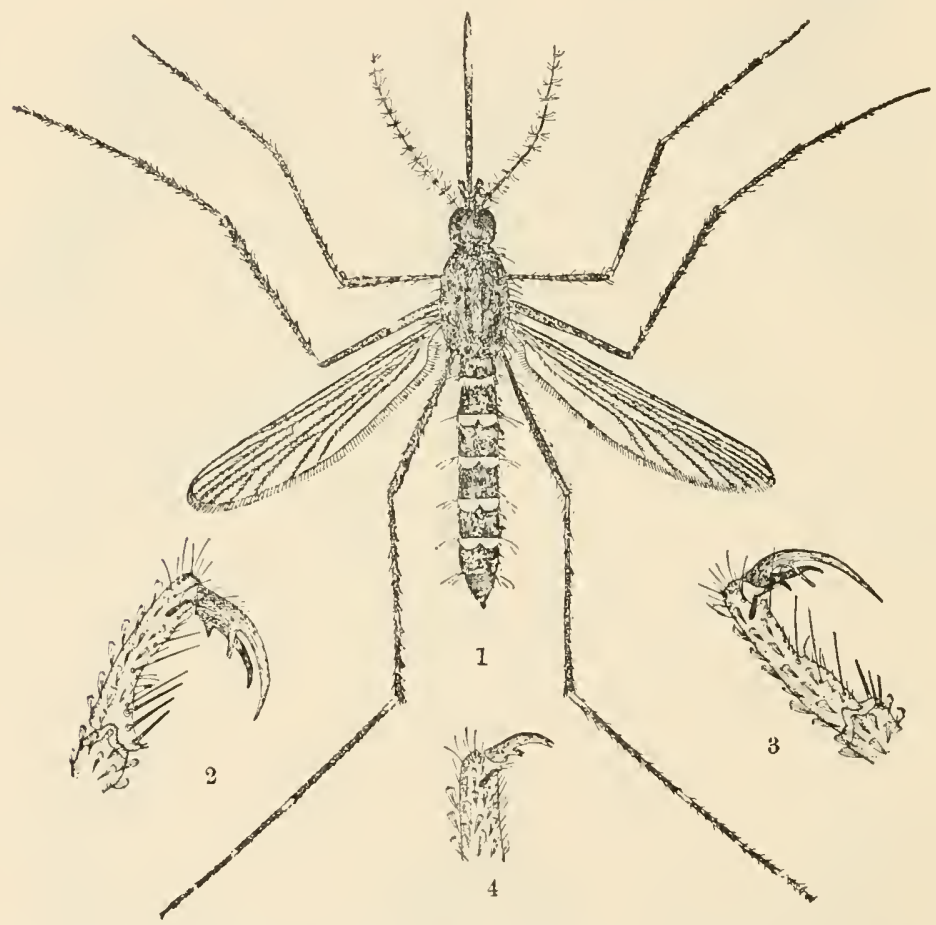

Fig. 40.-Adult of Aedes vexans. (After John B. Smith, New Jersey Agricultural Experiment Stations.)

1 , adult female; 2 , anterior; 3 , middle, and 4, posterior, claws of the male. All are greatly enlarged.

genitalia; the pipiens females have the abdominal banding continuous, while the females of fatigans generally have the pale bands interrupted at the sides. The life history of this mosquito and its habits are very similar to those of $C$. fatigans.

Culex restuans, Theob., is quite similar to $C$. pipiens in appearance, being distinguished from it only by the fact that, under a magnifying glass, two white spots are often noticeable on top of the thorax and in front of the other white marks. C. restuans 

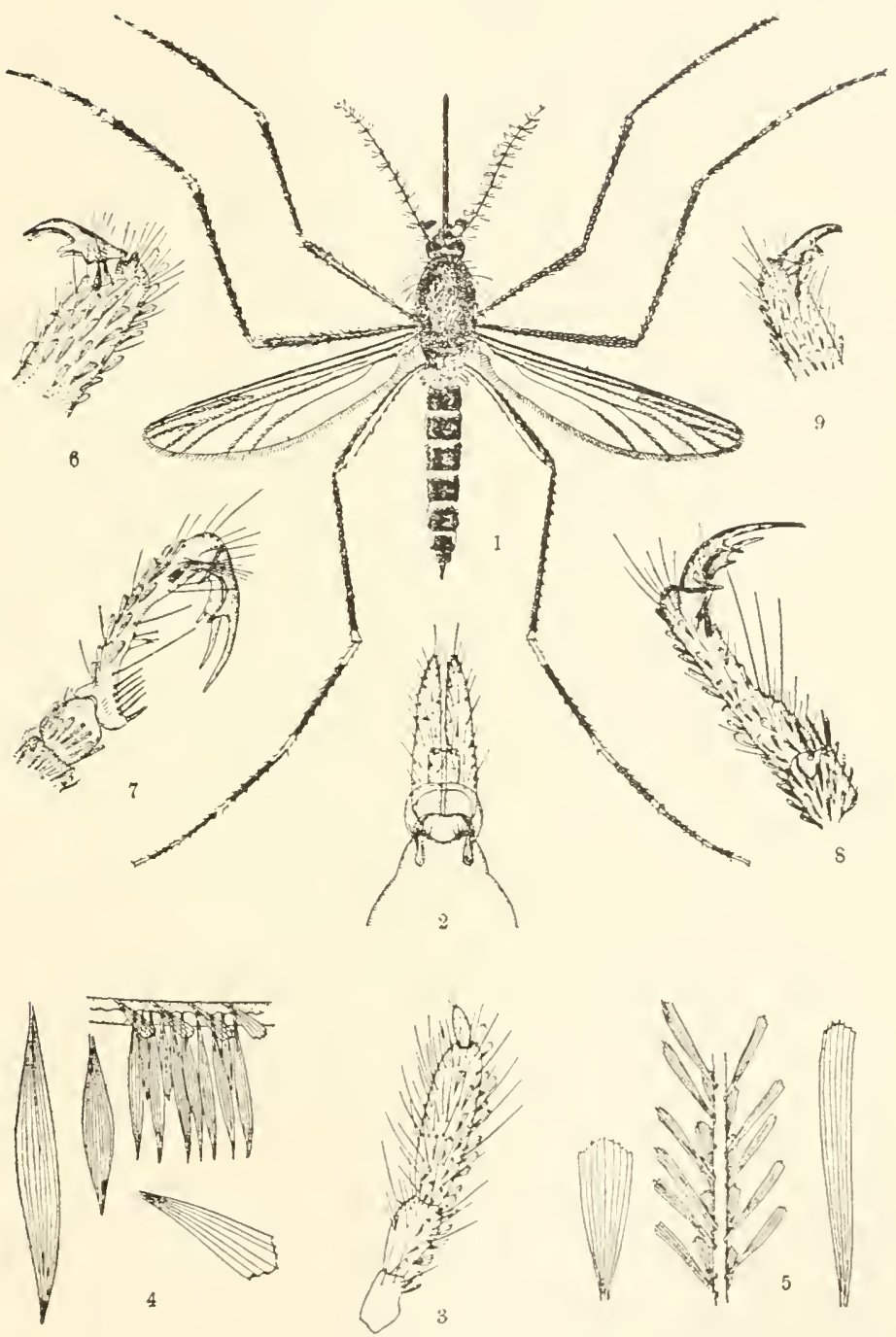

FIG. 41.--Adult of Aedes canadensis. (After John B. Smith, New Jersey Agricultural Experiment Stations.)

1 , adult female; 2 , ovipositor; 3 , palpus; 4 , margin of the wing, showing the fringe scales; 5 , part of vein, showing scales; 6 , anterior claws of female; 7 , anterior; 8 , middle, and 9, posterior claws of male. All are greatly cnlarged. 
differ's from $C$. pipiens in that it seems to prefer clear, clean water, but otherwise its habits, etc., are similar. The larva differs from that of $C$. pipiens in that the antennal tuft is less than halfway between base and tip, while in the case of pipiens larvae it is generally more than this.

\section{FRESH-WATER SYLVAN GROUP}

Aedes vexans, Meig, one of the most important mosquitoes of this group, is a smallish insect with unspotted wings and unbanded beak. Its tarsi have narrow light bands at the base, as do the abdominal segments. The larva has a spotted head. Its respiratory siphon is about three times as long as it is broad. The antennae spring from the sides of the anterior part of the head. This species breeds only in temporary puddles, eschewing permanent water. Some eggs hatch after every rain; frequently all perish by drying of the pool. A. vexans, it is said, will fly as far as 5 miles. This mosquito does not enter houses, but prefers shady places such as under trees and porches, and bites day and night.

Aedes canadensis, Theob., has a black proboscis, a brown, unmarked thorax and unspotted wings. The last tarsal segment is white; the others are brown with white bands at the base and tip. A. canadensis is found probably most frequently in forest pools, etc., and is not supposed to travel far. The larvae are gray with dark heads. In the early stages the larva has a light transverse band about its neck. The scales on each side of the eighth segment are isolated and elongated. The life history and habits of this insect, generally speaking, are similar to those of $A$. vexans.

Mansonia perturbans Wlk. (Coquilletidia perturbans Wlk.) is a large brown mosquito with a very irritating bite. Both tarsal and abdominal segments have narrow white bands at the base and the first tarsal joints have broad bands near the middle. The proboscis has a broad white band in the middle also. This species breeds only in permanent swamps. The larvae and pupae differ from all others in that they remain at the bottom of the pool, drawing their oxygen supply from certain plant roots, etc. They are light in color and have a respiratory siphon shaped like a bottle. The larvae of this species hibernate, attached to roots, etc.; they are able to withstand freezing. According to 
Headlee, ${ }^{1}$ there is only one brood a year, egg-laying starting when many of the previous season's larvae are still small. The fact that the larvae and pupae of this species get their oxygen from roots under the water renders them invincible to oil. In the case of this species, use of a larvicide is indicated.

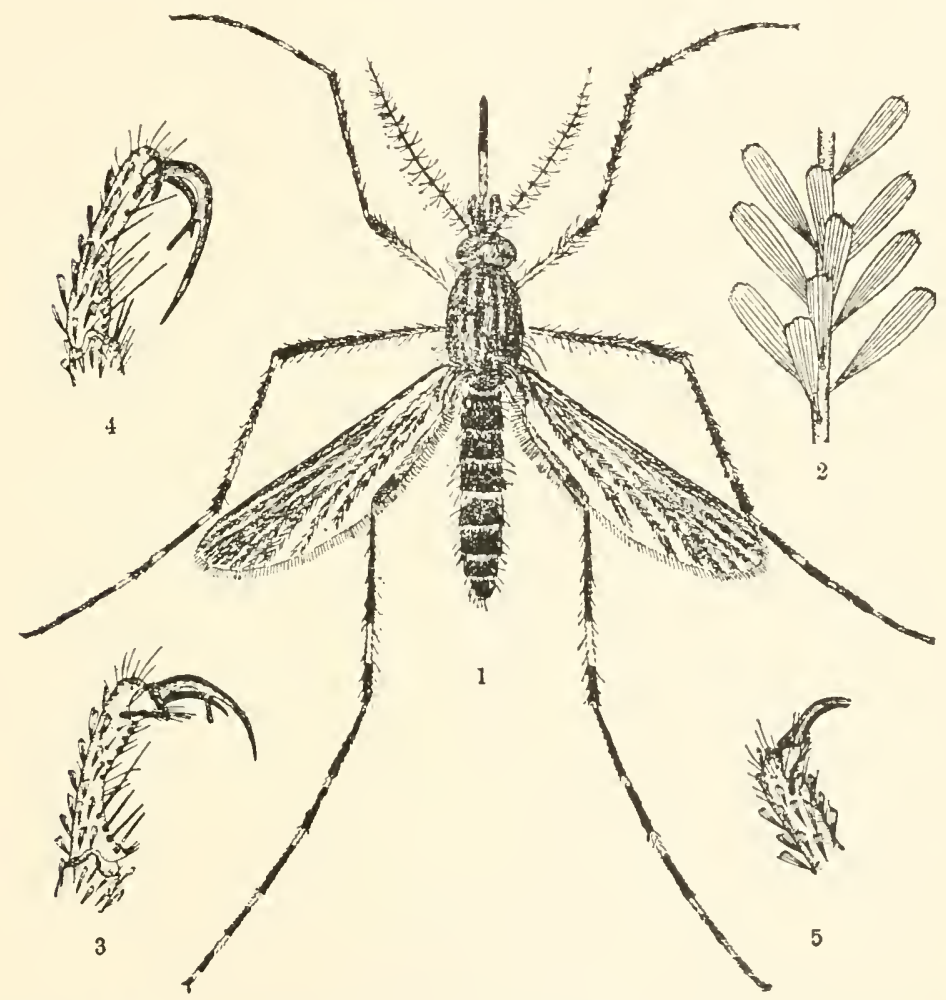

Fig. 42.-Adult of Mansonia perturbans. (After John B. Smith, New Jersey Agricultural Experiment Stations.)

1 , adult female; 2 , part of wing vein, showing scales; 3 , anterior; 4 , middle, and 5, posterior claws of male tarsi. All are greatly enlarged.

Psorophora ciliata, Fabr., is one of the largest mosquitoes in the Uniter States. It lays its eggs in depressions likely to collect water in time of rains. When the rains eome, the eggs hatch out. The larvae are very large, and feed entirely on the larvae of smaller species, aceording to Dyar.

1 "The Mosquitoes of New Jersey and Their Control," New Jersey Agricultural Experiment Stations, Bull. 276, 1915. 


\section{SALT MARSH GROUP}

Acdes sollicitans, Wlk., probably is one of the most troublesome of the salt marsh mosquitoes. The thorax of this insect is yellowish on top and the sides are white; broad white bands

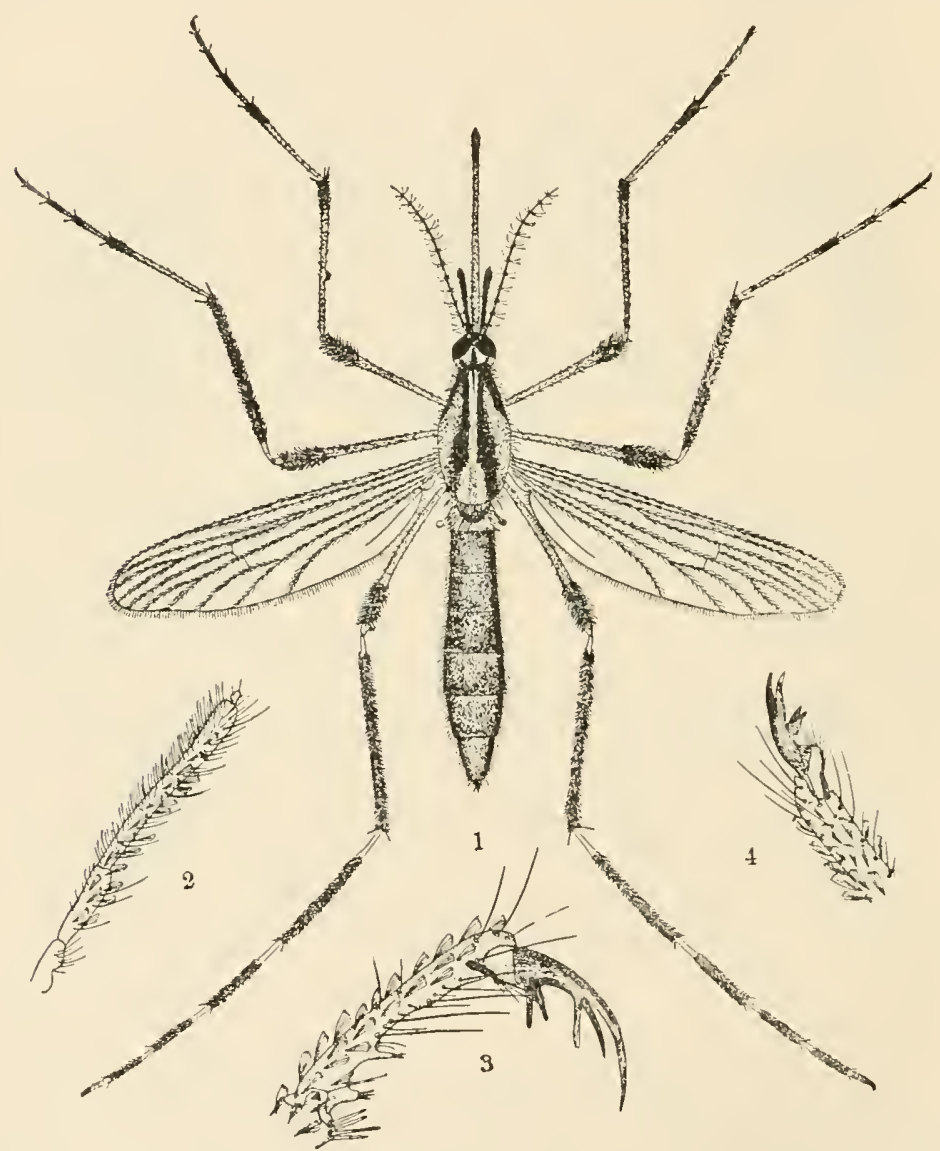

Fig. 43.- Adult of Psorophora ciliata. (After John B. Simith, Neu Jersey Agricultural Experiment Stations.)

1, adult female; 2 , palpus; 3 , anterior, and 4 , posterior claws of male. All are greatly enlarged.

encircle the proboscis and feet; and there is a yellow stripe along the bottom and a white stripe along the top of the abdominal segments. A. sollicitans breeds exclusively in the salt marshes, but occasionally, wind conditions being suitable, it travels great 


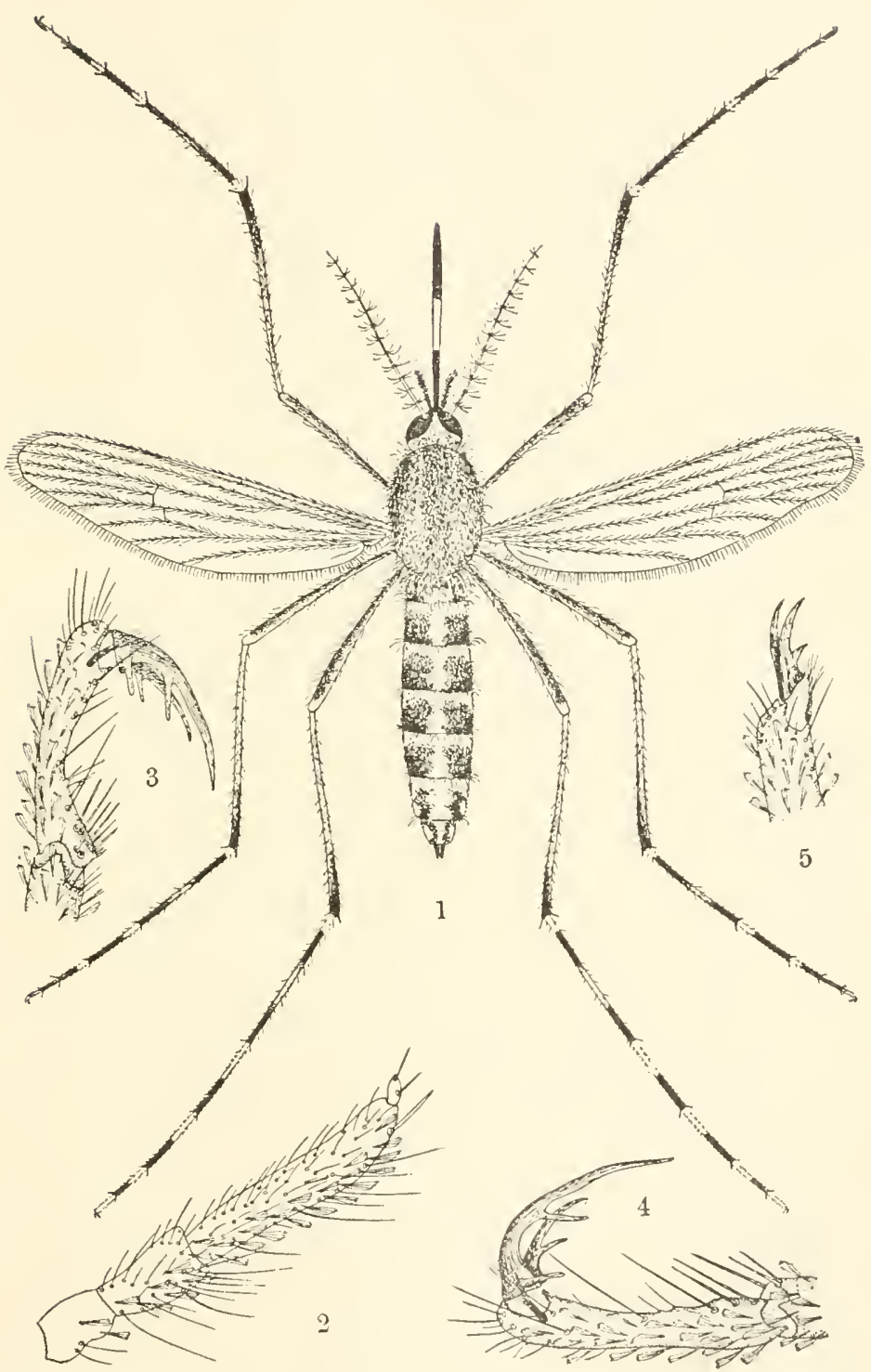

FIG. 44.-Adult of Aedes sollieitens. (After John B. Smith, Vew Jersey Agricultural Experiment Ntations.)

1, adult female; 2 , palpus; 3 , anterior; 4 , median, and 5 , posterior claws of the male. All are greatly enlarged. 
distances-sometimes, according to Headlec, ${ }^{1}$ as much as 40 miles. The same writer says of it: "It is the greatest single factor now operative in South Jersey in depressing real estate values and preventing the proper development of that section of the State." The larvae, of a grayish color, are large and have a respiratory siphon only about twice as long as broad. The head is unmarked. The antennae, sprouting from the sides of the anterior part of the head, are not pendant. The scales form a

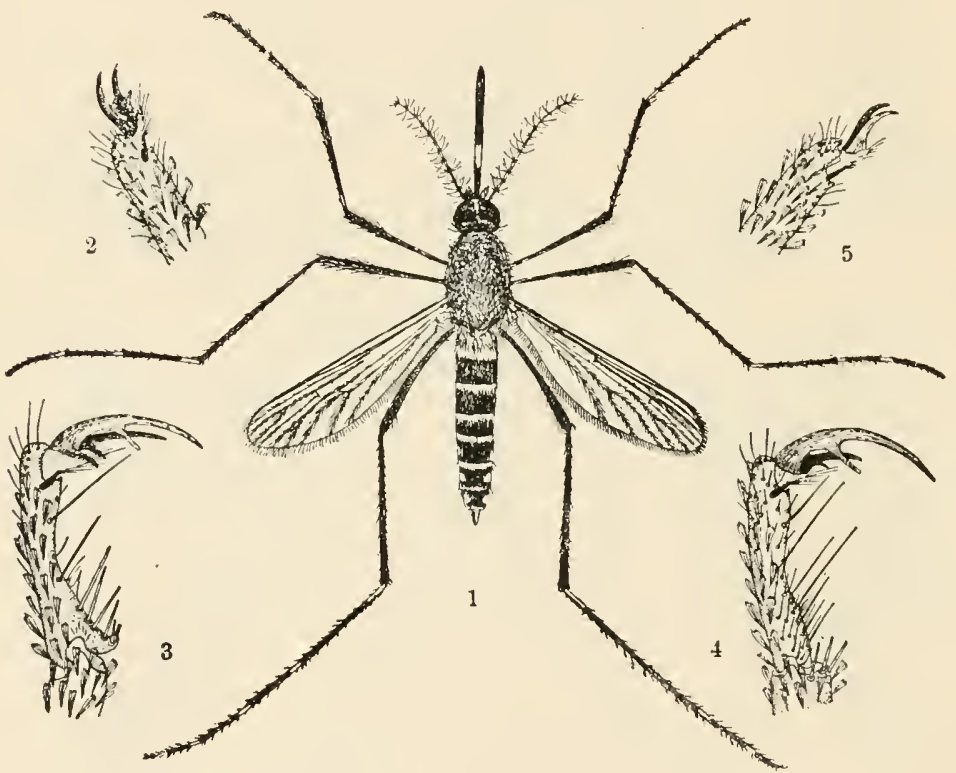

Fig. 45.- Adult of Aedes taeniorhynchus. (Afier John B. Smith, New Jersey Agricultural Experiment Stations.)

1 , adult female; 2 , anterior claws; 3 , anterior; 4 , median, and 5 , posterior claws of male. All greatly enlarged.

large patch on each side of the eighth segment. The race survives the winter in egg form in mud or damp earth. They are able to withstand several months of dry weather, and develop rapidly as soon as water covers them. Headlee' says that if the water lasts only long enough for the larvae to turn into pupae, the pupae will get enough moisture from the mud to enable them to live long enough to reach the adult stage. He continues: "Apparently, a considerable percentage of the eggs deposited

1 "The Mosquitoes of New Jersey and Their Control," New Jersey Agricultural Experiment Stations, Bull. No. 276, 1915. 


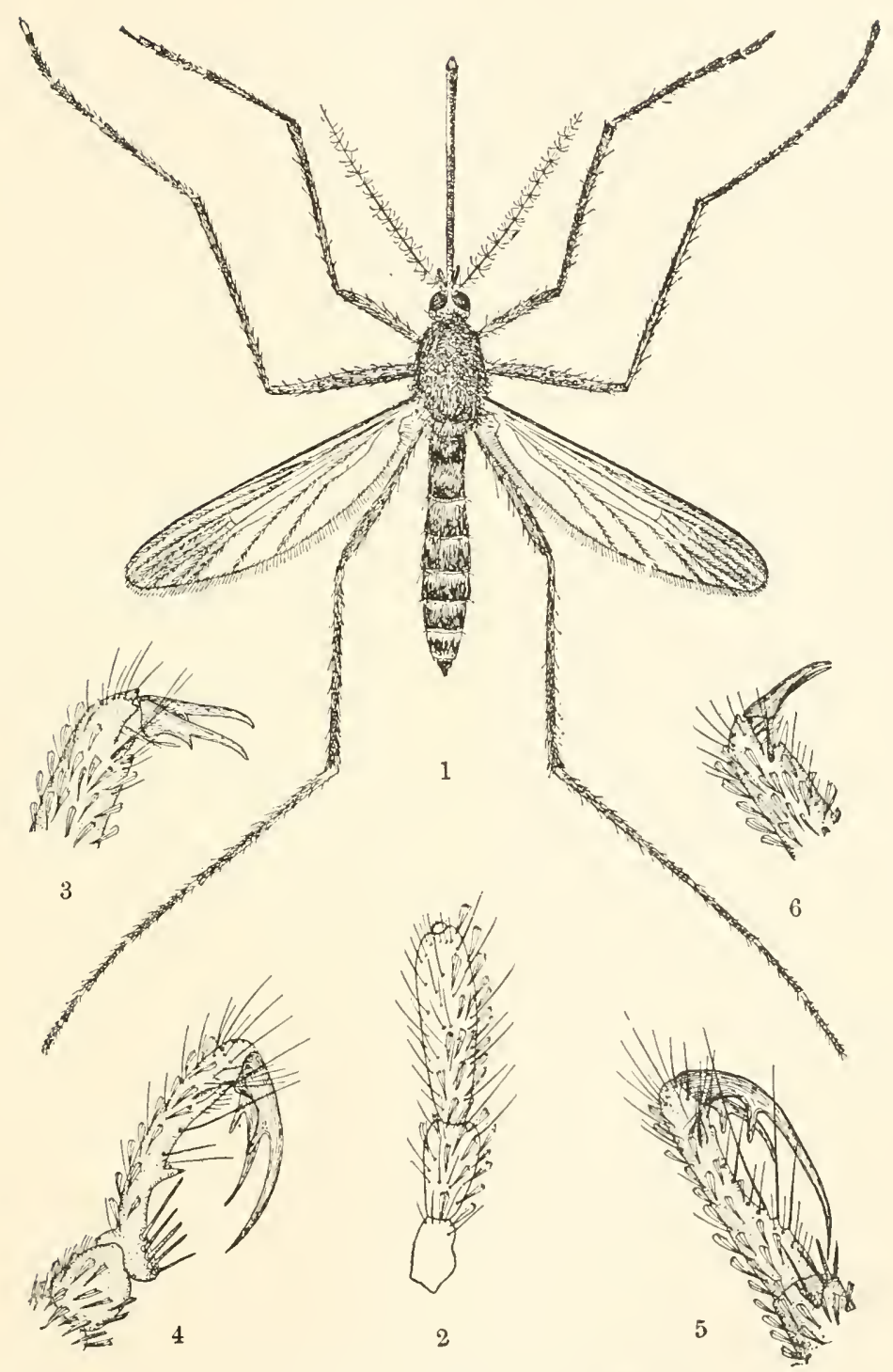

FIG. 46.-Adult of Acdes cantator. (After John B. Simith, New Jersey Agricultural Experiment Stations.)

1 , adult female; 2 , palpus, and 3 , anterior claws of same; 4 , anterior; 5 , median and 6 , posterior elaws of male. All are greatly enlarged. 
during any one season fail to hateh during that season and remain in the mud until the following one. By this provision of nature, the salt marsh is always stocked with eggs, and the appearance of the brood is a matter of water covering, high temperature and the absence of fish."

Aedes taeniorhynchus Wied., is a small, black insect, with narrow white bands around the proboscis, the bases of the abdominal segments and the bases of the tarsal joints, except the last, which is wholly white. The larva may be distinguished

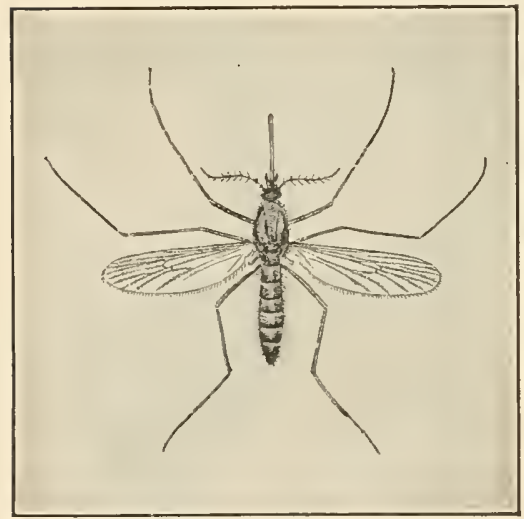

FIG. 47.-Culex salinarius, female. (After Howard.)

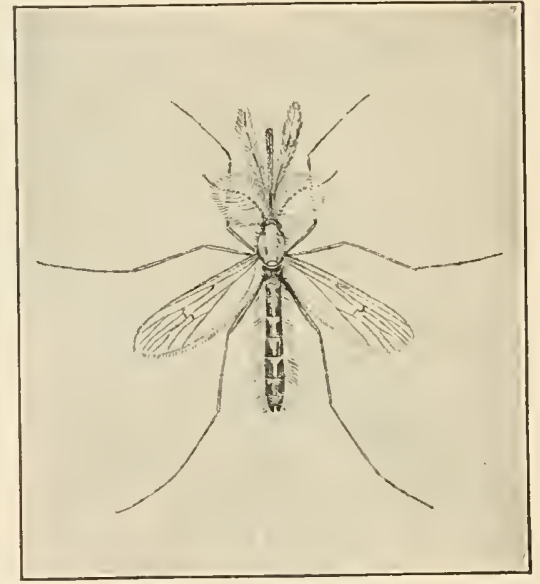

FIG. 4S.-Culex salinarius, male. (After Howard.)

from that of $A$. sollicitans by the fact that the head is usually slightly marked. Like $A$. sollicitans, and $A$. cantator, this mosquito does not breed in permanent marshes, but in temporary pools of comparatively fresh water along the coast; usually, $A$. taeniorhynchus selects less salty water than A. sollicitans. Otherwise, the habits of $A$. taeniorhynchus are similar to those of sollicitans, except that it is not believed to travel so far.

Aedes cantator, Coq., is a large, brownish mosquito with a hairy thorax; the bases of both the tarsi and the abdominal segments have a faint, white band about them. The head of the larva has black spots; otherwise, the larva is similar to that of $A$. sollicitans. A. cantator usually selects somewhat fresher water than does sollicitans, but not quite so fresh as does taeniorhynchus, its choice apparently being the "back pools," containing a large admixture of fresh water. 
Culex salinarius, Coq., is very similar to $C$. pipiens, except that it is somewhat darker and thimmer. The larva is distinguishable from that of $C$. pipiens by the fact that it has a longer breathing siphon, which tapers uniformly from base to tip. This species, like $C$. pipiens, winter's as an adult, eggs being laid by gravid females in the spring; the eggs are laid in rafts, similar to those of $C$. pipiens. This species occurs over the whole Eastern part of the United States, breeding in permanent water in the same way as pipiens, fatigans (quinquefasciatus) and restuans. It is, perhaps, most eommon in fresh-water swamps along the sea-coast but does not oceur there exclusively. 


\section{CHAPTER III}

\section{DEVELOPMENT OF CONTROL MEASURES}

\section{HISTORICAL ASPECTS}

For centuries, the origin of the mosquito-borne diseases was shrouded in mystery. At times they were, in common with other diseases, regarded as scourges sent by God to punish man. Finally, during the Middle Ages, malaria was discovered to be a definite disease, with definite symptoms and attributes. As it was generally prevalent in low, swampy areas, where humid mists and vapors arose, it is not surprising that the clisease was believed to be caused by this unhealthful atmosphere. From this belief, the disease derived its name, mal being the Italian word for "bad" and aria being the equivalent for "air."

Yellow fever was for many years considered as a form of malaria, and only in comparatively recent times was it discovered to be a distinct disease.

This belief as to the origin of malaria and yellow fever continued until well into the nineteenth century, when here and there a physician arose who, expressed the opinion that there was some connection between malaria and mosquitoes. A great step forward was made in 1880, when Alphonse Laveran, a French army surgeon, announced the discovery of the malaria parasite in the blood of persons suffering from malaria. In 1884, Laveran joined the protagonists of the mosquito theory, but was unable to offer definite proof as to the soundness of the belief.

Fifteen years later, Sir Ronald Ross, a British army surgeon working in India, discovered the parasites described by Laveran in the stomach walls of Anopheles mosquitoes which had been allowed to bite persons infected with malaria, and demonstrated that they underwent certain changes while in the body of the mosquito. The life-cycle of the parasite was soon afterward worked out and the whole course of the disease laid bare. Final proof of the correctness of the theory of transmission was afforded in 1900, when Manson and Warren were bitten in London by infected mosquitoes forwarded from Italy, and shortly thereafter developed malaria. 
Flint having shown in 1868 that yellow fever was distinct from malaria since its eourse was not affected by use of quinine, Finlay, in 1882, announced his belief that the disease in some way was transmitted by the mosquito. This theory was fully substantiated in 1900-1902 by a board of U. S. Army medical officers who proved conclusively that Aedes calopus was the culprit. Although the infective agent was not found, the discovery that yellow fever, like malaria, is transmitted by the mosquito was sufficient to make preventive work possible.

\section{BEGINNING OF MOSQUITO CONTROL}

The value of these two epoch-making discoveries was at once apparent. Since both malaria and yellow fever were transmitted in nature solely by mosquitoes, the only thing necessary to eliminate both was to control the mosquito. This might be done either by destroying the mosquito or by rendering it impossible for it to get aceess to malaria or yellow fever patients-in other words, by sereening-or by a combination of both methods.

These diseoveries meant, to put it in another way, that two of the chief obstacles to man's conquest of the tropics could be brushed aside. They meant that no longer could these scourges of humanity defy all sanitary and medieal measures. They meant that great engineering works like railroads, canals and other modern necessities of trade could be carried through to completion anywhere in the tropics.

No delay took place in applying the newly gained knowledge. The first great demonstration of its soundness was afforded in 1901, when Gorgas freed Havana, Cuba, from yellow fever in 3 months; the eity had not previously been without yellow fever for 150 years. In this classic campaign, both screening and anti-mosquito methods were utilized.

\section{SANITARY CONQUEST OF THE CANAL ZONE}

But it was in the sanitation of the Panama Canal Zone that Gorgas achieved his greatest triumph. Malaria and yellow fever had disastrously defeated two attempts by the French to complete the canal, so when the American government undertook the great task, Gorgas was placed in charge of the anti-mosquito work in the whole zone.

Within a few months, yellow fever was almost eliminated. The last case in the City of Panama was reported in 1905, while 
the last ease in Colon occurred in 1906. Thereafter, yellow fever was unknown in the Canal Zone.

Progress in malaria control was slower but no less sure. The following tablet will show in an abbreviated form the very material reduction in the malaria morbidity and mortality rate among Canal employes during the latter period of American construction. The rates are subject to the qualifieation that they are based on the number of names on the payroll and not on the true average number of persons employed:

\begin{tabular}{|c|c|c|c|c|c|}
\hline \multirow{2}{*}{ Year } & \multirow{2}{*}{$\begin{array}{l}\text { Average } \\
\text { number of } \\
\text { employes }\end{array}$} & \multicolumn{2}{|c|}{ Death from malaria } & \multicolumn{2}{|c|}{$\begin{array}{c}\text { Hospital cases of } \\
\text { malaria }\end{array}$} \\
\hline & & Number & $\begin{array}{c}\text { Rate per } \\
10,000\end{array}$ & Number & $\begin{array}{c}\text { Rate per } \\
100\end{array}$ \\
\hline 1906 & 26,547 & 233 & 87.8 & 21,739 & 81.9 \\
\hline 1907 & 39,343 & $15 t$ & 39.1 & 16,753 & 42.6 \\
\hline 1908 & 43,890 & 73 & 16.6 & 12,372 & 28.2 \\
\hline 1909 & 17.167 & 52 & 11.0 & 10.169 & 21.6 \\
\hline 1910 & 50,802 & 50 & 9.8 & 9,487 & 18.7 \\
\hline 1911 & 48,876 & 47 & 9.6 & 8,987 & 18.4 \\
\hline 1912 & 50,893 & 20 & 3.9 & 5,623 & 11.0 \\
\hline 1913 & $56,65 t$ & 21 & 3.7 & 4,284 & 7.6 \\
\hline 1914 & 44,329 & 7 & 1.6 & $2,8 \& 6$ & 6.5 \\
\hline 1915 & 34,785 & 9 & 2.6 & 1,570 & 4.5 \\
\hline 1916 & 33,176 & 3 & 0.9 & 493 & 1.5 \\
\hline
\end{tabular}

\section{ANTI-MOSQUITO WORK ELSEWHERE}

The work at Havana and Panama gave a great impetus to anti-mosquito eampaigns in other parts of the world, and slowly, but surely, one after the other of the great endemic centers of yellow fever were eleaned up. Several of the large eities of Brazil, for centuries known and recognized as foci of the dreaded "yellow jack," were successfully attacked. In 1905, Belize, British Honduras, was eleaned up, while in 1906-07 a suceessful campaign was condueted in the British West Indies.

In 1905, an epidemic of yellow fever broke out in New Orleans. Anti-mosquito measures were at once employed and the disease was soon stamped out, with a total of 3,389 cases and 443 deaths. This compares very farorably with the figures of the great epi-

1 "A Plea and A Plan for the Eradication of Malaria Throughout the Western Hemisphere," Prudential Insurance Company of America, 1917. 
demic of 1898 (before the manner of transmission of yellow fever was known) in which there were 13,817 cases and 3,984 deaths.

One of the most important compaigns for the suppression of yellow fever in recent years was waged in Guatemala in 1918 by the International Health Board. This campaign, directed by Ciorgas, stamped out the epidemic in a few weeks and eliminated one of the last important endemic foci of yellow fever in Central America. The report of the International Health Board says:

"The outcome was especially gratifying and encouraging in that it demonstrated that yellow fever could be controlled with the personnel and facilities available in Central American countrics and at a cost well within their financial ability."

\section{MALARIA CONTROL IN UNITED STATES}

Following the successful campaign for the elimination of yellow fever along the Gulf Coast and other parts of the South, the attention of sanitarians throughout that section began to center on control of malaria. The splendid results of the anti-malaria campaign in Panama served as an example of what might be done, but the people were slow to grasp the situation. The fact that elimination of yellow fever in the South had been brought about more by isolating patients from mosquitoes than by eradication of mosquitoes in general obscured the public appreciation of the possibilities of malaria control. The bulk of the people took the attitude that to attempt to eliminate mosquitoes and malaria would be a waste of time.

As a result of this misconception of the situation, it was not until several years had elapsed that anything very definite was accomplished. However, in 1914, the U. S. Public Health Service made an allotment of $\$ 17,000$ for anti-malaria work, and, within the next few years several valuable and far-reaching demonstrations were carried out. The results of a few of these will be mentioned here.

\section{INTERPRETING RESULTS}

It should be pointed out that, in the following tables, the percentages of infection, as found by blood tests prior to commencement of work, should not be considered as representing the total of infections during the previous malaria season. These blood test percentages should be regarded as merely that fraction of the 
total number of persons infected who had not been able, either by natural resistance or by the use of quinine, to banish the plasmodia from their systems. Thus at Roanoke Rapids, as will be seen later, the blood tests in the fall showed 13.75 per cent of the total population infected with plasmodia; during the mosquito season, however, about 75 per cent of the total population was infected, according to the health officer.

It should also be borne in mind, in interpreting the percentages of reduction of persons reporting infection or illness (history index) and of physicians' calls, etc., that what may seem like a heavy remaining infection, despite a considerable reduction due to control work, may be only recurrences of former infection. As intimated in Chapter I, chronic cases may regain their acuteness when the bodily resistance becomes clisturbed or weakened, without there being a new infeetion at all. Thus, the work may be very effective and, indeed, prevent any new infection at all, despite the fact that the history index and the records of physicians' calls may still show quite a percentage of eases. These chronic cases however, show a marked reduction year by year when the work is kept up.

Owing to the difficulty of ascertaining in cases of protracted illness whether the patient is suffering from one chronic infection or repeated new ones, it has been found generally that comparisons of physicians' calls gives a better idea of the effectiveness of the campaign than comparisons of eases. Just what the relation of calls to cases may normally be is not definitely known. It is believed, however, that in general, especially where the sickness is wide-spread, physicians do not average more than two calls to a case, and frequently not that.

\section{EARLY UNITED STATES MALARIA CONTROL DEMONSTRATION}

Roanoke Rapids, N. C., is a cotton-mill town in the northern part of the state, having a population, including two nearby mill villages, of approximately 4,100 in 1913. During the summers of $1910,1911,1912$ and 1913 , according to the health officer, 75 per cent of the people of Roanoke Rapids suffered from malaria. During the same periods, this physician's visits on account of malaria alone averaged about 50 a day.

Anti-mosquito work was begun under auspices of the U. S. Public Health Service in January, 1914 and continued until the end of the season of 1916 . The following table' shows the 1 "Demonstrations of Malaria Control," U. S. Public Health Service, 1918. 
reduction in prevalence of malaria as revealed by blood examinations, by house-to-house inquiry and by census of the sick, together with costs of the work year by year:

\begin{tabular}{|c|c|c|c|c|}
\hline & 1913 & 1914 & 1915 & 1916 \\
\hline Blood tests, per cent infected. & 13.75 & 4.48 & 3.51 & 1.58 \\
\hline Per cent reporting fevers..... & 46.60 & 33.00 & 19.10 & 16.70 \\
\hline Persons sick in bed, Oct. $1 \ldots$ & 200.00 & 1.00 & none & none \\
\hline Health officer's daily calls.... & 50.00 & 1.00 & 0.33 & \\
\hline Cost of anti-mosquito work.. & $\ldots \ldots$ & $\$ 36 \$ 3.41$ & $\$ 1233.20$ & $\$ 1237.31$ \\
\hline Per capita cost of work..... & & 0.80 & 0.27 & 0.27 \\
\hline
\end{tabular}

This big reduction in the incidence of malaria at comparatively small cost aroused great enthusiasm among the mill owners, who previously had suffered serious losses owing to illness of some employes and seasonal departure of others to escape malaria. The following is taken from a letter written by the treasurer of the Roanoke Mills Co. to Surgeon R. H. von Ezdorf:I

"I will frankly admit that I could not realize what a great change could be brought about by systematic work and with comparatively little expense. The money spent in anti-malarial work here has paid the quickest and most enormous dividends I have ever seen from any investment, and, after having had our experience, I would, if necessary, do the work over again if I knew it would cost ten times the amount."

\section{DEMONSTRATION AT ELECTRIC MILLS, MISS.}

Electric Mills, Miss, is a lumber town in northern Mississippi, situated in a flat, rolling country with numerous surrounding water-courses. The mill physician said that during September, 1912,95 per cent of all sickness for the month was due to malaria and that only two white families in town had not been afflicted with it.

Anti-mosquito work was commeneed in May, 1914, by and under the direetion of Assistant Surgeon General H. R. Carter of the U. S. Public Health Service. The following table ${ }^{2}$ shows the reduction in incidence of malaria year by year, and the cost thereof:

1 "Demonstrations of Malaria Control," U. S. Public Health Service, 1918. 


\begin{tabular}{l|r|r|r|r}
\hline & 1913 & 1914 & 1915 & 1916 \\
\hline Blood tests, per eent infected...... & 11.76 & 3.79 & $\ldots \ldots$ & 1.46 \\
Mill physician's cases yearly...... & 144.00 & $\$ 5.00$ & 70.00 & \\
Cost of anti-mosquito work........ & $\ldots \ldots$ & $\$ 725.50$ & $\$ 143.80$ & \\
Per capita cost of work........... & $\ldots \ldots$ & 1.21 & 0.24 & \\
\hline
\end{tabular}

${ }^{A}$ This blood test was made in May, 1914, but, as it represents the situation before control work started, it is placed under 1913.

\section{CO-OPERATIVE DEMONSTRATION AT CRCSSETT, ARK.}

Crossett, Ark., is a lumber town in the low part of the state. The population in 1916 was estimated at 2,029. Work was started there in May, 1916, under a co-operative arrangement between the U. S. Public Health Service and the International Health Board. The reduction in the incidence of malaria and costs for the years 1916-17 are given in the tollowing table ${ }^{1}$ :

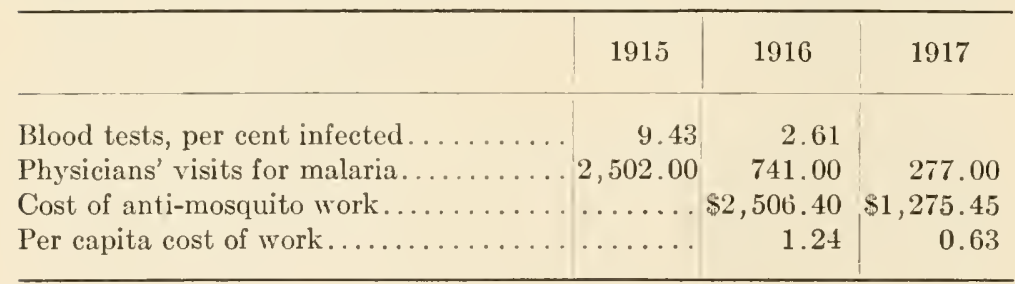

In 1917-18 further demonstrations were made in Hamburg, Lake Village, Dermott, Monticello and Bauxite, Ark. 'The reduction of calls for malaria ranged from 78.4 to 97.4 per cent and the per capita costs from $\$ 0.46$ to $\$ 1.45$.

\section{WORK OF ST. LOUIS \& SOUTHWESTERN RAILROAD}

During 1916, steps were taken by the St. Louis \& Southwestern Railroad to undertake measures for the control of what had been observed to be an undue incidence of malaria among its employes. It had been found that during the preceding 4 years, about 25 per cent of all admissions to the hospital at Texarkana had been for malaria, an annual average of 640 cases having been treated for about 5 days each; this was equivalent to about 4 per cent of

1"Malaria Control: A Report of Demonstration Studies,"and "Malaria Control: Results Obtained by a Local Community," U. S. Public Health Service, 1917 and 1918. 
15,000 employes, and did not include such cases as were treated by local physicians. An appropriation of about $\$ 3,000$ was made for the purpose of initiating anti-mosquito measures, which were begun, in co-operation with the U. S. Public Health Service, at Tyler, Lufkin and Keltys, Tex., early in 1917.

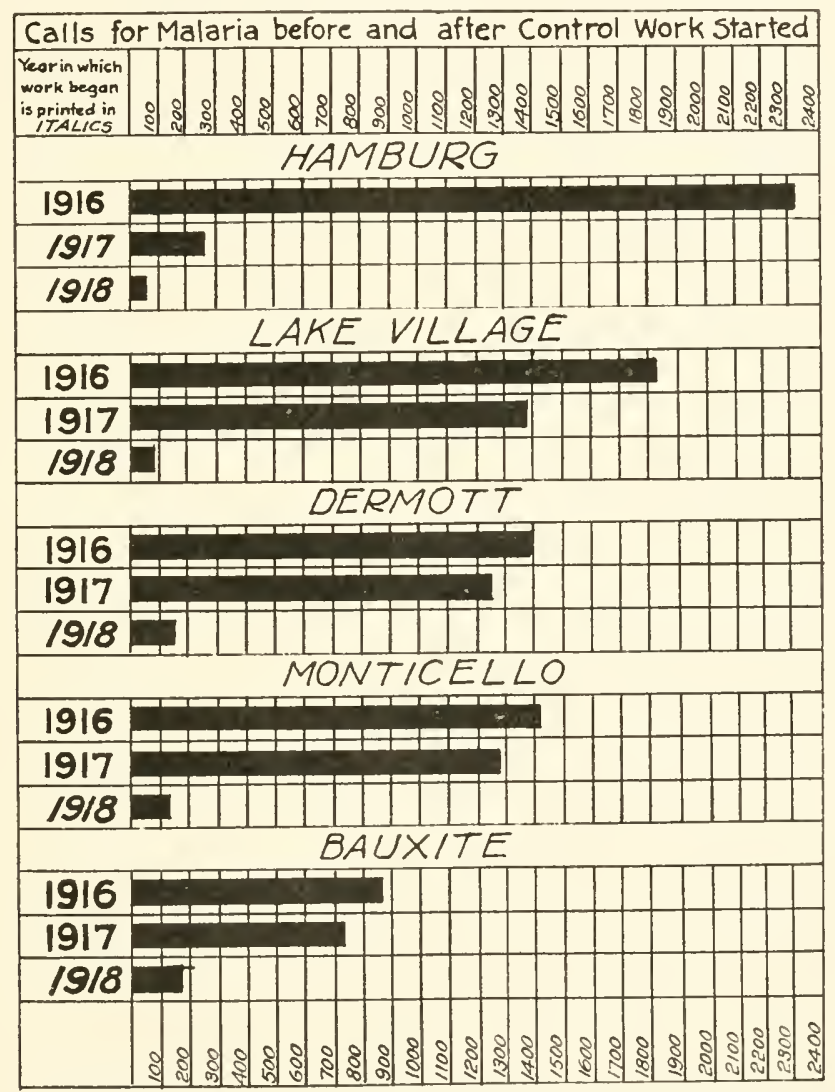

FIG. 49.-Results of mosquito eradication campaigns at Hamburg, Lake Village, Dermott, Monticello and Bauxite, Ark.

The following table shows the cases of malaria admitted to the hospital at Texarkana from places where anti-mosquito work was earried on in 1916 and 1917 respectively: 
At Tyler, the sale of physicians' prescriptions containing quinine decreased about 49 per eent in 1917, as compared with 1916.

Results obtained at Keltys, where malaria formerly had been severe, are particularly interesting. The nanager of the lumber mill there stated in 1917 that, had malaria prevailed to the same degree as in 1916, the mill would have been closed about onehalf the time. The net loss of this to the railroad in freight eharges alone would have been about $\$ 30,000 .{ }^{1}$

The railroad prompted by the suecess of this demonstration, considerably expanded its work against mosquitoes in later years. In 1920, its appropriation for this work amounted to $\$ 41,150$, while $\$ 15,000$ additional was appropriated by different towns along the line under a co-operative plan for mutual malaria protection. ${ }^{2}$

In 1920 , the Central of Georgia Railroad appropriated $\$ 14,000$ for similar work. Several other interstate railroads are also known to be contemplating making appropriations for this work.

\section{UNITED STATES ANTI-MOSQUITO WORK DURING WORLD WAR}

In view of the heavy morbidity records of army camps in the South during the Civil and Spanish-American wars, it was decmed essential, when the United States entered the World War in 1917, to institute, among other health measures, antimosquito eampaigns in the areas surrounding Southern military cantonments, naval reservations, aviation camps, munition plants, ship-yards and important war-industrial projects.

It was realized that the introduction of thousands of recruits and of large forees of labor from areas in which the mosquitoborne diseases were prevalent would produce new conditions at and about towns in which this war work was earricd on that would make extra precautionary measures essential. In order therefore, to provide complete protection, it was decided that anti-mosquito campaigns should be carried on, not only within the eantonments, ship-yards and war-industrial areas, but also within an area a mile wide surrounding such war establishments and towns near or in which they were situated.

In order to prevent conflict of jurisdiction, army and navy

1 Annual Report, U. S. Public Health Service, 1918, page 23.

${ }^{2}$ Annual Report, U. S. Public Health Service, 1920, page 20. 
organizations were placed in charge of the anti-mosquito work within the war-project reservations, while the U. S. Public Health Service was placed in charge of the work in the mile wide territories outside of and surrounding the war project areas and towns adjacent thereto.

"It was not known in advance," says LePrince, " "how many camps were to be established, when or where they were to be located, nor what forec of trained enginecrs, foremen and labor would be needed; but it was very apparent that as soon as each camp-site was approved, mosquito control measures and drainage operations should be expedited in order to head off malaria transmission in that locality."

The result of the work was that the sick-rate from mosquito-borne diseases was cut down to virtually nothing; what little malaria there was consisted almost entirely of men already infected before reaching the war-project arcas. As LePrince says, "The malaria sick-rate among enlisted men in camp has been very much lower than it would have been had they stayed at home."

\section{FORTY-THREE WAR-PROJECT AREAS PROTECTED}

This great anti-mosquito project was carried out by the Public Health Service in 43 war-project areas seattered over 15 states. The area protected covered 1,200 square miles; the population protected included a civil population of about 1,750,000 and an average, constantly-changing military and naval population of 800,000 . The total cost of the anti-mosquito work averaged about $\$ 1.80$ per acre of territory protected or about 54 cents for each person protected. About one-third of this cost was met by the communities involved.

This work was carried on at the following places in the South:

Alabama-Sheffield, Tuscumbia, Florence, Anniston, Montgomery.

Arkansas-Little Rock, Lonoke.

Florida-Jacksonville.

Georia-Macon, Augusta, Atlanta, Columbus, Americus.

KeNTuckY-Louisville.

Louisiana-Lake Charles, Alexandria.

Mississippi-Biloxi, Gulfport, Pass Christian, West Point, Hattiesburg, Jackson.

Nortu Carolina-Charlotte, Raleigh, Fayetteville, Wilmington.

South Carolina-Columbia, Greenville, Spartanville, Charleston.

Tennessee-Memphis, Millington, Nashville, Chattanooga.

Texas-Dallas, Fort Worth, Houston, San Antonio, Orange.

Viraixia-Newport News, Petersburg, Alexandria, Portsmouth, Quantico.

1 "Mosquito Control About Cantonments and Ship-yards," U.S. Public Health Service, 1919. 


\section{POST-WAR MOSQUITO CONTROL}

The brilliant results obtained through the war anti-mosquito work of the U. S. Publie Health Service aeted as a great stimulus to further efforts in this direetion throughout the South. Many of the towns in which these campaigns were conducted during the war have continued the work ever sinee.

In addition to these and other towns, which conducted their own work independently, and to the work condueted in many towns along its lines by the St. Louis \& Southwestern Railroad, more than 40 towns and cities throughout the South initiated campaigns in 1920 under a co-operative plan which included the State Health Departments, the International Health Board and the Public Health Service. This number was considerably increased in 1921.

Approximately $\$ 280,000$ was expended by various communities in anti-mosquito work between July 1, 1919; and June 30, 1920, according to reports received by the Public Health Service. These reports were by no means complete, as they included only those eommunities which were known to have been directly influenced in carrying on anti-mosquito work by the activities of the Service. They did not inchule many communities indirectly persuaded of the importance of the work through Service demonstrations nor thousands of individuals awakened to the value of protecting themselves from mosquitoes and informed as to praetical methods of doing so.

\section{THE SITUATION TODAY}

The following statement, bearing upon the value of antimalaria eampaigns, their progress and the recent notable change in public appreciation thereof, by LePrince, ${ }^{1}$ who has had direct supervision of such activities of the Public Health Service sinee they were first undertaken, is believed to be an accurate review of prevailing sentiment along anti-mosquito lines in the United States todlay:

"Malaria fevers cause an annual loss of efficiency each year in our country that is appalling, and the communities that suffer lack interest in public welfare. In many villages and towns, from 10 to 40 per cent of the inhabitants are infected. Where such conditions obtain, the community cannot and does not progress or develop normally.

${ }^{1}$ Annual Report, U. S. Public Health Service, 1920. 
"It has been definitely demonstrated that many of the localities so affected can eliminate malaria at a reasonable cost and that the hest way of inducing the public to do so is to carry on carefully planned demonstration campaigns in badly infected areas. The result of such campaigns means a much larger annual income for the community, the county, the state and the Federal Government. Preventive malaria work is in reality a sound business investment. Up to 1913, no county or state made any appropriation for malaria-control operations, although the value of such work was proved 12 years previousiy.

\section{CHANGE IN PUBLIC VIEW-POINT}

"As a result of the malaria investigation work directed by the I. S. Public Health Service, the public view-point has changed-villages, towns, county and state officials, as well as business corporations and railroads, now realize the extent of the large preventable financial loss they incur each year, and steps are being taken by them to prevent it. In 1913, one single demonstration control campaign was started. In 1914 , congressional appropriations permitted an allotment of $\$ 17,000$ by the Service for malaria-control investigations. The people have been watching the campaigns undertaken and, throughout the country, they are becoming more and more interested in having their own community and state undertake this work.

"During the past fiscal year, 64 separate communities carried out maliria-control campaigns, and appropriated $\$ 2 \$ 0,000$ therefor. Nearly all of these places will continue to maintain this freedon from malaria by proper safe-guards, because they find it a good investment to do so. This calendar year, 101 places are doing work under the supervision of the Public Health Service, and have already appropriated about $\$ 350,000$ therefor. Several states, for the first time in history, have made annual appropriations for malaria control and other states contemplate doing so. Two railroads are spending for malaria elimination this year more than four times the Federal allotment referred to-their past expcrience shows that it pays to do so.

\section{GROWTH OF APPRECIATION}

"Industries in infested areas report from 10 to 40 per cent increased output after control measures are in operation. Chambers of commerce report new industries establishing branches in towns where the elimination of malaria has rendered local labor more efficient, and factory managers report that, since malaria-control measures were carried out, there is a more steady supply of labor, that the quality of labor has improved and the earning capacity of the laborer increased. Lumbermill corporations have willingly contributed from $\$ 1,000$ to $\$ 10,000$ toward local anti-malaria campaigns, and state it pays them well to 
make such an investment. Because of the change of ideas concerning the cause and possibilities of prevention of malaria, there is a marked improvement in the method of screening of houses in malarial districts, and the percentage of houses kept efficiently screened has increased very largely. In sections where the hotels at sea-shore resorts were formerly filled only in the non-fever season, the proprietors report, as a result of malaria-control measures, they now have all the business they can handle throughout the entire year.

"Considering the fact that a few years ago hundreds of communities were seriously affected and with no apparent relief in sight, that the public in general had no visible proof of the possibilities of malaria eradication, and too large a proportion of our public was wrongly informed regarding the cause of malaria, it is gratifying to note that this year over a hundred of these same places have decided to finance campaigns for malaria elimination. They have already appropriated for this season's work nearly 20 times as much as the original annual Federal appropriation, 1914-1917.

"It is even more encouraging to note that there is a strong demand for state and county aid along these lines, and that such support has already been given and has the approval of the public. What is also important is that a large part of the public now realize that it costs them much more to continue to suffer and support the financial loss caused by malaria than it does to eliminate the disease from their community."

\section{ERADICATION CHEAPER THAN ENDURING MALARIA}

LePrince's last sentence embodies a truth that should be seriously considered by every community that suffers from malaria. The demonstrations already described in this chapter prove that the average town can free itself from malaria and kindred mosquito-borne diseases and the annoyance of mosquitoes for much less than it costs to endure them.

Estimates of the cost of an attack of malaria vary, but it is believed that Van Dine's estimate of 6.42 adult days' loss of time per average reported case is conservative. No matter what the wage may be, the loss will be considerable. If to this loss be added the loss occasioned by decreased efficiency, both before and after the acute attack, the physician's bill and the cost of medicine, it is apparent that the average cost of a case of malaria will not be much below $\$ 15$ or $\$ 20$ and may be considerably beyond the latter figure. In addition to this, there is another big, though not apparent, loss occasioned by decreased efficiency of those who have only comparatively slight attacks and do not consult physicians. 
It will easily be seen that, where the infection is at all considerable, the annual loss to a community from malaria may reach a very high figure. Take Roanoke Rapids for example. It is asserted that during the malaria season, 75 per eent of the population of 4,100 , or 3,075 persons suffered from malaria. To be conservative, let us say that only 25 per cent, or 1,025 suffered from it. Again, instead of putting the loss resulting from each case at $\$ 20$, let us put it at $\$ 10$. The annual loss, then, was $\$ 10,250$, nearly three times what the first year's cost of eliminating malaria was.

Take Crossett. Before work started, the malaria calls of physicians totalled 2,502 in a single year; the year that work started the calls totalled 741 ; the difference is 1,761 calls. Assuming the physicians made two calls to a case, the reduetion effected by the anti-mosquito work was 880 cases. At $\$ 15$ a case, the monetary value of the work was $\$ 13,200$. Yet the actual cost of the work for that year was only $\$ 2,506.40$.

Similar conclusions may be drawn from the facts given in the accounts of the other demonstrations. And, as a rule, the costs of the work are considerably less after the first year.

While loeal conditions are, of course, the determining factor in regard to costs of anti-mosquito campaigns, it is believed that, in the average town, the first year's cost should not, as a rule, much exceed $\$ 1$ per eapita. If this be true, it is clear that it will pay the community, on a dollar-and-cent basis alone, to initiate anti-mosquito work if only one person out of every $15 \mathrm{or}$ 20 be infected during the season. This, of course, does not take into consideration such aspects of the matter as comfort, upbuilding the health of the community, ete.

\section{SOME TYPICAL CAMPAIGN COSTS}

The following table gives the cost of anti-mosquito campaigns conducted in towns that co-operated in the 1920 joint demonstration by the U. S. Public Health Service, the International Health Board and the Health Departments of the States in which they are situated: ${ }^{1}$

1 Southern Medical Journal, April, 1921. 


\begin{tabular}{|c|c|c|c|c|c|}
\hline State and town & $\begin{array}{l}\text { Area in } \\
\text { square } \\
\text { miles }\end{array}$ & $\begin{array}{c}\text { Popul- } \\
\text { lation, } \\
1920\end{array}$ & Total cost & $\begin{array}{l}\text { Cost per } \\
\text { square } \\
\text { mile }\end{array}$ & $\begin{array}{l}\text { Cost per } \\
\text { capita }\end{array}$ \\
\hline \multicolumn{6}{|l|}{ Alabama } \\
\hline Dothan & 4. 0 & 10,300 & $4,796.33$ & $\$ 1,199.00$ & $\$ 0.47$ \\
\hline Eufala..... & 4.0 & 6,257 & $3,327.90$ & $\$ 32.00$ & 0.53 \\
\hline Demopolis ................ & 6.0 & $5,000^{*}$ & $2,696.97$ & 450.00 & 054 \\
\hline Gantt's Quarry ........... & 4.0 & $1,000^{*}$ & $2,092.50$ & 523.00 & 2.09 \\
\hline Shelby ........... & 4.0 & $1,000^{*}$ & $2,499.15$ & 625.00 & 2.50 \\
\hline Mignon.............. & 4.0 & $3,500^{*}$ & $1,882.45$ & 470.00 & 0.54 \\
\hline \multicolumn{6}{|l|}{ Arkansas } \\
\hline $\begin{array}{l}\text { Fidorado.............. } \\
\text { Malvern. }\end{array}$ & 4.5 & 5,500 & $2,355.85$ & 523.00 & 0.43 \\
\hline 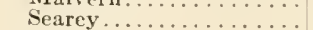 & $\begin{array}{l}3.5 \\
3.0\end{array}$ & $\begin{array}{l}3,804 \\
2,865\end{array}$ & $1,660.00 *$ & $\begin{array}{l}020.00 \\
553.00\end{array}$ & 0.58 \\
\hline 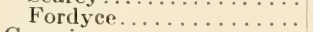 & 4.0 & 2.996 & $2,778.79$ & 695.00 & 0.93 \\
\hline \multicolumn{6}{|l|}{ Georgia } \\
\hline 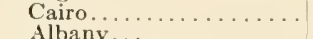 & 4. 0 & $1,908 *$ & 999.85 & 250.00 & 0.52 \\
\hline 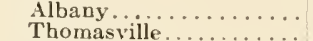 & $\begin{array}{r}12.5 \\
8.0\end{array}$ & $11,555^{*}$ & $\begin{array}{l}3,984,36 \\
4,452,02\end{array}$ & $\begin{array}{l}318.00 \\
557.00\end{array}$ & $\begin{array}{l}0.34 \\
0.54\end{array}$ \\
\hline \multicolumn{6}{|l|}{ Louisiana } \\
\hline Baton Rouge .......... & 4. 4 & $21,782^{*}$ & $4,775.36$ & $1,080.00$ & 0.22 \\
\hline Monroe............. & 8.6 & 12,675 & $9,040.00$ & $1,052.00$ & 0.71 \\
\hline \multirow{2}{*}{\multicolumn{6}{|c|}{ Mississippi }} \\
\hline & & & & & \\
\hline Columbus. & $\begin{array}{l}4.0 \\
4.0\end{array}$ & $10,055 *$ & $\begin{array}{l}3,059.69 \\
3,412.49\end{array}$ & $\begin{array}{l}765.00 \\
853.00\end{array}$ & $\begin{array}{l}0.61 \\
0.33\end{array}$ \\
\hline Batesville. & 1.8 & 1,050 & $2,019.09$ & $1,120.00$ & 1.92 \\
\hline Charleston. & 2.5 & 3,007 & $1,540.26$ & 615.00 & 0.51 \\
\hline Coffeeville.... & 1.0 & $411 *$ & $1,088.60$ & $1,089.00$ & 2.64 \\
\hline \multicolumn{6}{|l|}{ North Carolina } \\
\hline $\begin{array}{l}\text { Greenville. . . } \\
\text { Farmville... }\end{array}$ & $\begin{array}{l}3.2 \\
2.3\end{array}$ & $\begin{array}{l}5,700^{*} \\
2,100^{*}\end{array}$ & $\begin{array}{l}8,972.98 \\
4,980.00\end{array}$ & $2,800.00$ & $\begin{array}{l}1.57 \\
2.37\end{array}$ \\
\hline Goldsboro... & 5.5 & $11,300^{*}$ & $10,052.19$ & $1,827.00$ & 0.89 \\
\hline \multicolumn{6}{|l|}{ South Carolina } \\
\hline Bamberg.... & 7.0 & 2,211 & $29,400,00^{*}$ & $4,200.00$ & 13.30 \\
\hline Chester... & 8.0 & $5,000^{*}$ & $7,460.77$ & 934.00 & 1.49 \\
\hline Hartsville. & 7.5 & $3,100 *$ & $3,635.77$ & 485.00 & 1.17 \\
\hline \multicolumn{6}{|l|}{ Tennessee } \\
\hline Dyersburg. . & 5.1 & $\begin{array}{l}3,000 \\
6,544\end{array}$ & $\begin{array}{l}1,800.00 \\
2,367.00^{*}\end{array}$ & $\begin{array}{l}485.00 \\
465.00\end{array}$ & 0.36 \\
\hline \multicolumn{6}{|l|}{ Texas } \\
\hline Alto.... & 4.0 & 1,081 & $1,539.56$ & 384.00 & 1.42 \\
\hline Athens.. & 4.0 & 3,704 & 799.05 & 200.00 & 0.22 \\
\hline Bryan.. & 6.0 & 6,299 & $3,775.00^{*}$ & 627.00 & 0.60 \\
\hline Calvert... & 4.0 & 2,099 & $1,380.00^{*}$ & 345.00 & 0.66 \\
\hline Groveton. & 1.5 & $1,200^{*}$ & 315.00 & 210.00 & 0.26 \\
\hline Hearne.... & 5. 0 & $2,7+1$ & $2,250.00^{*}$ & 450.00 & 0.32 \\
\hline Jacksonville. & 3.0 & 4,723 & $1,622.01$ & 541.00 & 0.34 \\
\hline Livingston. . & 2.0 & 1,258 & 300.00 & 150.00 & 0.24 \\
\hline Navasota. & 6.0 & 5,060 & $3,000,00^{*}$ & 500.00 & 0.59 \\
\hline Rusk.... & 4.0 & 2,348 & $1,863.15$ & 466.00 & 0.80 \\
\hline Trinity... & 1.5 & $1,250^{*}$ & $\$ 14.00$ & 276.00 & 0.33 \\
\hline South Groveton....... & 1.5 & $1,250^{*}$ & 302.56 & 202.00 & 0.24 \\
\hline Rock Creek Lumber Co. & 1. 0 & $900^{*}$ & 520.00 & 520.00 & 0.58 \\
\hline Cameron............. & 6.0 & $4,290^{*}$ & 889.12 & 140.00 & 0.21 \\
\hline \multicolumn{6}{|l|}{ Virginia } \\
\hline West Point... & 0.6 & 1,635 & $3,636.32$ & $6,050.00$ & 2.22 \\
\hline Virginia Beaeh. & 3.6 & 840 & $2,448.79$ & 679.00 & 2.90 \\
\hline Grand total. . & 192.41 & 199,319 & $\$ 155,845.32$ & & \\
\hline Grand average & & & & $\$ 808.00$ & $\$ 0.78$ \\
\hline
\end{tabular}

Approximate.

It will be noted that at 32 out of the 45 towns the work cost less than $\$ 1.00$ per capita. Reducing the cost per square mile to cost per acre, it appears that the average cost per acre was only $\$ 1.26$. Apropos of this, LePrince ${ }^{1}$ says:

1 Southern Medical Journal, April, 1921. 
"Investigations that have taken place during past years show that our richest farms in the best part of our country are paying anywhere from $\$ 2.50$ to $\$ 10.00$ per acre per year as a malaria tax. Now here are 200 square miles, where the cost per acre was $\$ 1.26$.

"Public sentiment unquestionably is favorable to the control of malaria by drainage on a big scale; and drainage, supplemented by fish control and other measures is not only feasible, but it will be done beeause it is what the people desire." 


\section{CHAPTER IV \\ INITIATING THE CAMPAIGN}

\section{NEED FOR STATISTICS}

Although, in any community where mosquitoes are numerous, their eradication solely as a source of annoyance is probably well worth the cost of the campaign, it should be borne in mind that in most communities the campaign is launched primarily as a health measure, with the object of reducing the toll of malaria and other mosquito-borne discases.

Where such a campaign is under consideration, it is necessary to have some figures of the incidence of the mosquito-borne discases in order to show the necessity for the campaign and thus obtain the money required to conduct it. It is also advisable to be able to show the reduction in disease resulting from the work, so that the community will know that the expenditure was a profitable one from a financial viewpoint.

In order to do this, the director must have at hand reliable statistics covering the incidence of the mosquito-borne diseases for one or more years prior to the initiation of the campaign, as well as those covering the incidence of the same diseases cluring the campaign. There must be some basis of comparison.

Of course, the residents of the community will be able to get some idea of the efficacy of the work by the absence or presence of mosquitoes in general. However, it is well recognized that it may be possible to reduce malaria very considerably, and still have numerous non-Anopheline mosquitoes present. While anti-malaria campaigns as a rule include eradication of all mosquitoes, it is well known that certain other common domestic mosquitoes are much more difficult to control than the Anopheles.

\section{COLLECTION OF STATISTICS}

If the community is in a State where malaria and the other mosquito-borne diseases are reportable or notifiable, records of the past incidence of the diseases may be obtained from the State Health Department, the Registrar of Vital Statisties or other official source, If, however, the community is in a State 
where these diseases are not reported, it will be necessary to get the figures from other sources. In this case, a beginning should be made as far in adrance of the date of opening of the campaign as possible.

In an anti-malaria compaign with which the writer was connected in 1920, no figures as to the incidence of malaria, were available from official sources. It was, therefore, necessary to get some figures from the physicians of the community as to the incidence of the disease during the preceding 2 years.

Owing to the difficulty, in cases where the illness was prolonged, of determining whether the patient was suffering from one original infection or successive ones, it was considered preferable to obtain from the physicians figures as to their calls and consultations for malaria rather than as to cases.

Accordingly, each physician of the community was called on, the situation explained to him and a blank left with him, to be filled out promptly with data covering his malaria practice for 1918 and 1919 and returned to the director of the campaign. The blank form is reproduced below.

\section{FORM NO 1.}

1920

\section{Director,}

\section{Anti-malaria Campaign.}

\section{DEAR Sir:-}

In compliance with your request. I am giving below a summary of malaria ealls made by me during 1918 and 1919. Asterisks indicate that the figures are approximate only.

Number of CaLls for MaLaria

\begin{tabular}{|c|c|c|c|c|c|c|}
\hline \multirow{2}{*}{ Month } & \multicolumn{2}{|c|}{1918} & \multicolumn{2}{|c|}{1919} & \multicolumn{2}{|c|}{1920} \\
\hline & White & Colored & White & Colored & White & Colored \\
\hline 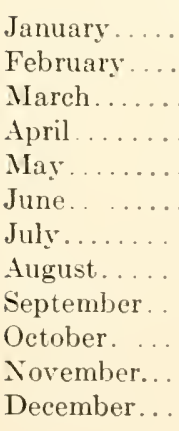 & $\begin{array}{l}\ldots \ldots \\
\ldots \ldots \\
\ldots \ldots \\
\ldots \ldots \\
\ldots \ldots \\
\ldots \ldots \\
\ldots \ldots \\
\ldots \ldots \\
\ldots \ldots \\
\ldots \ldots \\
\ldots \ldots \\
\ldots \ldots\end{array}$ & $\ldots \ldots$ & $\cdots$ & $\cdots$ & $\begin{array}{l}\cdots \\
\cdots \\
\cdots \\
\cdots \\
\cdots \\
\cdots \\
\cdots \\
\cdots \\
\cdots \\
\cdots\end{array}$ & 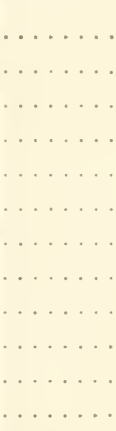 \\
\hline
\end{tabular}


Each physician was left a number of posteards upon which to report monthly the number of calls he had made upon persons suffering from malaria within the area of operations. These were entered, as soon as received each month, in the 1920 column of the No. 1 form sent in by that physician. In this way the efficacy of the control measures each month was visible at a glance.

To get the total for the town, each physician's figures by months for the years 1918 and 1919, and also for 1920 as they were received, were added together on another blank similar to Form No. 1, thus giving at a glance the situation for the town as a whole.

Where other mosquito-borne diseases are a factor, statistics regarding them should be collected also.

In cases where it is impracticable to obtain the desired information from the physicians of the community, a house-to-house malaria census may be taken. This method probably will not be so accurate as the method of obtaining figures from the physicians for obvious reasons, but will serve as a basis for comparison.

The following malaria census eard is suggested as suitable for use in ordinary cases:

\author{
FORM NO. 2 \\ Malaria Census
}

(city)

(date)

Head of House. Address.............. No, in Family...

How Long in City. . Previous Address

House Screened. . . . . . . Condition of Screens.

Potential Breeding Places on Premises

Malaria History

\begin{tabular}{|c|c|c|c|c|c|c|}
\hline Years & $\begin{array}{c}\text { Cases in } \\
\text { family }\end{array}$ & Deaths & $\begin{array}{l}\text { Supposed } \\
\text { origin of } \\
\text { infection }\end{array}$ & $\begin{array}{l}\text { Total } \\
\text { days } \\
\text { time } \\
\text { lost }\end{array}$ & $\begin{array}{c}\text { Total } \\
\text { calls of } \\
\text { physician }\end{array}$ & $\begin{array}{c}\text { Re- } \\
\text { marks }\end{array}$ \\
\hline & & & & & & $\ldots \ldots \ldots$ \\
\hline & & & & & . & $\ldots \ldots$ \\
\hline & $\ldots$ & $\cdots$ & & & $\cdots$ & ….... \\
\hline$\cdots$ & $\ldots$ & $\ldots \ldots$ & $\ldots \ldots \ldots$ & & & $\ldots \ldots$ \\
\hline & & $\ldots \ldots$ & $\ldots \ldots \ldots$ & $\ldots \ldots$ & & $\ldots \ldots \ldots$ \\
\hline
\end{tabular}


Where practicable, data for the 2 years previous should be obtained; if this is not possible figures for the preceding year will do. At the conclusion for the season's work, a second census should be taken, using the same eard for the same house and recording the second results below the first. This will show the comparison in incidence for each family, before and after initiating the work.

\section{THE SURVEY}

As soon as it has been determined by means of the collection of statistics relative to the incidence of the mosquito-borne diseases in the community, that an anti-mosquito campaign would be justified, the next step is to make a survey of the proposed area of operations, with a view to ascertaining the probable cost of such a campaign. If at all possible, this should be done by a sanitary engineer familiar with costs of this kind of work. Frequently State Departments of Health will send an engineer to make such a survey gratis.

The following suggested mode of procedure in making the survey and estimate is taken from the instructions issued sanitary engineers engaged in the co-operative anti-malaria demonstration work of the U. S. Public Health Service and the International Health Board:

"Assuming that it is concluded, from information gathered, that the making of a survey is worth while, obtain, if available, a map of the area involved or make a copy of an existing one. If none has been previously made, you will make a sketch map as you proceed. (Maps generally may be obtained from the city authorities; if not, an insurance map may be borrowed from a fire insurance agent.)

"On this map, mark all water-courses, swamps, ponds, ditches, wet lands, land subject to overflow and other wet places or possible sources of mosquito-breeding. On flat lands, make inquiry as to how long water stands thereon in wet periods; look for vegetation that is indicative of a high water table. Let the map extend to about half a mile from the residences on the outskirts of town.

\section{WHAT TO OBSERVE}

"It is next necessary to note the ditching and filling and clearing ol" regrading (of streams and old ditches) that is essential and that which will probably be necessary. It is not adrisable to make estimates for ditching from observations immediately after rain-storms. The information must be carefully gathered; the character of soil, amount of 
roots to be encountered, extra ditches to eare for scepage outcrops, widths of ditches or streams, ete., must be considered in estimating costs. Go along each water-course and its branches, estimate the lengths by paeing, mark them on the map and note at the same time your estimated cost of such brush-clearing, regrading, ditehing, ete., as is necessary, step by step. Where ponds, marshes and other wet places necessitate the installation of new ditches, indicate them on the map, and enter in your notes the extent and cost of each.

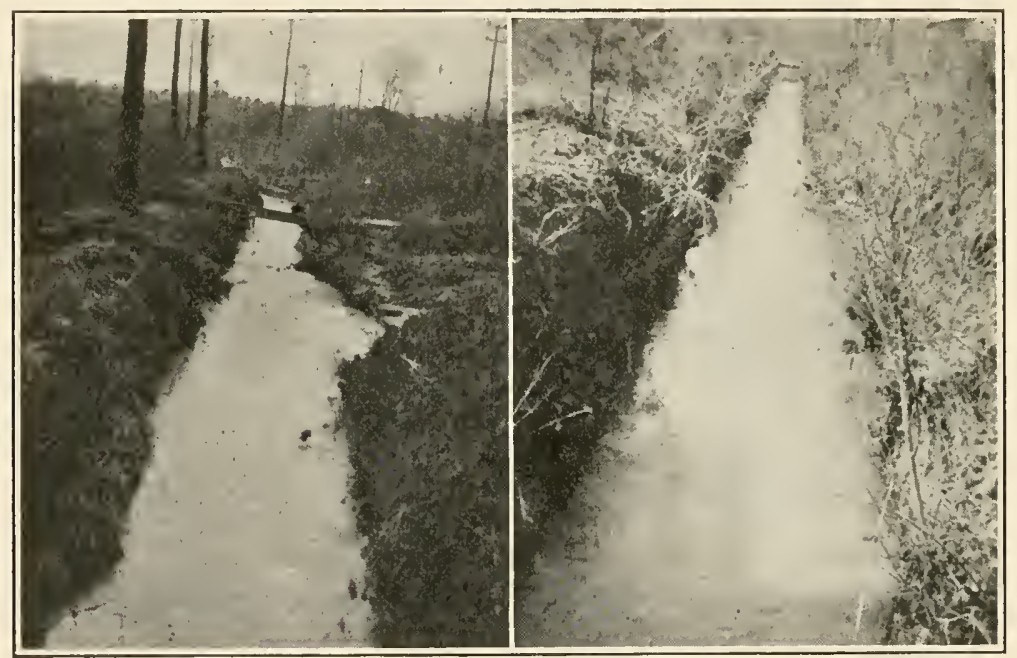

(Photos by E. B. Johnson, C.E.)

FIG. 50.-Brushing streams. The objects are to improve fish control, facilitate inspection and eliminate shade.

"On flat territory during dry periods, it is frequently difficult to judge of the amount of water that may stand intermittently on the land, and it is advisable to note the character of the vegetation and make frequent inquiry of the native population. If you can get a man well acquainted with the locality to aceompany you, so much the better.

"When the mapping of all breeding-places and collections of water is concluded and the data collected, sum up the different classes of exeavation, brushing, etc., and make an itemized statement thereof to accompany the report of the survey. Determine the local cost of kerosene and oil, delivered, find out, if necessary, what transportation could be obtained from the town for oil distribution, ascertain whether ditches and soil would warrant use of a ditching plough, what size ditehing gang is necessary and what number of men will be needed for oiling and maintenance (of ditches and streams). As a rule, the brushing (clearing) of one bank of a ditch (or stream) is sufficient for oiling and inspection purposes." 


\section{THE ESTIMATE OF COST}

When the data mentioned lave all been collected, work on the estimate may be started. The instructions already quoted provide for estimation of the costs of brushing streams or existing ditches (one side only) clearing streams or existing ditches (clearing channel of obstructions, connecting pools in stream bed, etc.) and of new ditching, as follows:

FORM NO. 3

\begin{tabular}{|c|c|c|c|c|}
\hline Waterway & $\begin{array}{c}\text { Length, } \\
\text { feet }\end{array}$ & $\begin{array}{c}\text { Brushing, } \\
\text { feet }\end{array}$ & $\begin{array}{c}\text { Clearing, } \\
\text { feet }\end{array}$ & $\begin{array}{c}\text { Ditching, } \\
\text { feet }\end{array}$ \\
\hline $\begin{array}{l}A \\
\mathrm{~A}-1 \ldots \ldots \ldots \\
\mathrm{A}-2 \ldots \ldots \ldots \\
\mathrm{B} \\
\mathrm{B}-1 \ldots \ldots \ldots\end{array}$ & $\begin{array}{r}5,000 \\
1,000 \\
750 \\
475 \\
230\end{array}$ & $\begin{array}{r}4,600 \\
\cdots \\
200 \\
\cdots \\
\cdots\end{array}$ & $\begin{array}{r}1,000 \\
250 \\
\\
\cdots \\
\cdots\end{array}$ & $\begin{array}{l}475 \\
230\end{array}$ \\
\hline $\begin{array}{l}\text { Totals . . . . . . . . . . } \\
\text { Average cost per hineal foot. } \\
\text { Cost . . . . . . . . . . . . }\end{array}$ & $\begin{array}{l}7,455 \\
\ldots \\
\ldots\end{array}$ & $\begin{array}{r}4,800 \\
.01 \\
\$ 45.00\end{array}$ & $\begin{array}{r}1,250 \\
.03 \\
\$ 37.50\end{array}$ & $\begin{array}{r}705 \\
.05 \\
\$ 35.25\end{array}$ \\
\hline
\end{tabular}

NCTE.-A-1, A-2, ete., indicate branches of Ditch or Stream A shown on map. The lineal foot costs, given above for the sake of illustration, should by no means be taken as applicable to all conditions.

The above estimate gives the cost of the new work necessaryin other words, the construction cost.

The next thing required is an estimate of the maintenance cost for the scason-that is, the cost of keeping the ditches, streams, etc., in shape. This consists of keeping grass, weeds, floating matter and other obstructions out of them. Owing to the great variations encountered, due to differences in topography, soil, precipitation, etc., it is impossible to give any general rate for this work.

The next thing that requires attention is estimation of the cost of the oil that will be needed and the cost of applying it, including transportation. Some general information on oiling jobs is given in the chapter relating to oiling.

The cost of control by means of fish should next be calculated. This is variable, according to local conditions and the scope of the work. It should include costs of collection, aquaria, distribution, protection, pond and stream cleaning, etc. 
If the campaign is to include screening, the probable amount of the work should be figured out and an estimate of the total cost made. Figures on sereening costs may be found in the chapter on screening.

Individual jobs of magnitude should be listed next. They may comprise such measures as filling holes and other odd jobs.

A sufficient allowance should be made for cost of tools and equipment. This can generally be estimated as soon as the size of the labor force is decided upon.

Another item to be considered is cost of general direction and inspection for the season. This should inchude wages and salaries of the director, inspectors, clerical help, etc., and cost of any transportation furnished them for directing or inspection purposes.

Then, to provide for unforeseeable factors, such as floods, long-continued bad weather and the like, a contingency fund should be allowed for. The writer usually estimates this at 10 per cent of the total cost of the work.

These various items should be combined into one general estimate, which would be approximately as follows for a campaign in a typical small town.

FORM NO. 4

Brushing, 44,800 lineal feet at $0.01 \ldots \ldots \ldots \ldots \ldots \ldots \ldots \ldots+\ldots \ldots \ldots . \ldots \ldots$

Clearing, 21,250 lineal feet at $0.03 \ldots \ldots \ldots \ldots \ldots \ldots \ldots \ldots \ldots \ldots \ldots$

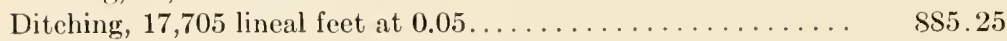

Maintenance, 77,455 lineal feet at $0.005 \ldots \ldots \ldots \ldots \ldots \ldots \ldots \ldots . \ldots \ldots$

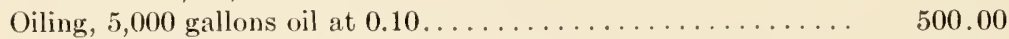

Applying oil, 1 man 4 months at $\$ 90 \ldots \ldots \ldots \ldots \ldots \ldots . \ldots \ldots 00 . \ldots \ldots$

Hauling oil, 1 horse and rig, 4 months at $\$ 50 \ldots \ldots \ldots \ldots . . \ldots 200.00$

Fish control, 1 man 4 months at $\$ 90 \ldots \ldots \ldots \ldots \ldots \ldots \ldots \ldots . \ldots \ldots$

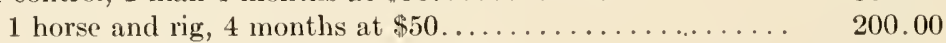

Aquatic plant removal at Smith's Lake............ 100.00

Individual jobs, eutting brush and weeds at marsh........ 180.00

Filling big hole at Jones and Brown streets.......... $\quad \mathbf{7 5 . 0 0}$

Tools and equipment, 2 sprayers at $\$ 12.50 \ldots \ldots \ldots \ldots \ldots \ldots . \ldots \ldots$

10 picks and 10 shovels.................... 40.00

5 faucets for oil-barrels....................... 2.00

Miscellaneous articles..................... 25.00

Inspection, 1 inspector 8 months at $\$ 100 \ldots \ldots \ldots \ldots \ldots \ldots . \$ \$ 00.00$

Total.......................... \$5,225.03

Contingeney fund, 10 per cent................ 522.50

Grand total..................... $\$ 5,747.53$ 
Note.-It is presumed here that one man with a horse and rig will be able to do both the oiling and fish work, giving about half of his time to each. For this reason, the total engagement of $S$ months for the man and the horse and rig is split up into 4 months at oiling and 4 months at fish work.

Figures here given for the sake of illustration should in no way be relied upon as unit costs for work.

\section{QUESTIONS OF POLICY}

With the survey completed and a careful estimate made as above outlined, the next step is to get the money for the eampaign, but before efforts are made in this direction, a definite poliey as to what part of the cost of eradicating breeding places on private property should be met by the property-owner or tenant and what part should be defrayed out of the anti-mosquito fund must be decided on.

This question must be definitely settled at this point, because it is a certainty that a very large portion of the work required will be on private property. If the public funds are to be spent without restrictions on private property, the entire amount of the estimate should be asked for. If, however, private propertyowners are to be compelled to do their own work, the sum required for the prosecution of the eampaign will be greatly lessened. It will, of course, be necessary to put the public property, such as streets, parks, mmicipal grounds, ete., in shape and keep it in shape, as well as to maintain an adequate inspection force, but most of the heavy items, such as drainage, oiling, ete, will be eliminated.

In most of the demonstration projects with which the writer has been connected, it has been eustomary to lo at least a part of the work necessary to prevent breeding on private property. In some cases, everything was lone without cost to the propertyowner; in others, the cost of dramage, ete., was charged up to them, but oiling, fish control, etc., were free; in still others, routine oiling, fish control and drainage were free, but propertyowners were expected to look after their own cistems, fish-ponds and other special breeding places.

There are many angles to this question, which must be earefully thought out. The average property-owner does not want to bother himself with drainage, inspections, oiling, etc. nor can he be depended upon to do such work thoroughly. And too many prosecutions will arouse antagonism toward the campaign 


\section{SUGGESTED POLICY TOWARD PROPERTY-OWNERS}

It is the belief of the writer that some sort of compromise is best. It would appear to him that oiling, fish control and other routine measures rendered necessary by the presence of natural streams, etc., by rains or other causes not due to the fault of the property-owner should be earried out by the eity forces without cost to him. On the other hand, he should be compelled to remedy any condition originating through his negligence, the continuance of which would cause extra work to the eity forces, such as letting his drain pipes leak and form a pool under his house, having unscreened or untreated water-barrels about, letting his pond grow up with aquatic plants so as to impede control by fish, failing to do necessary drainage work bearing a reasonable relation to the value of the property, etc. In ease of failure to do the work after reasonable notice, it should be done by the anti-mosquito forces and its cost charged up to him.

It is not suggested that there be adopted a set rule in the matter under consideration, sinee all sorts of situations are bound to arise which cannot be forseen. The director should be left a certain latitude to meet these situations. Thus, it would be unreasonable to ask the owner of a tract of swamp land on the outskirts of town, worth, say, $\$ 5$ an acre, to spend $\$ 25$ an acre to drain it. There must be power to co-operate and a willingness to meet the situation on a fifty-fifty basis. On the other hand, unless there is some general policy determined upon, there is danger that too much will be asked of willing citizens, while the unwilling ones get the benefit of the work without having done their "bit."

\section{RAISING FUNDS}

Assuming that a definite decision is made along the lines suggested by the writer, and that the estimate has been made accordingly, the next step is to get the money. This should be obtained preferably from the city, since the work is for the benefit of all eitizens alike. Furthermore, protecting the health of its citizens is one of the first duties of a municipality.

The first step is for those interested in the matter to put it before the eity authorities. The ineidenee of the discases locally, the large economic loss they cause and the saving to the community in dollars and cents in eradieating the diseases should be fully outlined. If possible, the City Health Officer and the 
leading physicians should handle the references to the incidence of the diseases, while the director or a sanitary engineer of the State Department of Health should rouch for the estimates and recount achievements against mosquitoes elsewhere.

At the same time the proposed anti-mosquito ordinance should be submitted with a request that it be adopted. ${ }^{1}$

As soon as the matter has been presented to the comeil, a publicity campaign should be started with the object of bringing home to the tax-payers the advantages of the proposed work, so that they may intelligently indicate to the couneil their desires in the matter. Newspaper articles, illustrated lectures and other methods of publicity should be among the measures used.

$\mathrm{By}$ the time the council meets again, a good delegation of citizens should be prepared to go before it and urge making of the appropriation and adoption of the ordinance. If the money is available, and the council sees that the citizens want the campaign, there should be no further difficulty.

However, as is frequently the case, the council may be in favor of the campaign, but may not have enough money available, especially if the appropriations for the year have already been made. In this ease, it may be possible to have the council adopt the ordinance and appropriate as much as is available, provided enough money can be obtained elsewhere to meet the estimate.

In this case, the protagonists of the campaign will have to raise the balance from other sources. This is generally practicable, if the publicity work has been effective, so that the people really know what is proposed. The writer has found that county authorities, chambers of commeree, women's chubs, individual citizens and corporations and even church and fraternal organizations will contribute liberally for anti-mosquito work, provided they are convinced: (1) that the project is feasible; (2) that it is economically advantageous; and (3) that the persons proposing it know what they are talking about.

\section{HANDLING THE FUNDS}

Once the balance is raised, it should be turned over to the proper eity official, to form, with the sum appropriated by the eity, the anti-mosquito fund. The director of the campaign should have absolutely a free hand in expending this money

${ }^{1}$ An approved anti-mosquito ordinance is printed as Appendix B. 
and in eondueting the eampaign generally, although, of course, all payments should be made by the eity disbursing officer.

The agreement made by the U. S. Public Health Service, the International Health Board and the State Health Departments of the States which participated in the malaria-control demonstrations, with the towns in which the demonstrations were made, provided as follows with reference to handling of the anti-mosquito fund:

"It is understood that the city's appropriation will be made available not later than March 1, in a lump sum, to be known as the 'Appropriation for Malaria Control Work.' It will be deposited in a local bank and be subject to draft by the Mayor as provided for below:

(a) "The eity council or commissioners will empower the Mayor or other local authority to issue drafts against the appropriation account, upon certification by the Sanitary Engineer or other duly accredited officer.

(b) "All bills and vouchers will be presented to the Sanitary Engineer for his certification for payment. This certification will be made only after the accuracy of the time-books and bills has been verified.

(c) "The salary of the inspector and the wages of other employes will be determined from time to time, and will be submitted to the Mayor for his approval.

(d) "Changes in the salaries of any of the employes will be made only upon recommendation by the Sanitary Engineer.

(e) "A financial statement will be made at the end of each month by the Nayor or his legal representative to the city council or board of commissioners and to the Sanitary Engineer.

(f) "All accounts will be kept in a multiple column cash-book furnished by the city, and each item will be charged to its appropriate item number as given in the estimates of the Sanitary Engineer.

$(g)$ "Drafts for the payment of laborers will be issued by the Mayor or his legal representative, after certification by the Sanitary Engineer, and for all money paid to them the local inspectors and laborers will be required to sign receipts in duplicate, one copy to be retained in the office of the Mayor and the other given to the Sanitary Engineer."

\section{OBTAINING CO-OPERATION}

The financial details all settled, the next step is to make arrangements with property-owners in so far as possible for eo-operation in eonducting the eampaign. In almost every town, the railroads, street and road departments, industrial concerns and many individuals with large mosquito-breeding problems will 
be glad to co-operate in a large measure to make the campaign a success.

In connection with this feature of the work, Derivaux ${ }^{1}$ says:

"Public works, and more especially railroad construetion operations, have long been notorious for their ineidental contributions to malaria hazards by creating conditions favoring the development of Anopheles mosquitoes. Among these conditions may be mentioned: Badly located and undrained borrow-pits, at times uninterruptedly traversing thickly settled communities; improperly cut right-of-way ditches

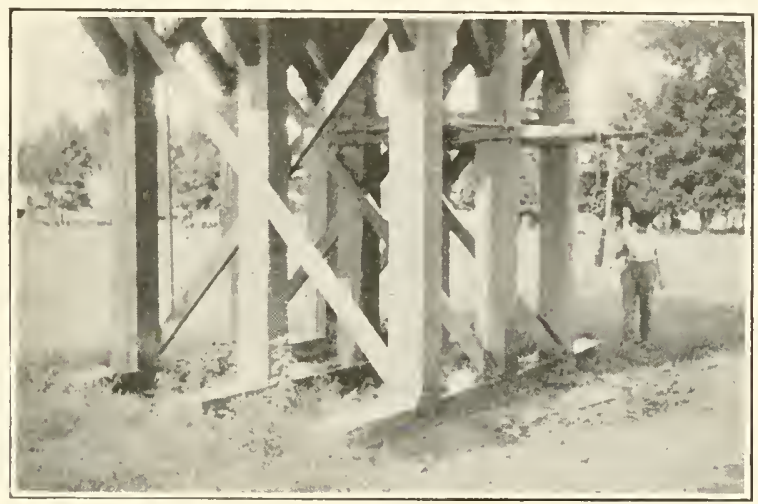

(Photo by E. H. Magoon, C.E.)

Fig. 51.--Leaky railway water tower. Mosquitoes bred here in abundance before control work started.

that have not been provided with outlets; improperly placed culverts and crossings, installed possibly with a view to saving a few feet of pipe or yards of masonry, but preventing the off-flow of normal and storm waters and at times interfering with an entire system of natural surface drainage; inadequate provision for drainage behind or through embankments and fills across valleys, resulting in the impounding of water or interference with the normal off-flow of a natural watershed; installation of leaky water-towers or failure of provision to carry off their over-flow."

It appears well to summarize in some detail the steps which railroads can take in dealing with the moscuito-borne diseases. Derivaux ${ }^{2}$ suggests the following:

(a) "Old Construction Conditions.-Correction or alleviation of Anopheles-breeding and malaria-producing conditions created in

1 "The Relation of the Railroads in the South to the Prohlem of Malaria and Its Control," U. S. Public Health Service, 1918.

2 "The Relation of the Railroads in the South to the Problem of Malaria and Its Control," U. S. Public Health Service, 191 S. 
connection with previous construction by: Drainage or filling of borrow pits and low areas where practicable; proper provision for drainage (in a sanitary sense) behind embankments and fills across valleys; replacing to true gradient of culverts where necessary; drainage or other provision for care of over-flow waters at tanks and towers; clearing of weeds and refuse at regular intervals (supplemented by oiling, if needed) from right-of-way ditehes, especially in and adjacent to settlements.

(b) "New Construction Conditions.--Consideration of sanitary features in eonnection with new construction works; that is prevention or correction of eonditions menacing the health, especially of settlements and

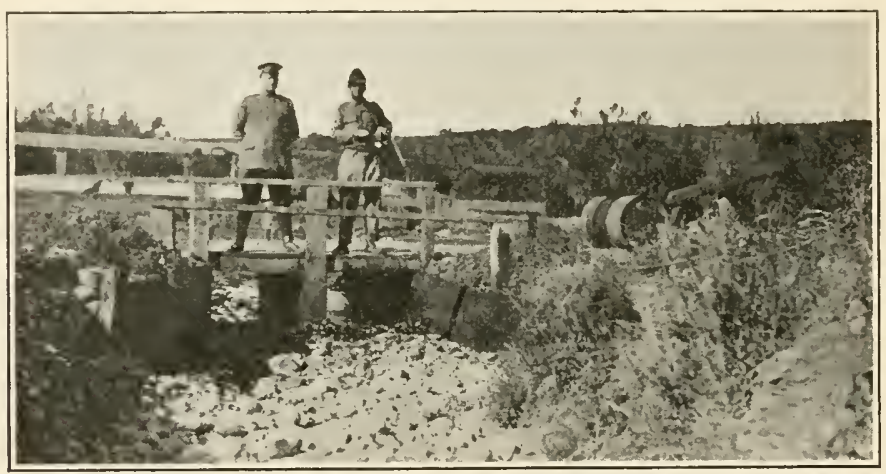

FIG. 52.-A culvert properly placed; it is neither too low nor too high. No pool can form about it.

communities. To this end, consultation should be had with the sanitary or medical departments before construction is begun. Preference should invariably be given to sanitary works which will influence as large a number of individuals as possible."

\section{OTHER POSSIBLE SOURCES OF AID}

The same considerations apply, in large measure, to street and road departments.

Industrial plants often, through carelessness or ignorance, cause conditions favorable to mosquito-breeding. Cisterns and fire-barrels may be unsereened or untreated, water may be allowed to enter under the buildings, drainage may be neglected, processes that may with little cost be modified may cause abundant breeding.

Private individuals may have large problems in swamp areas, in swimming, recreation or fish poncls, cess-pools, ete.

In all the above-mentioned cases, the director should call on 
the person in charge, point out the necessity of complying with the anti-mosquito ordinance, make suggestions as to the best methods to follow, give, if desirable, some idea of the cost and offer free supervision. In case the problen is one of considerable magnitude, in relation to the value of the property, it may not be amiss to offer to participate in doing the work.

It has been the writer's experience that, in most cases, people will voluntarily co-operate along the lines indicated, if the matter is properly placed before them. In cases where they will not, prominent loeal persons may exert pressure upon them. If this fails, the only alternative is prompt prosecution.

\section{PLANNING THE WORK}

When the above-mentioned eanvass of the situation is completed, the clirector of the campaign will have a pretty good idea of what work he will have to do-that is, how much drainage, oiling, etc., will have to be done by his own forces. The next step is to lay plans for doing it seasonably and effectively.

It is a good idea to start the actual work early. In the Public Health Service demonstrations in the South, it was generally the rule to begin active work by March 1 or shortly thereafter.

In planning the work, it should be remembered that work which will benefit the largest number of people should be done first. Hence, problems in the center of town should ordinarily be tackled before those on the outskirts.

As a general rule, drainage should be completed as early as possible, since the earlier it is done, the less will be the amount of oiling required. Furthermore, with the direction of the drainage gang off his hands early, the director will have more time for inspection and supervision of oiling and fish control just as these matters are becoming of greater importance.

If active work is to start by March 1, enough laborers should be put on, if practicable, to complete the drainage work in not more than 3 months, since, by June 1, the director will have enough other problems before him to keep him busy.

If there is much drainage to do, two or more gangs of laborers should be organized, each gang having its own foreman. In this way, it is possible to compare the work of each gang, so that poor men may be weeded out. The principle of competition or rivalry also may be utilized in this way to hasten the work.

At the same time, an inspection, oiling and fish control service 
should be instituted, the size depending upon the amount of of work and the area of operations. Generally speaking, this service should be organized in such manner that immediately an inspector discovers some situation which needs remedying,

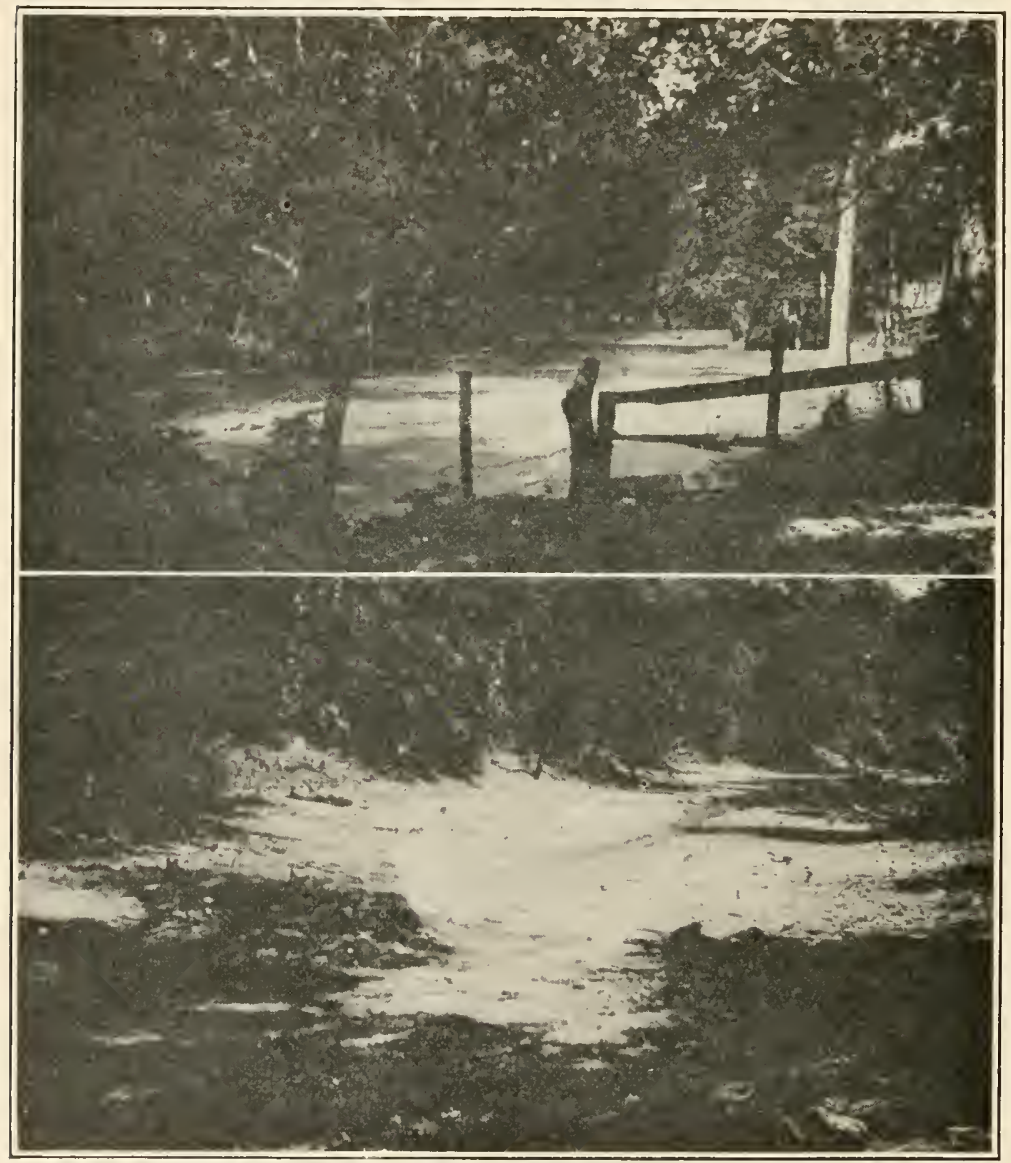

Fig. 53. - Mhove, large pool of stagnant water, affording an ideal breedingplace for moscuitnes. Below, same pool drained.

the appropriate action is taken without delay, be it emergeney drainage that is required, weekly oiling or stocking a place with fish.

\section{PERSONNEL}

Generally speaking, the man in eharge of the drainage work should have had some experience as a labor foreman, preferably 
in earth-work. This does not mean, however, that he will not need careful drilling in the objectives, methods and management of anti-mosquito drainage work. He should also be given some idea as to the eosts of this class of work.

For the first few weeks at least, the director himself should lay out the ditches. He should also frequently inspect the work to assure himself that money is not being wasted by divergence from his instructions.

It is the inspection staff, however, that should be picked with the utmost care. An inspector must be tactful, honest, energetic; he must also have a good working knowledge of mosquito eradication in general, so that when he uncovers a breeding place, he will know at once what measures to take in dealing with it, whether to drain, oil or stock with fish. He should also be able to identify at once any of the disease-bearing mosquitoes.

If the inspector is not tactful, he will get the campaign "in wrong;" if he is lazy and dishonest, he will lie as to conditions; if he does not understand the work, he will increase costs and reduce the efficieney of the campaign. It is imperative to get good men for this work. Such men as deseribed are not picked up everywhere. Generally, the writer has had to train his own men; but it is essential that they be made of the right material. LePrinee ${ }^{1}$ says:

"The success of the work will depend very largely on the ability and personal interest taken in the work by the inspector or foreman in charge of the oiling and the oiling squad. There must be one reliable and active person held responsible for the efficiency of the fietd work. He must go to all possible production areas at frequent intervals and see and know that the work is being satisfactorily performed, that no known places are mised, that no mosquito larvae reach the pupal stage of development and that places needing attention are promptly attended to. A knowledge of the local conditions of topography and possibilities of water being retained in any locality during unusually wet seasons is essential. When the pook, ditches and stream-beds become dry, they must be re-inspected after showers, as some of them may retain water in pools and need attention. This frequently happens in out-ofthe-way places. The inspector must never assume that everything is in a satisfactory condition, but must go and see and be certain of it."

In regard to laborers, LePrince adds:

1 "Control of Malaria: Oiling As an Anti-mosquito Measure," U. S. Public Health Service, 1915. 
"In all mosquito control work, it is economy to select intelligent laborers, who take an interest in the work, and to pay them a higher wage as they become skilled. The extra pay is saved many times over in results and saving of material as compared with the work of untrained labor. The man who notes at a glance whether oil-drips he sees are working properly and goes out of his way to remove an obstruction in a stream, because he knows it may save extensive re-grading, and attends to other apparently trivial but important details, is worth two ordinary laborers. Incompetent laborers are apt to increase operating expenses, and are careless about using oil properly. The work to be done may be scattered over a relatively large area, and the inspector eannot watch the men closely. His work is of such a character that he must of ten leave his laborers and devote his time to inspection."

\section{MATERIALS AND EQUIPMENT}

As soon as it is definitely known that a campaign is to be put on in any community, the director should immediately take steps to order his materials and equipment.

Arrangements should at once be made for an adequate supply of oil. Frequently this may be obtained from local concerns, such as railroads, ice-plants, oil refineries, pumping plants, oil-wells, oil dealers ete. If possible, it is generally preferable to get it from local sources, since this may result in lower charges for freight and also may obviate the necessity of arranging for storage. If obtained locally, it usually may be delivered a few barrels at a time as needed. Should this be impossible, however, or should very large quantities be neerled, it probably would be preferable to buy from the refinery direct, the oil to be shipped in tank or carload lots. In any event, a definite contract, with optional amounts stated, if necessary, should be entered into, so that there will be no possibility of having the supply give out at a critical time.

Equipment should include enough sprayers and drip cans to handle any situation that may develop. The sprayers should be ordered early, like the oil, as it may take some time for them to reach the seat of the campaign. Enough tools should also be bought locally for the drainage gang. 


\section{CHAPTER V}

\section{ADMINISTRATIVE ASPECTS OF THE CAMPAIGN}

\section{MOSQUITO-BREEDING ABOUT HOMES}

While in previous chapters something has been said of the breeding habits of the various speeies of common American mosquitoes and of the necessity for careful inspeetion, it is desired here to emphasize the fact that, in the average inland town, the people themselves raise most of the mosquitoes that afflict them.

It has been the writer's observation that it is a comparatively simple matter to eradicate Anopheles mosquitoes, which, as has already been pointed out, breed mostly in ditches, pools and other natural breeding places. But when it comes to eliminating breeding of house mosquitoes, the director of the campaign has a man's job on his hands.

Yet, even though the ampaign is primarily a health measurethat is, direeted in the first instance against malaria-bearing mosquitoes-it must nevertheless include suppression of all mosquitoes to be eonsidered a success by the people who put up the money. The average person regards mosquitoes as mosquitoes, and he would be very apt to consider as "phony" any malaria reduction figures if he did not notice a corresponding abatement in the numbers of house mosquitoes.

Yet these average persons are, as intimated above, frequently responsible for the presence in the eommunity of more mosquitoes than all the pools, ditches, swamps and streams in flight distance.

The writer has repeatedly found homes in which mosquitoes were breeding abundantly in 10 to 20 different breeding-places. There would be a number of tin cans containing water scattered about different parts of the yard; a rain-water barrel or two; a non-mosquito-proof eistern; a couple of pools under the house caused by leaky pipes or drip from the ice-box; an uneovered cess-pool; a water-trough for stock; and, perhaps, stopped-up roof gutters. And these cases were not in the slums or the negro quarter; on the contrary, they were often at the homes of the leading people of the community.

The writer once received a complaint from the wealthiest 
woman in town. She had been one of the principal factors in raising money for the campaign and had taken great pains, as

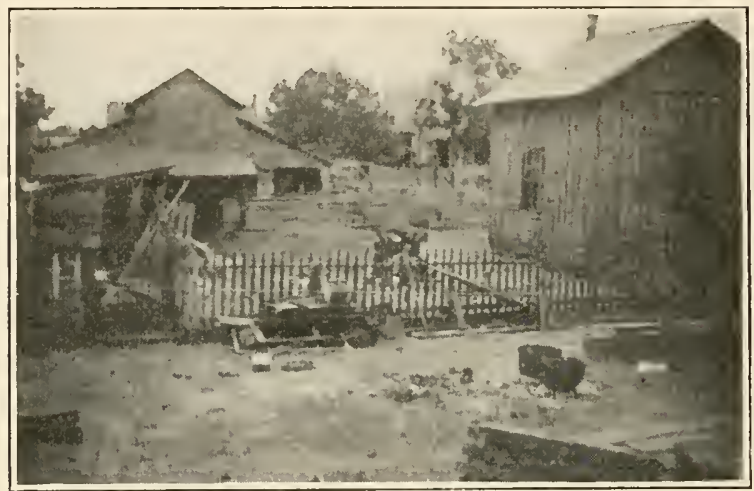

(Photo by E. H. Magoon, C.E.)

FIG. 54.- View of a home-yard in which 21 potential breeding places were found, 17 of them aetually containing larvae.

she thought, to keep her home in shape. Yet, upon brief investigation, he found mosquitoes breeding abundantly in five different breeding places - the cellar, which had partly filled

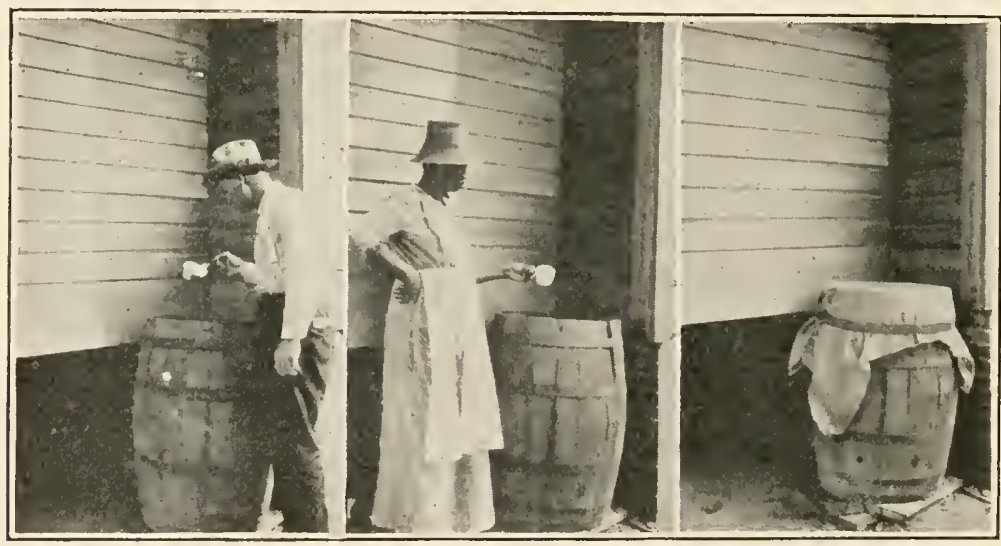

(Photos by E. H. Magoon, C. E.)

FIG. 55.

FIG. 56.
FIG, 57.

FIG. 55.--Inspector finds larvae in the inevitable rain-water barrel at the home of a southern darky.

Fig. 56.-He prevails upon the lady of the house to pour some kerosene into the barrel to kill the larvae.

Fia. 57.-And to keep the barrel covered thereafter, so that mosquitoes cannot lay any more eggs in it.

with water after a heavy rain, a large private swimming-pool, an old, forgotten, defectively-covered cess-pool, a choked-up roof gutter and an old well, not then in use. 
In many Southern towns, parts of the negro districts are not supplied with city water. In these cases, the negroes either have shallow wells or else haul water for drinking purposes, which is generally kept in barrels. Each of these conditions give rise to a problem of considerable magnitude.

\section{PLANNING THE INSPECTION SYSTEM}

The only way in which the conditions above-mentioned can be overcome is by means of a rigorous system of inspection of

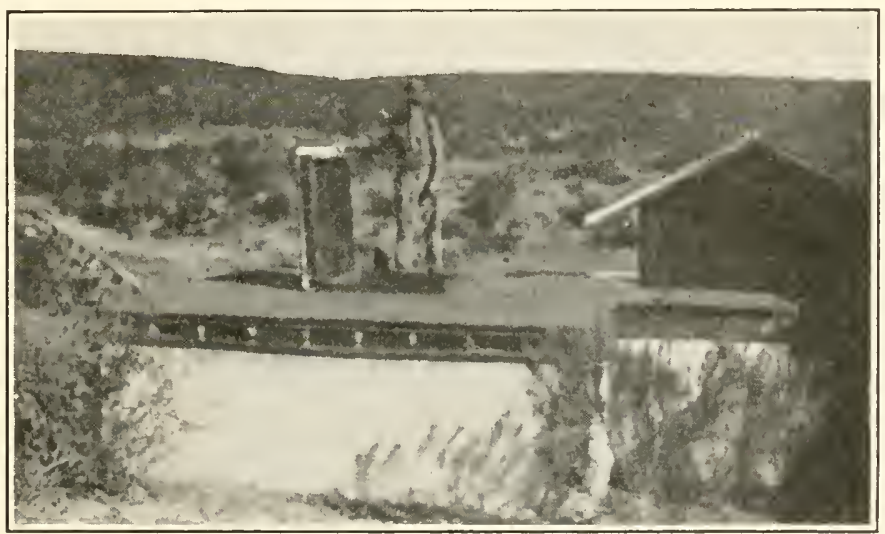

FIG. 55.-Septic tank with screening rotted away-an ideal brecling place for Culex pipiens.

premises. This should be coupled up with the inspection of streams, marshes, ete, in the outlying area in such manner that every spot in which breeding may, by any possibility, take place be visited once a week or once every 10 days at most.

In planning the inspection work, the community, if large, should be divided up into inspection areas, with an inspector in charge of each. If the town is small, perhaps one inspector can handle it. It has been the writer's experience that one inspector, doing nothing else, should be able to handle from 30 to 50 average resiclential blocks, covering the whole area thoroughly once a week or once every 10 days. Inspection of the outlying area-pools, streams, ponds, etc. does not take nearly so long comparatively as inspection of premises. 
The inspector should be equipped with a long-handled dipper, preferably of white enamel, and a small hand mirror, to facilitate finding larvae. The dipper is used to dip up water from pools, barrels, ete., for eloser serutiny. The mirror is used to reflect sunlight upon the surface of the water, so that larvae may be easily spotted whether at the surface or in the depths. According to Parham, ${ }^{1}$ it was found that one inspector, equipped with

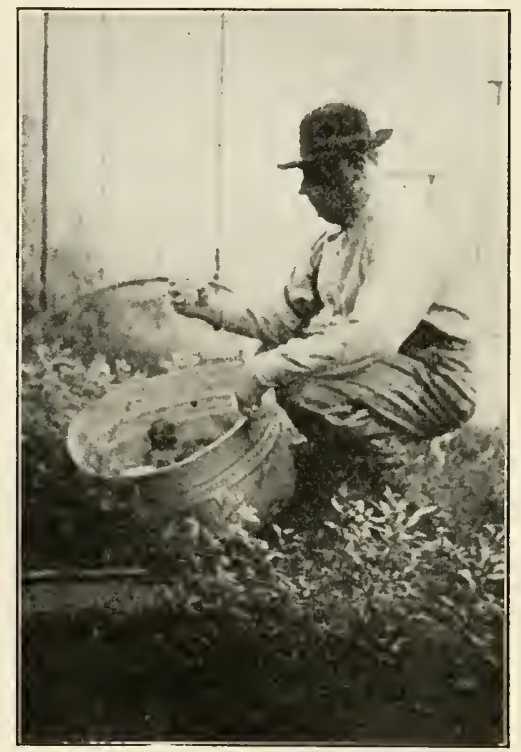

(Photo by E. H. IFagoon, C.E).

FIG. 59.--Inspector looking over tub of old bottles and tin cans for mosquitobreeding.

dipper and mirror, could cover territory requiring four inspectors not so equipped.

In dealing with conditions found by the inspectors, the following procedure has been found effective:

On his first eovering of his beat, the inspector should take his time. He should explain his mission to the occupants of the houses he visits, point out any actual or potential breeding places, insist politely that they be done away with immediately and leave an anti-mosquito leaflet. ${ }^{2}$ If he sees any condition

' Naval Medical Bulletin, vol. 15, No. 2, April, 1921.

${ }^{2}$ A suggested anti-mosquito leaflet is printed as Appendix C. 
that he considers should be handled by the anti-mosquito forces, such as a big pool in a street ditch that needs draining, emergency oiling to prevent early hatching of a large number of pupae, etc., he should make a note of it and, on arriving at the office, should transcribe these notes on appropriate slips of paper made out somewhat as follows:

FORM NO. 5

WORK ORDER

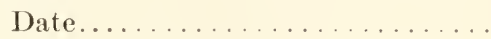

To......

Foreman

Location

Work needed

Inspector

The work described above has

Foreman

These work orders are then gone over by the director and turned over to the appropriate foreman, be it oiling, fish control, drainage or maintenance. The foreman to whom it is turned over performs the work, if the situation requires it, in any case making a report on the matter in the space left for that purpose.

Should such action be desirable, the inspector may take a malaria census, as clescribed in Chapter IV, while covering his beat for the first time. While it would require some extra time to do this, the valuable information gained probably would be worth it.

\section{HANDLING THE NEGLIGENT CITIZEN}

On his second trip of inspection, the inspector, wherever he finds breeding going on through fault of the occupant: of the premises, should leave a formal notice. A form more or less similar to the following has been used successfully by the writer: 


\author{
FORMI NO. 6
}

CITY OF

OFFICIAL NOTICE

To

You are herewith notified that a mosquito breeding-place exists on your premises.............. Street, in violation of the City Ordinances.

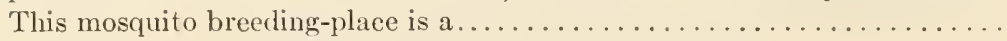

Iou are respectfully advised that you have three days in which to abate the mosquito breeding-place above mentioned. Failure to do so within the three days will render you liable to a fine of from $\$ 1$ to $\$ 25$ and costs.

Each day that the breeding-place exists, after the three days mentioned, constitutes a separate offense, under the City Ordinances.

\title{
Direetor, City Anti-Mosquito Campaign.
}

The above form is the formal notice required by the ordinanee before prosecution may be initiated. At the end of the 3 days, the inspector should return to the offender's home. If the work has not been done, he should consult immediately with the director of the campaign with a view to laying a complaint.

If a eharge is laid, it is neeessary that the inspeetor be on hand at the proper time to testify. Until he knows his inspectors thoroughly, it is expedient that the direetor himself view the spot to make sure that the situation falls within the scope of the ordinance, that the inspeetor has given the notice and that the demand made is not unreasonable, as, for example, suggesting expensive drainage work when the situation can just as well be handled by inexpensive fish eontrol.

Streams, ponds, ditehes, pools, ete., which the anti-mosquito forees are oiling or otherwise working should, of course, also be carefully inspected weekly and, should any breeding be found, the inspector should at once report it to the director for appropriate action. This has a tendency to keep the workers on the alert.

\section{COMPLAINT BUREAU}

While engaged in co-operative malaria eradication demonstration work in Texas, the writer tried out the idea of opening a complaint bureau. It was considered that this would afford 
a good clue to areas in which breeding might be taking place unknown to the anti-malaria personnel. It was also believed that the knowledge that poor work would soon be revealed to

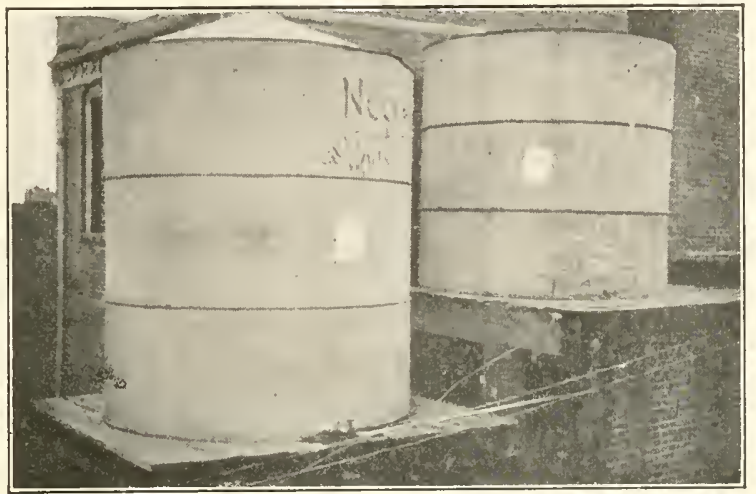

(Photo by E. H. Magoon, C.E.)

Fig. 60.-Surface cisterns placarded by inspector. Such cisterns make ideal breeding-places, when, as is usually the case, they are not mosquitotight.

the director by sufferers therefrom might stimulate the inspection staff. Both of these beliefs materialized.

The system followed was repeatedly to outline the plan through the newspapers, requesting all residents suffering from mos-

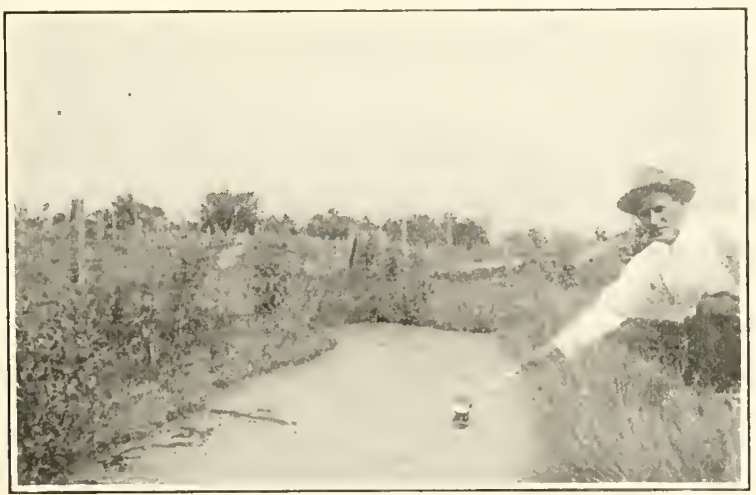

(Photo by E. H. Mogoon, C. E.)

FiG. 61.-- Inspector dipping for larvae in a borrow-pit.

quitoes to any considerable extent to file complaints, either by telephone or personally with the anti-malaria office, but not until each complainant had first thoroughly inspected his own premises. 
A number of blanks were printed on which to take down the complaints. These blanks were somewhat as follows:

FORM NO. 7

Complaint

Date

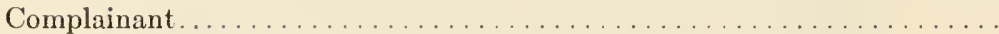

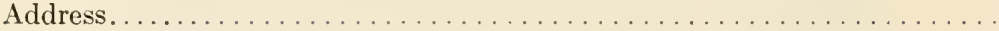

Suspected Source of Breeding

Found

Address.

Action Taken

Date

Inspector

As indicated by the form, these complaint cards were turned over by the dircetor to the appropriate inspector, who then investigated the complaint and reported back what he had found and what action he had taken.

On the whole, the writer was very well satisfied with the operation of the complaint bureau. It unquestionably had a good effect in revealing breeding-places that the anti-malaria forces were not aware of and also in stimulating the inspectors. It also helped convince the people that sineere and eonscientious efforts were being made to keep down domestic mosquitoes and, at the same time, did much to teach them to keep their premises in shape, sinee, in a very high proportion of the eases, the complainant himself was found to be raising the mosquitoes.

One slight disadvantage was that people oceasionally would make complaints for which no basis could be found-that is, no breeding places could be loeated in the vicinity and neighbors would report that they had noticed no mosquitoes. In such eases, the time spent in trying to trace down the supposed breeding-places was wasted. Another disadvantage of the plan was that it led people to expect too much; often, they would file a complaint on the strength of having noticed only a single mosquito. 


\section{PUBLICITY}

Properly got-out publicity is probably one of the greatest helps the director of an anti-mosquito eampaign can have. If must be remembered that, in its larger aspects, the whole work is more than anything else an educational endeavor. If this be true, the educational end of it is really more important than the reduction of mosquitoes and should, accordingly, be given the attention it merits. Even on selfish grounds, the people should be taught to protect themselves sinee, in this way, the work of the director and the expenses of the eampaign are correspondingly decreased.

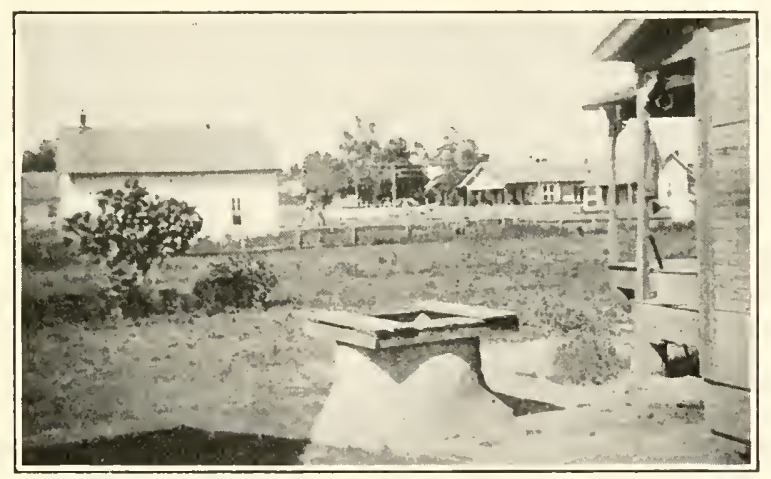

(Photo by E. H. Mogoon, C. E.)

FIG. 62.-Top of underground cistern, in which breeding was very abundant until a few Gambusia were put in it.

In much anti-mosquito work, it is customary to eease publicity activities, onee the funds have been raised, but this is a mistake. The publicity designed to get the money should be but the beginning.

It has been the practice of the writer to keep up a steady flow of publicity from the time the work is first broached to and beyond the end of the campaign. Thus, as soon as it was definitely deeided that the campaign was to be put on in a town, he would explain the seientifie facts upon which the work is based, refer to the great suecess of similar work in Cuba, Panama and elsewhere and then recount the local problems and the methods to be used in handling them.

Then, as the work progressed, he would issue statements as to the progress being made, the percentage of drainage eompleted, the formation of an oiling gang, its mode of functioning, the 
appointment of inspectors, their duties, habits of Gambusia (the anti-mosquito fish), establishment of aquaria, stocking of streams and ponds, etc.

Accounts of prosecutions should be brief, but complete, with no comment.

\section{TEXTS FOR ARTICLES}

Texts for articles from time to time may be found in diseoveries of unusual breeding-places, decrease in incidence of mosquitoborne diseases as reported by the physicians, eompared with previous years, statements by prominent local persons as to the reduction of mosquitoes, comments by traveling men as to conditions compared with other towns, visits by health officials, etc.

The writer used to make a practice of issuing a statement immediately after every heavy rain, advising citizens to look over their premises, dump the water out of any collections of tin eans, inspect their roof gutters, screen their rain-water barrels and eisterns, ete. The articles would be arranged a little differently each time, but the substance would be virtually the same.

Editors of the various newspapers are almost invariably genuinely willing to co-operate in this way, taking the view that the work is a public benefit for the town and worthy of being "boosted."

A few points, however, should be borne in mind in dealing with the editors. They are usually busy men and have little or no time for long-drawn-out conversations. When the director has oceasion to consult with them, he should be brief and to the point. For the same reason, the director: will stand a much better chance of getting his publicity matter "over," if he will write it out himself, than if he asks the editor to write it.

In form, the articles should be short and snappy. Rarely should an article reach half a column in length. Generally, they should not run more than a quarter of a column. Nor should they have long, involved preambles. The very first sentence should uneover the root of the whole business. Long, technical words should be avoided. Write the article "as though you were telling it to the policeman."

Another important point to be remembered is that the articles must contain no disagrecable references to any person. No comment should be made in regard to any one. Nothing will 
get one "in wrong" with an editor quicker than ill-considered references to local persons or institutions.

\section{OTHER METHODS OF OBTAINING CO-OPERATION}

Other methods of obtaining the co-operation of the public in eradicating mosquito-breeding are summarized by LePrince ${ }^{1}$ as follows:

1. "Short talks, direct to school children, showing them how mosquitoes are produced in water-containers and asking them to inspect the back-yards every saturday morning and empty or oil stagnant water.

2. "At West Point, Miss., the Mayor sounded the fire siren every Saturday morning at 9 o' clock as notice to the town folks to go out into the house-yards and climinate containers breeding mosquitoes and also to put a little kerosene into the closet and flush it to get a good oiling of the Culex pipiens producing sewer ditch.

3. "At Bastrop, the children in the school were asked to look after their own back-yards. At the end of the season, the teachers asked each child what he or she had done, and about 92 per cent had helped in the campaign.

4. "A composition by each pupil on the way to eliminate mosquitoes, with the best ones published in the local press and one or two small prizes offered by Chambers of Commeree for the boys and by women's clubs for girls will help. Don't forget to advertise the progress in the local paper.

5. "The motion picture houses are generally willing to show notices to the public without cost, and a few new ones each month will keep up interest in the work. Radio mat slides are used in preparing these notices, and cost about $\$ 3.00$ per $50 . "$

\section{DAILY REPORTS}

A complete recond of everyactivity of the anti-mosquito forees should be kept, together with full cost data as to the different kinds of work. These records should be kept, not only to aceount for the money spent, but also to form a basis for estimates for work in future years or in other places.

Fach foreman should be required to submit a daily report of

${ }_{1}$ Circular No. 10, Office of Maluria Investigations, U. S. Public Health Service, April 6, 1920. 
his work. The experience of the writer has been that it is impossible for the majority of foremen properly to fill out a report form that is at all complex. With the average foreman, about all that can be expected is a record of the number of men he has and the amount of their time, together with a short statement of the work accomplished, and even these simple data will have to be carefully checked.

The following form, and slight modifications of it, have been used by the writer for several years for all kinds of mosquito eradication work:

FORM NO, 8

Foreman

Date

Time Summari

\begin{tabular}{|c|c|c|c|c|c|}
\hline No. & Classification & $\begin{array}{l}\text { Hours } \\
\text { worked }\end{array}$ & $\begin{array}{c}\text { Hourly } \\
\text { rate }\end{array}$ & Amount & Remarks \\
\hline & Foreman. . & & & & \\
\hline & Laborer. . & & & & \\
\hline$\ldots \ldots$ & $\ldots \ldots \ldots \ldots$ & $\ldots \ldots \ldots$ & .. & $\ldots$ & . \\
\hline$\cdots \cdots$ & $\cdots \cdots \cdots \cdots$ & & & & \\
\hline $\begin{array}{l}\cdots \cdots \\
\ldots \cdots\end{array}$ & $\begin{array}{l}\text { 1 eam or truck.. } \\
\text { Driver......... }\end{array}$ & & & & \\
\hline & & & & & \\
\hline
\end{tabular}

WORK SUMMARY

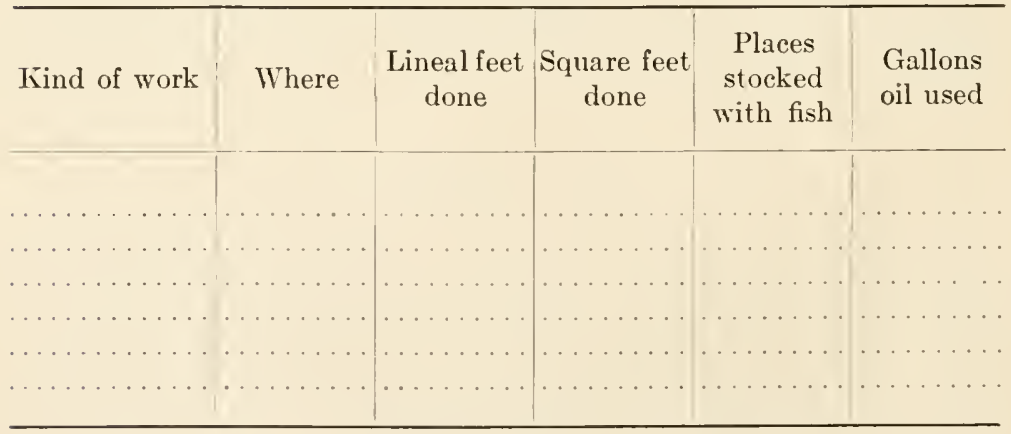

Foreman

The inspectors also should make out a general report daily, 
in addition to the notices, etc., mentioned in an earlier part of this ehapter. A form, more or less similar to the following, is suggested:

FORM NO. 9

Inspector's Daily Report

Dite

Number of houses inspected this date

Number of houses found raising mosquitoes

Kinds of mosquitoes.

Other places inspected.

Other places breeding mosquitoes

Kinds of mosquitoes

Number of official notices issued.

Number of prosecutions attended.

Number of work orders issued.

Remarks

These reports will provide some interesting information as to the progress of the citizens in keeping their homes in shape. After the campaign has been in progress for a few months, it will be found almost invariably that, as a result of the edueational work, the ratio of houses visited to houses found raising mosquitoes will show a great improvement.

\section{RECORDS}

There should, of course, be a complete record of expenditures of all kinds, and entries in this should be made immediately the expenditure is made or authorized. This record should preferably be of such form that the kind of work to which the expenditure is to be eharged is clearly apparent.

The following form was used by the writer for several years. It may be modified to suit the occasion: 
FORM NO. 10

EXPENDITURES RECORD

......... Ending..............

\begin{tabular}{|c|c|c|c|c|c|c|c|}
\hline Payee & $\begin{array}{l}\text { For } \\
\text { what }\end{array}$ & $\begin{array}{c}\text { Order } \\
\text { No. }\end{array}$ & Amount & $\begin{array}{l}\text { Date ap- } \\
\text { proved }\end{array}$ & $\begin{array}{l}\text { Date } \\
\text { paid }\end{array}$ & $\begin{array}{c}\text { Charge } \\
\text { to }\end{array}$ & $\begin{array}{l}\text { Re- } \\
\text { marks }\end{array}$ \\
\hline & & & & & & & \\
\hline & & & & & & & \\
\hline & & & & & & & \\
\hline & & & & & & & \\
\hline
\end{tabular}

In case any of the bills, payrolls or other entries should include sums chargeable to two or more different things, such as a combined drainage and inspection payroll or a bill for equipment for both oiling and fish-control work, such sum should be appropriately divided between the two kinds of work and explanation made under the heading of "Remarks."

Taking the sums expended from the expenditures record and the quantities of work done from the daily reports of the foremen or other sources, the director is then able to assemble his cost data for the different kinds of work. Thus, at any time, he can add together his expenditures on drainage work-payrolls and material-as recorded in the expenditures record, add up his figures of work accomplished from the drainage foreman's daily reports (or, better yet, accurately measure the work done) and learn just what his drainage is costing him per lineal foot or other unit. The same can be done with maintenance, oiling, fishcontrol, individual jobs, etc.

On work with which the writer has been associated, it has usually been customary to do this work every month, as a basis for the monthly reports required.

It is suggested that separate records of this kind be kept for the following activities:

Activity

Supervision
Charges to be Included

Salaries of director and elerieal help, if any; transportation of director.

Inspection............. Salaries of inspectors; transportation, if any.

Drainage............. Payrolls of laborers and foremen; materials.

Maintenance of drainage..... Labor payrolls.

Oiling. . . . . . . . . . . . . Cost of oil; transportation; labor payrolls.

Fish-control............ Labor payrolls; transportation.

Miscellaneous............Equipment and other miscellaneous expenses 
The records of malaria calls made by physicians, described in Chapter IV, should also be gone over carefully each month, and any physicians delinquent in reporting should be seen without delay, since it is imperative, for effective comparison that complete and accurate figures be obtained.

\section{MAPS}

As stated in an earlier chapter a map of the community in which the work is to be undertaken should be obtained and, if practicable, several copies should be made of it. A scale of 1 inch to 200 feet or 1 inch to 400 feet is recommended.

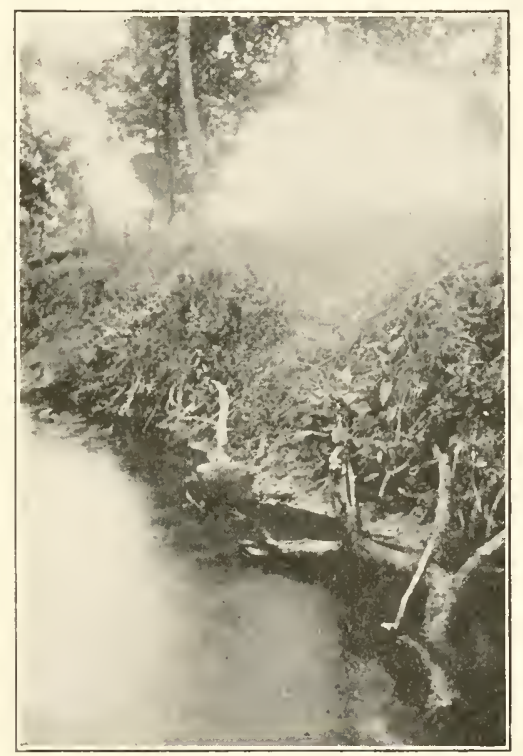

(Photo by E. H. Hagoon, C. E.)

F1G. 63.--Mosquitoes were breeding abundantly in a little water in the old kettle clinging to the bank. There was no breeding in the stream itself, however, owing to the activities of larva-destroying fish.

On one copy of this map, there should be marked all the topographical features of the community bearing on mosquito production, as found during the survey. As old ditehes and channels are cleared (re-channeled), as new ditehes are completed, as marshes are clrained, as holes are filled up, as ponds, culverts, streams, etc., are stocked with fish, as oil stations are organized, they should be indicated on the map in an appropriate manner, either by the use of symbols or otherwise. 
One complete eopy of the map should be kept in the office of the director for reference. One, on which places that require oiling and oil stations, ete., are indieated, should be given the oiling foreman to assist in working out an oiling schedule. Another, showing places that may profitably be stocked with fish, such as pools, streams, swamps, etc., should be given the fish-control foreman. Another, showing the ditches, etc., should be given to the ditch maintenance foreman. Each inspector also should be provided with a copy of the map, with each one's precinet indicated thereon. 


\section{CHAPTER VI}

\section{INLAND DRAINAGE}

\section{IMPORTANCE OF DRAINAGE AS AN ANTI-MOSQUITO MEASURE}

Drainage is one of the most reliable and permanent methods of mosquito control. Where there is no water in which the mosquito eggs may develop, there ean be no mosquitoes, and when once a place is properly drained, it should remain in good shape for a consiclerable period, with a certain amount of maintenance. Unless the anti-mosquito work is a mere temporary expedient, therefore, drainage will play a large part in it.

The term "drainage," however, as applied to anti-mosquito work, signifies a procedure somewhat different, as a rule, from drainage for agricultural and other purposes. Such drainage work, as a matter of fact, sometimes produces mosquito breedingplaces. For mosquito eradication, the land must not only be properly drained, but the ditches themselves must be so designed as not to become sources of breeding.

Drainage, as an anti-mosquito measure, may include any or all of the following, and maintenance thereof: Ditching, open and lined; sub-surface tile drains; vertical drainage; re-channeling of natural water-courses; filling; diking; construetion of tide-gates; pumping.

The last three will be considered in the chapter on "Salt Marsh Drainage," since it is in salt marsh work that they are generally employed.

In addition to being a most effective measure by itself, drainage frequently may be used to great advantage in comnection with fish-control, oiling and other procedures. Examples of such cases are: Construction of a diteh connecting an isolated, fishless pool with water stocked with mosquito-destroying fishes, or lowering of a pond to recluce the area that requires to be oiled.

\section{LIMITATIONS OF DRAINAGE}

While drainage, in the long run, probably is considerably cheaper than most other control methods, especially oiling, it 
should not be employed without discrimination. There is no use in going to a large expense in draining a pond that can be controlled for much less money by stocking it with fish. Nor will it pay to try to drain a swamp that ean be protected at much less expense by means of levees or dikes and tide-gates.

On the other hand, drainage has many advantages in addition to its value as an anti-mosquito measure. Large areas of swamp and marsh lands have been rendered cultivable by proper drainage. Furthermore, in many places in the United States today,

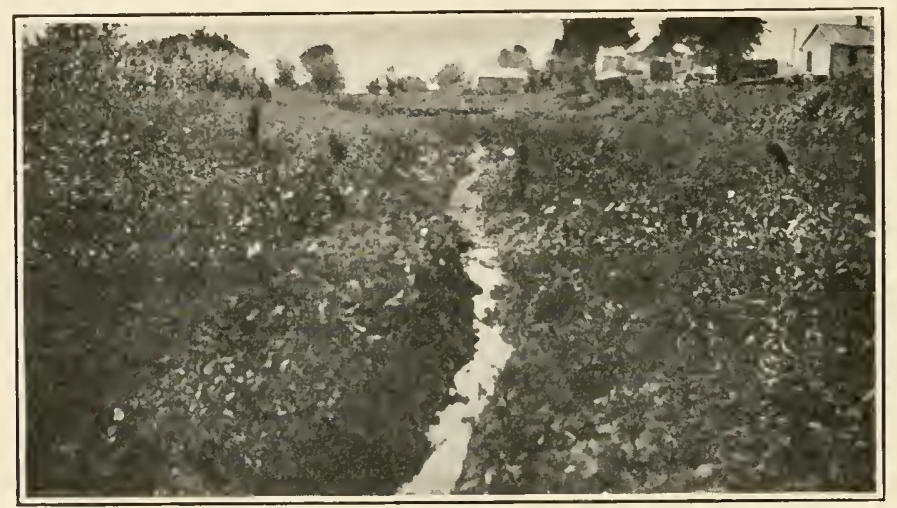

Fig. 64.-Typical anti-mosquito ditching location.

the land is not producing what it should, because it is not drained. For this reason, money spent on anti-mosquito drainage frequently returns a double profit-it improves the health of the occupants of the land and also increases the productivity of the land.

Again, it often happens that the cost of draining swamp land is more than paid for by the natural resources thereby rendered accessible. Frequently, the lumber alone thus made available is worth more than what the drainage cost.

\section{PRELIMINARY WORK}

Whether the project be large or small, it generally will pay to study pretty closely the topography of the area. If the project be large and the area involved be low and flat, sufficient levels should be run to enable a contour map to be prepared; the main ditch systems should be laid off accurately on the map and then be 
located by instrument in the field, stakes being set at 50- or 100 -foot intervals, with the ent at each stake marked thereon.

Even if the project is not large enough to justify this amount of preliminary work-as will often be the case-it may frequently be necessary in low, flat country to run various lines of levels to ascertain the fall available and the best location for the main ditehes.

Where the country is hilly or rolling, the eye alone may be

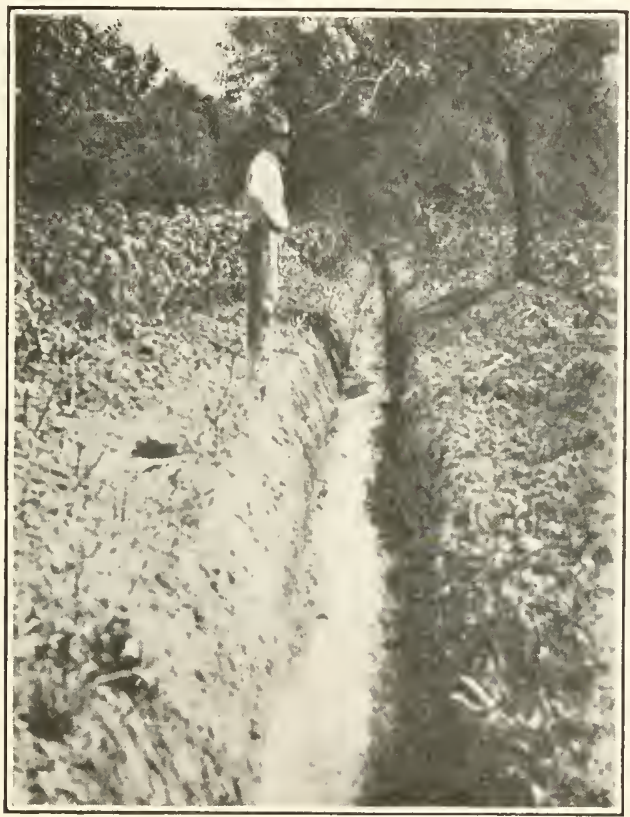

Fig. 65.-A A common type of anti-mosquito diteh.

sufficient for open-ditch work, although in all cases of doubt, the level should be used.

As a general rule, open ditches in anti-mosquito work need not be graded with the aceuracy of a sewer trench, though there should be no low spots. With lined ditches and sub-surface drains, however, this is not the ease; stakes should be set for these in all cases.

Owing to the fact that mosquitoes do not develop in standing water for several days, anti-mosquito sitches do not always have to be as large as ditehes for agricultural drainage and other purposes. Thus, if a diteh will carry off the standing water in 
4 to 6 days, its capacity is sufficient, from a mosquito control stanclpoint, although this may not be the case from the standpoint of agricultural drainage.

\section{TYPES OF INLAND DRAINAGE PROBLEMS}

Once the area in which the campaign is to be undertaken has been gone over, it will often be found that the problems to be met are variect and numerous. Some breeding-places may be handled

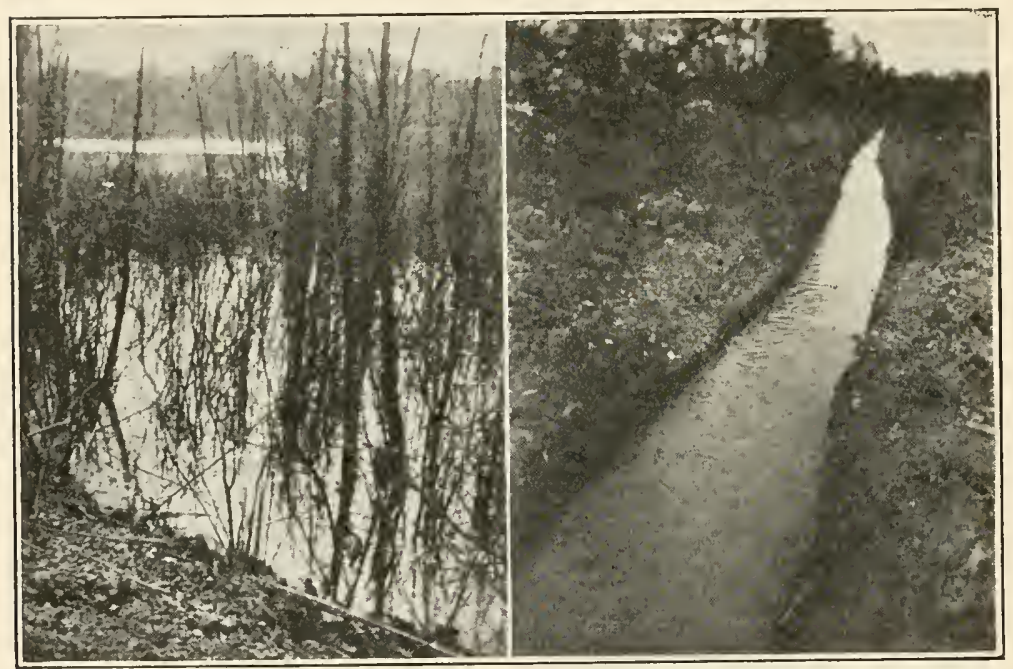

(Photos by E. B. Johnson, C. E.)

FIG. 66.-Left, large cat-tail swamp fed by a spring; right, ditch dug to lead water around the swamp.

best by means of fish-control; others best by oiling; and still others best by drainage. The director of the campaign will have to study each problem by itself and decide which is the best method of dealing with it. In case of doubt, the method that seems cheapest for that particular problem should be adopted.

After eliminating those places in which fish-control and oil may be used to best advantage, a considerable number of places generally will be left that obviously require drainage. In any large project, these will, as a rule, be of several different types, and hence will require different methods of treatment. Among the different types of areas requiring drainage may be the following: Temporary puddles, stagnant ditches, blocked-up streams, borrow-pits, ponds, lakes and swamps. 
Of these, the first three usually present no serious problems, requiring simply open ditching or re-channeling.

Borrow-pits should be treated in accordance with conditions. If fairly shallow and advantageously located, they may be ditched; many are too deep for other than vertical drainage, and may, perhaps, be stocked with fish or oiled. If they are to be drained by ditching, the procedure is generally simple.

"It is when we come to ponds, lakes and swamps," says Metz," "that the real problems arise, and it is best perhaps to consider these three together. Since the difference between lakes and ponds is only one of degree, and since swamps may include either or both of the other two, it is obvious that, in actual practice, little distinction can be made that would involve different methods of drainage. It is more important to classify such areas according to the sources of the water, for, in this case, the distinctuons correlate with modes of treatment.

\section{PROBLEMS OF POND, LAKE AND SWAMP DRAINAGE}

"For instance, one pond or" swamp may be caused by the accumulation of rain-water and may fluctuate greatly with the seasous, another may be simply a basin in the channel of a sluggish

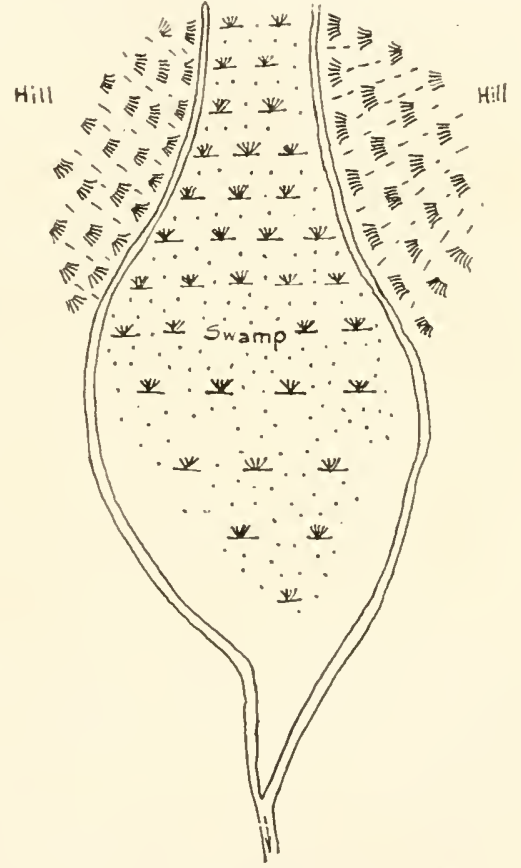

FIG. 67.-Seepage outcrop, Case No. 1. (After Metz.) stream, while a third may be fed from springs and may be bordered by a seepage outcrop.

"In the first of these, the rain-water swamp, it is merely necessary to provide a small channel to carry off the surplus water left after the main flood waters have passed. As a rulc, one or two ditches will suffice.

"In the second case, the situation is more difficult, for the water" supply is continuous and fluctuating. The swamp will vary in size with high and low water in the stream, and a drainage operation of

1 "Some Aspects of Malaria Control Through Mosquito Eradication," U. S. Public Health Service, 1919. 
considerable magnitude may be required to eliminate it . . . In case drainage is decided upon, it will probably take the form of channeling the stream below the swamp to lower the water and increase the flow. . . .

"The third case mentioned-that of a swamp fed by a seepage outerop-presents the most difficult problem of all. Here we have, not only an area of standing water, probably full of vegetation, but also a series of tiny puddles in the form of hoof-prints, etc., along the outcrop margin. Each of these is a potential breeding-place of the worst kind. The treatment of such an area requires a special procedure, and, since the proposition is one that is apt to be found in most any locality, it may be considered in some detail.

\section{TREATMENT OF SEEPAGE OUTCROPS}

"Seepage water usually appears on the hillsides, ete., at the outcrop of a stratum of water-bearing sand or gravel underlain by an impervious stratum of clay, shale or other material. The outerop may be in the nature of more or less clistinct springs or simply a gradual oozing out through the soil. In either case, it is fed by a water-table below the surface, and treatment must be aimed particularly at this water-table. It does not suffice to dig ditches directly away from the springs and down the hillside. Such a method would require a separate ditch for each spot from which water is issuing, and would mean, in many cases, a series of ditches about 12 inches apart along the whole hillside. The only effectual way of collecting the water in such places is by means of ditches dug at right angles to the flow of the seepage water, or, in other words, across the exposed end of the water-table. Such ditches may then be connected to one or more main ditches, if necessary, and the water carried down the hillside parallel to the seepage flow. These points are illustrated roughly in the accompanying sketches of actual swamps.

"In No. 1, there was a scepage on both sides of a narrow valley, the water coming out of two hills opposite one another, as shown in the sketch. As a result, the bottom of the valley in this region was a typical cat-tail swamp, with water from 1 inch to 2 feet in depth. Since the source was somewhat up on the hillside, it was useless to dig a ditch through the bottom of the swamp and down the valley. This would simply carry off the deep water and leave the seepy marsh as it was. Instead, a deep, narrow ditch was dug along the margin of each hill, just at the upper edge of the seepage outerop and at right angles to the flow of the seepage water. In this manner, the water-table was intercepted, and all the water that formerly oozed out down the hillside now seeps into the ditch and is carried off. As a result, the swamp, no longer fed from the hillside, has dried up. 


\section{DRYING UP A SWAMP}

"In ease No. 2, a more complicated situation is presented. Here the seepage flow is from a large U-shaped bend in a hillside, resulting in a swamp many acres in extent, with a small lake at the outer edge. The water-table in this case extended clear across the swamp, but was concealed along a slight elevation rumning down the middle. On aceount of this elevation, it was necessary to drain the right and left halves of the swampy area separately. As shown in the sketch, a ditch was put

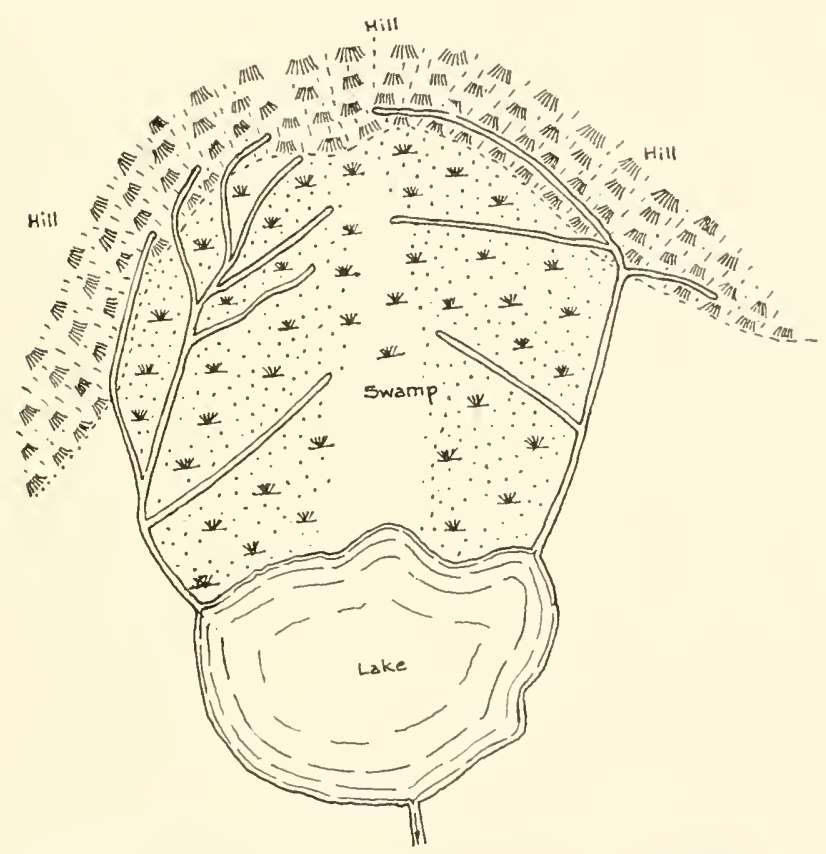

Fig. 65. - Seepage outcrop, ('ase No. 2. (After Hetz.)

along the toe of the hill on each side at the upper margin of the outerop and then run off into the lake. But the water-table this time was too deep to be intercepted entirely by one ditch, and it was neessary to dig additional intereepting laterals at intervals lower down. On one side, five such ditehes, more or less parallel to one another and at right angles to the seepage flow, were required to eatch all of the water before it eame to the surface.

"In case No. 3, an outerop on a relatively steep hillside is represented. Here it was necessary to dig several intercepting laterals parallel to one another and only a few feet apart in order to catch all of the flow. When this was done over the area in which the seepage water was actu- 
ally coming out of the ground, the remainder of the swamp lower down the hillside became completely dry.

"In each of these cases, collection of the water depended upon the ditches being constructed primarily as intercepting rather than conducting ditches. In the case of swamp No. 1, the ditches happened to be intercepting and conducting at the same time; but more often separate conducting ditches must be constructed to carry off the water after it has collected in the intercepting ditches."

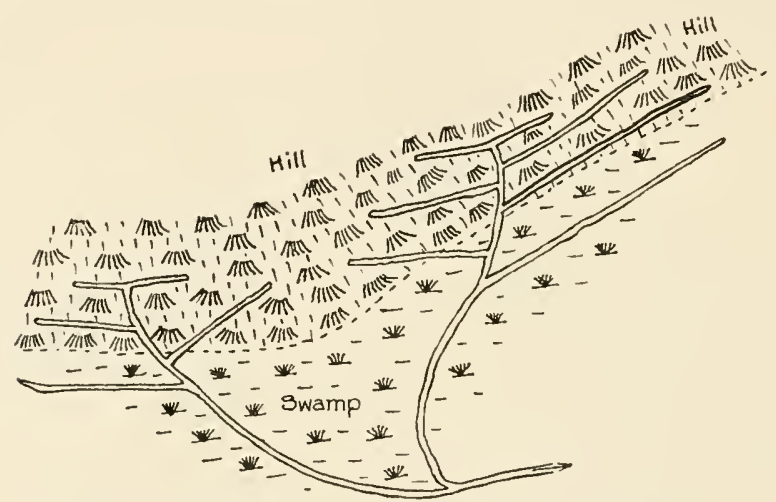

FIG. 69.- Seepage outcrop, Case No. 3. (After Metz.)

\section{DITCH CONSTRUCTION IN GENERAL}

The open ditch is the type of ditching most frequently employed in anti-mosquito clrainage. While the first cost is undoubtedly less, it is belicved, however, that, over a period of years, some more permanent type of ditch is cheaper, owing to the more or less continuous maintenance expense that open ditches require. Open ditches must be kept free from grass, weeds, debris, etc., and the scomring action of the water in flood-times must also be repaired.

Ditching may be required on firm, open land, where the expense is at a minimum, or in wooded swamp areas, where the work becomes costly and tedious. The methods, of course, will vary with conditions; thus, on firm ground, machinery may be employed to great advantage; in swamps, dynamite may be cheapest.

In all cases, however, the following principles are applicable:

1. The ditches should be just as few as will answer the purpose.

2. Wherever possible, they should have clean-cut, sloping edges, narrow bottoms and straight courses. 
To comply with the first prineiple mentioned, the main diteh should, in all cases, be constructed first. Frequently it will be found that laterals, which appeared to be needed before the main diteh was dug, will not be required at all. If there is any doubt as to the need for a lateral, it should not be dug.

In regard to the second prineiple, it may be suggested that, in average soils, the slopes of the sides of the ditches should be about 45 degrees; in sand and soft mud, the slope may be flatter, while, in hard clay and rock, it may be almost vertical. The bottoms should be made narrow so that, when the flow is small, the water will have no opportunity to spread out and form pools. Straightness of course, where the ditches are not laid out by instrument, may be attained by use of a line, where necessary. Branch ditches should join main ditches at acute angles or eurves, in order to lessen depositing of silt, sand, debris, ete., at the junction point.

\section{HAND DITCHING ON FIRM GROUND}

Most anti-mosquito ditching is done by hand, probably because most projects are too small to justify the purchase of machinery. However, when machinery is available, it should be used wherever practicable.

The chief tools needed for hand ditching are picks and shorels. Where the earth is full of roots, a mattox will come in handy. A tiling spade may be used for finishing off the bottom. Sometimes a hoe will prove valuable. The phosphate drag, a tool somewhat resembling a potato-hook, only hearier, is useful for eleaning out ditches or for general work in marshy land that is full of roots.

In cutting ordinary ditehes by hand, no great technical skill is necessary. Common sense and ability efficiently to handle men are the chief requisites. Upon beginning work, the diteh should be laid out by means of lines, so that it will be dug straight. The men then should be scattered out along the lines, a section being allotted to each team of two men. As each team finishes its section, it should be moved forward and given another section.

Constant vigilance is essential to see that the men keep the bottom even-that is, avoid alternate humps and depressions. Probably the best way to do this is to select two or three intelligent men and assign them the job of finishing the bottom of the whole ditch. 
In cases where no instrument is available for checking the aceuracy of the bottom-finishing, water may be admitted to

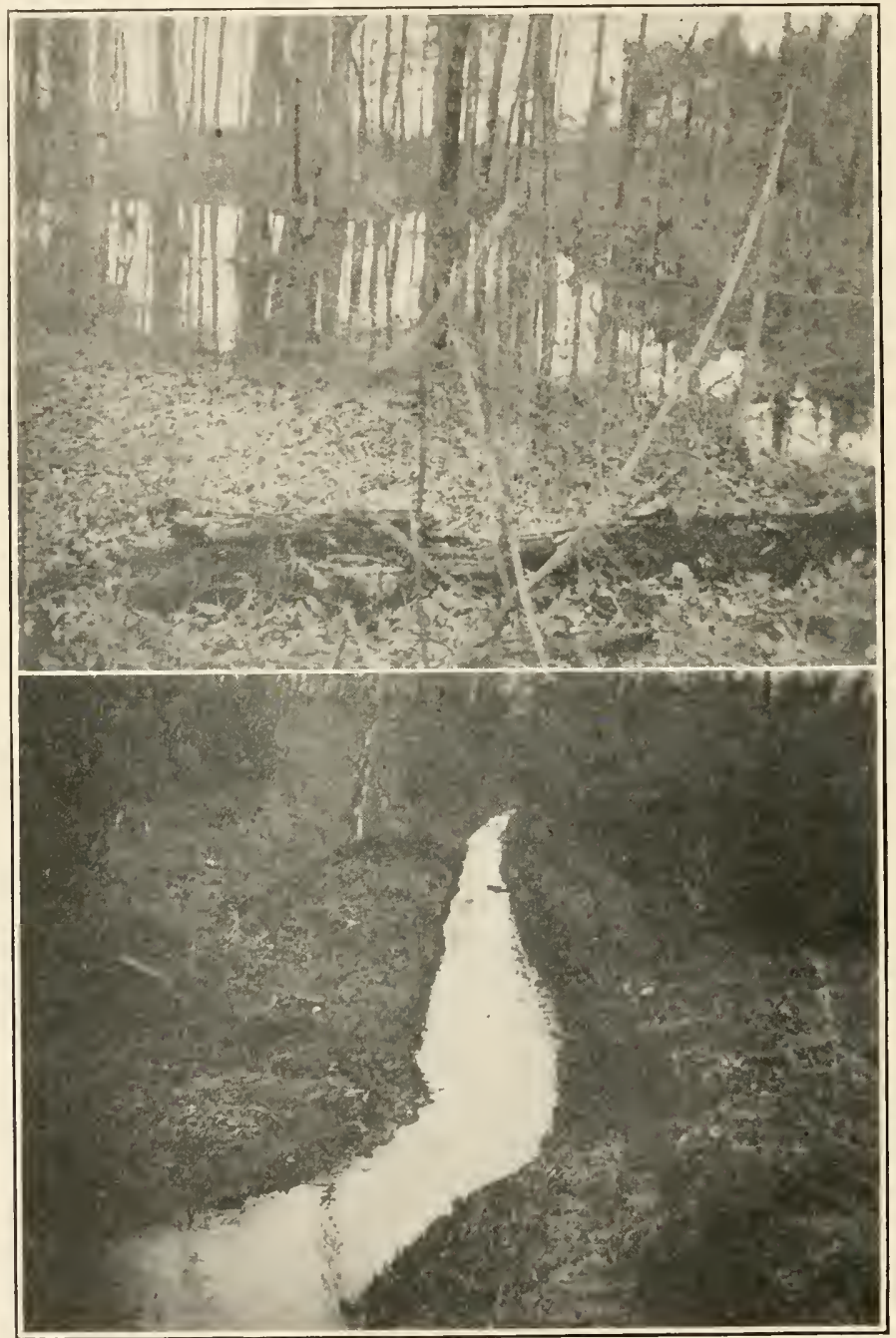

(Photos by E. B. Johnson, C. E.)

FIG. 70.-Above, extensive swamp; below, ditch that drained it.

the ditch at its upper end and allowed to descend to the lower end. Presenee of pools will indicate a ridge or a depression, as the case may be, and enable the finishers to correct their errors. 


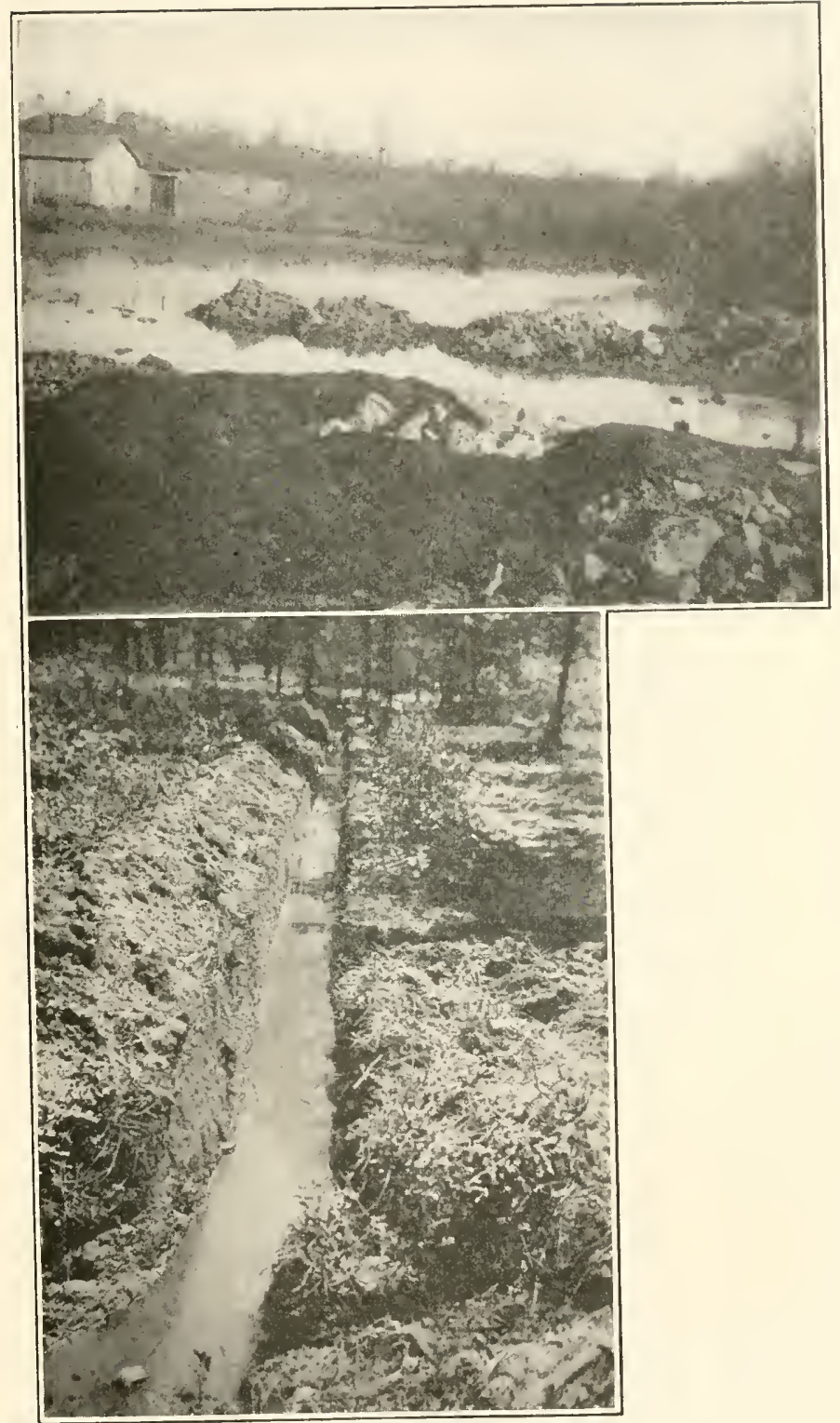

(Photos by E. B. Johnson, C, E.)

Fig. 71.-Above, pond caused by seepage from hill; below, ditch at base of hill, intercepting seepage. Shortly after the ditch was completed the pond dried up. 
If no water is available, the ditch should be inspeeted after the first shower, and any corrections that may be needed made then.

\section{COST OF ORDINARY HAND DITCHING}

Anti-mosquito ditching is generally estimated on a lineal foot, rod or mile basis, instead of a cubic yard basis. Costs, of course, vary materially with the size of the diteh, the nature of the soil, the rate of wages paid and the efficieney of labor. For these reasons, it is impossible to give any exact figures as to costs of hand ditehing.

As a general proposition, it may be said that, with ordinary soil, unskilled labor and wages from $\$ 2$ to $\$ 3$ a day, the cost of the average hand-dug ditch should range somewhere between 2 cents and 5 cents a lineal foot. Swamp work, of course, will greatly exeed these figures. The presence of large numbers of roots and stumps also will inerease costs.

The following figures represent approximate hand-ditching costs on several jobs handled by the writer in the South, the ditches having an average sectional area of from 2 to 4 square feet and the diteh mileage on each job ranging from 4 to 10 miles:

\begin{tabular}{l|r|c}
\hline \multicolumn{1}{c|}{ Project } & Wages & Cost per lineal foot \\
& & \\
& & \\
No. $1 \ldots \ldots \ldots \ldots \ldots \ldots \ldots \ldots$ & $\$ 3.00$ & 0.056 \\
No. $2 \ldots \ldots \ldots \ldots \ldots \ldots \ldots \ldots$ & 2.50 & 0.027 \\
No. $3 \ldots \ldots \ldots \ldots \ldots \ldots \ldots \ldots$ & 2.50 & 0.011 \\
No. $4 \ldots \ldots \ldots \ldots \ldots \ldots \ldots \ldots$ & 2.00 & 0.023 \\
& & \\
\hline
\end{tabular}

\section{HAND DITCHING IN SWAMPS}

Ditehing by hand in real swamp areas is tedious and eostly in the extreme. Where practicable, the ditches should be laid out with lines and the men spread out as already described. In some cases, however, this is not practieable.

In a large anti-mosquito swamp drainage projeet in Georgia, with which the writer was eonnected, the earth was so soft that 
pails had to be used to dump it out with, and the sides of the ditches caved in as soon as any considerable depth was reached. Laborers sank in the mud up to their hips. In order to make any progress at all, it was found necessary to build a retaining wall of poles on either side of the proposed ditch. Even then, much of the mud would seep back into the diteh, so that it was found practicable to excavate only a few inches at a time. The

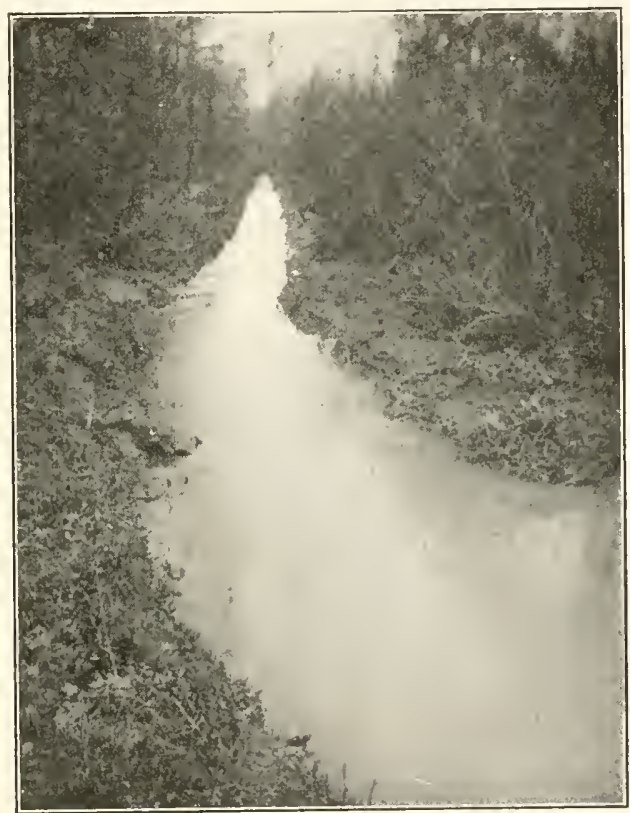

(Photos by E. B. Johnson, C. E.)

Fig. 72.-Oceasionally, it is necessary to ditch a slough. Here, a channel 3 feet deep and 4 feet wide was dug through the lowest part of the slough.

diteh would then be left to dry out for two or three days, when a few inches more would be dug. This kind of work may cost from 25 cents to $\$ 1.00$ per lineal foot.

Not all parts of a swamp will be as bad as this, of course, but, wherever the earth is soft and sloppy, it is a certainty that the costs are going to be high. Frequently, it is also difficult to maintain an adequate gang of laborers under such conditions.

While costs of hand ditching in swamps will vary in accordance with circumstances, it is believed that they will, on the average, run several times as higli as costs of hand-ditching on firm earth. 
In the project above-mentioned, nearly 40 miles of ditches were dug, a large proportion of them being in the swamp alluded

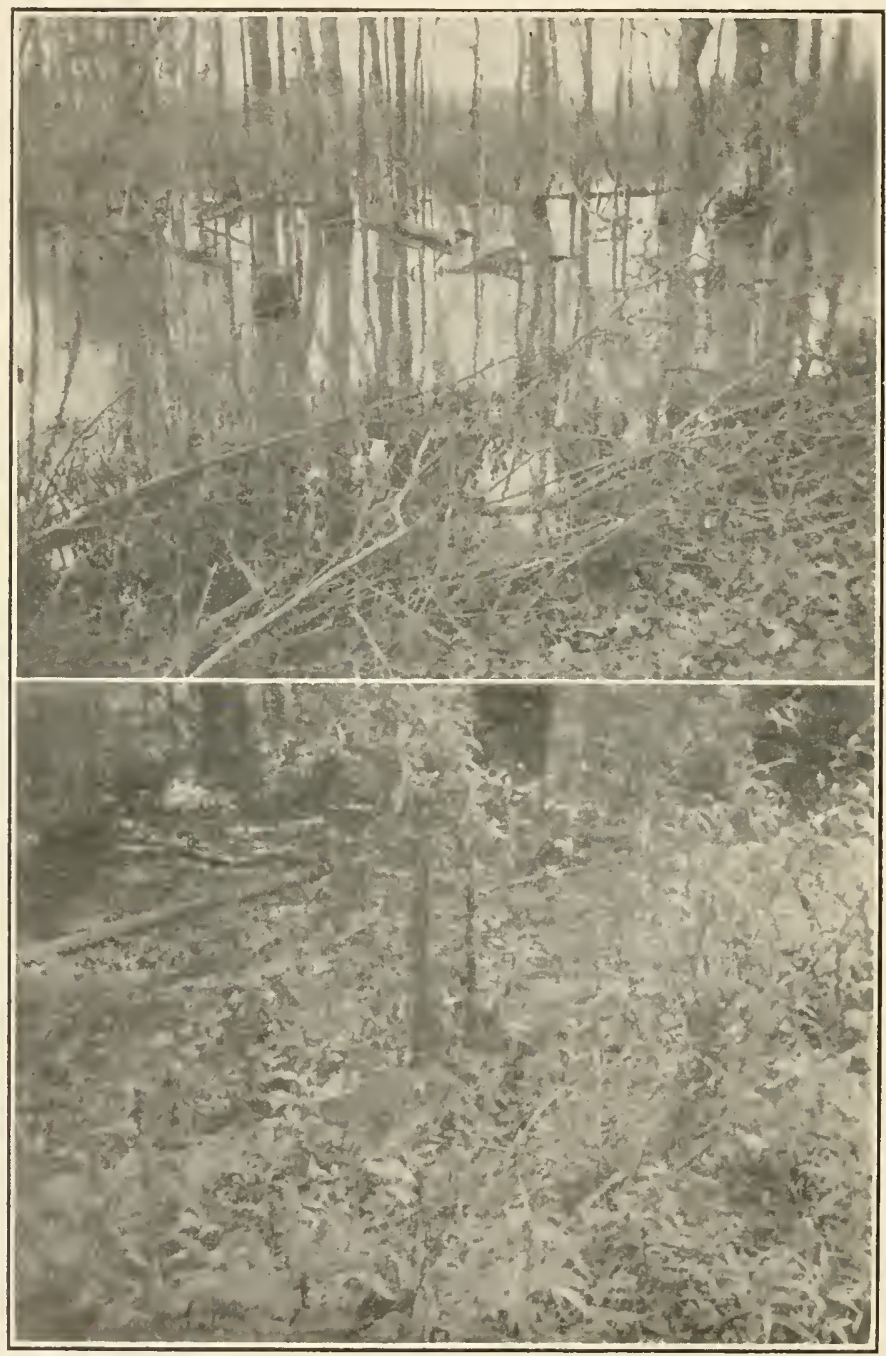

(Photos by E. B. Johnson, C. E.)

Fig. 73.-Above, lagoon that was a bad Anopheles breeding-place; below, lagoon completely dried up. This was accomplished by a ditch that cost less than $\$ 50$.

to. The cost averaged $\$ 723.05$ per mile or 13.7 cents per lineal foot. 


\section{BLASTING DITCHES IN SWAMPS}

A cheaper and much more satisfactory way of ditching in swamp areas is by use of clynamite.

There are two distinct methods of blasting ditches - the propagated or transmitted and the electric. The propagated method can be used only in wet soils, while the electric method can be used in fairly dry, as well as wet soils. The explosives and blasting supplies needed and the methods of loading vary somewhat in the two methods.

Propagated firing requires only the explosive itself and a cap and some fuse for each couple of hundred feet of ditch, while electric firing requires wiring, an electric blasting cap for each charge and a blasting machine or other source of current. This advantage of the former method is sometimes offset, however, by the fact that it requires nearly twice as many holes as electric firing. Theoretically, both methods require about the same amount of explosive; in practice, however, more will be used in transmitted firing, unless the work is done very skilfully. The economy of this method comes largely from a saving of electric blasting caps and time and the need for little equipment.

\section{MAKING TRIAL SHOTS}

In blasting ditches by the propagated method, the first thing to do is to try a few trial shots to determine the best depth and spacing for the holes. For ditches up to 3 to $3 \frac{1}{2}$ feet deep, the depth of the holes will generally be from 24 to 30 inches and the spacing between holes from 18 to 24 inches, although it may be necessary to change these figures slightly. If water covers the cartridges in the holes, no tamping is necessary; otherwise the cartridges should be well tamped with earth. Eight to ten holes should thus be loaded for the test shots; one hole should be charged with an extra primer cartridge, and it is also well to put one additional in each hole adjoining the primer.

If the test shot makes too large a ditch, the spacing may be increased a little, but should seldom be greater than 24 inches and then only in warm soil. If the ditch is too deep, it will be an indication that the depth of holes should be decreased.

Small ditches, say 2 feet deep and 3 feet wide, may be excavated by using half cartridge charges, but in such case the spacing between holes should seldom be more than 18 to 20 inches. Larger 
ditehes may be obtained by using two or more cartridges to a hole or by planting a second row of eartridges parallel to the first. In this case, one electric cap should be used in each row of holes or else an extra charge or two should be put in between the rows to insure simultaneous detonation of all the charges.

After the test shots have been fired and the proper loading and spacing for the material in question thus determined, the line of the ditch should be laid out; if the area is forested, all trees of

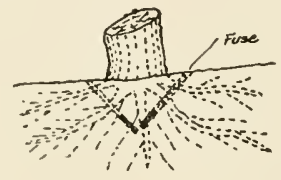

Loading to blow out a stump
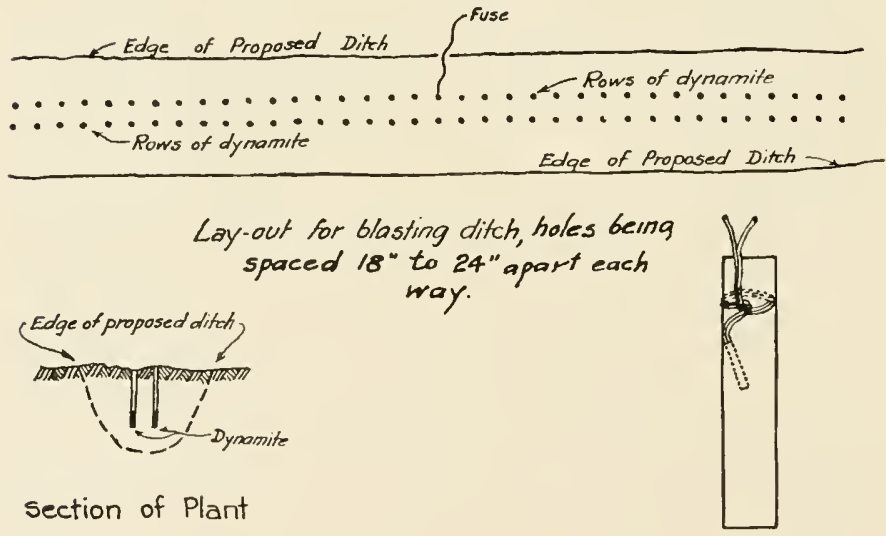

Attaching cap to dynamite

FIG. 74.- Sketches showing details of blasting ditches by propagated method.

any size along the proposed diteh should be cut downand removed. Then one man should make the holes with a crowbar or shovel handle and a second should insert the charges. An extra charge or two should be planted about large stumps, logs, etc. Ordinarily lengths of from 150 to 200 feet may be discharged at a time. The hole midway along this distance should be fitted with a cap and fuse. When this fuse is ignited, the concussion resulting from the explosion of this charge explodes the other charges. 


\section{CLEANING OUT THE DITCH}

The ditch resulting from the explosion will be rough and somewhat uneven in depth; occasionally, a few stumps and other debris will roll back into it. To open it up and even the grade, two to four men, equipped with phosphate drags and hoes should follow the blaster's, raking out the debris and removing the humps. This work can be done in a comparatively short time, and greatly improves the ditch.

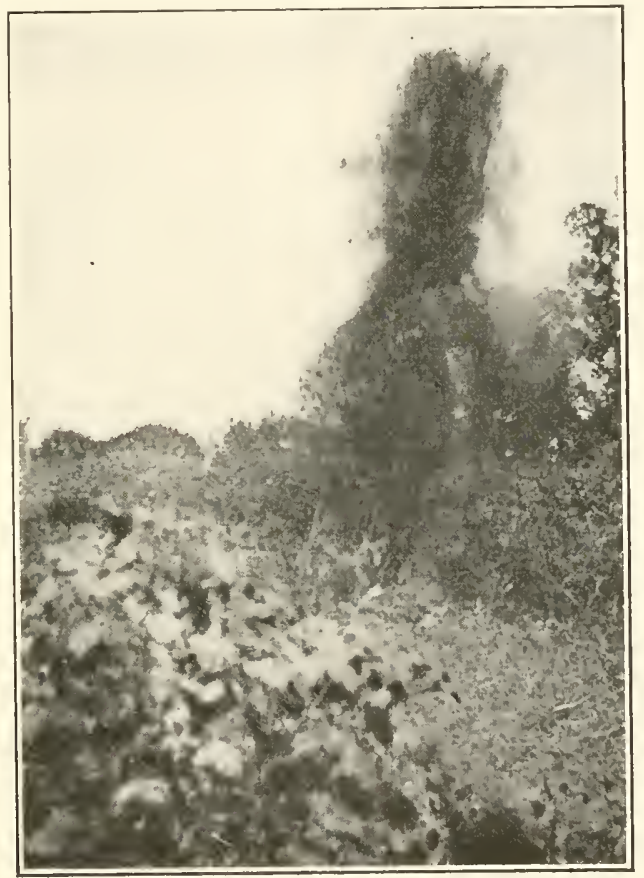

FIG. 75.-Blasting ditch in tangled underbrush.

For electrical firing, the procedure is much the same. A few trial shots should be made for determining the proper depth and spacing of the holes. As an electric eap is used in each hole, it is possible to space them further apart in the row than in the case of propagated firing. The usual distances are 24 to 32 inches for small ditches and up to 48 and 52 inches for large ditches and heavier loadings. After the charges are planted, the blasting cap wire from cach is connected with the loading 
wire from the blasting machine. The charges are then exploded simultaneously by operating the machine.

For larger ditches, the loading may be in deeper holes and with an explosive of greater strength, or parallel rows of charges may be employed as already described in the case of propagated blast-

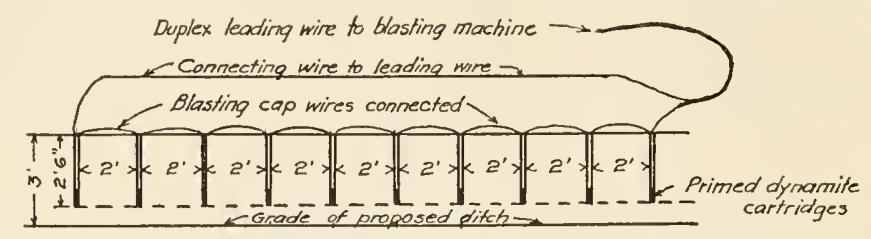

FIG. 76.-Loading for blasting ditch, having only a single row of holes, by electrical firing.

ing. Where very deep ditehes are needed, a wide shallow ditch should be blasted first and then a row or two of boles should be blasted in the bottom of this ditch.

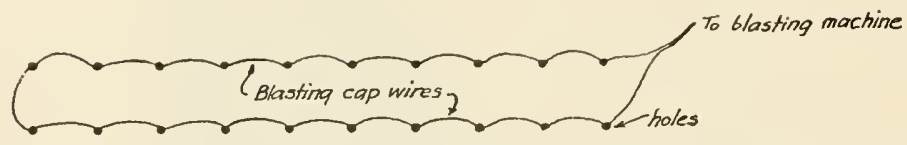

FIG. 77.- Ilan of loading for blasting a ditch, having 2 rows of holes, by electrical firing.

\section{ADVANTAGES OF BLASTING DITCHES}

The personnel required for blasting ditches is small. One laborer should make the holes, another distribute the dynamite in them under the direction of the foreman, a third and fourth transport the dynamite to the scene of the blasting and a fifth and sixth clean out the ditch after the blasting. An experienced blaster should be in charge of the work.

Under favorable conditions, the work may be carried on at the rate of 100 to 200 feet per hour by the propagation method with the crew indicated above, omitting from consideration, of course, any preliminary clearing that may be required.

Costs of ditching by dynamite vary, of course, with the character of the soil, size of the ditch and number of roots and stumps. At six different extra-cantomment jobs in 1918, costs per lineal foot were: $13,14,28,18,12$ and 33 cents. Wherever comparisons with hand ditching in swamps were made, it was the consensus of opinion that blasting was cheaper. ${ }^{1}$

1 Transactions of The First Annual Conference of Sanitary Engineers, U. S. Publie Health Service, 1919. 


\section{MACHINE DITCHING}

The various types of ditehing and trenehing machines may be divided into four general classes, as follows: (1) plows and scoops; (2) wheel excavators; (3) enclless-chain excavators; and (4) scraper excavators.

For eonstruction of open, V-shaped ditches-the usual type of anti-mosquito diteh-only the first two classes are generally used. The endless-chain excavators, designed chiefly for digging trenches for installation of pipe, which are filled up after the pipe is laid, usually eut a narrow and, where necessary, a deep ditch, with vertical banks. Owing to the possibility of frequent eavings, a trench of such a shape does not, as a rule, make a satisfactory open diteh.

The scraper exeavator is designed chiefly for digging very large ditches or channels and does not appear to be suited for the type of ditching usually required in anti-mosquito work.

The last two types of trenching machines, therefore, are, generally speaking, of value in anti-mosquito work only when the use of tile drains on a large seale is contemplated or when a very large excavation, as a new ehamnel for a stream, is required.

Plows and seoops are usually drawn by horses or mules or tractors. Almost all of them are lacking in any device for eutting aceurately to grade, thus requiring some hand-work to make the bottom smooth. There are many types of these implements, ranging from derices designed primarily to loosen up the earth to quite elaborate machines that dig a $V$-shaped ditch up to 3 or 4 feet in depth. Two types of this class of machine are deseribed below.

Wheel exeavators supply their own power for digging and traveling; this may be generated either by internal combustion engines or steam engines and boilers. Many of the heavier machines are equipped with apron tractors. The digging is done by buekets upon the rim of a wheel that is revolved in the trench, and, as each bucket reaches the top of the circle, the dirt falls upon a conveyor belt, which deposits it on the spoil bank. A shoe of ten follows the wheel, removing the erumbs and smoothing and grooving the bottom. One machine of this type is described below. 


\section{SOME TYPICAL DITCHING MACHINES}

Implement A.-This device ${ }^{1}$ consists of a cutting knife, which loosens the earth, and a bucket, which removes it. Two men and a team are required to operate this machine. The cutting knife is mounted on a steel frame; trimmers for widening the ditch are bolted to the end of it. The bucket, which holds about 5 cubic feet of earth, is linged to the cutter frame by steel

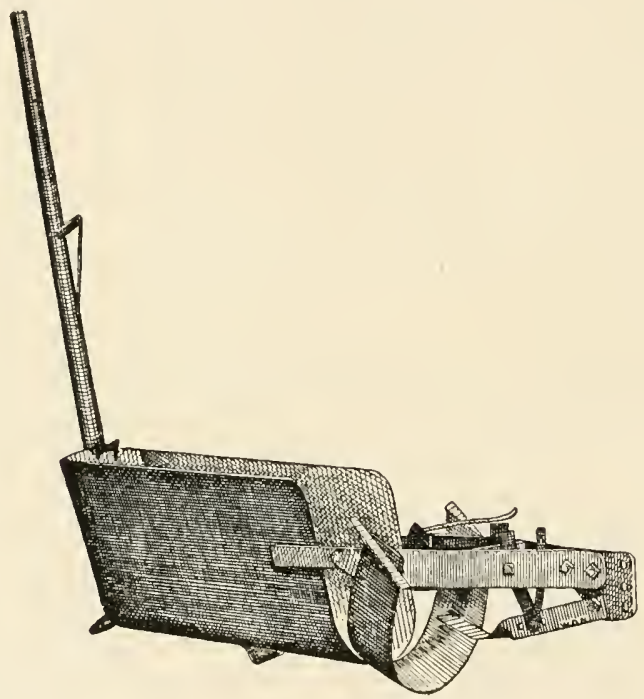

Fig. 78.-Implement A. (After U. S. Bureau of Public Roads.)

straps. The lower end of a wooden handle is attached to a loop near the bottom of the bucket; a hook on it engages the top of the bucket between guides that keep the bucket from tipping while the handle is straight. The depth of each cutting is controlled by an adjustable shoe in front of the cutting knife. The bucket, when full, slides out of the ditch, the handle is lifted to disengage the hook and the bucket falls on its side.

Implement B.-This implement consists essentially of a reversible cutting blade attached to a steel landside at an acute angle. The cutting blade not only loosens the earth, but also throws it up on the side of the ditch. The device may be reversed to cut on

${ }^{1}$ Based largely on Farmer's Bulletin No. 698, U. S. Department of Agriculture, 1915 , by D. L. Y ARNell. 
either side and may also be adjusted as to width of ditch. It comes in various sizes and weighs 290 to 425 pounds. Four to six horses or a tractor are required to operate the largest model, while the smallest may be operated with 2 or 3 horses. It does not, of course, cut accurately to grade.

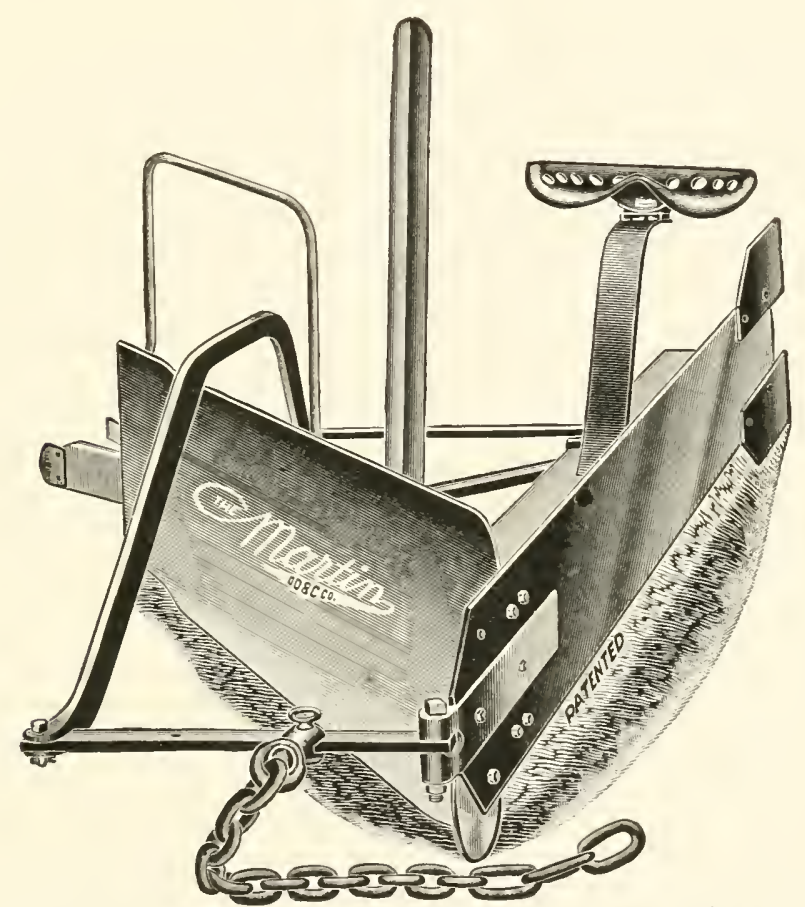

FIG. 79.-Implement B. (Courtesy of Owensboro Ditcher and Grader Company.)

Implement C.-This machine is one of the various types of wheel excavators and, of course, is considerably more expensive than the two machines described heretofore. However, it follows grade very closely and usually makes a perfect ditch at one cut. Only two men as a rule are required to operate it, the average daily operating cost, according to the manufacturers, running from $\$ 16.75$ for the smallest model to $\$ 43$ for the largest model. This machine will average half a mile of completed ditch of the usual anti-mosquito type and ordinary size every day according to the manufacturers. 
There seens to be no doubt that, in localities to which it is suited, machine ditching is considerably eheaper than ditching by hand.

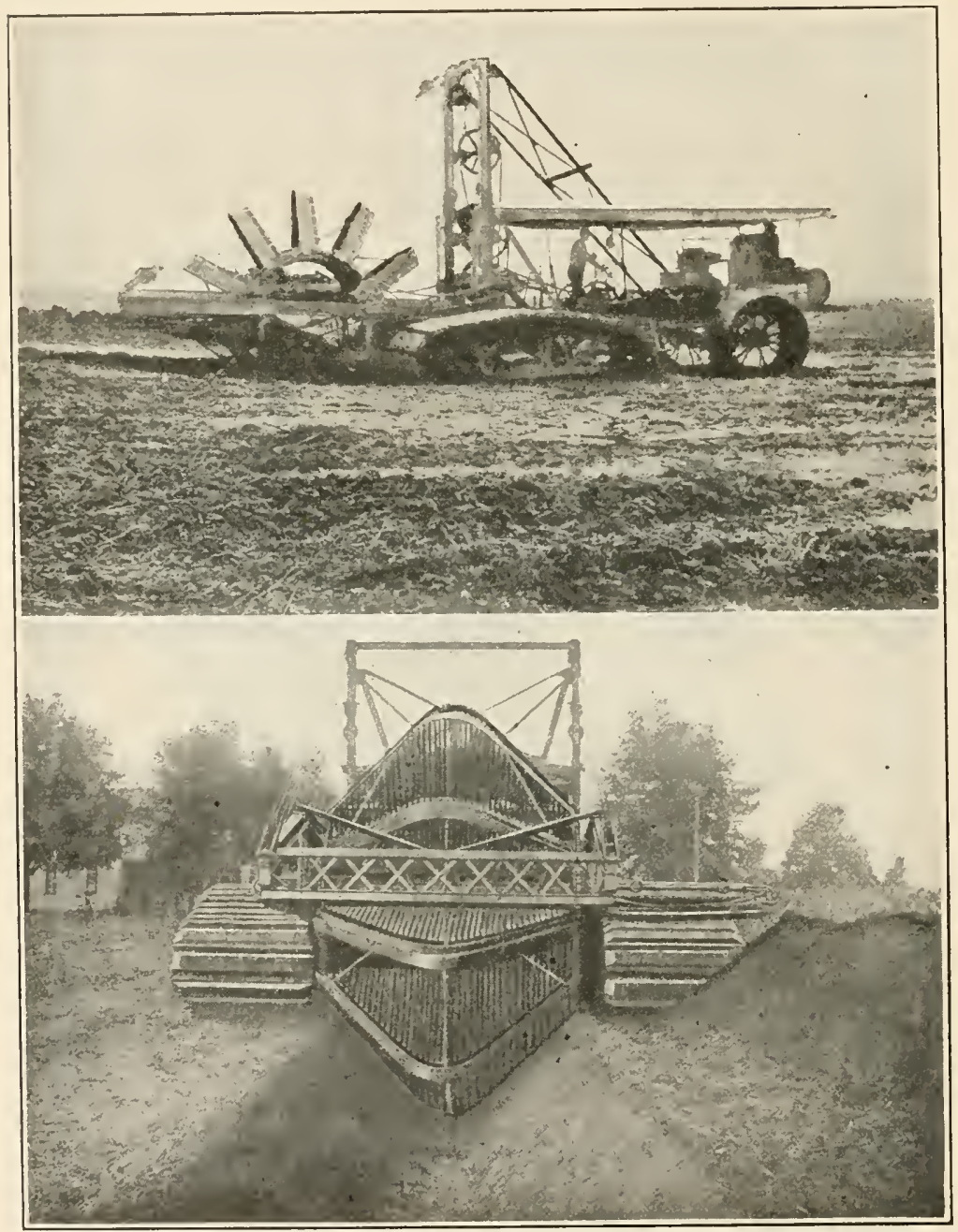

Frg. 80.-Implement C. (Courtesy of Buckeyc Traction Ditcher Company.)

\section{MAINTENANCE OF OPEN DITCHES}

One of the most objectionable features of the open ditch, from an anti-mosquito viewpoint, is the necessity of maintaining it in 
proper condition-that is, keeping it in such shape that it will properly drain the area it is supposed to drain and also keeping it in such shape that it itself will not become a breeding place. Due to local topography, character of soil and other conditions, some open ditches or parts thereof may be relatively expensive to keep in shape.

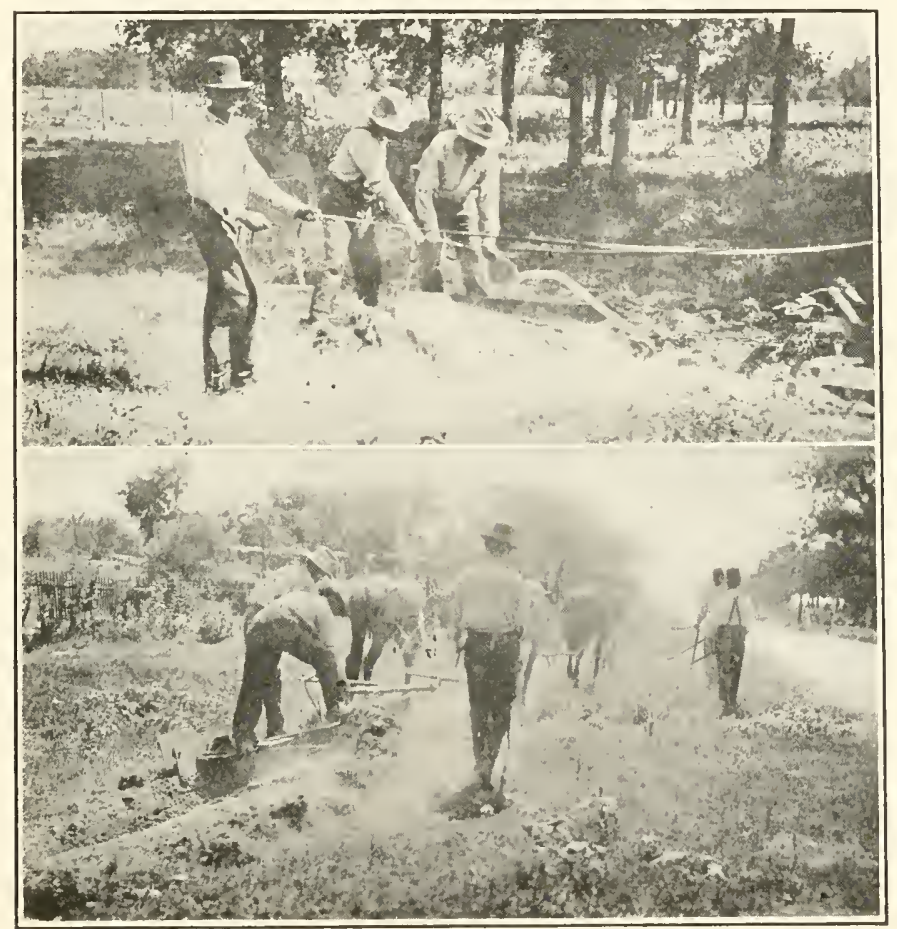

FIG. 81.-Cleaning out road-side ditches with a ditching marhine.

In order to preserve their ability to drain the areas they are intended to drain, ditches should be kept to the established grade and proper cross-section; in order to prevent ditches from themselves becoming breeding-places, obstructions, such as sticks, leaves and other floatage, deposits of silt and sand and all vegetable growth, including algae, should be removed from the ditch periodically. Shovels and hoes are the tools best suited to this work. Where the ditch is in soft ground, great care is required not to spoil the grade.

For the removal of rank grass and weeds from ditches, a weed- 


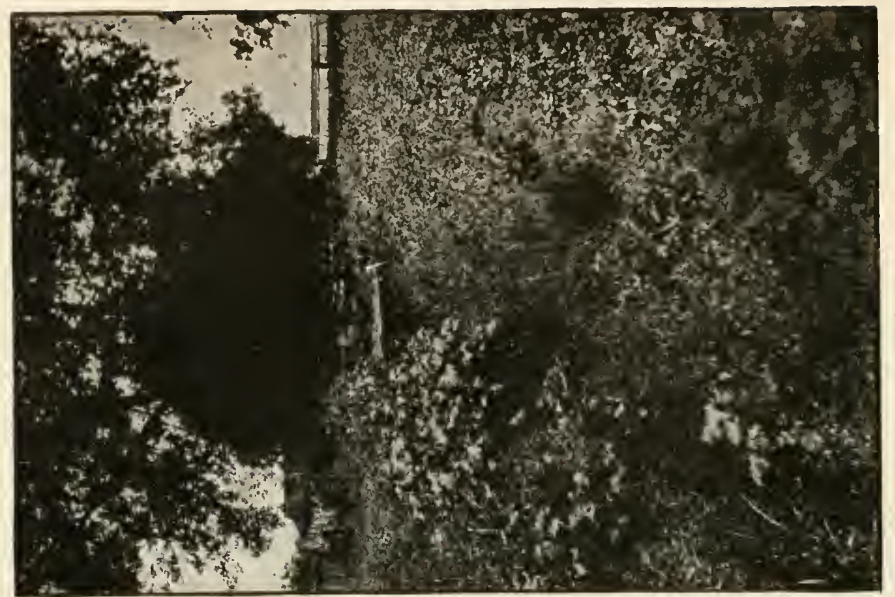

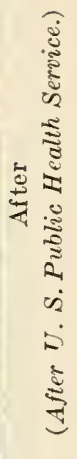
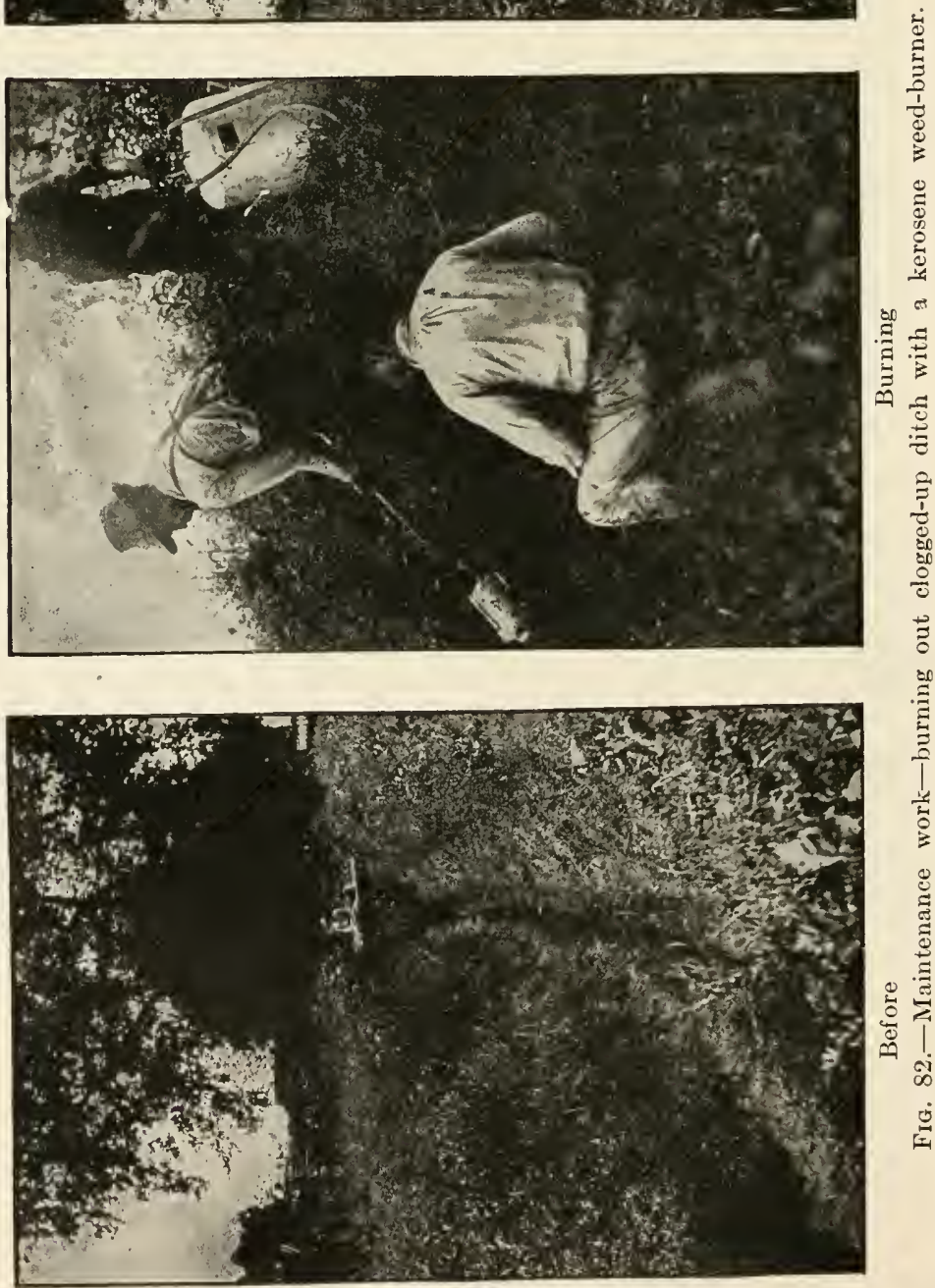
burner may sometimes be used to advantage, although this method is some more costly than doing it by hand.

\section{THE WEED-BURNER}

The weed-burner consists of a steel tank (large enough to hold 15 gallons of kerosene and to leave a good-sized air-space above it) equipped with a double-acting, long-stroke pump, which has automatic valves and a pressure gage, and two burners, each connected by a long rubber hose to metal pipes reaching to the bottom of the tank. The burner is a short length of straight pipe with a coil at the end. The oil passes down the straight pipe, through the eoil and back to the base of the coil, where it is atomized through a nozzle. To begin operations, the supply valves are elosed, the burner coils heated until red and the air pressure brought to 40 pounds. Upon opening the supply valves, the oil is forced through the hot coils and readily ignites, producing a bluish flame about 30 inches long and 4 inches in diameter. If the coil is not heated sufficiently, the flame will be of a reddish color and of low heat value.

Three men are considered necessary for the operation of this device-one at each burner and a third pumping to keep the pressure up to 40 pounds.

Sha $w^{1}$ reports that the cost of burning out with this device a ditch overgrown with weeds and grass amounted to 1.4 cents a lineal foot as against a cost of 0.35 cent by hand. Lenert ${ }^{1}$ reports that a similar burning cost 1.5 cents a lineal foot.

Several commereial arsenical preparations designed to kill weeds are also on the market and may be used in anti-mosquito work, where they will not endanger stock.

In periods of drought, a diteh may become a series of stagnant pools. A small temporary ehannel may then be made to concentrate and drain off this water, or, if the holes are not too numerous, they may be filled with stone or earth. Otherwise, they may be oiled or stocked with fish.

In cases where the banks of ditches in pasture lands are flat and soft, both above and below the flow-line, deep impressions, which hold water, are sometimes made by the hoofs of cattle and horses. Where practicable, such soft areas should be protected by fences, and a barrel without a bottom should be installed at a

1 Transactions of Second Annual Anti-Malaria Conference of Sanitary Engineers, U. S. Public Health Service, 1921. 
suitable place where it will remain filled with water for the stock to drink.

While recleaning of open ditches along the lines described will be required from time to time during the mosquito season, it is a good plan to get all such ditches in shape early in the season before the first new broods of mosquitoes appear.

\section{MAINTENANCE COSTS}

Maintenance costs vary considerably with local conditions. In areas where weeds grow rapidly, they probably will prove the

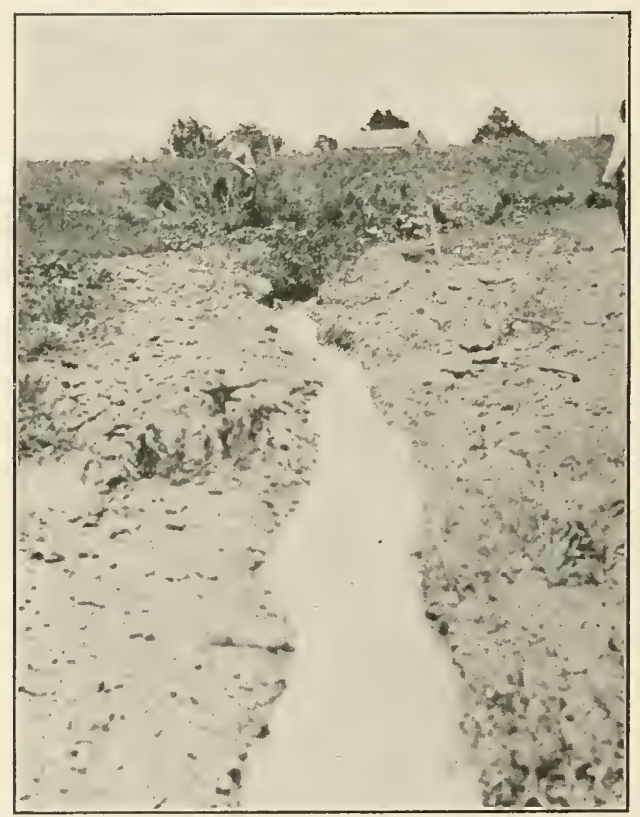

FIG. S3.-Cleaning out an old, clogged up ditch by hand.

most troublesome factor. In some places, the writer has found it necessary to remove these growths every month or so; this runs into a large amount of money in a season on a large project. Again, heavy rains, resulting in rapid run-offs, sometimes ruin the grade of miles of ditches; sand and mud will be deposited at many places, while deep holes will be eut into the banks and bottom at others.

During 1918, on a job with which the writer was connected, 
approximately 29 miles of ditehes were maintained at a cost of $\$ 0.045$ a foot or $\$ 241.52$ a mile for the season; estimating the season as lasting 6 months, the cost was less than $\$ 0.008$ a foot or $\$ 40.25$ a mile a month. These ditehes were kept in almost perfect conclition at all times-free from grass and weeds and obstructions of all kinds.

\section{PERMANENT LINING OF ANTI-MOSQUITO DITCHES}

Anti-mosquito drainage ditches may be lined to advantage, where excessive crosion takes place or where maintenance costs otherwise beconte excessive.

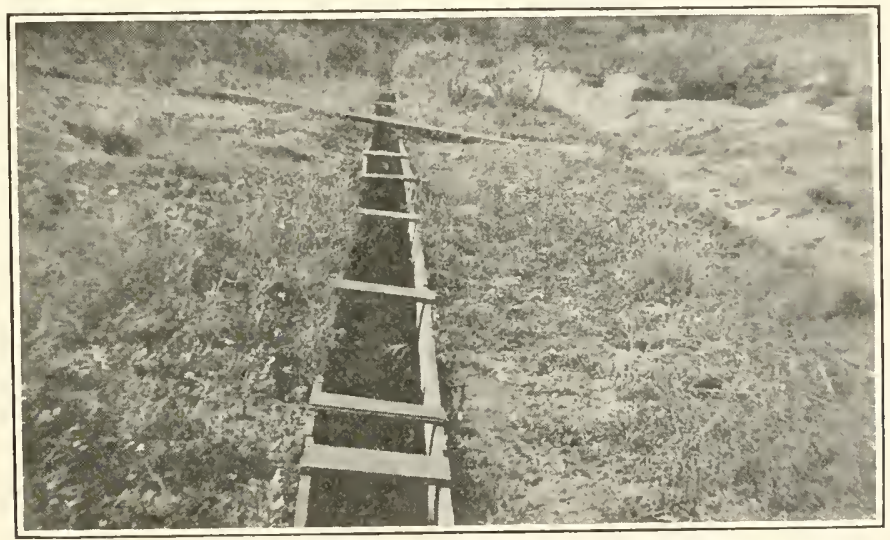

FIG. 84.- Section of ditch lined with redwood boards.

Materials usually employed for lining ditches are concrete, stone set in mortar and planks. While the fomer are more expensive, they are more permanent and generally give more satisfaction in the long run.

LePrince ${ }^{1}$ says: "Lined ditches are more permanent, easily cleaned, require less inspection and are ultimately less costly. At some of the settlements in the Panama Canal Zone, it was found that a large saving was made by lining certain ditches and parts of ditches with concrete as against repeated regrading, cleaning and oiling of open earth ditches."

As a rule, the lining should be U-shaped with sloping sides; it is not always necessary, however, to line the whole depth of the

1"Malaria Control; Drainage As An Anti-mosquito Measure," U. S. Public Health Service, 1915. 
diteh. The lining of the bottom and sides up to 3 or 4 inches above the normal water line generally will answer for small ditches. In wide ditches, the bottom should slope toward the center and the side walls may often be nearly vertical.

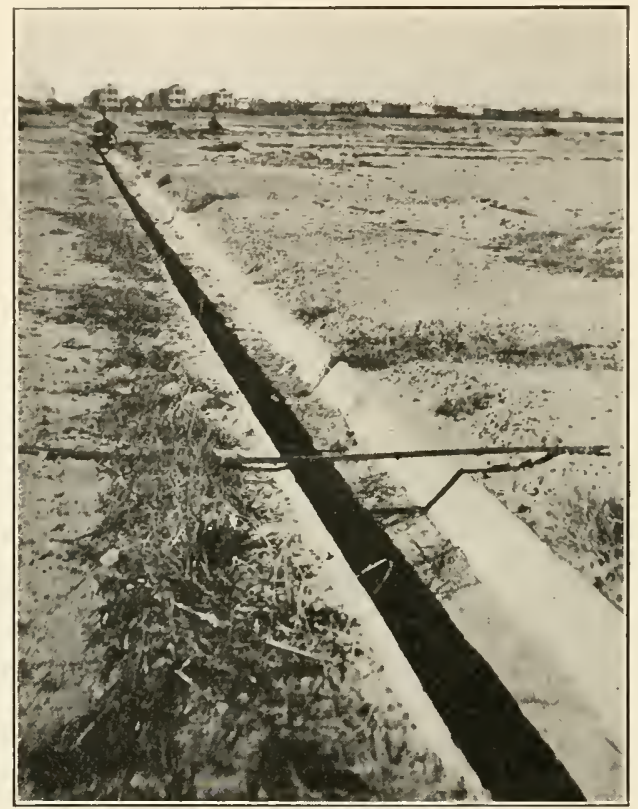

FIG. 85.-Open_ditch lined with concrete.

A smooth or faney finish, which adds to the cost, is not essential. The ditch may be lined roughly with flat stones, the holes being chinked up and mortar plastered about them. Where

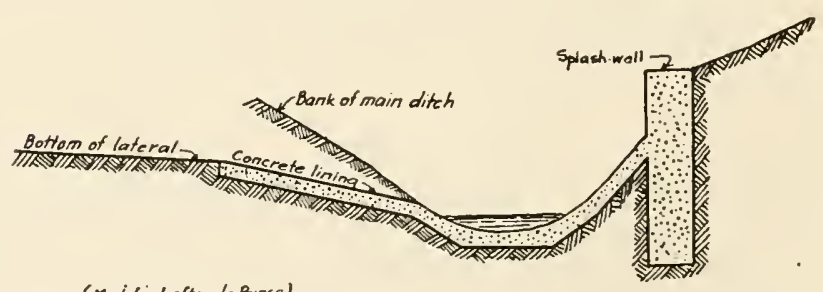

(Modified offer Le Runce)

FIG. 86.-Cross-section of lined main ditch and unlined lateral.

flat stones are not available, a 2 -inch layer of concrete, reinforeed with chicken wire of about 2 -inch mesh may be used.

LePrince continues: 
"In order to avoid scouring out of banks above the lining by storm water, particularly at sharp curves or bends of ditches, the outer wall lining should be raised to meet the condition, or the ditch may be widened or key-walls installed. Key-walls. . will prevent the side-scour and under-scour of linings of straight ditches of heavy grades. The key-wall should extend 6 inches to a foot or more into the ground below the bottom ditch lining. Branch ditches shoukl enter lined ditches at an acute angle or on a curve, with a sharp grade near the junction.

"In all cases, weep-holes or seepage-holes, sloping toward the center or bottom of the ditch and located just above the keywall, should be provided. This is required to prevent the effect of currents which may be under

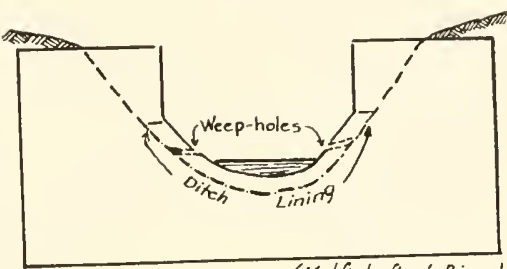

(Madifiet after LePrince)

Fic. 87.-Cross-section of key-wall. or behind the concrete ditch lining. Weep-holes should be made in side walls before the concrete has set. They should be used wherever water might be behind the lining.'

\section{SUB-SURFACE TILE DRAINS}

Tile drainage within the last 25 years has become of great importanee as an agricultural measure to improve crops by reducing excessive moisture in the soil. Such drainage is of great

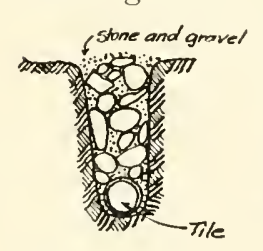

Fig. 88.-Crosssection of fill over intercepting tile drain.

for agricultural value in anti-mosquito work, inasmuch as it lowers the water-table, thus allowing pools of surface water to be absorbed more rapidly. Tile drains also may be used to intercept seepage water and for other purposes in connection with anti-mosquito drainage.

Sometimes in an anti-mosquito campaign it is possible to persuade owners of low-lying, swampy lands about a town to tile drain them benefit is derived-the lands are made more productive and the mosquito breeding-places thereon permanently eliminated.

Again, in purely anti-mosquito work, it has been found that in the long run it frequently pays to substitute tile drains for open ditches. According to the report of the Panama Canal Zone Health Department for 1919, substitution of tile drains for open ditches in pasture lands resulted in a considerable saving by 
rendering unnecessary previous oiling of hoof-prints, etc., along their margins in the wet season. Another considerable economy resulted from elimination of the necessity for periodical cleaning of grass and weeds from open ditehes.

\section{TILE DRAINS VERSUS OPEN DITCHES}

Ditches in which drainage tiles are to be installed must follow grade exactly; hence, they should be laid out by instrument or other accurate method and the bottom finishing checked from time to time. Where the fall is less than 2 inches to 100 feet, very careful work is required.

Tile drains generally should be laid from 2 to 4 feet deep, depending upon character of soil and other local conditions. As

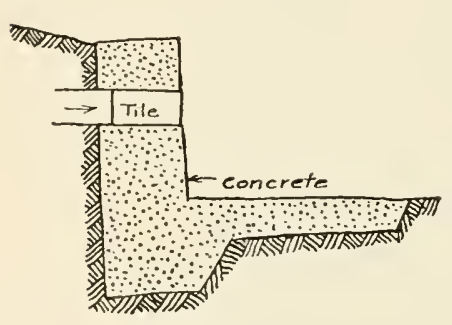

FIG. 89.-Cross-section of outlet for a tile drain. the ditches in which they are laid are filled up as soon as the laying is completed, they need be of no particular shape, such as is required in the case of open ditches; they may be dug with vertical sides, if the nature of the soil will permit.

In digging ditches for tile drainage by hand, special tile spades are generally used. Another useful instrument is the drain scoop, which comes in various sizes to suit the size of tile. However, a very large proportion of the ditehes for agricultural tile drainage are dug by machinery today.

A system of tile drainage may consist of a main, sub-mains, laterals and sub-laterals, or only a main and a lateral. The main is the drain through which all the water eventually flows. Sometimes, only a single line may be needed.

A proper outlet for the main should be provided in all eases in order to prevent caving and possible closing of the pipe. Probably the best protection is a concrete wall, into which the end of the pipe is set. Where the outlet is low and liable to be submerged in time of flood, a valve should be installed to keep the water from backing into the drain.

\section{LAYING OUT A TILE DRAINAGE SYSTEM}

In laying out a tile drainage system, as few mains and as many long laterals should be used as possible, as a rule, since, near the mains, both the laterals and the mains drain the land. For this 
reason, the system shown in Fig. 91 is preferable to that shown in Fig. 90, since the cost is less and the drainage more uniform.

In the East, for general farming purposes, the laterals are placed from 32 to 70 feet apart. In the Middle West, on the higher lands and closer soils, 132 feet frequently has proved satisfactory. On level lands with porous subsoils, drains from, 160 to 192 feet apart have given good service. For truck land

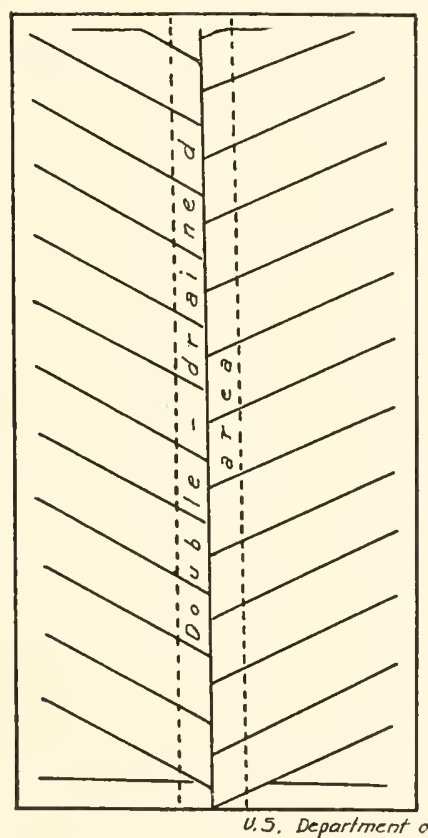

Fug. 90.--Too much double-draining a waste of money.

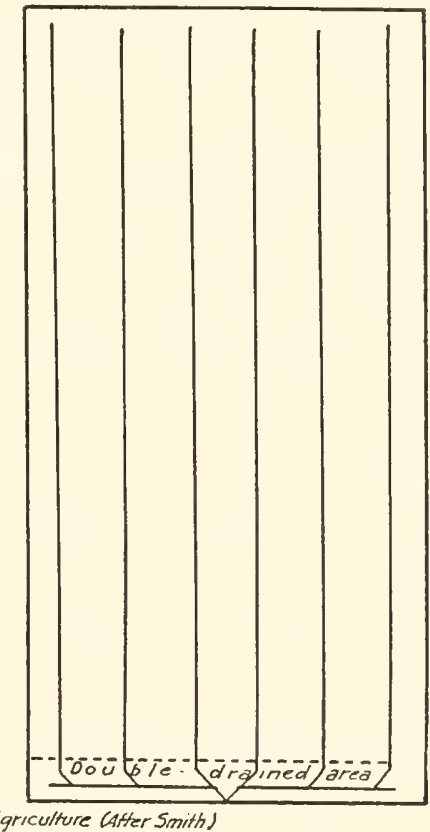

Fra. 91.-Double-draining reduced to a minimum by proper design.

the laterals should be eloser together than for land on which general farming is carried on.

No tile less than 3 inches in cliameter should be used, and best practice today in the Middle West seems to be to make 5 inches the minimum size. However, no hard and fast rule can be given. According to Smith, ${ }^{1}$ in the dark silt-loam soils of Illinois and Iowa, where the rain-fall approximates 36 inches a year, an 8inch tile with a fall of 2 inches to 100 feet will furnish an outlet for

"“Tile Drainage on the Farm," Farmer's Bulletin No. 524, U. S. Department of Agriculture, 1917. 
the complete drainage of 40 acres, while a 4 -inch tile will drain only 6 acres. On the level soils of the South Atlantic and Gulf States, where the rain-fall is heavier, only about three-fourths of these areas can be drained with the same size of tile, according to the same writer.

\section{PLACING THE TILE}

"Laying the tile, like digging the ditch, should begin at the outlet," says Smith." "Under ordinary conditions, tile should be laid every day as far as the ditch is made. Any delay in laying may eause injury to the diteh by rain or by particles falling into it. If the banks are likely to cave, the tile should be laid as fast as the ditch is completed.

"The smaller sizes are laid from the bank with a hook. Large sizes must be laid by hand from the bottom of the diteh. All mis-shaped and eracked tile should be discarded. If a tile does not join closely with a preceding one, it should be turned over until it fits at the top. Any large cracks are covered with pieces of tile. Where a lateral joins to a main or sub-main, the connection should be made with a Y. Neither a $\mathrm{T}$ nor an elbow is desirable, as these check the flow of the water.

"When the tile are laid and inspected, they are ready for prining. This is done by eaving a little earth from the sides of the ditch and letting it settle gently, so as to keep from knocking the tile out of line. In sandy soils, there may be danger of sand entering the tiles and clogging the drain. This ean be prevented by covering the joints with pieces of old sacks or straw.

"After the tile are primed, they may remain without injury for several days until all the ditehes are ready for filling. If the soil is close and it is desirable to aid the water in reaching the tile quickly, the ditch can be partially filled with straw or brush, or, better still, with stones and pieces of brick. Under ordinary conditions, the ditch is most easily filled with a turn-plow and an evener, which is 12 or 14 feet long. Two horses are hitched to this plow, one on each side of the ditch and, with one man to lead or drive and another to hold the plow, the earth is turned in. There may be extraordinary conditions, however, when a plow cannot be used. By placing the team on one side of the ditch and a wooden scraper on the other side in such cases, the dirt can be pulled in rapidly. Filling by hand is usually the most difficult and most expensive method."

In laying tile for the purpose of intercepting seepage water, best practice seems to call for a stone or gravel fill over the tile, instead of the usual earth fill.

${ }_{1}$ "Tile' Drainage on the Farm," Farmer's Bulletin No. 524, U. S. Department of Agriculture, 1917. 


\section{TILE DRAINAGE COSTS}

Tile drainage costs may be divided into two phases-that of the tile delivered at the trench and that of the digging, laying and filling.

Prices of tile vary in the different sections of the United States, being cheapest in the Middle West. In the East and South, tile is about 50 per cent higher than in the Middle West, and in the Far West about 70 per cent higher, according to Smith. ${ }^{1}$ Haulage costs depend, of course, upon the distance.

"Digging the ditch and laying and priming the tile are usually figured as one operation," says Smith. " "This is done either at so much per rod or by the day, the former being the more common practice . . . On ordinary soils in the Middle West, the average capacity of a good workman with a 3 -foot ditch and not over 5 -inch tile is 10 rods a day. In the East and South sometimes, on account of the character of the soil, the capacity of a man is from 4 to 8 rods, with the same depth and size of tile."

"For tile trenching and laying" by hand," says Yarnell,2"where experienced men are employed, the rate of progress for one bottom man and one top man, for the smaller sizes of tile not more than 3 feet deep, is ordinarily 15 to 30 rods per day, depending largely upon soil conditions. In some sections of the country where the use of unskilled colored labor is necessary, the same number of men will put in, even with good supervision, only 5 to 8 rods per day per man."

\section{VERTICAL DRAINAGE}

That vertical drainage is an economical and effective method of eliminating pools of standing water in districts where the water is held by an impervious stratum overlaying a pervious one has been repeatedly demonstrated. The principle of course, is to sink a hole through the impervious layer so that the water may escape through the porous material. This may be sand or gravel or limestone and other formations that contain seams and fissures.

While there is a degree of uncertainty about vertical drainage, the costs are so low, where the pervious material lies close to the

1 "Tile Drainage on the Farm, " Farmer's Bulletin 524, U. S. Department of Agriculture, 1917.

" "Trenching Machinery Used for the Construction of Trenches for Tile Drains," Farmer's Bulletin 698, U. S. Department of Agriculture, 1915. 
surface, as compared with an expensive ditching project, that it is often well worth while to try it out in favorable areas.

As a rule, the holes should be lined to prevent clogging up the avenue of escape for the water by erosion. For the same reason,
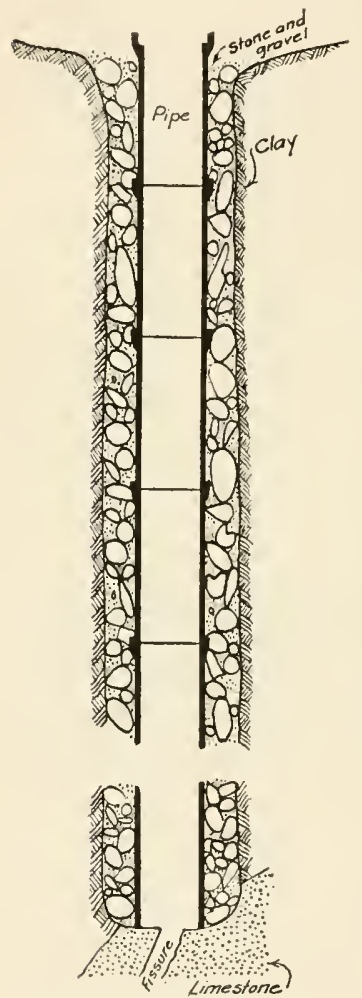

FIG. 92.- Sketch of a vertical drain. it is of ten desirable to install a drain-head or other device to keep out the coarser material carried along by the water.

Gorman ${ }^{1}$ describes a typical operation, which resulted in the complete drying up of a pond covering nearly an acre, as follows:

\section{TYPICAL VERTICAL DRAINAGE OPERATION}

"Beginning at a few feet from the water's edge, on shore, at a shallow part of the pond, a hole was dug to the limestone stratum with a post-hole digger. Then, with a long drill, a hole 12 inches deep was made in the limestone and a stick of dynamite inserted, wellpacked and exploded. The hole was then cleared out, the drill again used and another stick of dynamite exploded. This was continued for three or four times, until drilling had been carried to a depth of 4 feet or more in the limestone. Water from the pond was then directed into the hole. This same thing was done at two or three other places around the pond . . . As the water drained and the pond became smaller, other holes were dynanited as described above, and, after eight holes had been made, the pond was dry. By observing the rapidity with which the different holes drained, it was noticed that four of them were especially effective . . showing that, in the case of these four, seams in the limestone had been reached.

"These four effective drains were dynamited several more times and then, at each of them, holes 2 feet in diameter were dug through the clay to the limestone. In these holes, resting on the limestone stratum, 12-inch vitrified clay sewer pipes were placed vertically, being built up to a few inches above the ground. The rest of the hole around the pipe

${ }^{1}$ Transactions of the First Annual Conference of Sanitary Engineers, U. S. Public Health Service, 1919. 
was then filled with coarse stone and cinclers. A main ditch was then dug in the center of the pond its entire length, with occasional laterals. This main ditch and the lateral led to the four effective drains described above.

"The cost of this work, labor at 30 cents per hour, was $\$ 173.42$. This included 1,500 feet of ditching and the work on the four rejected drains, which were filled in."

Bishop ${ }^{1}$ describes a vertical drainage project, in which it was necessary to pierce 40 to 50 feet of elay before the limestone was reached. The holes were dug with an orchinary post-hole auger with sectional pipe extensions at a cost of 2 cents per foot. It has been found, however, that the post-hole auger will not work in certain soils.

\section{VERTICAL DRAINAGE FOR LARGE AREAS}

Sometimes, when the area to be drained is extensive, it is necessary to make the hole of eonsicterable size. This, of course,

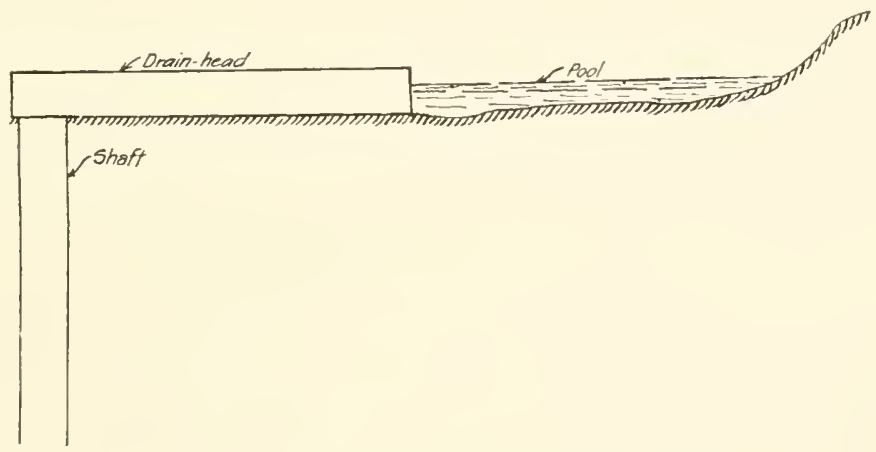

FIG. 93.- Profile of pool, drain-head and shaft.

greatly increases the eost of the operation. Stromquist ${ }^{2}$ lescribes such a hole, which drained a pond covering more than to acres in extent.

A shaft, 7 feet square, was sunk to a depth of about 41 feet, at which point a fissure, about $4 \frac{1}{2}$ feet high by $1 \frac{1}{2}$ feet wide was found in a vertical wall of limestone. The shaft was curbed with 2 by 6 material, double bracet, at intervals of 3 feet, and

${ }^{1}$ Transactions of the First Annual Conference of Sanitary Fngineers, U. s. Public Health Service, 1919.

${ }_{2}$ T'ransactions of the First Annual Conference of sanitary Engineers, U. S. Public Health Service, 1919. 
2 by 12 -inch sheathing. A flume was built from one side of the shaft to the end of the ditch connecting with the lake. The outlet thus formed proved sufficient to clrain the entire lake and keep it dry.

Sometimes, if the fissure be small, there is a tendency for the hole to silt up, especially when the water enters the hole directly. This may be avoided by the use of a drain-head, designed to keep out floating matter and the coarser sediment. Such a drain-head may be an elongated, narrow box, laid as a pipe

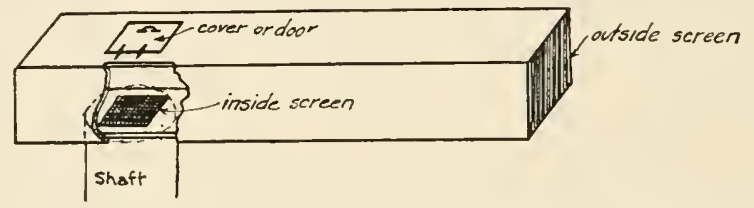

FIG. 94.-Sketch of a drain-head for vertical drainage.

from the ditch to the hole; the end toward the ditch should be heavily screened and the other tightly closed; a hole in the bottom near the closed end, through which the water is to enter the shaft, also should be well sereened; a door on the top of the box will allow this latter screen to be cleaned from time to time; the entrance sereen of course may be kept clean from the outside.

\section{STREAM RE-CHANNELING}

Contrary to the popular belief that mosquitoes breed only in stagnant water, they may often be found breeding in abundance in numerous flowing streams, since in most streams there are many places where the current is almost imperceptible.

Thus, in a stream in flat country, where the fall is slight, there are apt to be many quiet pools, suitable for breeding. Even in a stream with a considerable fall, obstructions may stop the current or a soft bottom may wash out, resulting in a large, deep hole. Furthermore, the numerous bends in most streams cause a considerable loss of fall and henee of velocity.

LePrince ${ }^{1}$ says:

"A stream should be made to have steep banks directly above and below the flow line, uniform grade and width and a straight course,

1 "Malaria Control: Drainage as an Anti-malaria Measure," U. S. Public Health Service, 1915. 
and be free from grass, sticks, stones or other obstructions that would interfere with the current. These conditions are seldom found in nature, but the nearer a stream approaches them the less will mosquito breeding be found."

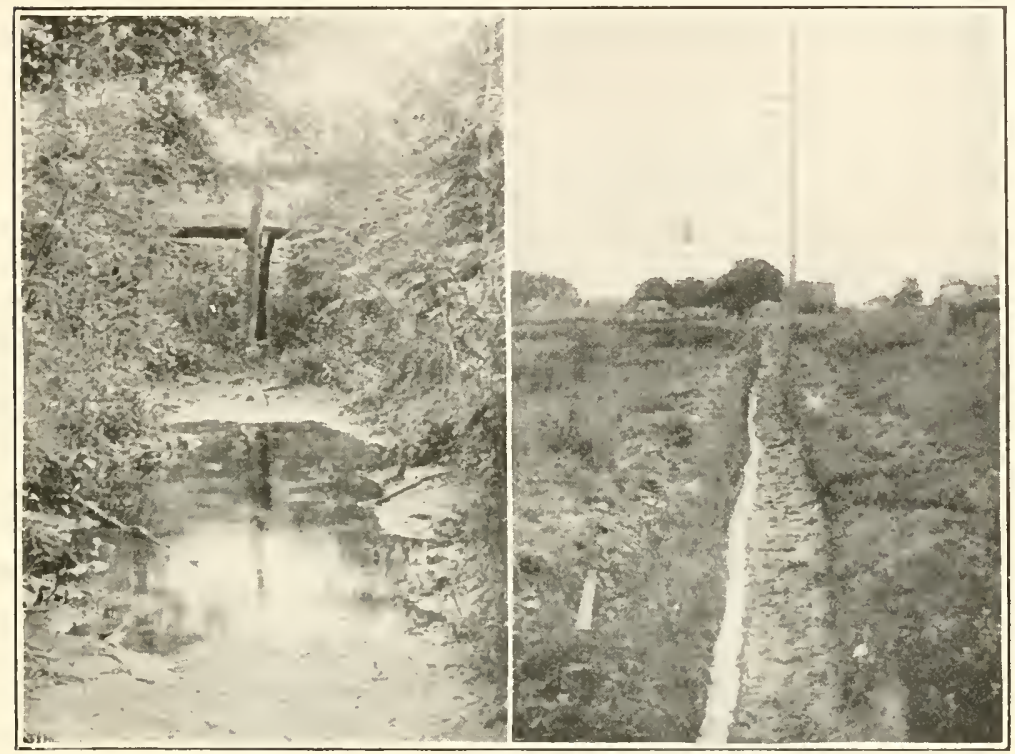

(Photos by E. H. Magoon, C. E.)

FIG. 95.

Fig. 96.

FIG. 95.-This pretty pool in a stream-bed was a breeding-place for Anopheles. Mosquito control was secured by connecting it with a nearby larger pool that was stocked with minnows.

FIG. 96.- Water in a ditch confined to a narrow channel in order to facilitate mosquito control. The diteh is oiled by means of a drip-barrel at its upper end.

\section{BLASTING NEW CHANNELS}

The writer has found that, if the stream is very crooked and much regrading is necesssary, it frequently will pay to disregard the old channel completely and make a new and straight one. If the soil conditions are adapted to it-that is, if the soil is wet and water-soaked-dynamiting probably will prove to be the cheapest method. The writer once had oceasion to rechannel with dynamite about a mile of a large ereck in Georgia, which averaged 20 feet wide and from 1 to 6 feet deep. A hard sand stratum which underlay the soft surface ooze at a depth of about 6 feet provided an ideal base for reaction of the explosion. 
The cost was 33 cents per lineal foot. The total cost of $\$ 1,516.35$ was divided as follows:

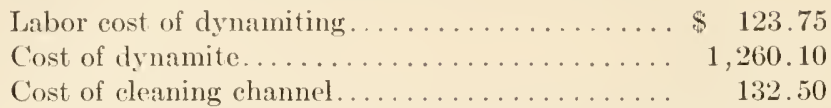

Where the old channel is not so erooked, however, it may be cheaper to utilize it, straightening and regrading it where most

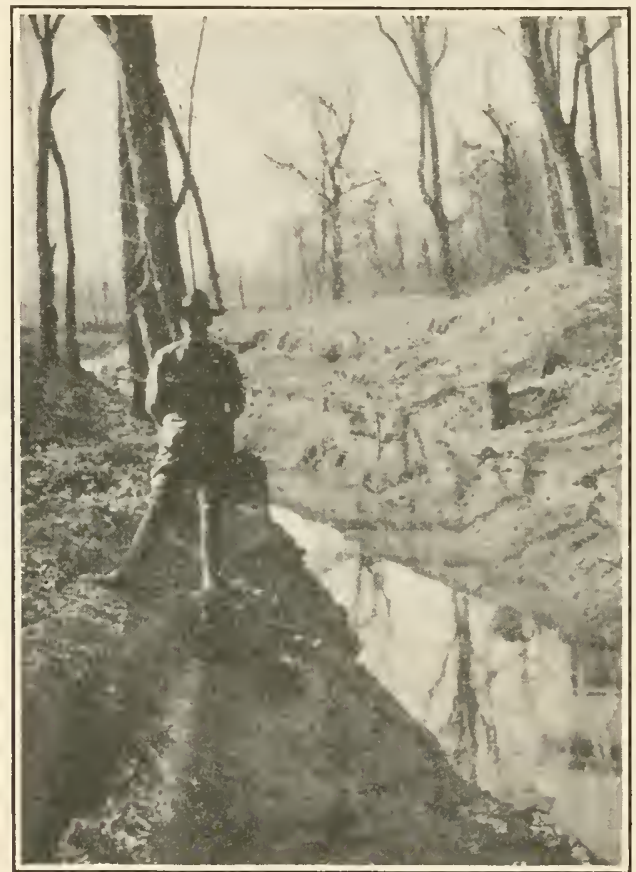

FIG. 97. A new channel for a stream. Note the straight course and clean edges.

needed. Places where the stream widens out, probably will give the most trouble. The best way of dealing with these is to dig out a channel and use boards or a rough plastered wall, where necessary, to keep it open; if boards are used, they should be well filled in behind. Sharp bends where storm water may scour out and erode the banks may also be advantageously treated in this way.

\section{CLEARING STREAMS OF LOGS, ETC.}

Where the bottom of the stream is soft, so that large poekets or pools have formed in the channel, such holes may be filled 
with stone in such manner as to prevent further extension of them.

Sometimes streams will be found clogged up with log jams, started by individual logs catching against stumps and trees on the bank. Such jams will range in size from 20 to $30 \operatorname{logs} u p$ to more than a thousand. Aceording to Williams ${ }^{1}$ the best way to deal with them is to explode three or four bundles of dynamite (20 pounds each) among the logs at the lower end of the jam;

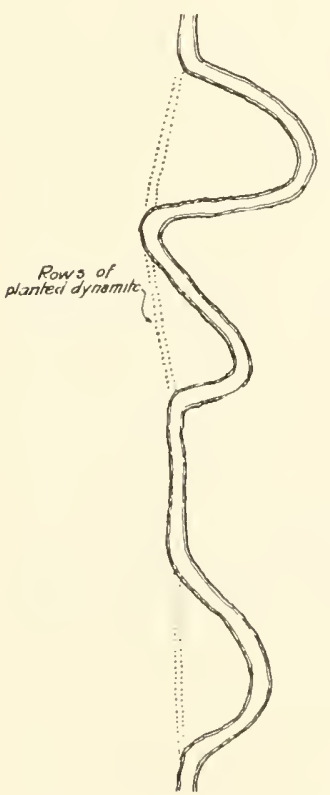

Beíore

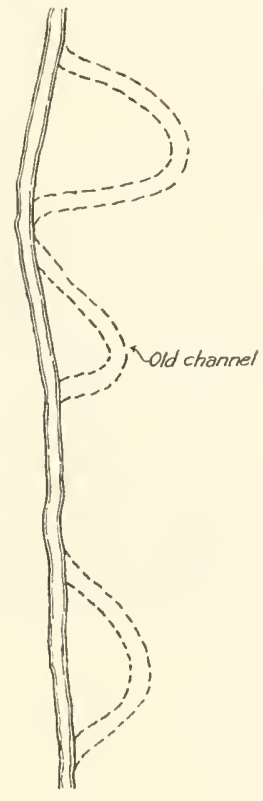

After

Fic. 9s. creck before and after straightening by blasting.

the explosion will bosen the logs and the majority of them will start downstream; a suffieient foree of laborers should be posted along the banks to prevent any new jam formations.

Where the logs are not so numerous but are scattered out along the banks, they may be cut loose by laborers and then hatuled up out of the water by means of teams.

Any other obstructions, together with weeds, grass, algae and similar growths, should be removed from streams periodically.

I Transactions of the First Anmual Confereuce of Sanitary Engineers, U. S. Public Health Service, 1919. 
Streams which, during a period of drought, partly dry up, leaving depressions or "pot-holes" along their courses, should be treated similarly to ditches which give rise to similar troubles.

\section{FILLING}

Collections of water that cannot economically be drained should be filled when practicable. Wet areas that are most expensive to control should be eliminated first. Shallow water in places that are too low to be drained may be concentrated by filling, so that the remaining water is easier and cheaper to control.

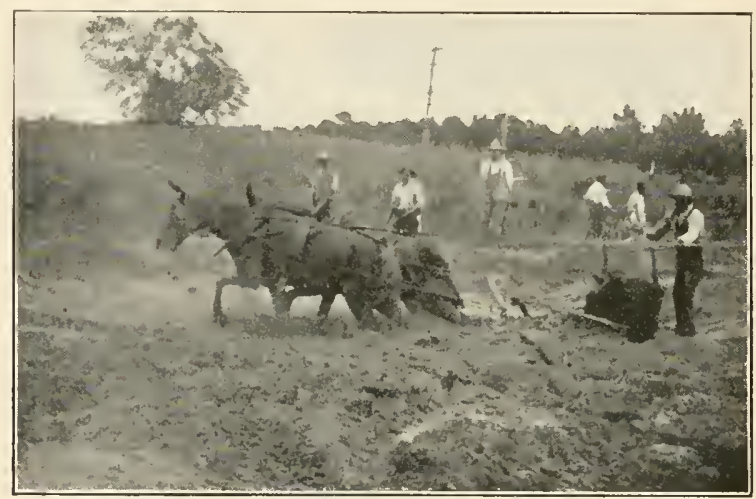

(Photo by E. H. Magoon, C. E.)

FIG. 99.-Making a fill.

Frequently, it is possible to procure that eity trash be dumped at the place it is desired to fill. This course may not be practicable, however, where the haul is too far or where the place is in a thickly-inhabited section. In all cases, the trash must be levelled off so as to prevent the formation of pools, and should be covered with 6 inches or more of earth in order to prevent odors, especially in summer. Under no circumstance should potential water-containers, such as old cans, bottles, etc., be left exposed.

Porous materials, such as cinders, are very good for filling. In the vicinity of lumber-mills, waste, saw-dust and shavings are available in quantity, and, when used for filling, should extend several inches above the surface of the ground.

Areas kept wet by seepage water can seldom be satisfactorily treated by making a shallow fill of earth. 


\section{CHAP'TER VII}

\section{SALT MARSH DRAINAGE}

\section{THE SALT MARSH PROBLEM IN GENERAL}

The salt marshes that abound along the Eastern and Southern coasts of the United States from New York to Mexico constitute probably the greatest single breeder of mosquitoes in the country.

These low-lying marshes, swept from time to time by the tides, which fill every hole and depression, make idleal breeding places and present probably the most difficult problem that there is from an anti-mosquito point of view, not only on account of the huge areas they cover, but also on account of the enormous expense involved.

Fortunately, not all parts of the salt marsh breed mosquitoes in equal abundance, owing to the activities of larva-destroying fish, which, when they are present in considerable numbers, eat the larvae nearly as fast as they hateh from the eggs. However, there are many parts of the marsh that the fish eannot reach, such as high-lying and shut-in meadows over which the tides rise only occasionally. Even where an extra high tide has stocked the heies with fish, the water soon dries up and the fish die; then, rain rater fills the holes, larva appear and a brood of mosquitoes gets on the wing.

The problem of preventing mosquito breeding in salt marshes is thus seen to be one of determining just what parts of the marsh constitute mosquito production areas and then so treating them that the ticte-water will run off at frequent intervals, will be constantly stocked with larva-destroying fish or will be kept out altogether. The methods of accomplishing these results are ditching, filling and dliking and tide-gating.

\section{AGRICULTURAL VS. ANTI-MOSQUITO MARSH DRAINAGE}

In the drainage of salt marshes, as in upland drainage, there is a distinetion between drainage for agricultural purposes and drainage for anti-mosquito purposes. As a general rule, it may be said 
that drainage for agricultural purposes is usually more intensive, as well as more expensive, than drainage for mosquito control purposes.

"It secms elear," says Headlee," "that the drainage necessary to prepare and maintain the marsh in condition for suecessful agriculture keeps the water-table so far below the surface that the original regetation is destroyed and the marsh undergoes a large shrinkage. In some cases, this shrinkage is sufficiently great to bring parts of the marsh below mean tide and to necessitate the use of pumps to keep the water far enough below the surface of the marsh to permit the growth of crops.

"In that type of clrainage necessary to eliminate mosquito-breerling, the water need not be maintained at a level lower than 12 inches below the surface, even during the height of the mosquito-breeding season. Indeed, at seasons of the year when breeding is not oeeurring, the gates ean be opened and the tide allowed to circulate freely. It would seem that this type of drainage should not destroy the salt marsh vegetation and that the meadow should not, therefore, materially shrink. There is some evidence to show that, with a proper system of letting the water on the marsh, the vegetation will not only not be destroyed, but maximum crops of salt marsh har can be produced."

\section{DESIGN OF SALT MARSH DITCHES}

As a result of the investigations of Dr. John B. Snith, pioneer in anti-mosquito work in New Jersey, it has been found that the best type of ditching for the usual salt marsh is a ditch 10 inches wide by 30 inches deep, with smooth perpendicular sides. This depth normally reaches the bottom of the sod, and should be maintained, except where natural slope calls for a deeper cut to insure the free flow of the water. As the upland is approached and the sod and underlying muek becomes thinner, the depth of the diteh is decreased accordingly, neither sand nor subsoil being cut into, unless the drainage of a pool or other shut-in area requires it.

Two general plans of ditehing have been used in New Jersey. One plan, known as the parallel system, calls for division of the territory to be drained into districts on the basis of possible 7 outlets, each distriet to be drained by parallel ditehes, sufficiently close together to remove the surface water. The other plan, known as the pool-connecting system, consists of running ditches

1 "The Mosquitoes of New Jersey and Their Control," New Jersey Agrieultural Experiment Stations, Bulletin No. 276, 1915. 
from one pool or hole to another, and finally into one or more outlets. According to Headlee, ${ }^{1}$ the parallel plan is now considered the best practice in New Jersey.
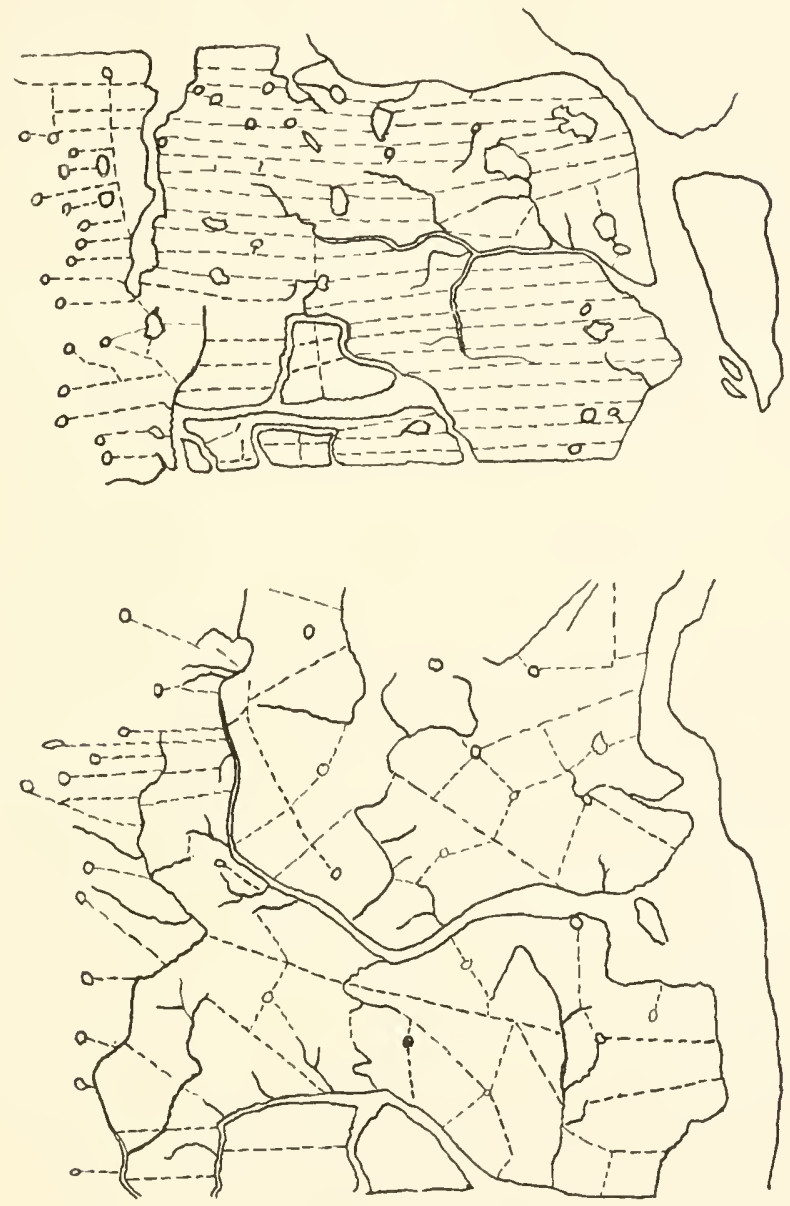

New Versey Agricultural Experment Stations

Fig. 100.- Dbove, parallel, and below, pool-connecting, systems of salt marsh litehing. (After Hearlec.)

Referring to the amount of ditching per acre necessary, on the average, to prevent mosquito-breeding in the New Jersey salt marshes, Headlee ${ }^{1}$ says:

I "Some Recent Advances in Knowledge of the Natural History and the Control of Mosquitoes," New Jersey Agricultural Experiment Stations, Bulletin 306, 1916. 
"The estimated requirements range from 90 to 600 lineal feet of 10 by 30 inch ditching, or its equivalent, per acre. As a matter of fact, only rarely is the former figure practicable, and then under especially favorable conditions, and never on the New Jersey salt marshes has the latter figure been reached. It seems probable that between 200 and 300 feet is the real average. To this must be added an amount of hole filling and shallow spurring which will add about 10 per cent to the acre cost."

\section{SALT MARSH DITCHING BY HAND}

The type of ditch just described is dug both by hand and by machinery, the latter being considerably the cheaper.

In hand ditching, the chief tools commonly used are patented spades of various types, these having been found superior to ordinary shovels. There are several different makes of these spades on the market.

In cutting the ditehes by hand, it has been found best to remove the sods in pieces about 10 inches wide by 6 to 8 inches thick by 30 inches long. These are heavy and not easily moved by the tide; they can also easily be hauled away if desired.

As a general rule, numerous small, shallow pools are found scattered throughout the marsh; some of these will not drain readily into the ditches, but are too small to merit drainage by means of spurs. Such holes may be filled with sods from the ditehes and then smoothed over, in such manner as to prevent formation of suceeding pools. In a year or so, the grass will grow over the fill and the hole will be entirely obliterated as a breeding-place.

Sometimes, portions of the marsh are so shut in that opening them to the ocean is impracticable. In these cases, the area may be trenched with the usual ditches to concentrate the water which should then be stocked with larva-destroying fish.

Particular care should be taken in connection with the outlet of the ditches. The greater the tide drop and the shorter the ditch, the greater is its efficiency and its ability to keep clean. According to Headlee, ${ }^{1}$ every ditch should have a strong tidal outlet, and no ditch depending on a single outlet should be more than a quarter of a mile long.

1 "Some Recent Advances in Knowledge of the Natural History and the Control of Mosquitoes," New Jersey Agricultural Experiment Stations, Bulletin 306, 1916. 


\section{MACHINE DITCHING}

Several types of ditching machines are used in salt marsh mosquito control work. Headlee ${ }^{1}$ mentions a machine consisting of a gasoline power plant, equipped with revolving drums in
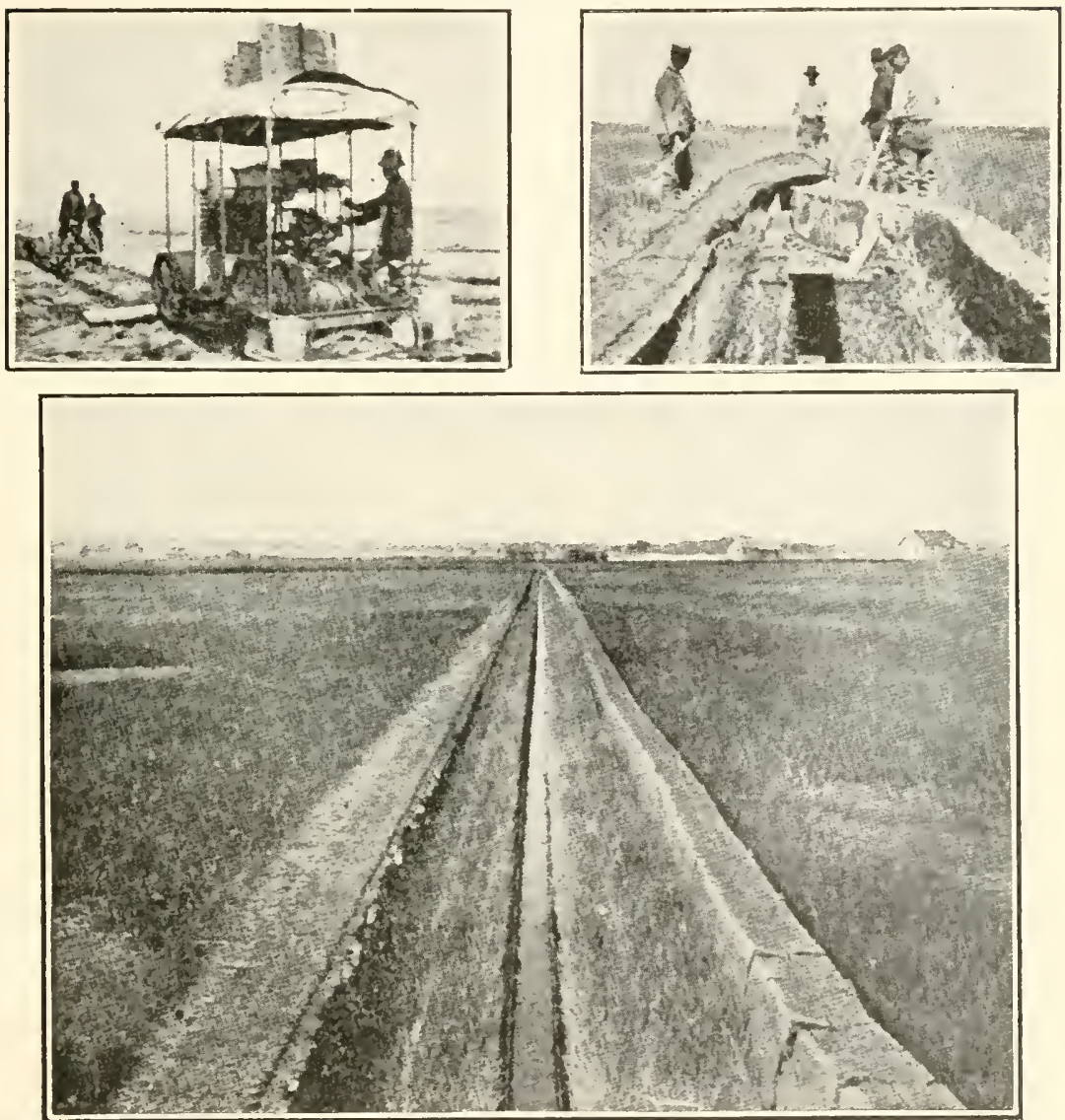

(Photos by Allantic County, N. J., Mosquito Extermination Commission.

Fig. 101. - Above, left, front view of the Eaton ditches, showing plow in distance; above, right, rear view of the plow, showing the ditch and the way sods are disposed of; below, a ditch cut by the Eaton ditcher.

front and rear, and a plow or trencher which makes the excavation. The power plant, mounted on planks, pulls the trencher forward by means of a 500 foot steel cable; when it becomes necessary to move the power plant, an anchor is carried forward, power is applied to the other drum, which is connected with the 
anchor by another steel cable, and the plant is drawn up to the anchor.

With a machine of this type and five men, it is possible to cut 3,000 feet of ditches a day, and, under favorable conditions, sometimes more. Headlee ${ }^{1}$ states that this machine cut the cost of ditching from $21 / 2$ cents a lineal foot in 1912 to less than $1 \frac{1}{2}$ cents in 1916. At that time, he states, the operating and up-keep cost of ditching with this machine, as shown by cutting hundreds of thousands of feet, did not exeeed 1 cent a lineal foot.

\section{FILLING}

While the method of ditching outlined above is perfectly satisfactory for the larger part of the salt marsh areas, there are certain sections of marsh that cannot be successfully treated in this way. There are areas which are so shut in by ridges, fills, railroad grades and roadways, or so low-lying, that they may be flooded by every storm or extra high tide and stagnant water remain on them for weeks. Again, it may happen that on a broad, open marsh, especially if the range of tides be small, there are spots or pockets back near the upland too low to drain by ditching.

In such cases, the problem nay be solved either by filling or by diking and tide-gating.

Filling is applicable only under certain circumstances. Thus, it is too expensive for general purposes, and is used chiefly in cases where the area to be filled is small, where it is very valuable or where it proves to be the most convenient place for a clumping ground. In making the fill, the trash should be smoothed down and levelled in such manner that there will be no opportunity for rain-water pools to form in it.

\section{DIKING AND TIDE-GATING IN GENERAL}

This is the accepted method of dealing with the areas described in the last section. It should be recognized at the outset that diking and tide-gating a given area is strictly an engineering problem and that it should be handled as such. Failure to recognize this fact may result in ineffective work and a waste of money.

1 "Some Recent Advances in Knowledge of the Natural History and the Control of Mosquitoes," New Jersey Agrieultural Experimnent Stations, Bulletin 306, 1916. 
Diking is necessary, as a rule, only when the fall of the tite is not sufficient to draw all the water out of the ditches, when the drainage ditches pass through material of such a nature that it is impracticable or unduly expensive to keep them open or when the area in question is too low to be drained.

Diking implies the construction and installation of tide-gates, since it is necessary that the streans and ditches carrying water be given an opportunity to discharge. The main purpose of the diking is to keep out all but the very highest tides, so that low areas will not constantly be covered with water and so that the

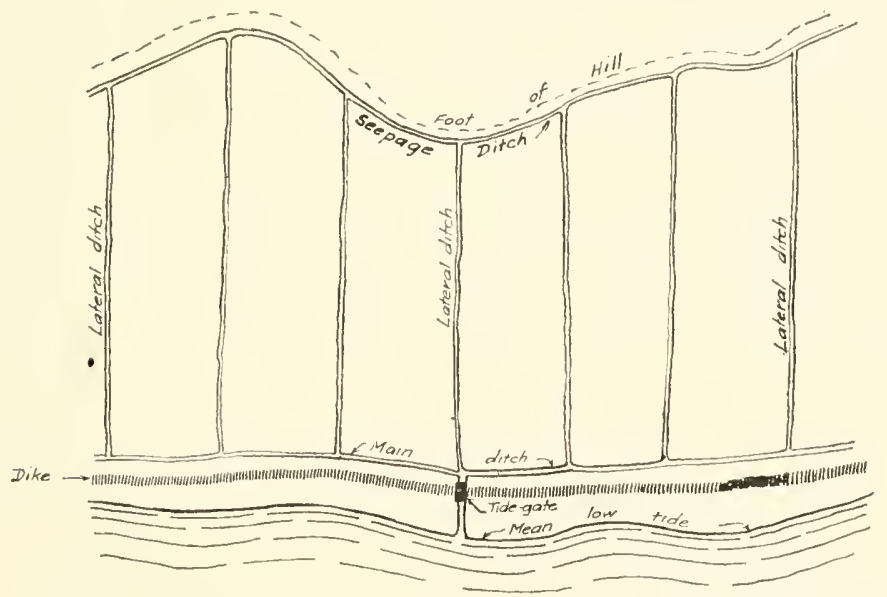

Fra. 102.-Method for control of abandoned coistal rice-field.

water-table in the ground will remain at at sufficient depth. Otherwise, a eomparatively slight rain-fall or a high tide would result in pools that would remain for days.

The dike should, as a rule, be located from 25 to 50 feet from the edge of the water, so as to leave a narrow strip of marsh to protect it from wave action. It should be sufficiently high to keep ont all but the very highest of high tides, and proportionatcly wide. In eonstructing the dike, due allowance must be made for shrinkage.

\section{CONSTRUCTING THE DIKE}

In construeting the average dike, mut and sods are the chicf materials. A core ditch, about 1 foot wide and 1 foot or more deep, should first be excavated along the center line of the pro- 
posed dike; the purpose of this is to get a good bond with the earth. Sods are then laid on either side of this core ditch, and the interval between them tamped with mud. Another layer of sods is then placed on top of the first, only a few inches closer together, and more mud tamped in. This procedure is continued until the necessary height is reached. The whole may then be capped with sod or plastered with mud.

The sods and mud generally are obtained from a ditch paralleling the inside of the dike. Sometimes, this ditch receives the flow from the laterals and conducts it to a convenient tide-gate. Sometimes, a supply ditch is dug outside the dike, but, if this is done, care should be taken that it is properly connected with adequate outlets. In order to prevent eaving, no ditch, either inside or outside the dike, should be located less than 8 or 10 feet from the dike.

"Some dikes," says Headlee, "'have been constructed entirely with mud, but always in places where sod was not available. In such instances, the mud has been scooped from a trench back of the dike (forming a ditch paralleling the work and giving useful drainage), and piled up until a dike of requisite height, with due allowance for shrinkage, had been built, which was 2 feet wide at the top and as broad at the base as was demanded by the normal angle of repose. This type of dike does not withstand the weather or the water as well as the sod type, but is efficient if carefully looked after."

Dikes vary in size, of course, with the height of the tides. Usually, along the Atlantic coast, they average from 2 to 4 feet high, 2 feet wide at the top and 4 to 6 feet wide at the bottom. The cost varies with the size. Fuchs ${ }^{2}$ reports construction of a dike averaging 2 feet high, 2 feet wide at the top and 4 feet wide at the bottom at a cost of 35 cents a lineal foot.

To protect the dikes against muskrats, brown rats and other rodents which may burrow through and undermine the dikes, it is customary in New Jersey, to insert a piece of chicken wire vertically in the middle of the core of the dike letting it extend down as far as 2 to 4 feet below the surface of the marsh.

1 "Some Recent Advances in Knowledge of the Natural History and the Control of Mosquitoes," New Jersey Agricultural Experiment Stations, Bulletin 306, 1916.

${ }^{2}$ Transactions of the First Annual Conference of Sanitary Engineers, U. S. Public Health Service, 1919. 


\section{THE TIDE-GATE AND SLUICE-BOX}

At points where streams or large ditches cross the dike, tidegates are required. There are several types of these devices, each being applicable to eertain eonditions. The type most commonly used includes a sluice-box and a swinging gate.

The sluice-box ordinarily corresponds to a eulvert and lies at right angles to the dike and underneath it. The length is determined by the height of the fill and the slope of the filling material. The eross-section is determined, as for culverts, by the drainage area, rain-fall and run-off.

The swinging gate is a gate or shutter attached by hinges to the outer end of the sluice-box and so arranged that it will readily open with the falling tide and readily close with the rising tide.

The purpose of the sluice-box and gate is to discharge water at low tide and close up at high tide in such manner as to prevent the tide from entering. In good construction, the water in the ditehes and streams should be maintained virtually at the elevation of low tide. A heavy rain may result in the accumulation of several inches of water, but this will be discharged at the next low tide.

\section{CONSTRUCTION OF SLUICES}

When the outlet of the diteh or stream is deep enough to prevent the tide forcing back accumulations of mud, etc., into the sluice-box, it is a good plan to submerge the sluice-box below mean low tide, in order to prevent floating debris from interfering
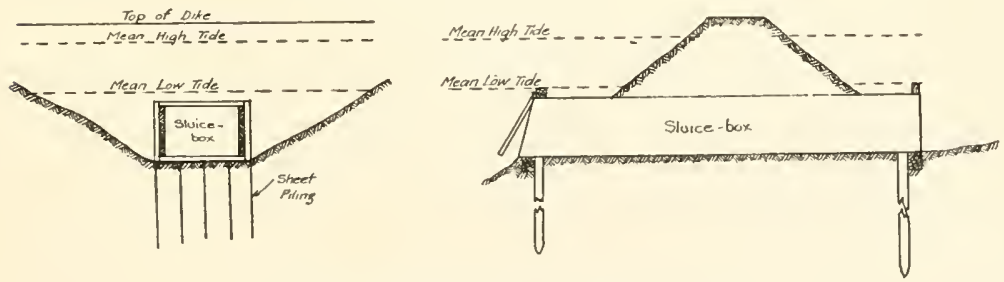

FIG. 103.- Installation of a sluice-box.

with operation of the tide-gate and also to avoid periodical wetting and drying, which greatly shortens its life. If it is not submerged, it must be sereened with heavy material. -

Where excavation for the sluice-box is necessary, a rude cofferdam may be eonstructed, using earth for the ends, the water being bailed or pumped out. The box may be set directly on 
the earth bottom, if the bottom is hard and smooth, or on piling driven under the ends and middle of the box. Care should be taken in installing a box to prevent any possibility of a leak developing around or under it.

Sluice-boxes are generally built on the dry ground and lowered into place; to avoid difficulty in this connection, it is usually well not to make them too large. Should the stream or ditch carry off too much water for one box, two or more boxes should be installed side by side.

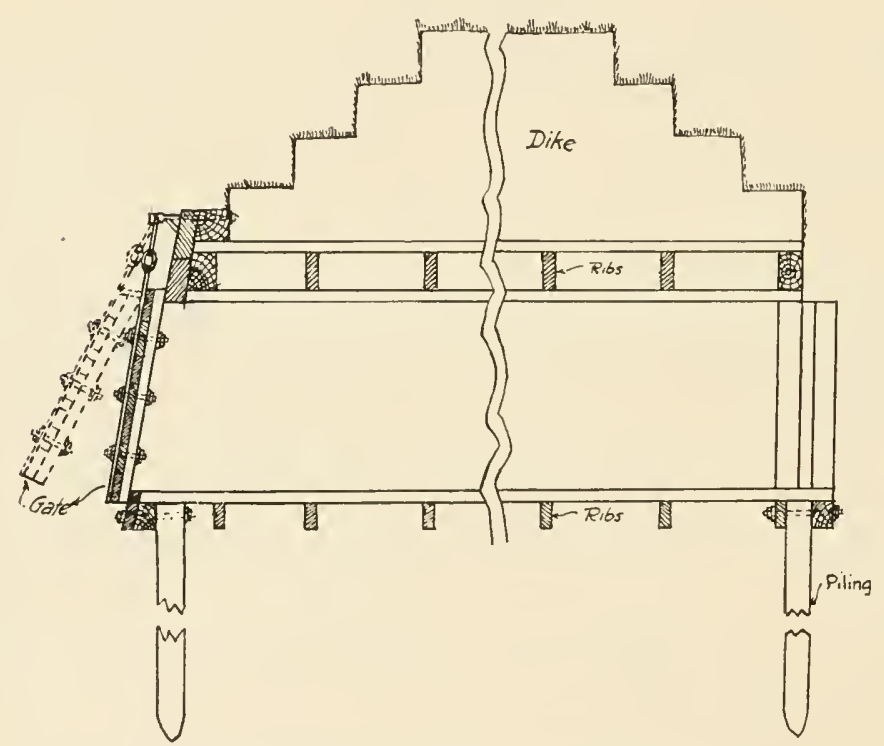

FIG. 104.--Sketch of sluice-box and tide-gate.

Shuice-boxes may range in size from a section of 1 or 2 square feet and a length of 6 or 8 feet up to a section of 15 to 18 square feet and a length of 20 to 30 feet. They are generally made of 2-inch planks nailed to outside ribs at distances of $1 \frac{1}{2}$ to 2 feet apart. In order to insure tight closing of the gate or shutter, the outer end of the box is often given a slight slope, usually about 1 inch per foot.

According to Gies, ${ }^{1}$ it is customary in New Jersey to put a coarse rack or screen at either end of the box, made of 2 by 4-inch lumber, the pieces being spaced parallel to each other about

${ }^{1}$ Transactions of the First Annual Conference of Sanitary Engineers, U. S. Public Health Service, 1919. 
4 inches apart, to keep out heavy floatage and debris, which might interfere with operation of the gate.

\section{GATE CONSTRUCTION}

The gate, like the sluice-box, is usually built of 2 -inch plank, tongue-and-groove material being best. Sometimes, two thicknesses of plank are used. To prevent floating of the gate on the

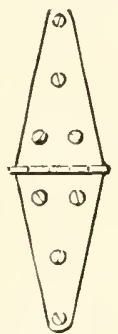

(a) UROINARY STRAP HINGE

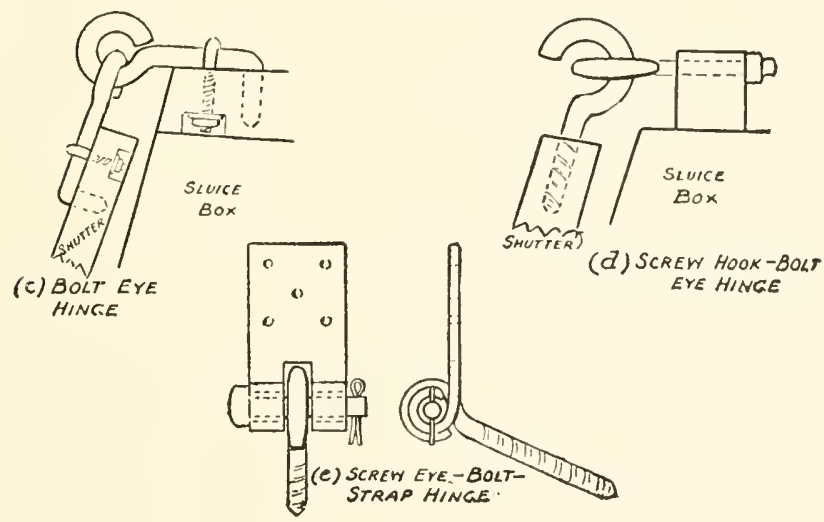

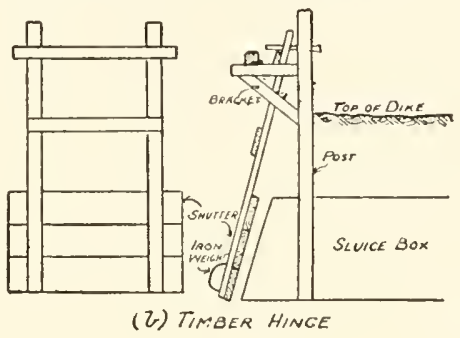

(2) TIMBER HINGE

(1)

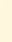


eye-bolts welded together, one bolted to the box, the other to the shutter. (4) Screw hooks in the shutter, working on eye-bolts on the box. This works fairly well. (5) Screw eyes in the shutter, working on a bolt supported by a strap attached to the box. By knocking out the cotter pin, the bolt can be pulled out and the shutter removed."

Sluice-boxes, according to Fuchs, ${ }^{1}$ are the cheapest and most satisfactory type of tide-gate, where the stream is not too large. With labor at 35 cents an hour, he gives costs of various boxes as follows: A 3 by 4 by 16 foot box, placed several feet. under water, $\$ 202$; a 2 by 3 by 16 foot box, placed just below low water, $\$ 33$; a 2 by 3 by 20 foot box, placed just below low water, $\$ 105$. These eosts include both labor and materials.

\section{SPECIFICATIONS FOR LARGE SLUICES}

Headlee $^{2}$ gives the following specifications for sluices and gates employed as an outlet for a large ereek in New Jersey, measuring from 75 to 80 feet wide:

1. "All sluices shall have an inside measurement of 6 by 3 feet, and shall be built of 3-inch tongued and grooved long-leaf pine, free from knots or serious blemish; they shall not be shorter than $15 \frac{1}{2}$ feet and shall extend from the outside of the dike, facing back under the dike. These boxes shall be stiffened with 4 by 5 -inch ribs, bolted at each corner with a $1 / 2$-inch bolt, properly washered and drawn up with a satisfactory nut. These ribs shall be placed around the outside of the box, fitting it closely, at distances of 18 inches apart. The first and last shall be made flush with the ends of the box. The planking shall be firmly spiked to these ribs with 6 -inch galvanized spikes. The top of the box shall be covered with 2-inch long-leaf pine spiked on the top of the ribs.

2. "The dike shall be faced on the river side with plank pilng for 120 feet. . This facing shall consist of 3-inch long-leaf pine planking, free from knots and serious blemish, not less than 14 feet long, driven in until the top shall be 1 foot below the level given for the top of the dike. If the tops of the piles are splintered, split or broomed by driving, they shall be cut off below the lowest point of injury. In any case, the cut of ends shall not be such as to make length of pile less than provided. The top of the piling shall be even and bound together

${ }^{1}$ Transactions of the First Annual Conference of Sanitary Engineers, U. S. Public Health Service, 1919.

2 "Some Recent Advances in Knowledge of the Natural History and the Control of Mosquitoes," New Jersey Agricultural Experiment Stations Bulletin 306, 1916. 
by running a 3 by 8 -inch stringer along the outside and inside surfaces. Each pile shall be bound to this stringer by a 1/2-inch bolt, which shall be furnished with large washers and a suitable nut. The opening for the sluice-boxes shall be made closely to fit the boxes. The cut ends of the piling above the box shall be bound together by 3 by 8 -inch stringers, which shall extend, one on the inside and one on the outside, from a point 2 feet beyond one edge of the opening to a point 2 feet beyond the opposite edge of the opening. These stringers shall be set flush with the cut ends of the piling, and each pile which they cover shall be bound to them by a $1 / 2$-inch bolt, properly washered and fitted with a nut. The cut ends of the piling below the box shall be bound together in the fashion above described.

\section{INSTALLATION}

3. "All sluice-boxes shall be laid on two extra rows of sheet-piling composed of 3-inch long-leaf pine closely set together. The planking shall be 10 feet long and driven in until the top shall be 9 inches below mean tide. The above provision regarding injury due to driving and its correction shall be observed here. Each row of this sheet piling shall extend 4 feet each side of the sluice-boxes. Each row shall be bound together at the top in a fashion similar to that provided for the dike facing, and the piling at the sides of the boxes shall extend up through the stringers 1 foot, and the rectangle thus formed shall be made closely to fit the boxes.

4. "At the sluice-boxes, the inner side of the dike shall be protected by sheet-piling wing-walls made of 2 -inch long-leaf pine without serious blemish, 14 feet in length, driven in until the top is 1 foot below the level of the dike. The above provision regarding injury due to driving and its correction shall be observed here. They shall be bound together at the top in the same fashion as the dike facing, and shall extend 6 feet on each side of the sluice-boxes.

5. "The river side of each sluice-box shall be furnished with a 7 by 4-foot gate made of tongued and grooved white pine. It shall be composed of two layers, the inside one being made of 3 -inch, 7 -foot planking and the outside one of 2-inch, 4-foot-long planking, laid at right angles to one another and firmly spiked together. The gate shall be hung in front of the opening with a suitable hinge, so that it will readily open with the falling tide and readily elose with the rising tide."

\section{OTHER TYPES OF TIDE-GATES}

Headlee $^{1}$ describes another type of tide-gate, said to be advantageous on account of the greater ease with which it can be kept in order, as follows:

1 "Some Recent Advances in Knowledge of the Natural History and the Control of Mosquitoes," New Jersey Agricultural Experiment Stations, Bulletin 306, 1916. 
"In this case, no box is constructed, but heavily-timbered bulk-heads are built into the stream until they stand within approximately 6 feet of each other. To render their relation to each other constant, they are bound together by heavy cross-timbers. At a point half-way between the two ends, a pair of heary, 6 by 6 -inch well-braced timbers are set

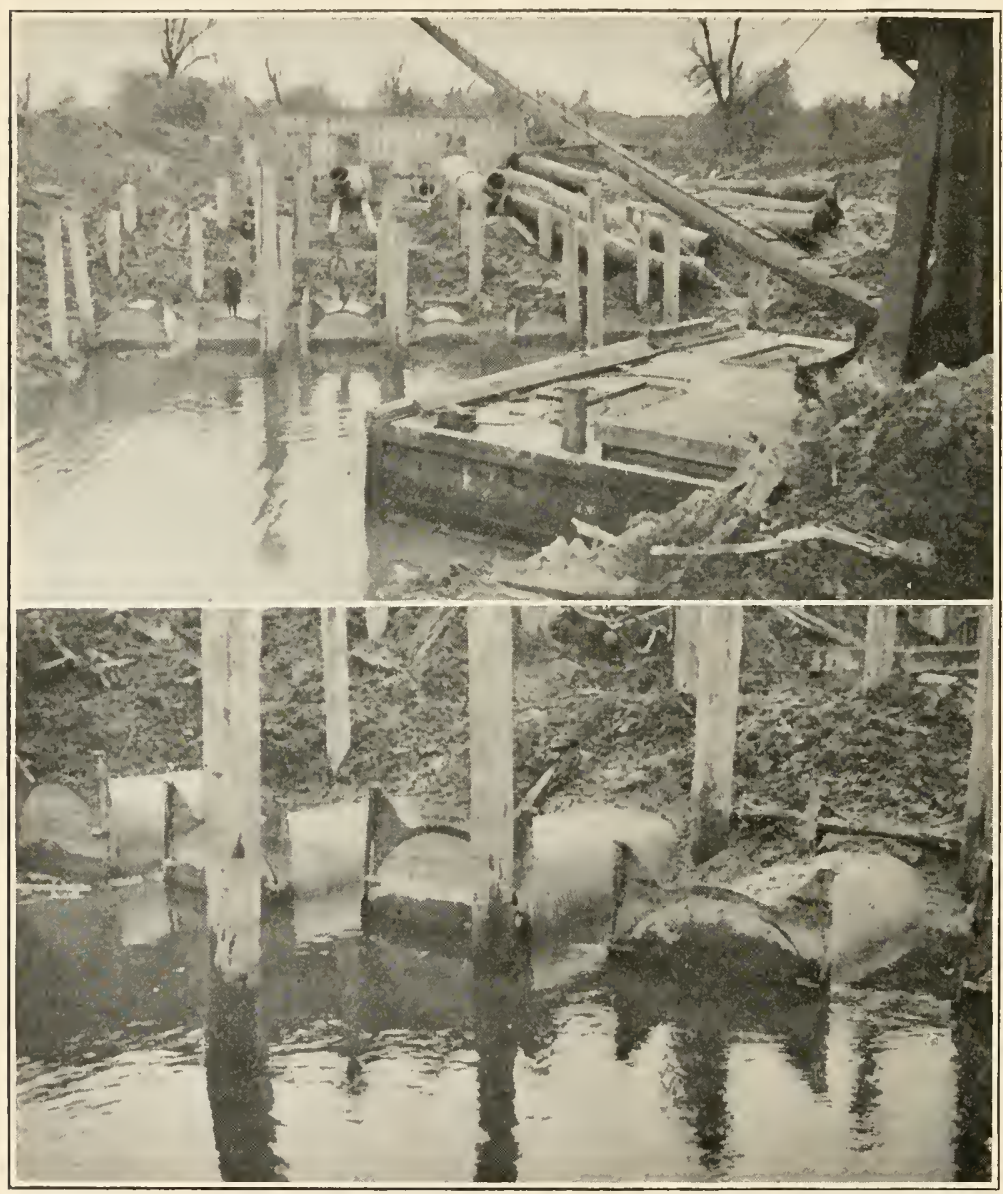

(Photos by Catifornia Corrugated Culvert Company)

Fig. 106.-Battery of Calco culverts and gates in process of installation.

down in such a fashion as to form the support and resting-place for the tide-gate. Of course, the joints between each of the upright posts and ths bulk-head against which it stands and between the lower cross timbers and the bottom are made tight.

"The tide-gate is suspended from a cross-timber located well above extreme high tide, and hangs against the upright posts. At each end, 
the bulk-heads are fitted with slots, in which planking can be dropped to form a coffer-dam. The water between the two bulk-heads has merely to be pumped out, when these dams are in place to expose the gate for repairs and the sluice-way for cleaning. The top of the sluice-way thus formed is left open."

Frequently in salt marshes, areas are found separated from the main body of water by sand-bars. The outlets from these areas are channels through shifting sands. Ordinary tide-gates quickly fill up. A satisfactory way of dealing with such places, according to Carroll, ${ }^{\perp}$ is to construct a planked well on the iuner side of the bar; the well is connected with the marsh area in question by a planked ditch; at the entrance of this ditch into the well, a tide-gate is hung; the well discharges at low tide through a terra-cotta pipe that passes under the sandy beach and connects with an iron pipe rumning out under the water', so as to deliver the water from the well a foot or two below mean low tide. The iron pipe is protected against drifting ice, etc., by means of heary piling and cross-timbers.

For small streams having a firm sub-soil, a single line of sheet piling, well braced with large piles, is suggested by Fuchs. ${ }^{2}$ In this case, the gate would fit over a hole cut in the piling. This type of gate would have the advantage of cheapness and simplicity, but it would have to be extremely well-braced to withstand the recurring pressure at high tide, which would have the effect of loosening it, causing leaks. Fuchs ${ }^{2}$ reports that one gate of this design that he tried out failed as a result of this tide pressure.

\section{THE CALCO GATE}

The Calco automatic drainage gate, made by an iron-culvert company, has given satisfaction on several large cliking and drainage projects. This gate is attached to one end of a corrugated iron culvert, somewhat after the fashion that a wooden gate is attached to a sluice-box. These gates are said to be sensitive to a difference of head of less than an inch.

The method of installing these gates is similar to that outlined for wooden gates, except that it is sometimes advisable to put

1 Transactions of the First Annual Conference of Sanitary Engineers, U. s. Public Health Service, 1919.

${ }^{2}$ Transactions of the First Annual Conference of Sanitary Engineers, U. s. Public Health Service, 1919. 
a concrete core-wall in the fill, so as to avoid any possibility of leakage along the pipe.

The following description of a large drainage job, covering 5,600 acres of Columbia River overflow land is compiled from information furnished by the company:

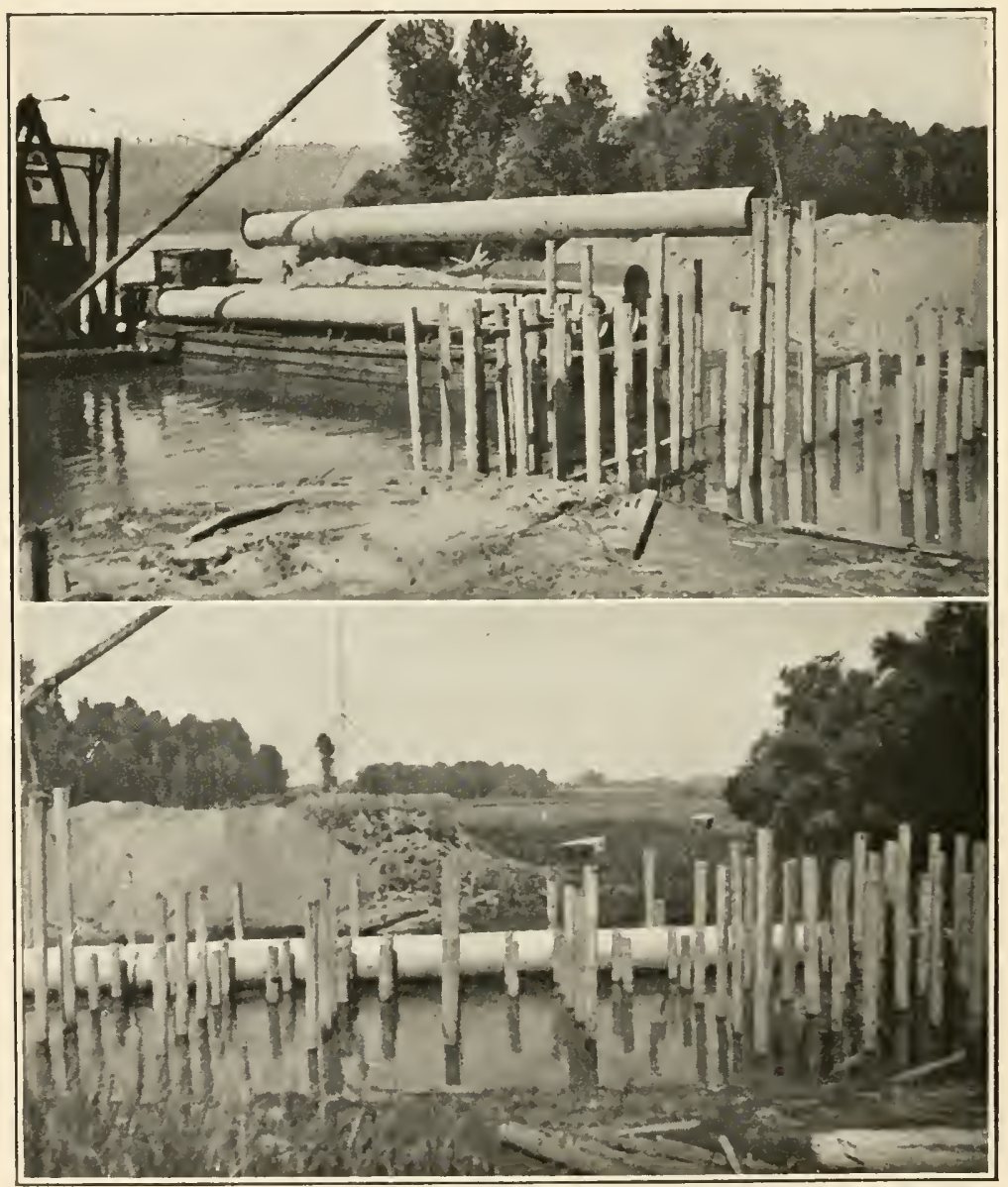

(Photos by California Corrugated Culvert Company)

FIG. 107.- Installing a $\mathbf{i}$-ton Calco culvert and drainage gate, Columbia River project.

Two sloughs were selected for the drainage outlets. At one of these, a battery of five Calco gates, attached to five corrugated culverts, 6 feet in diameter and 110 feet long, were placed side by side. A row of piling, 8 feet on centers, intercepted each 
length of culvert pipe to assure proper settlement and avoid misplacement after filling over the culverts. At the other slough, a battery of six gates and culverts was installed in a similar manner. Owing to the fact that the eulverts at the time of placement would lie below water level, it was necessary in both installations to lay the culverts with the gates attached. Each eulvert and gate unit weighed more than seven tons. Two clam-shell dredges employed in the dike work were used to lower them in place.

As an auxiliary proposition, to take care of high water periods and freshets, a pumping plant was provided at each slough. Both installations of pumps and pipe lines were placed directly over the eulverts and gates.

To enelose the 5,600 acres against high water required $71 / 2$ miles of dike, of an average height of 12 feet. At the culvert and gate installations, the height of the embankment over the top of the culverts was 20 feet. The total cubic yardage of embankment amounted to 800,000 .

The appraised value of the land before improvement was approximately $\$ 50$ an acre, and after improvement, $\$ 250$ an acre. The cost of all diking, dredging and spillways, was $\$ 60$ an acre, leaving a net profit of $\$ 140$ an acre.

\section{OPERATION OF TIDE-GATES}

Tide-gates, like all other contrivanees, need a certain amount of attention. In addition to this, it is imperative that they be operated intelligently.

Tide-gates should be inspected at least once a week and preferably twice a week. Despite the use of racks and sereens, there is a certain amount of fine debris that is almost bound to enter the gate and possibly interfere with its operation. Even though the gate be below mean low tide level, sunken logs and other like objeets frequently enter and lodge in the gate. These must be removed, if the gate is to function satisfactorily.

There is also another problem in connection with tide-gates. When the gates are elosed, fish cannot enter the marsh and, when the fish supply gets low, there is apt to be more or less mosquito breeding. This is particularly the case when sewage is discharged into the marsh. In order to overeome such breeding, the practice in New Jersey has been to raise the tide-gates for a week or two each month during the period of the lowest 
tides, throughout the summer. This allows the fish supply to be kept up.

"Moreover," says Gies, "by raising the gates on one side of the marsh and allowing water to enter, while keeping the gates on the other side of the meadow closed, except for discharge of water, it is possible to get circulation of the water through the ditches across the marsh, and sweep out breeding by this mechanical action. The gates are all closed during periods of monthly high tides or storms, so the unusually high tide-water will not back up over the meadows . . .

\section{SALT MARSH SHRINKAGE}

"There is one other point that has not been touched on-that is, the matter of meadow shrinkage, if the gates remain permanently closed. Most salt marshes are composed of a top layer chiefly of decayed vegetation or peat on a foundation of blue clay, mud, sand, etc. The elevation of the meadow surface is kept up to a point slightly above mean high tide by the continuing growth and decay of the salt grasses, sedges, rushes, etc. This class of regetation needs plenty of salt water to attain maximum growth, and, hence, if the tide-gates are kept continually closed and the salt water excluded from the marsh, the growth of the surface vegetation stops and the spongy top layer of peat dries out and begins to pack down hard, and the marsh settles down lower and lower. In parts of Hudson County, New Jersey, this shrinkage has amounted to several feet.

"Finally, a point is reached where the elevation of the meadow has become so low that it can no longer be drained by ditches or tide-gates, and it is necessary to install pumps, which increases the cost of mosquito control ...

". . We are keeping the tide-gates open in our own district, not only for about 2 weeks out of every month churing the summer, but during the entire non-mosquito-breeding season, from November until March. We hope, in this way, to keep up our marsh elevation by continuing our vegetation growth, so that we will not be forced to the extra expense of pumping."

\section{PUMPING}

White small areas of marsh, so low that they will not drain at low tide, may be filled, large areas of this kind probably will require pumping.

Whether a given area shall be pumped, what type and what capacity of pump shall be employed, what ditching must be used

1 Transactions of the First Annual Conference of Sanitary Engineers, U. S. Public Health Service, 1919. 
to bring the water to the pump and to take it away are engineering questions that can only be decided by a competent engineer after detailed study of the particular problem.

In parts of Hudson County, New Jersey, where the meadow elevation is very near mean sea level or lower and in the lowlying marshes near Philadelphia, Pa., very excellent systems of pumping have been worked out. These pumps are electrically driven and are automatic in operation, being regulated as to starting and stopping by a simple float, which is raised or lowered by the water on the marsh, and starts or stops the pumps accordingly.

A 12-inch low-head centrifugal electrically driven pump, installed in a low area of Hudson County, N. J., in 1915 at a cost of about $\$ 1,300$, satisfactorily drained a territory of about 700 acres at a cost during the mosquito season of about $\$ 80$ a month. 


\section{CHAPTER VIII}

\section{OILING}

\section{PLACE OF OILING IN ANTI-MOSQUITO WORK}

Oiling of water surfaces should be considered as merely supplementary to drainage and other measures of mosquito eontrol. While oiling alone might, under certain circumstances, suffice, the expense, over a term of years, would be excessive. For these reasons, oiling is usually confined to areas which it is impracticable to drain, stock with fish or otherwise eliminate as sources of mosquito-breeding, or else is used temporarily, pending application of other measures.

The purpose of oiling is to cover the surface of the water with a film of oil, which kills larvae already present in the water and prevents further deposition of eggs, so long as the film retains its strength. The larvae are suffocated, through inability to penetrate the film with their breathing tubes.

The necessity of oiling as a mosquito control measure will vary, of course, with temperature, topography, aquatic plant growth, presence of larva-destroying fish, the nature of the breeding areas, etc.

\section{WHERE OILING IS APPLICABLE}

The greatest virtue of oiling, perhaps, is its applicability to treating small rain-water pools, too numerous to drain and too transient to stock with fish, yet often lasting long enough to produce a brood of mosquitoes. There seems to be no other method so effective as oiling for dealing with these. Streams, ponds, swamps etc., may be treated by drainage methods or by means of fish; breeding in artificial containers about homes may be eliminated by removing the containers or, where necessary, screening them; but neither of these methods is suitable for dealing with rain-water pools.

Another large use of oiling is to handle production areas while steps are being taken to control them by other means. Thus, the edges of ponds may be oiled, while the process of removing 
larva-concealing vegetation (to facilitate control by means of fish) is being carried out. Also swamps may be oiled pending construction of drainage ditches.

\section{APPLYING THE OIL}

Ordinarily, oil need be applied only around the edges of large bodies of water and of swift-flowing streams, since larvae rarely are found in deep water and are readily wafted away by a swift eurrent.

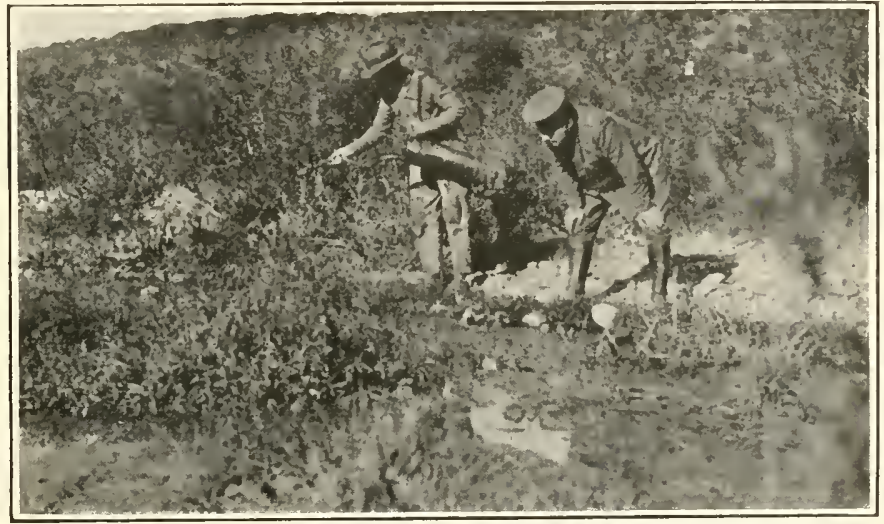

FIG. 108.-Oiling a grassy stream until regetation can be removed for fish control.

Should deep water be covered with algae, debris or aquatic plants, such as water lily, closely matted grass, ete., breeding may take place-since the larvae will be more or less concealed from the fish-and oil should be applied heavily over the whole surface, unless other measures are put into effect.

In slowly moving streams, quiet pools, back-waters, ete., are often found which may prove to be breeding places. These should be well oiled, unless other steps are taken to prevent breeding.

Also in cases, where the flow of streams is obstructed by sticks, weeds, debris and other matter, the oil cannot be depended upon to penetrate the mass, unless the whole surface is covered liberally.

Ordinarily, it is not neeessary that the film of oil be thick; indeed, much oil is wasted in this way. Where the water surface is clean, a very thin film, such as will show a faint display of colors in the sunshine is sufficient. Where the water is foul or 
covered with a seum, more oil is required. The amount of oil needed in such a case must be determined largely by experience, since the factors in the case vary so much that no definite statement on the matter can be made.

\section{KIND OF OIL REQUIRED}

The oil used must be thin enough to spread and form a film, sinee, unless there is a uniform film over the water surface, many of the larvae will not be suffocated. Probably the best oil for the purpose is a light fuel oil; frequently such an oil ean be proeured thin enough not to require mixing with kerosene; where only a heavy grade of oil is available, it must be mixed with enough kerosene to eut it thoroughly, often from 50 to 75 per cent. Proper mixing requires vigorous stirring until the mixt ure has merged into a thin and quick-spreading fluid. The main practical considerations are that it be thin enough not to clog up the sprayer and that it spread enough to form a film.

Kerosene alone is fairly satisfactory, but it has a tendeney to evaporate too quickly. It is also generally somewhat more expensive than the fuel oil. Furthermore, in using kerosene, there is a tendency to use more oil than is essential, as kerosene has a secondary "spread," or, in other words, covers a larger area after an hour or two than when at first applied. A film that is almost too thin to be measured, but which will give an irridescent reflection in sunlight, will kill Anopheles larvae.

\section{LARVICIDES}

Larvicides or substitutes for oil may be utilized to advantage under some circumstances. On the other hand, however, it should be remembered that they are often poisonous, less effective and more costly than oil. These considerations naturally limit their profitable use, and LePrince ${ }^{1}$ suggests that they be used only under the direetions of boards of health or health officers.

In cases where rains are so heavy and frequent that the oil is likely to be washed away before it has time to kill the larvae, use of a larvicide is indicated, provided conditions are such that there is no danger of poisoning cattle or other stock. Larvicides

${ }^{1}$ "Control of Malaria: Oiling as an Anti-mosquito Measure," U. S. Public Health Service 1919. 
usually act differently than oil, as they mix with the water and poison it, killing the latvae rapidly.

Larvieides also may be used, with the same proviso mentioned above, to treat large wind-swept pools, where the oil film is blown off to one side, before it has time to kill the larvae. They have been used successfully in unpastured swamp lands, in fire-barrels, catch-basins, etc.

\section{THE PANAMA LARVACIDE}

LePrince ${ }^{1}$ summarizes the constituents, method of manufacture and application of the Panama larvicide-one of the most popular-as follows:

"One hundred and fifty gallons of erude carbolic acid, containing not less than 15 per cent of phenols, are heated in an iron tank having a

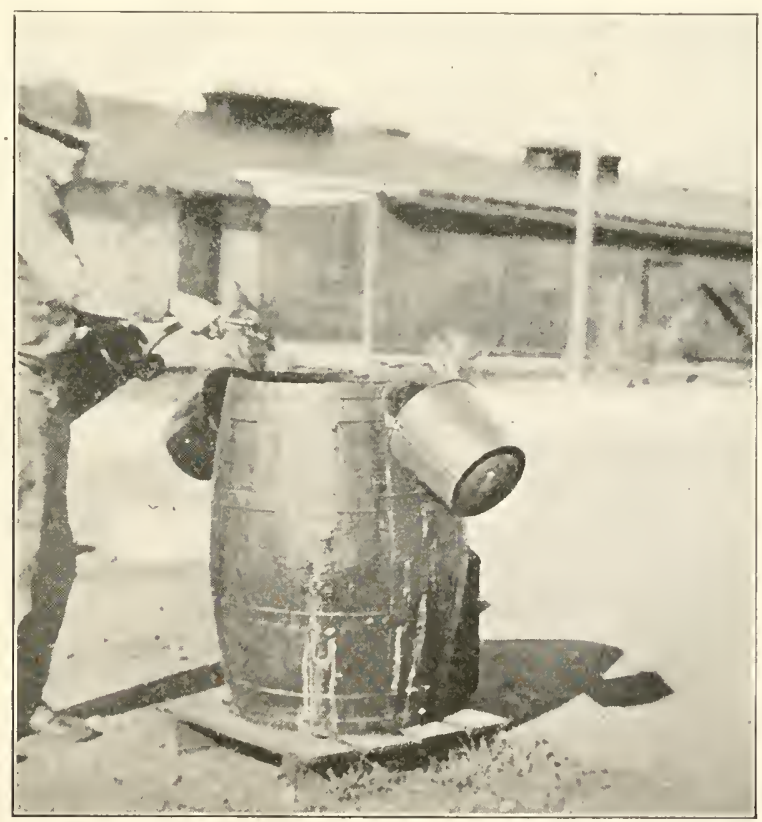

Fig. 109.- Treating a fire-barrel with the Panama larvicide.

steam coil with steam at 50 pounds pressure; 200 pounds of finely crushed and sifted common rosin are dissolved in the boiling acid, and then 30 pounds of caustic soda, dissolved in 6 gallons of water, are added. There is a mechanical stirring-rod attached to the mixing 
tank. The product is ready in a few minutes, yielding about $3 \frac{1}{2}$ barrels. As a mosquito larvicide, it is used by spraying an aqueous emulsion ( 1 part of larvicide to 5 of water) over the surface to be treated and along the margins of pools and ponds or other mosquito-breeding places, so that the resultant dilution of the larvicide has a thin, milky opalescence, representing approximately a dilution of 1 to 5,000 . A 1 to 1,000 dilution kills the larvae more rapidly, and was used for destruction of larvae in overflowing pools, etc., and where the use of oil was not practicable."

This mixture, LePrince reports, in addition to being a good larvicide and a good disinfectant, also proved to be very useful in destroying algae. He also found it very useful for thinning down heavy oil.

\section{OTHER LARVICIDAL SUBSTANCES}

Niter cake is a by-product of the manufacture of fertilizer, the active principle of it being free sulphuric acid. It has been used successfully for fire-barrels, 3 or 4 pounds of it being dropped into each barrel. It has not proven altogether satisfactory for pools, catch-basins, etc., as, it is believed, the alkalinity of the soil often neutralizes much of the acid. As niter cake, where it is available at all, can generally be obtained gratis, it may be used profitably in artificial containers, provided its poisonous properties do not make it objectionable.

Creosote has been used successfully on a small scale, parallel with the Panama, mixture, as a substitute for oil. It is, of course, open to the same objections regarding its poisonous properties as the Panama mixture. It is said to be particularly useful in protecting the edges of ponds and streams and in places where heavy verdure interferes with oil spraying. Fish in a flowing stream or in a large body of water are not injured by spraying the margins with creosote, it is reported.

Water gas tar, a by-product of the manufacture of gas, containing phenol, creosote and other larvicidal substances, has also been reported as a satisfactory substitute for oil. It is applied similarly to oil. It is said to make a very effective mixture with kerosene or with kerosene and fuel oil. The proportions recommended by Bishop ${ }^{1}$ are: 1 gallon tar to 5 gallons kerosene, and 1 gallon tar to 2 gallons fuel oil and 5 gallons kerosene. He states

${ }^{1}$ Transactions of the First Annual Conference of Sanitary Engineers, U. S. Public Health Service, 1919. 
that this mixture does not blow off to one side of a pool so readily as does the film of oil alone. Water gas tar can generally be obtained at a nominal cost from any water gas manufacturing plant.

Paris green, diluted with a large proportion of inert dust and sown on the breeding-place, much as grain is sown, is reported by Barber and Hayne ${ }^{1}$ to be a satisfactory larvicide for Anopheles larvac. It is, however, useless for other kinds of larvae, since they do not feed on the surface. It is reported that 10 cubic centimeters of Paris green will suffice for at least 1,000 square feet of water surface. One part of Paris green to 100 parts of some inert dust, such as road dust, seems to be a favorable mixture. Barber and Hayne report that the minute quantities of Paris green used appear to have no effect upon top minnows or other fish. They suggest, however, that the sower of the poison always keep to the windward side of the dust cloud.

\section{THE SPRAYER}

The usual-and, for general purposes, the best-method of applying oil to quiet water surfaces is by means of a spray-can, which consists essentially of a container, a pump and a spray nozzle at the end of a short rubber tube. The type which seems to have proven most satisfactory for all-around anti-mosquito work is what is known as the Panama knapsack sprayer. This sprayer holds 5 gallons of oil and fits on the back like a knapsack, the pump being worked over one shoulder and the spray tube being directed by the opposite hand.

This sprayer will distribute the oil satisfactorily to a distance of 20 to 30 feet from the operator-a valuable consideration in swampy or bushy areas. Another advantage is the fact that the opening of the nozzle can be adjusted, so that heavier oils than those ordinarily used may be employed. The weight is so distributed that the operator should not easily become fatigued. The fact that in walking over rough ground or through bushes, the operator may have both hands free is also important.

Occasionally, men who oil continuously for several days develop a sore back, caused by leakage of oil from the spray-can. This leakage can generally be prevented by using care in not filling the can too full and by replacing any damaged washers with good ones.

'Public Health Reports, Dec. 9, 1921. 
Several other types of sprayers are also in use. There are various styles of pumps adapted to use on barrels, ete; the.barrel
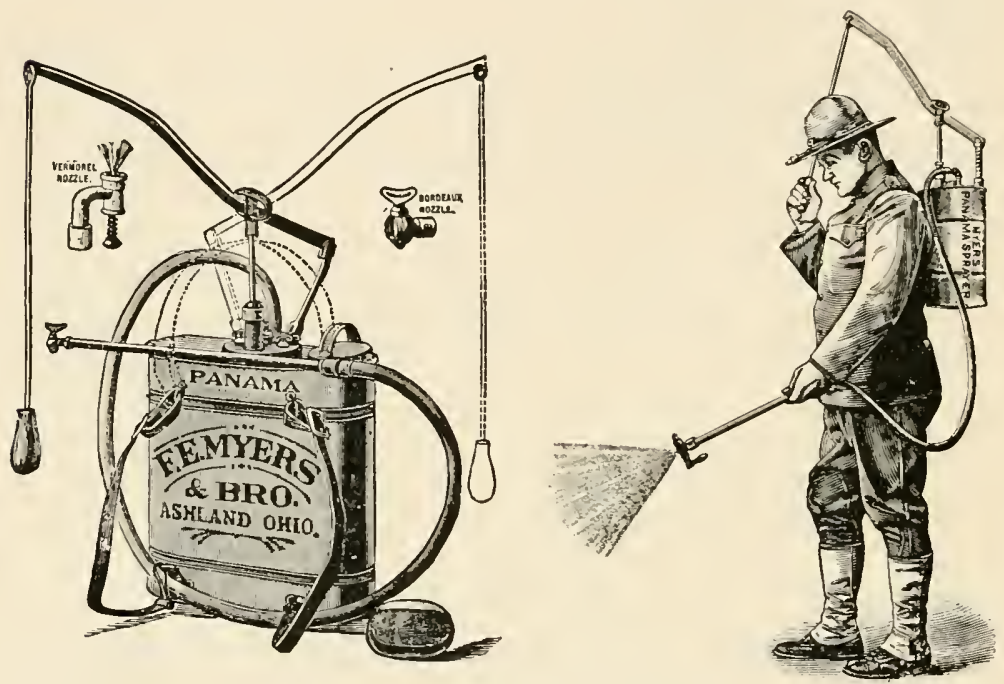

FIG. 110.-The knapsack sprayer.

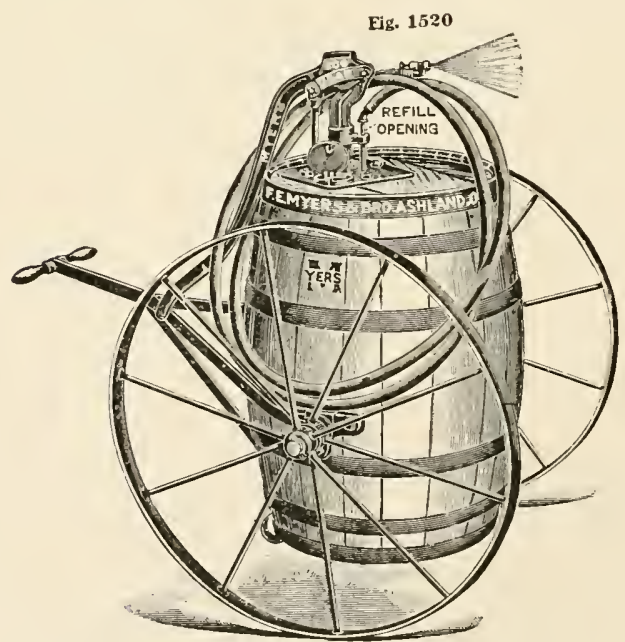

Fig. 111.-Barrel sprayer mounted on a cart.

may be mounted on a barrel eart or, where conditions will permit, on a truck or wagon or on a boat. Considerable pressure may 
be developed with some of these pumps, so that a stream of oil may be thrown 50 feet or more.

While such spray-pumps are very useful for oiling parts of ponds, lakes, ete., or edges of rivers and strcams or pools in open, accessible territory, they lack the portability of the knapsack sprayer and usually are of but little value in swamp work or in areas where the terrain is rough or timbered.

For limited areas and for use about homes, etc, the oil may be distributed by means of a garden watering-pot or a small insecticide sprayer. An oil-soaked broom may be stirred into many small pools with good effect.

\section{DRIP CANS}

For flowing ditches or streams, "drip-cans" have proven very satisfactory. These may be adapted to either continuous or intermittent application, as the case may recuire.

Drip-cans consist essentially of a receptacle for oil, arranged in such a mamner that a small quantity of the fluid drips from it into the water. This is wafted along by the current and bathes both banks, also, if the stream is in good condition - that is, free from obstructions and vegetationcovering pools and backwaters, where breeding is most likely to take place.

Drip-cans should be suspended three or four feet above the stream. If heavy oil is used, this elevation may profitably be increased, since the impact of the drops of oil on the water breaks them up and accelerates formation of the film. The precaution

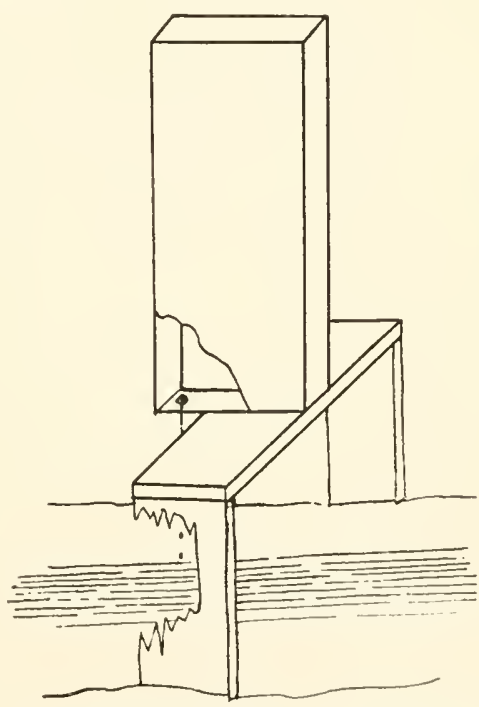

Fig. 112.- Sketch of easily-made drip-ean. should be taken of securing the drip-can in such manner that it will not be swept away by high water.

In making the drip-can, the outlet ordinarily should be placed an inch or so from the bottom of the can, so that any settleable solids in the oil will not cover up the hole. The outlet should be 
large enough to allow a sufficient number of drops to fall to form and maintain the film, and no more, it being borne in mind that the drip will decrease at night and on cool, cloudy days and increase on hot, sunny days. Sometimes, it has been found that a more even flow is obtained by introducing a short, soft wick into the outlet.

"A crude, but cheap and easily made, drip-can," says LePrince, ${ }^{1}$ "consists of a 5-gallon can, such as is used for shipping illuminating oil.

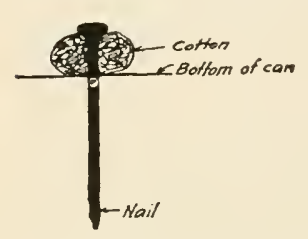

F1 G. 113 .-Detail of drip-regulating device.

A hole is made in its bottom with a 2 or 3 -inch lound nail. A wad of loose cotton is wrapped around the nail just below its head. The nail is then pushed through the hole on the inside of the can, and . . oil is put in the can, which is suspended or placed on a stand over the ditch. By pulling the point of the nail downwards and gently pushing it upward, the flow of oil may be decreased or increased, as desired."

Frequently, a 5-gallon can, having a metal discharge tap, is used. The tap can generally be adjusted to give within a few drops of the number desired to be discharged per minute.

\section{USE OF DRIP-CANS}

The quantity of oil that should be allowed to drip out depends upon the spread of the oil, the size and alignment of the stream, its grade and the absence or presence of obstructions in it. LePrince $^{1}$ suggests from 10 to 20 drops of oil a minute for water surfaces 1 foot wide. He continues:

"For economical control, a trial should be made at each ditch or stream where a drip-can is used to determine the desired rate of flow. The drip-can should be regulated accordingly. In many cases, the drip need be operated continuously for only 1 or 2 days of each week. With larger streams, it may be found necessary to operate the drip continuously, day and night. On long streams or ditches, it is at times necessary to use several drip-cans. They are then so located that the next drip-can is installed approximately at the point where the effect of the drip at the source disappears.

"Coutinuous dry weather may make it become necessary to discontinue the use of some drips or to change their location. At such seasons, pools will be left isolated at the sides of a stream and will have to be filled or separately treated with oil by other methods. When the stream

1 "Control of Malaria: Oiling as an Anti-mosquito Measure," U. S. Public Health Service, 1915. 
stops running, the use of drips is discontinued, and any water left in the stream-bed is oiled with a knapsack sprayer or watering-pot.

"With the best of eare, oil drips will elog, due to suspended solids or" heary constituents in the oil, and must be adjusted as often as necessary. The disadrantage of oil drip-cans is that they will not give satisfactory service without proper attention, may become clogged or be washed away by floods. Their use is generally more effective and economical than the chrect application of oil by sprinkler or knapsack sprayer for water in motion."

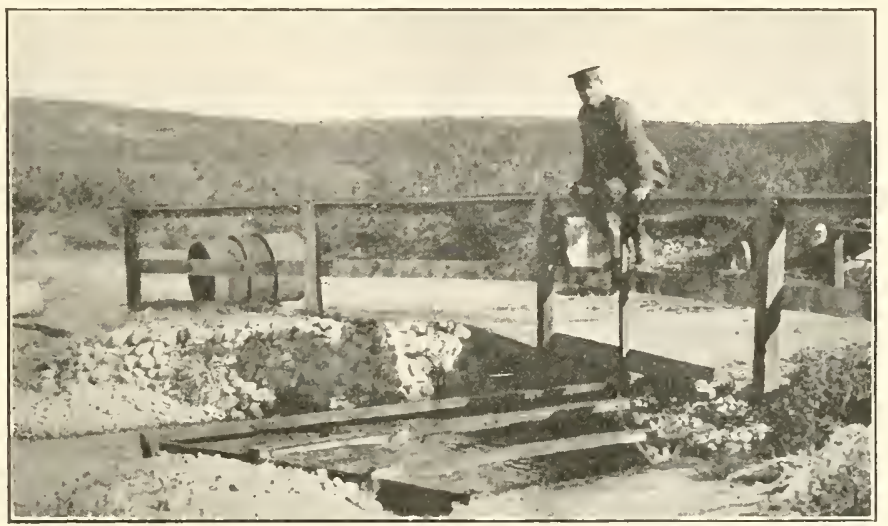

FIG. 114.-Utilizing a drip-can for a flowing stream. Note the drip-can fastened to the rail to the left of the officer.

\section{OTHER METHODS OF APPLYING OIL}

Occasionally, the moving water in a ditch or stream may be so little that use of a drip-can is not justified. In such cases, a small bundle of oil-soaked waste, placed at the source of the water will often prove very efficacious. This will give off a thin film for a week or so, after which it may be re-soaked in oil and used again. This same method may be used to control small springs, seepage water outcrops, ete.

A somewhat similar device, suited for use in similar situations, is a small bag or box of oil-soaked saw-dust.

Oil-soaked saw-dust has also been used successfully in treating ponds, lakes, swamps, etc., where there is considerable floatage or vegetation. In such cases, it is simply broadeast over the surface, somewhat after the fashion of sowing grain.

There are many other devices for applying oil to water-surfaces, several of which distribute the oil from above the water; others 
are submerged, the oil rising to the surface. It is the opinion of the writer, however, that usually equally as good work can be done with the devices alrearly described.

\section{FREQUENCY OF OILING}

The frequency with which oiling should take place depends upon several different factors. Ordinarily, one oiling a week or every 10 days is sufficient, and this was the basis upon which most of the oiling was done in the extra-cantonment work of the U. S. Public IIealth Service cluring the World War.

The resistance of larvae and pupae to oil varies with the different kinds of oil used and with the different genera of mosquitoes. The Anopheles succumb more easily than the Culex. Frequently, a good film of oil will kill virtually all the larvae in a pool in an hour or so. On the other hand, the writer has observed Culex still active in a cess-pool 2 days after it had been well oiled. The oil, in this ease, may have been prevented from forming a perfect film by the floating matter in the pool or by the gas bubbling to the surface.

Whatever the period necessary to kill the larvae and pupae may be, once they are dead, several days must elapse before a new breed ean reach the pupal stage. The exact time will, of course, depend upon the temperature and other factors. If the weather is very hot and, through early disintegration of the film, new eggs are deposited promptly, a second brood of larvae may appear within 3 or 4 days and, within a week, may reach the pupal stage. Again, if the weather be cold and cloudy the development of the new brood will be correspondingly delayed.

With the above considerations in mind, it has been suggested that oiling should be done by inspection-that is, that there should be no set times for oiling, which should be done only when it has been determined by careful inspection that oiling is necessary. However, in view of the obvious risks of this method arising from possible changes in weather conditions, possible incompetence or carelessness of inspectors, etc., the writer's experience has been that best results are obtained by regular weekly oiling of each place that requires it - that is, has not dried up or has not been treated effectually by some other method. If the project is a small one, all the oiling may be clone on 1 day of each week; if a large one, it may be necessary to have a gang to oil all the time, visiting each place once a week. 


\section{DISTRIBUTION OF OIL}

Where a large area is to be protected from mosquito breeding by means of oiling, it is obvious that some convenient means of transporting or distributing the oil must be worked out. In other words, there must be some system of getting the oil to the places where it is to be applied.

Even in a small town of from 5,000 to 10,000 inhabitants, the area in which operations must be conducted will cover several square miles. Usually, the places that will require oiling will be found seattered over all parts of this area. Obviously, the oiler cannot get his oil to all these places without some means of transportation.

It has been the experience of the writer that procurement of one or more light trucks, each earrying a barrel or two of oil and each barrel being equipped with a faucet, is the best solution of this problem for the average town. The driver of the truck should also, where practicable, be foreman of the oiling gang. Knowing the places which must be oiled, he ean disperse his men in such manner that he can easily keep each supplied with oil, putting in the intervening time in following up and inspecting the work. If the gang is a small one, or in ease of an emergeney, he may assist in the actual oiling.

In smaller towns, where the available funds will not justify employment of a truck for this purpose, a one-horse wagon, carrying a barrel of oil on the rear, will serve the purpose.

Where even this is not available, barrels of oil may be distributed at the principal breeding-places in such manner as to minimize the amount of walking required of the oiler. This method also was employed on a very large swamp project upon which the writer was engaged. At each distributing pointcarefully selected, so as to obviate as much "toting" of oil as possible-a rack was built, upon which 4 or 5 barrels of oil were left. A bung-borer and a faucet were also issued to the oiler, so that, when one barrel was exhausted, he could open another. When the supply got down to a barrel or so, the oiler would requisition more oil.

\section{STORAGE OF OIL}

Whenever possible, supplies of oil should be stored in isolated buildings, and if these buildings are fire-proof, so much the better. Laborers frequently using oil soon become careless with it, and 
every reasonable precaution should be taken to guard against fire. LePrince ${ }^{1}$ reeommends a $140^{\circ} \mathrm{F}$. flash-test oil, if the oil is to be stored near any valuable property.

LePrince ${ }^{1}$ continues:

"Oil stored in unsafe containers, as wooden barrels or improperly covered tanks near railroad tracks, is very apt to catch fire. Small quantities are usually shipped in wooden barrels and, if left exposed in the sun, leakage occurs and danger from fire is increased. Provision must be made for fire protection and precautions taken to aroid spilling on the ground at or near the place of storage. Sufficient sand or loose earth should be kept a vailable close to where the oil is stored for use in extinguishing a flame. Oil-storage houses and faucets of storage tanks or barrels should be kept locked when not actually being used. No smoking is to be allowed near them."

As indicated above, barrels of oil should not be stored nor left in any place where the sun ean beat down upon them, since, not only is the fire risk increased, but a very large quantity of oil is likely to be lost. The warmth of the sun thins the oil, and some of the barrels are almost eertain to leak. The anount of oil that may be lost in this manner is surprising.

In case it is found necessary to distribute barrels of oil at various places throughout the area of operations, care should be taken to place the racks in the shade or else to eover them over.

\section{COSTS OF OILING}

So many factors enter into the situation that it is almost impossible to give any rules to estimate the cost of oiling or even the amount of oil to be used in any projeet.

The weather is, perhaps, the most important factor in the ease. A given area may require twice or thrice the amount of oil and labor one year as another, depending on the amount of rain-fall and its distribution. Topography is also an important element, as is soil-type. Again, the conduct of the eampaign itself has an effect upon oiling; if fish control and drainage are pushed, less oiling will be required, and vice versa.

The following figures; taken from five different projeets with which the writer was conneeted, shows the wide fluctuations in amount of oiling required, costs of oil and costs of applying oil, even in places of approximately the same area:

1 "Control of Malaria: Oiling as an Anti-mosquito Measure," U. S. Public Health Service, 1915. 


\begin{tabular}{|c|c|c|c|c|c|c|c|c|}
\hline $\begin{array}{l}\text { Pro- } \\
\text { jeet }\end{array}$ & $\begin{array}{l}\text { Area in } \\
\text { square } \\
\text { miles }\end{array}$ & $\begin{array}{l}\text { Months } \\
\text { oiled }\end{array}$ & $\begin{array}{l}\text { Oil per } \\
\text { gallon }\end{array}$ & $\begin{array}{l}\text { Cost } \\
\text { of oil }\end{array}$ & $\begin{array}{l}\text { Applying } \\
\text { the oil; } \\
\text { bauling }\end{array}$ & $\begin{array}{l}\text { Total } \\
\text { cost for } \\
\text { season }\end{array}$ & $\begin{array}{l}\text { Cost per } \\
\text { square } \\
\text { mile per } \\
\text { season }\end{array}$ & $\begin{array}{l}\text { Cost per } \\
\text { square } \\
\text { mile per } \\
\text { month }\end{array}$ \\
\hline C $\ldots .$. & 4 & 5 & $\$ 0.03$ & 47.525 & 443.00 & 490.52 & $\$ 122.63$ & $\$ 24.53$ \\
\hline$N \ldots$. & 6 & 4 & 0.03 & 64.35 & 702.00 & 766.35 & 127.39 & 31.85 \\
\hline H. & 4 & 5 & 0.05 & 176.25 & 578.35 & 754.60 & 188.65 & 37.73 \\
\hline B... & 6 & 6 & 0.08 & 324.86 & $1,365.91$ & $1,690.77$ & $2 \$ 1.80$ & 46.96 \\
\hline $\mathrm{W}^{*} \ldots$. & 221,2 & 5.12 & 0.16 & $4,486.85$ & $6,425.30$ & $10,912.18$ & $4 \$ 1.56$ & 87.56 \\
\hline
\end{tabular}

* This project was mostly swamp work.

Wages on all the above-mentioned projects averaged around $\$ 2.50$ a day. Colored labor was employed principally on all the jobs. The heading "Applying the oil; hauling," also includes wages of foremen. 


\section{CHAP'TER IX}

\section{FISH CONTROL}

\section{ADVANTAGES AND LIMITATIONS}

There is no doubt that fish control, where it is applicable, is one of the cheapest and most satisfactory methods of fighting the mosquito. Once a natural breeding-place, such as a lake or stream, is stocked with the proper kind of fish, about the only

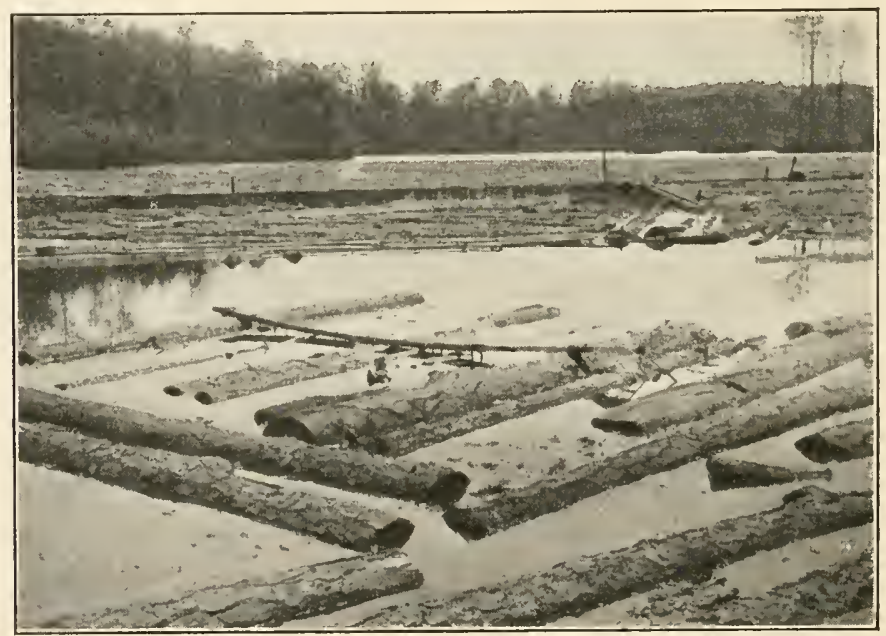

(Photo by E. B. Johnson, C. E.)

Fig. 115.-Perfect fish control at a $\log$ pond in Alabama.

work required to maintain their efficiency is occasional cleaning of its edges. In certain artificial brecling-places, such as fountains, underground cisterns, etc., even this is not required.

Even where such cleaning is necessary, it has been the writer's experience, however, that, in the long run, fish eontrol is often cheaper and easier than oiling or ditching. In some places, such as large, shallow ponds, water-filled clay-pits, ete., fish eontrol is about the only solution, since of ten it is not possible to drain such places, while weekly oiling of large water-surfaces quickly runs 
up into money, even assuning that such a procedure is practicable. Again, in the writer's opinion, there is no other method so effective for controlling breecling in shallow wells, some kinds of cisterms, low culverts that hold water, ete. It is also believed that fish control, either by itself or in conjunction with ditching, is the best and cheapest method of control for flowing streams and ditches, marshes, swamps and many other types of mosquito breeding-place.

Fish control has its limitations, however. It is not applicable usually to rain-water pools, since they soon dry up and the fish

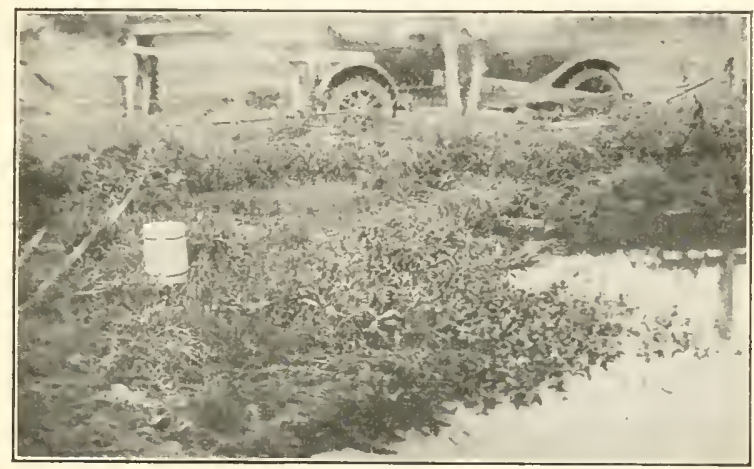

(Photo by E. H. Wagoon, C. E.)

FIs. 116.- The bucket indicates the water's edge. The water area concealed by the regetation affords an ideal breeding-place, as it is inaccessible to the larva eating fish, which keep the rest of the pond free from larvae.

would die. Nor, as already intimated, is it feasible to stock a breeding-place with fish and depend upon their unaided efforts to eliminate mosquito breeding. On the contrary, they will have to be helped from time to time.

\section{HOW FISH DESTROY LARVAE}

Some interesting observations on the nanner in which fish detect and destroy mosquito larvae and on the marvelous selfprotective instincts manifested by the larvae are recorded by Hildebrand, ${ }^{1}$ who says, in speaking of Gambusia affinis:

"I took several large Anopheles larvae from dense vegetation and placed them in open water among top minnows. With one larva was a

I "Fishes in Relation to Mosquito Control in Ponds," U. S. Bureau of Fisheries, 1919 
small piece of bark. The larva hovered over this piece of bark, and the fish did not detect it. When it was placed in open water, without the least protection, the fish swam around it, even 'nosed' it, while the larva lay perfectly motionless. At last, a rather small minnow seized it and swallowed it. Placed another larva in open water among fish. This one too lay perfectly still, drifting like a small stick, while fish swam all

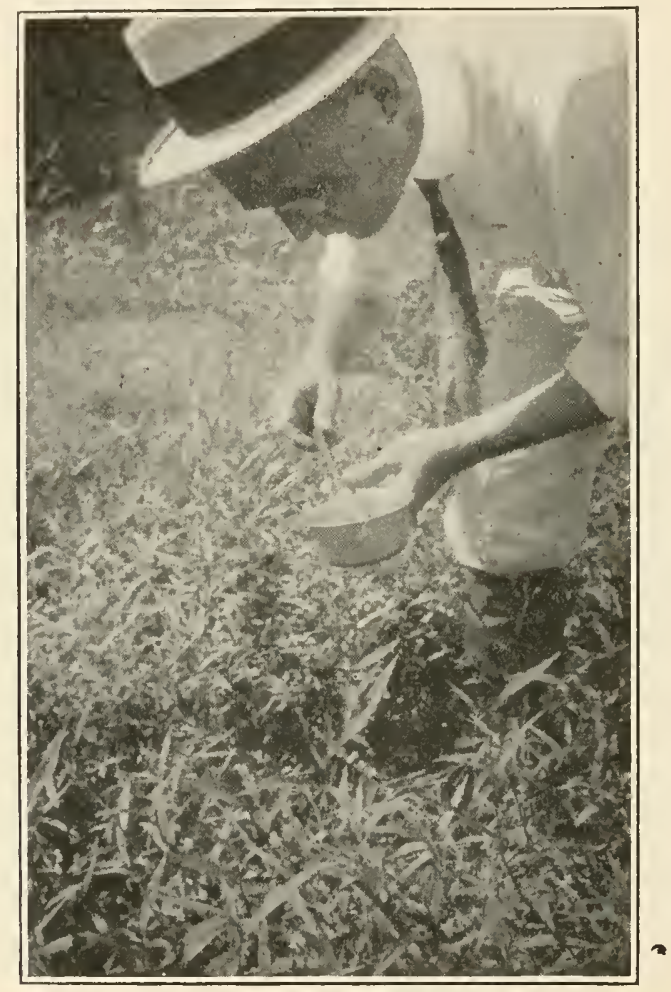

(Photo by E. H. Magoon, C. E.)

FIG. 117.-Dipping up larvae concealed by dense vegetation.

about it, nosing it a time or two, but apparently not detecting that it was alive and something to eat. Finally, it drifted near a tuft of grass and, with a surprisingly quick motion, it swam into the vegetation. It was removed and placed in open water. There it lay motionless for about 5 minutes, when at last it was snapped up by an under-sized minnow.

"These feeding experiments, which were repeated many times, demonstrated that the protective instinct in mosquito larvae is highly developed. It was shown many times that the only protection an Anopheles larva has from fish in open water is inactivity. When the larva thus 
drifts along, fish evidently mistake it for an inanimate object. The slightest movement, however, on the part of the wriggler apparently never goes unseen, and it is instantly seized and clevoured by the fish. It often happens that a mosquito harra placed in open water drift. toward places of protection before it is discovered by the minnows, and, if no fish are very near, it moves toward it with a remarkable rate of speed and quickly places itself orer the object."

\section{THE TOP MINNOW (Crambusia affinis)}

The top mimnow, Gambusia affinis Baird and Gerard, so far as is known at present, is probably the best fish for general antimosquito work, within its habitat, of any of the North American pisces. It is known on the Atlantic from Delaware to Mexico and in the Mississippi Valley from Illinois to Louisiana. It inhabits both fresh and brackish water, while an occasional

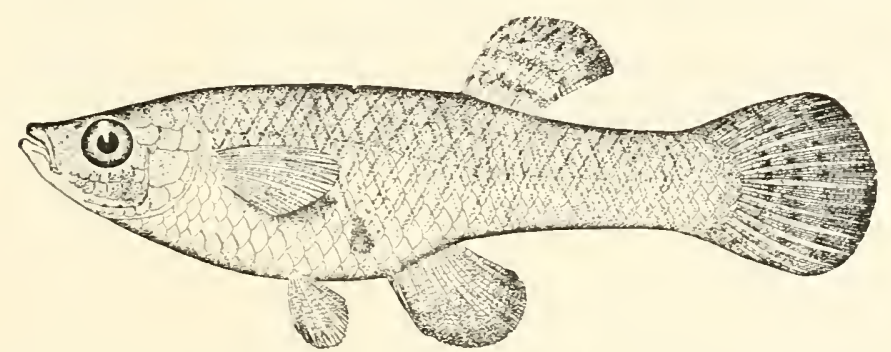

FIG. 118. Gambusia affinis, female. (After $L$. S. Burcau of Fisheries.)

straggler is taken in strictly salt water. This fish is viviparousthat is, it gives birth to its young. It, therefore, requires no special environment for depositing and hatching its eggs.

The female, which is larger than the male, rarely measures more than 40 to 45 millimeters in length, although specimens have been taken measuring as much as 65 millimeters in length. The average length of the adult male is 25 millimeters. The young, at the time of birth, are from 8 to 10 millimeters in length. They grow rapidly at first, but several months elapse before they reach full size.

The sexes in the young cannot be distinguished externally, but the anal fin in the male gradually becomes modified into a long, sharp process which in the sexually mature fish serves as an intromittent organ. This process is the characteristic identification mark of the adult male Cambusia. Cravid female Gambusia may be identified by a black spot on each side of the 
abdomen, above and in front of the vent. These spots increase in size and, wher they join on the ventral surface, the period of parturition is near.

The young are extruded singly or in twos and threes; the labor may last from an hour to a day. The proportion of males born to females appears to be about 1 to 8 or 9 . As many as six broods a year may be born, each brood ranging from 2 or 3 to 50 or 60 . A peculiar fact in connection with the fertilization of the eggs is that, apparently, one copulation is sufficient to produce several broods.

This little fish is one of the hardiest known. It will live equally well in salt, fresh or stagnant water. In foul or stagnant

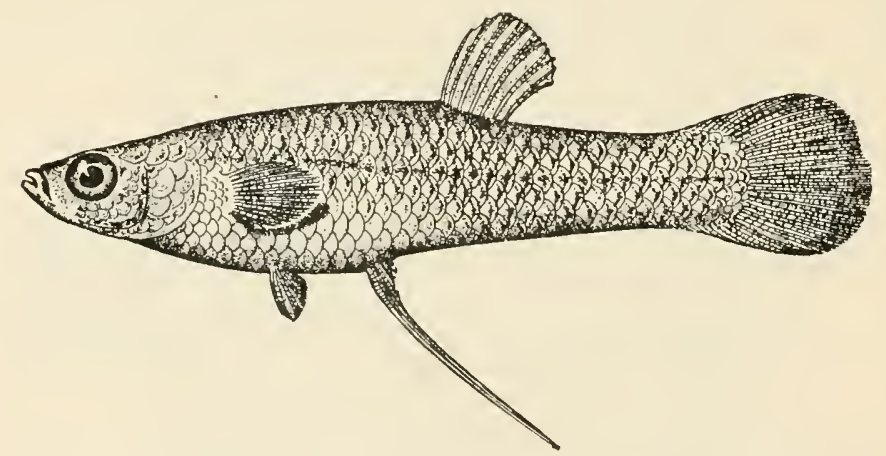

Fig. 119.-Gambusia affinis, male. (After U. S. Burrau of Fisherirs.)

water, it has been observed to stick its mouth above the surface from time to time, making a sucking noise. The object of this action, it is believed, is to get more oxygen. Its habit of swimming near the surface is correlated with the fact that it secks most of its food near the surface. This habit is what gives the fish its value for anti-mosquito work.

Gambusia affinis is a very voracious feeder. One mediumsized female has been observed to eat as many as 165 mosquito larvae in a single dtay. The young begin feeding a few hours after they are born, and even at this age, the young fish will swallow a larva half as big as itself.

\section{THE BARRED KILLIFISH (Fundulus heteroclitus)}

The barred killifish, also known as the mud-fish, pike-minnow and salt-water minnow, is probably one of the most effective 
of the fish enenies of the salt marsh mosquito in the north, beyond the range of Gambusia.

This fish attains a length of from 4 to 6 inches, and is characterized by banded markings, rounded fins, a short head and obtuse snout, a projecting lower jaw, a convex tail and a very flat area between the eyes. While the killifish has the faculty of changing its color somewhat to approach its prey or to escape

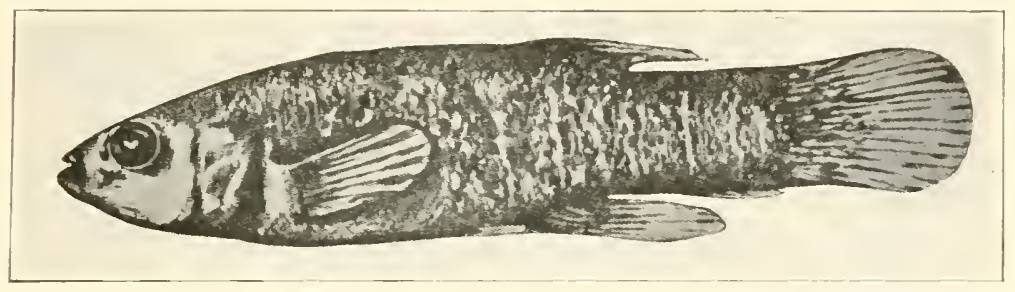

Fig. 120.-Fundulus heteroclitus, female.

an enemy, the general color of the female is olivaceous on top with a lighter belly, and the male is darkish green on top with a yellowish belly. Both male and female generally have numerous spots and markings.

This fish is oviparous. The eggs are very resistant and, as soon as they are laid, they sink to the bottom in the mud, which

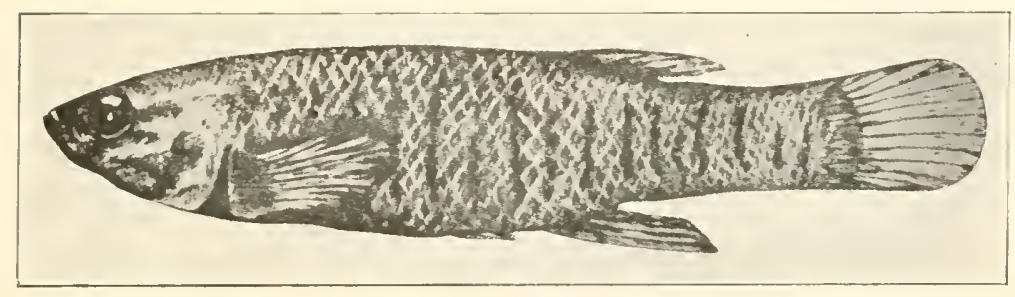

FIG. 121.-Eundulus heteroclitus, male.

protects them. They hatch out in about 21 days of warm weather. The young fish hatches with a yolk sac, which soon disappears, after which it feeds on minute plankton.

Many of the eggs are eaten by its own kind. Other enemies of the killifish are weakfish, dogfish, smelt, striped bass, etc. Man frequently uses the young as bait.

The spring migration begins as soon as the weather becomes warm, and gravid females are found shortly thereafter. The 
spawning season lasts until late summer, the yearlings starting after the elder ones finish. When cold weather comes, the killifish return to deep water.

Young killifish only a few months old have been known to devour large numbers of mosquito larvac. Adults have devoured as many as 25 larvae in succession. Stomach examinations
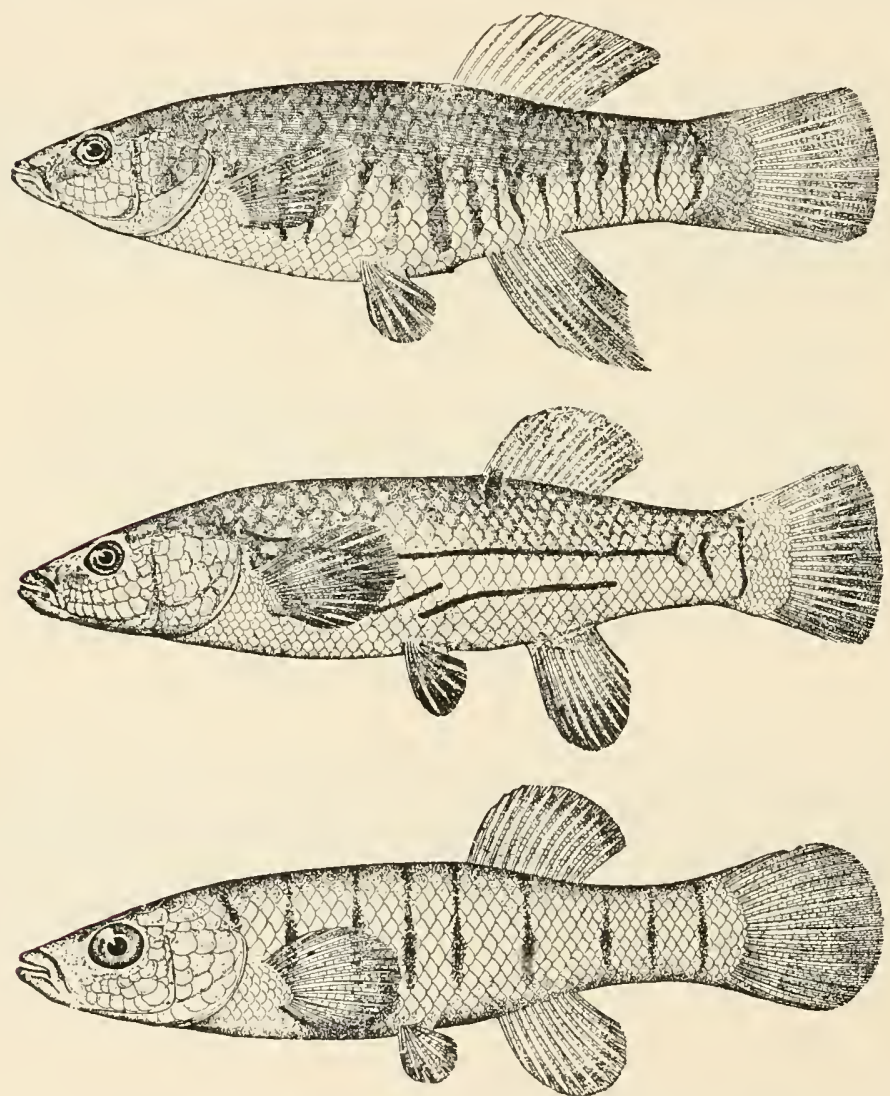

FIG. 122.-Fundulus majalis; male above, female between and young below. (From Jordan and Evermann, Bull. 47, U. S. National Museum.)

have also revealed adult mosquitoes. This killifish is also an important enemy of the green-headed fly.

Like Gambusia, Fundulus heteroclitus is equally at home in salt, fresh or stagnant water. It is found in the most insignificant pools and ditches, and has been known to push its way over places where there is barely enough water to cover its back. 
The ease with which $F$. heteroclitus may be artificially fertilized and the hardihood of the young embryos make the stocking of pools and streams with this fish an easy and satisfactory method of mosquito control.

THE STRIPED KILLIFISH (Fundulus majalis)

This killifish, which may be distinguished from $F$. heteroclitus by its color, the fact that its tail-fin is not so convex and that its average length is an inch or more greater, is also considered as having some value in anti-mosquito work.

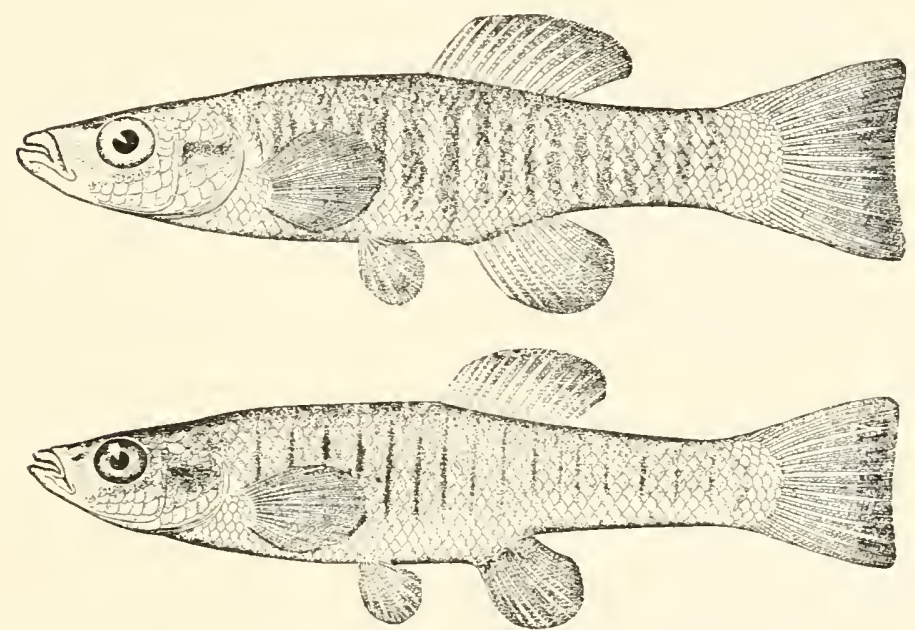

FIG. 123.-Fundulus diaphanous; male above and female below. (From Jordan and Evermann, Bull. 47. (.. S. National Huseum.)

Males of this species show vertical markings on the sides, while the females have more or less horizontal markings on the sides.

This fish enters the marshes with the tide and goes out with it. Should it get cut off from the ocean, it will, according to Mast, ${ }^{1}$ travel overland toward the sea by flopping itself along. Mast also shows that this fish seems to keep its sense of direction while traveling overland, which he attributes to internal factors.

THE FRESH-WATER KILLY (Fundulus diaphanous)

This species differs from both of the preceding in that its tail-fin is not rounded at all, but is squarely cut off. The females

1 The Behavior of Fundulus with Especial Reference to Overland Escape from Tide-pools, Journal of Animal Behavior, 1915. 
are olivaceous with pale fins and with sides markerl with 15 to 20 dark, vertical bands. The males are a pale, olive color, and have about the same number of white vertical bands on their sides.

While this killifish is more or less similar to those previously described in its other habits, it sticks more closely to fresh water than do they, and indeed is rarely found in salt or brackish water.

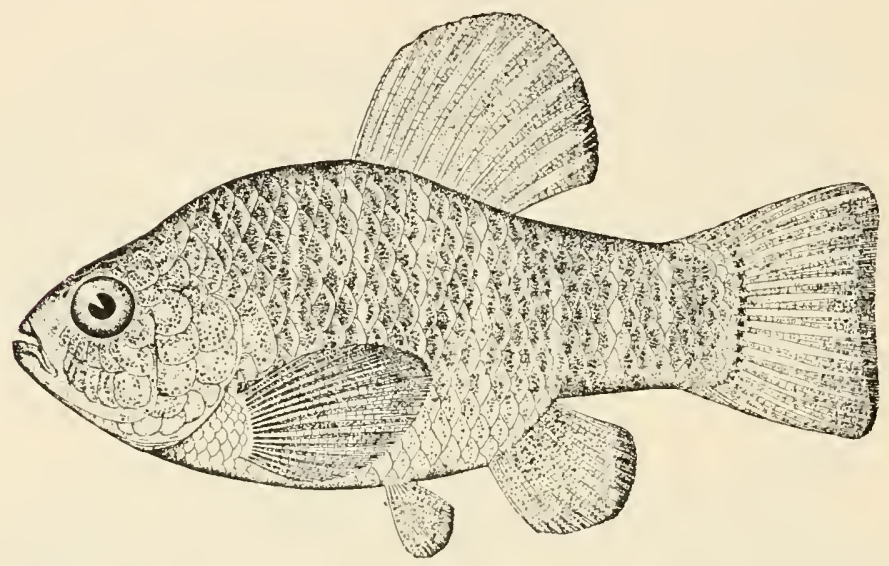

Fuc 124.-Cyprinodon varicgatus, male. (From U. S. Burcau of Fisheries.)

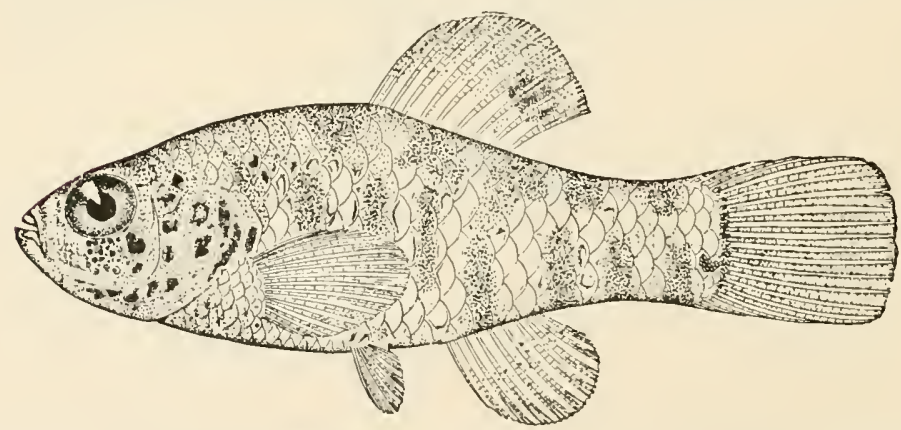

FIG. 125.-Cyprinodon varicgatus, young. (From U. S. Burcau of Fisheries.)

THE VARIEGATED MINNOW (Cyprinodon varicgatus)

This minnow, which occurs on the Atlantic Coast from Cape Cod to the Rio Grande, ascending streams and inhabiting brackish water's, is believed to be of some value in anti-mosquito work, although it subsists mainly upon vegetable matter.

The variegated minnow, also known as the sheeps-hearl minnow, 
is very prolific and very active. It is oviparous, the females spawning virtually the whole summer. The eggs are somewhat heavier than salt water. This little fish is oceasionally found in strictly salt water, and foul water does not seem to inconvenience it.

Adult females average about 45 millimeters in length; males about 48 millimeters. Newly-hatehed young are about 4 millimeters long.

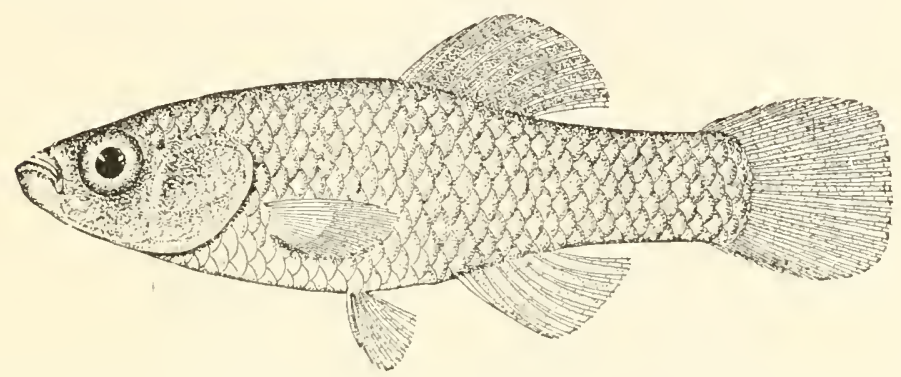

FIG. 126.-Lucania parvia. (From Jordan and Evermann, Bull. 47, U. S. National Museum.)

\section{THE RAIN-WATER FISH (Lucamia parvia)}

This fish, which ranges from $1 \frac{1}{2}$ to 2 inches in length, is not a top feeder, but has been considered as of some value in antimosquito work. The males are olive or light-brown, the edges of the scales being darkish; the females have light, olive fins, with no dark markings.

\section{THE SPOTTED TOP MINNOW (Fundulus notatus)}

The spotted top minnow is found in the Mississippi Valley from Michigan to Louisiana and regions adjacent thereto. It occurs only in fresh water. While its value in anti-mosquito work is not fully understood, it appears to be worthy of further investigation.

\section{THE STAR-HEADED MINNOW (Fundulus notii)}

This little fish closely resembles in habits and appearance the spotted top minnow. Its habitat, however, does not appear to be large, sinee, according to Hildebrand, it seems to be confined to the Atlantic slope from North Carolina to Florida. The star-headed minnow occurs in fresh water only. 


\section{OTHER FISHES}

Several species of sun-fishes have been mentioned by different writers in connection with anti-mosquito work, but the observations of Hildebrand indicate that they are of cloubtful value.

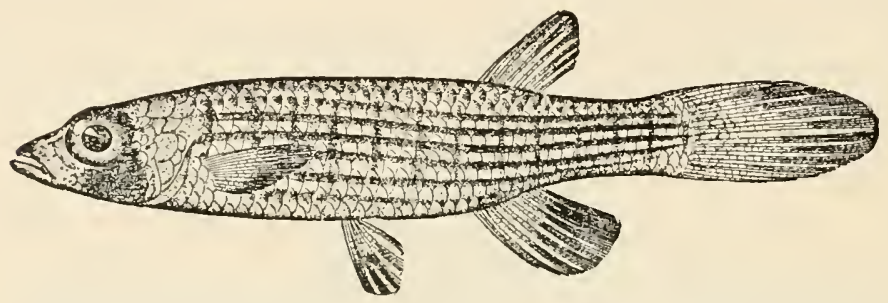

FIG. 127.-Fundulus notii. (From U. S. Bureau of Fisheries.)

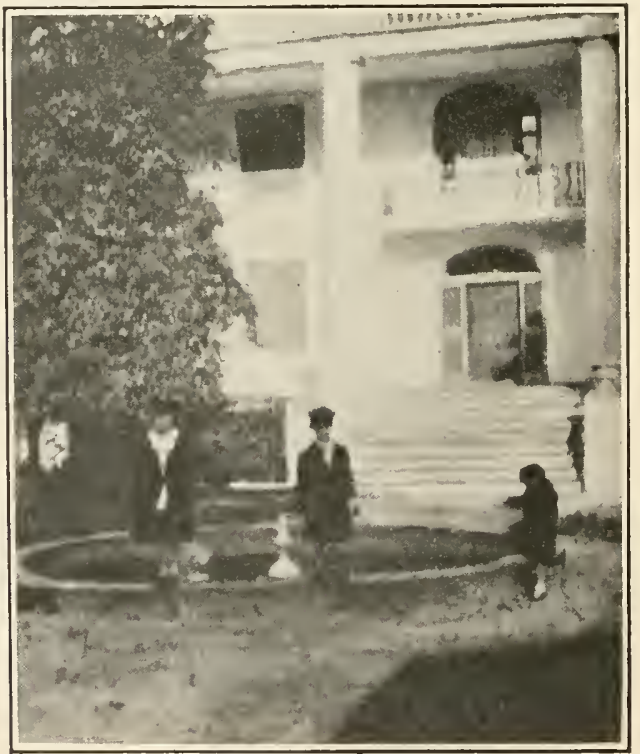

Fig. 128.--Fountain protected by gold-fish.

Hildebrand ${ }^{1}$ considers gold-fish useful in confinement, although probably of but little value in large bodies of water. Fountains stocked with gold-fish and kept fairly clear of debris and vegetation will rarely show any breeding.

1 "Fishes in Relation to Mosquito Control in Ponds," U. S. Bureau of Fisheries, 1919. 
Chidester ${ }^{1}$ has compiled the following list of other fishes classed as enemies of the mosquito: Heterandria formosa, Abramis chrysolenca, Mollinesia latipennia, Girardinus poeciloides, $G$. caudimaculatus, IIaptochilus, Lucius americanus, Cyprinodon calaritanus.

\section{PROCEDURE IN FISH CONTROL}

The first procedure in connection with the use of fish as an anti-mosquito measure is to look over the local fishes and ascertain what kinds of larva-destroying fishes there are and which will be most suitable for the work in land. Important considerations in this connection are the species of mosquito-destroying fishes most numerous in the vicinity and the character of the places in which they are to be used.

In general, it may be said Gambusia affinis should be used wherever it may be found, since for all-around work it seems to be superior to any other. Indeed, Gambusia is frequently imported to regions outside of its natural range on account of its superiority to the native fishes.

When these matters have been determined, the next step is to arrange for an aquarium or "hatchery," so that an abundant supply of fishes will always be at hand for stocking purposes. Crenerally, a small, shallow pond can be found for the purpose. The pond should not be so big, however, that eatching will be difficult. Nor should it, as a rule, be located in the bed of a stream that is subject to floods, since, in this case, it is possible that a storm will disperse all the fish. Care should also be used to obtain an aquarium that is free from bass and other game fish which feed on Gambusia and other minnows.

On aceount of the cannibalistic habits of Gambusia affinis, as well as some of the other larva-eating fishes above-mentioned, Hildebrand $^{2}$ suggests that one corner of the aquarium be sereened off with a 3,16 inch wire netting to serve as a refuge for the young.

Steps should also be taken to prevent local fishermen from helping themselves to the minnows or other small fish for use as bait. It has been found that a little publicity, explaining the

1"A Biological Study of the More Important of the Fish Enemies of the Salt Marsh Mosquito," New Jersey Agricultural Experiment Stations, Bulletin 300, 1916.

2 "Fishes in" Relation to Mosquito Control in Ponds," U. S. Bureau of Fisheries, 1919. 
purpose of the work and perhaps a notice or two put up at the aquarium, will generally prevent any considerable losses in this way.

Fish for stocking the aquarium, if it is not alrearly stocked with them, may generally be obtained in abundance from nearby streams or swamps. In this conncetion, care should be taken not to draw too many from one source, so as to leave such source unprotected against mosquitoes.

The number of fish that should be placed in the aquarium will vary with the size of the aquarium, the requirements of the fishcontrol work and the abundance of fish in the vicinity. It should be borne in mind that these fish, particularly Gambusia, multiply with great rapidity, especially if those installed in the aquarium include a number of pregnant females.

Should the aquarium be small and the number of fish therein very large, it will be necessary to feed the fish. Minced meats or fish, bread, corn-meal and similar substances are considered suitable for this purpose.

\section{NUMBER OF FISH REQUIRED}

When the aquarium has once been established, the work of distributing the fish among the places where they are necded may begin.

The first question that arises in this connection is: How many fish are necessary in a pond, stream or other breeding-place in order to prevent mosquito production? Hildebrand ${ }^{1}$ answers this question as follows:

"Data upon which a definite answer could be based are extremely" difficult to obtain, for there are scarcely two ponds which offer identical conditions. The size of the pond of course must be considered; whether or not it is subject to wave action is of importance; the presence or absence of vegetation is very important; and the presence or absence of enemies of Gambusia (or other larva-eating fish) must not be overlooked. Even then, we can only make a guess, for Anopheline mosquito larvae, at least, breed much more prolifically in some ponds than they do in others for reasons not understood. . . .

"It has been shown. . . that a small number of nimnows freed badly infested pools of mosquito larvae in a short time; also that they destroyed the mosquito larvae in ponds and kept the ponds free of the

1 "Fishes in Relation to Mosquito Control in Ponds," U. S. Bureau of Fisheries, 1919. 
aquatic stages of the mosquito, unless protection was provided by plants and debris. From the knowledge which has thus been gained, we may conclude that, if a pond furnishes little or no protection for mosquito larvae, a small number of top minnows is sufficient, but, if it does furnish protection, a much larger number is desirable. Anti-mosquito work, however, may be started with a very small number of Gambusia, for this fish multiplies rapidly. There appears to be no danger of overstocking, as observations indicate that the more fish a pond supports the more certain are the practical results."

Precisely similar considerations apply to control of streams and ditches, swamps and marshes.

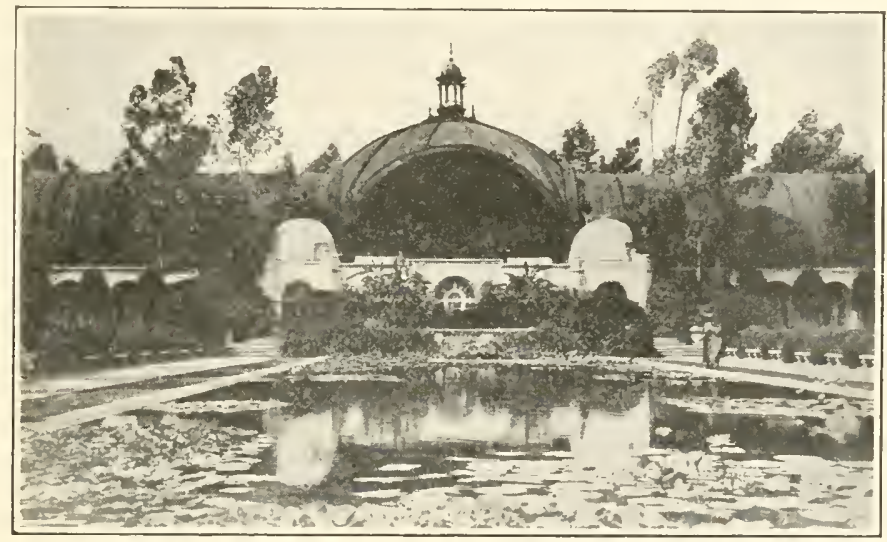

FIG. 129.-A pool in which fish control cannot be entirely effective on account of regetation.

Underground concrete or brick cisterns should be stocked with anywhere from 5 to 50 fish, depending upon the degree of infestation, size of the cistern and other conditions. Fish, particularly Gambusia, cannot be employed in metallic, surface cisterns, since the water gets too hot and kills the fish.

Low-lying eulverts that hold water for any considerable time should also be stocked liberally with the fish. The writer has found this to be the cheapest way of handling such culverts.

Shallow wells, where they are abundant, are frequently troublesome breeding-places. The writer has found that satisfactory results follow, if from three to five male Gambusia are lowered into each of them. Such wells should be inspected frequently, however, as it often happens that users of the wells haul out the fish with the water and, not knowing their purpose, do not put 
them back. When the fish are let alone, however, they do satisfactory work.

\section{DISTRIBUTING THE FISH}

In anti-mosquito work in which fish are used, best results are obtained by making some one certain individual responsible for this phase of the work. This individual should be in charge of the collection, care and distribution of the fish and of the pond, marsh and stream cleaning essential for their advantageous use.

Requests for fish made by inspectors or other persons should be at once turned over to the fish control foreman for action. In order to speed up distribution of the fish, it is essential that he have necessary facilities for his work. Among these may be mentioned nets for eatching the fish, suitable receptacles in which to transport them and means of transportation.

A very useful net for collecting top ninnows is a small bobbinet seine. A net about 12 feet long by 3 feet deep is a good size. Such a net, if made of good material, is light and durable, and it can be easily and quickly handled. A dip-net, also made of bobbinet, may be used to advantage in places where there are so many roots or' so much vegetation that a seine cannot be operated.

Almost any kind of a receptacle for the fish will do, but for ordinary use in an anti-mosquito campaign, the writer suggests a milk can, with a cover of gauze or burlap substituted for the metal cover. When about half-full of water, such a can will hold several hundred fish very comfortably and but little water will splash out in ordinary travel.

Transportation may be either by automobile, truck or wagon. For ordinary use in a small town, the writer suggests a light roadster with the turtle-box removed or a buggy or buckboard. Such a vehicle will comfortably carry two cans of fish on the back. On small jobs, it is likely that the same vehicle used for carrying oil may be utilized on certain days for hauling fish.

\section{NECESSITY OF AIDING THE FISH}

Throughout the South, even in inland areas, it probably will be found that most streams, ponds, lakes, swamps and similar natural breeding-places already are stocked with Gambusia or other larva-destroying fish. In such cases, very little new stocking will be necessary, but the fish will have to be aided, if best results are to be obtained. 
This aid must take the form of removing or otherwise eliminating vegetation and other floating matter, which serve to conceal the larvae from the fishes and to prevent the fishes from reaching

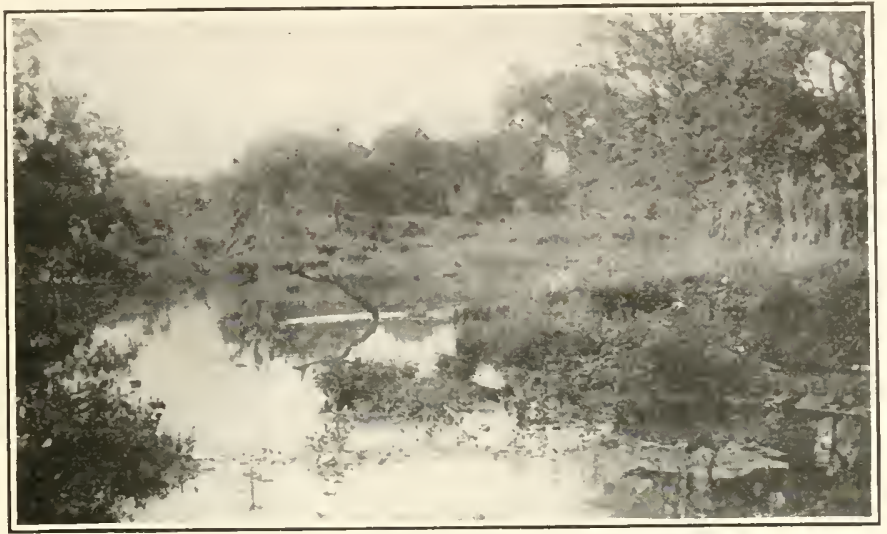

FIG. 130.-This formidable looking mosquito breeding-place offered quite a problem. To have cleaned all the circumference, so as to make fish control practicable, would have cost a lot of money. Instead, it was drained into a large abandoned gravel pit nearby, the edges of which were already clean. In this way, complete and permanent fish control was obtained at slight cost.

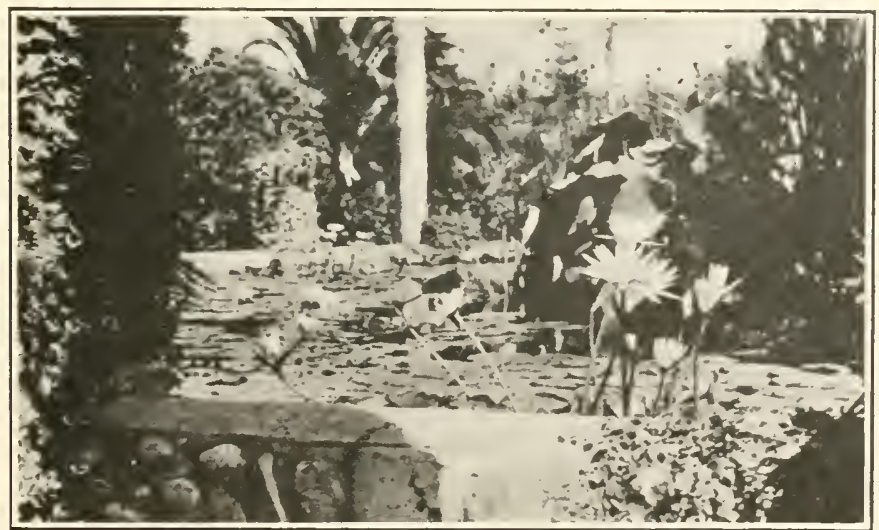

FIG. 131. - Too much regetation in this pool for effective fish control.

the larvae, even though the larvae be visible. Just how important this matter is is shown by the following observation of Hildebrand : ${ }^{1}$

1 "Fishes in Relation to Mosquito Control in" Ponds," U. S. Bureau of Fisheries, 1919. 
"It is very interesting to observe how quickly the top minnows learn to follow the workmen engaged in eutting and raking vegetation from ponds. They soon become quite tame, and seliools of them work almost under the tools of the laborers, catching mosquito larvae and other insects as quickly as their hiding-places are destroyed."

All aquatic plants, however, do not furnish protection for mosquito larvae and pupae against fish, and some even may be positively repellent to them. Grasses and rushes and other plants having straight stalks and no submerged leaves afford no protection. Areas overgrown with plants of this nature have been repeatedly examined for breeding, but, if the water was stocked with mosquito-destroying fish, no larvae were found. Plants which are likely to hang over into the water after maturity or after freshets, etc., should be removed.

\section{PLANTS IN RELATION TO FISH CONTROL}

The following plants appear to provide good protection, and may cause considerable trouble, according to Hildebrand: " the aquatic grass, Hydrochloa carolinensis; "coon-tail moss," a species of Myriophyllum; and algae. Continuing, Hildebrand ${ }^{1}$ says:

"The aquatic grass grows in shallow water and along the shores. It has many slightly submerged leaves, over which the horizontally floating or swimming Anopheles larvae hover, out of sight and out of reach of the fish. Wherever this plant occurs, some Anopheles larvae are almost sure to be present regardless of the abundance of Gambusia. It, therefore, is obvious that, if this plant occurs in ponds in which mosquito control is desired, it must be removed. This may be done by cutting and raking it or, if growing in soft mud, it may be pulled up by the roots.

"The plant locally (at Augusta, Ga.) known as 'coon-tail moss' causes trouble only when it becomes detached and rises to the surface. . . This floating mass must be removed from time to time; this can best be done on a windy day, when it drifts inshore.

"Algae often form mats which float at or near the surface. Mosquito larvae, particularly Anopheles, find protection from fish over and in these mats. Copper sulphate was used in the proportion of $S$ pounds to 100,000 gallons of water for killing the algae, but this treatment must be repeated frequently. . . . Oil, if used in moderatequantities, is not injurious to fish; it can be quickly and conveniently applied and it

1. "Fishes in Relation to Mosquito Control in Ponds," U. S. Bureau of Fisheries,"1919. 
is very effective, for the algal pads act like sponges, retaining the oil and making them uninhabitable for the mosquito.

"Water lilies do not, as a lule, appear to furnish much protection while growing, but some of the plants die from time to time. The leaf then partly sinks, forming a depression orer the center, while the edges

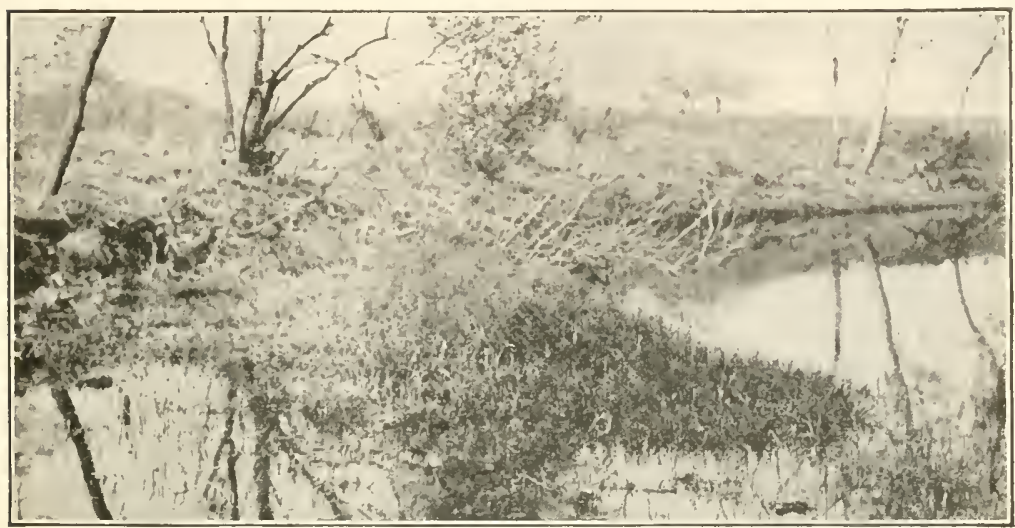

FIG. 132.-Showing growth of aquatic grass in corner of pond. Such grass furnishes excellent protection for mosquito larvae. (After U. S. Publie Health Service.)

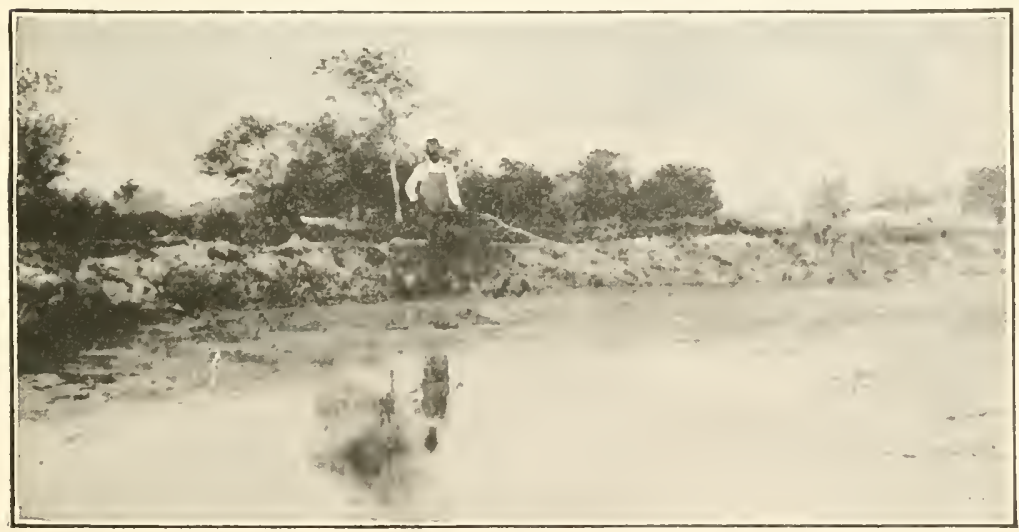

(U. S. Public IIealth Service)

FIG. 133.-Treating pond with copper sulphate to kill algae. Laborer is dragging a small bag of the chemical through the water by means of a pole.

remain at the surface. The cup thus formed kolds enough water to support mosquito Iarvae, and with respect to fish the larvae contained therein are perfectly safe. When the dead leaves drift inshore they, of course, frequently make places inaccessible to fish." 
The aquatic plant, Naias flexilis, which is common in many ponds and lakes, forming a thick growth over the bottom, normally does not afford protection, as it does not reach the surface of the water. During severe droughts, however, it sometimes reaches the surface, forming a dense mass, and, in such eases, it makes excellent protection for larvae and pupac.

The duck-weed, Spirodela polyrrhiza, sometimes forms an almost continuous cover over a pond or a portion of it, but observations indicate that larvae are rarely, if ever, found therein. It is considered likely that the covering is so dense that breeding cannot take place.

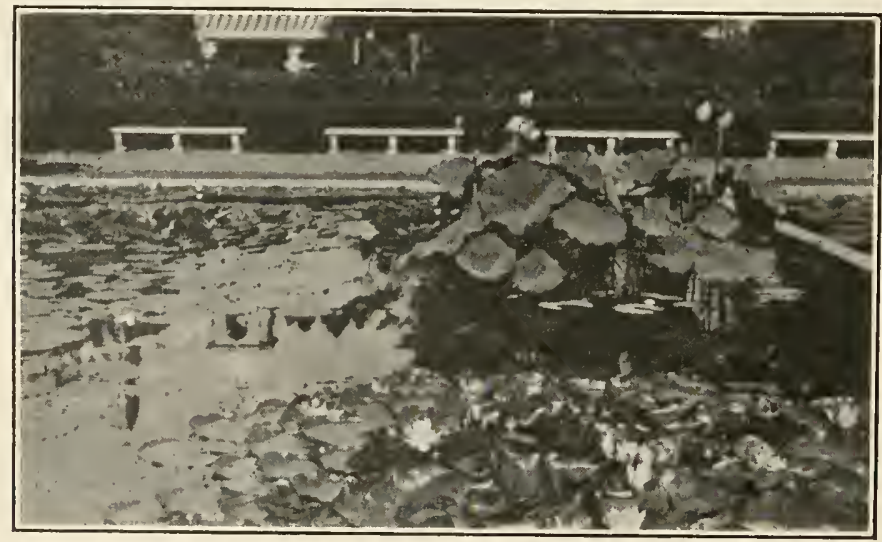

FIG. 134.-Picture showing how water-lilies furnish protection for mosquito larvae. Note the water in the leaves with turned-up edges, and how completely the larvae therein are protected from fish.

The smart-weed, Polygonum, is another plant that usually does not afford protection, and which may sometimes be obnoxious to mosquito larvae, according to Hildebrand, ${ }^{1}$ who says: "Many places overgrown with this weed were repeatedly examined, but mosquito larvae were not found, even in apparently favorable hidling-places."

\section{ELIMINATING LARVA-PROTECTING PLANTS}

It is evident from the study of plants in relation to fish control that to get full results, it is necessary to remove from the pond lake, stream or other natural breeding-place algae and other

1 "Fishes in Relation to Mosquito Control in Ponds," U. S. Bureau of Fisheries, 1919. 
larva-protecting plants or else to treat them in sueh mamner as to make them obnoxious to the larvae.

The first eonsideration is to get rid of the shore vegetation, which frequently is thickest in the shallow areas where mosquitoes are most apt to breed. This, generally, ean be done very effectively with a hoe or shovel, the idea being to leave a clean edge, devoid of grass, brush and other debris which may conceal the larvae from the fish.

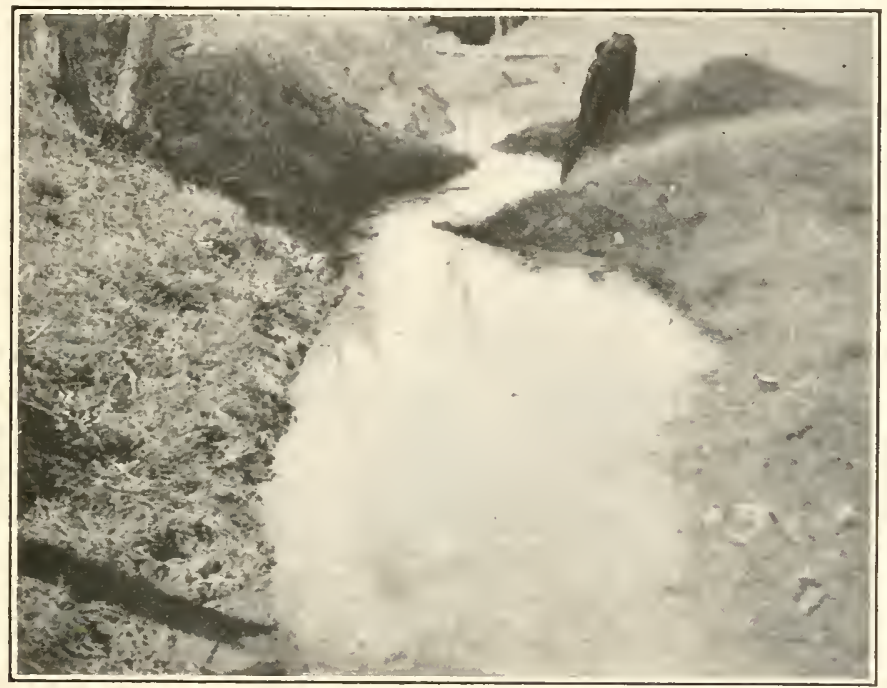

(Photo by E. B. Johnson, C. E.)

Fig. 135.-Breeding in this stream is eontrolled by means of larvadestroying fish. Note the elean edges and the cow helping to keep them clean.

In some cases, this cleaning of the edges may be accomplished more cheaply by lowering the water level from 6 inches to a foot. If the water has stood at its former level for some time, the new shore line probably will be quite clean.

Often, there will be some shallow eoves or other areas thiekly covered with algae or other aquatic growths or debris, most of which will be beyond the reach of the man with the hoe or shovel. In such cases, it may be sufficient to oil these areas very liberally once every week or ten days. It should be borne in mind, however, that applieation of oil probably will drive away the fish, thus making it necessary to rely solely on the use of oil to control the area. 
In oiling such growths, it sometimes happens that nearby portions of the pond, lake or stream may be used for bathing or other purposes for which oil would be objectionable. In such cases, the oil required to deal with the aquatic growths must be prevented from escaping to other parts of the water surface.

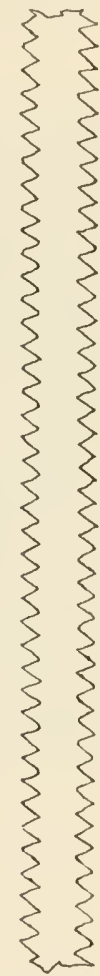

FIG. 136.

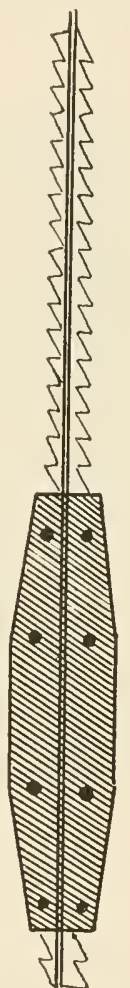

FIG. 137.

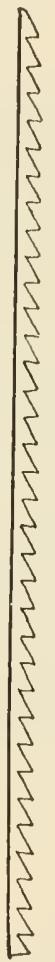

Fig. 138.

Fig. 136. - Section of Ziemsen subaqueous saw, slightly reduced in drawing.

FIG. 137.- Section of improvised saw of "licker-in" wire, showing metlod of joining.

Frc. 138.- Section of "licker-in" wire, slightly reduced in drawing.

This is best accomplished by ruming a boom about the area in which it is desired to confine the oil.

These booms may be made of logs tied together and to the shore or of boards, which are preferable, owing to their straightness and lesser liability to become water-logged and sink, thus allowing the oil to get out. 


\section{THE SUB-AQUEOUS SAW}

Should the aquatice growths be extensive, it generally will pay to remove them. This may be accomplished by nuesns of seythes and sickles from a boat, but the best method, in most cases, is by use of a sub-aqueous saw. This saw, a pliable, toothed strip of steel, 100 or more feet in length, will cut many kinds of aquatic plants successfully, providing only that the water is not studded with brush or stumps. Probably the best saw of this kind is the Ziemsen saw, a patented article.

A somewhat similar, but not so effective, a saw, may be made very cheaply from "licker-in" wire, which is used in a combing process in cotton mills and which may be purchased from mill supply houses. This wire resembles a single-edge saw. By tying two wires together firmly, back to back, at intervals of $\delta$ to 10 inches, with the cutting edges in opposite directions, a doubleedged saw may be made, capable of cutting in either direction. Twisting seems to improve the cutting action. In order to make the saw follow the contour of the bottom, weights should be attached to it at 4 or 5 -foot intervals. Ropes should be tied to each end to take hold of in sawing.

To use the saw, it should be dropped to the bottom, the ropes stretching to either shore. If the saw is not more than 100 feet long or so, one man at each end can handle it; if it be several hundred feet long, however, two men at each end probably will be required. If there are many bushes or stumps, there shoukl be a man ready in a boat to disengage the saw or lift it over the obstacle, whenever necessary. Should the span exceed the length of the saw, one end will have to be worked from a boat. This is tedious and difficult.

\section{USING THE SAW}

The sub-aqueous saw is worked on the principle of a cross-cut saw, the men pulling alternately on each end. The work is very fatiguing, and the men will have to rest frequently. Where there is a current, it is best to begin at the downstream end and work upward against the current; this permits the cut-off growths, as they rise, to float down stream out of the way, to be collected and hauled ashore later. If there is no current, it is preferable to eut in the direction of the wind, if there is any.

One annoying factor in connection with the use of the subaqueous saw is the frequent breaks, especially in the case of the 
saw made from the "licker-in" wire. The patented article appears to be made of better steel, and the breaks are not so frequent. However, they are bound to oceur with either type, but either ean be easily mended by overlapping the ends at the break about 2 inches and tying them together with a strong wire.

With labor at 30 eents an hour, the cost of sawing probably will average about $\$ 5$ an acre. However, it is likely that the cost will vary with the type of growth, condition of the pond and many other factors. In any event, it would appear that use of a saw is much cheaper than doing the work by hand.

In most cases, one or two sawings per season should be sufficient for most aquatic plants. It is believed that repeated sawing will ultimately destroy many of the plants. 


\section{CHAPTER X}

\section{SCREENING}

\section{PLACE OF SCREENING IN ANTI-MOSQUITO WORK}

While sereening eannot, of course, be eonsidered a method of mosquito eradication, the fact that it is very useful under certain circumstances in anti-mosquito work makes it desirable to inelude a chapter on the subject.

These circumstances may include cases where sufficient funds for complete drainage, oiling and fish control under a general community organization are not available or where the breeding areas are too extensive to be controlled economically byantimosquito measures. Screening is particularly valuable for control work in rural areas, where the population is not sufficient to warrant the expense usually involved in eradieation work.

Moreover, as it is becoming eustomary to screen houses, anyway, it is well to know what the requirements for antimosquito screening are, so that the screening may be as adequate a protection against mosquitoes as against flies and other insects.

There is no doubt that screening, where the houses are in such condition that screening may properly be undertaken and where the sereening is done earefully and thoroughly, is one of the most effective methods of protection against mosquitoes.

It should not be inferred, however, that sereening is a satisfactory substitute for mosquito eradication. Screening protects only the house screened, and people do not stay in the house all the time. Unless eradication work is carried on, therefore, they are subject to ammoyance by mosquitoes whenever they leave it. Furthermore, screening rarely keeps out all mosquitoes. If they are abundant outside, some will always manage to get into the house.

It will thus be seen that sereening is at best only a partial protection. It is only one of the many phases of mosquito control work. 


\section{RARITY OF GOOD SCREENING}

Observations indicate that a very large percentage of the screening ordinarily done is not 100 per cent effective. This may be due to three general reasons, which are as follows: (1) Attempts to screen houses that are so poorly constructed or are in such poor condition that they cannot be effectively screened; (2) poorly constructed or improperly fitted screens or screens having

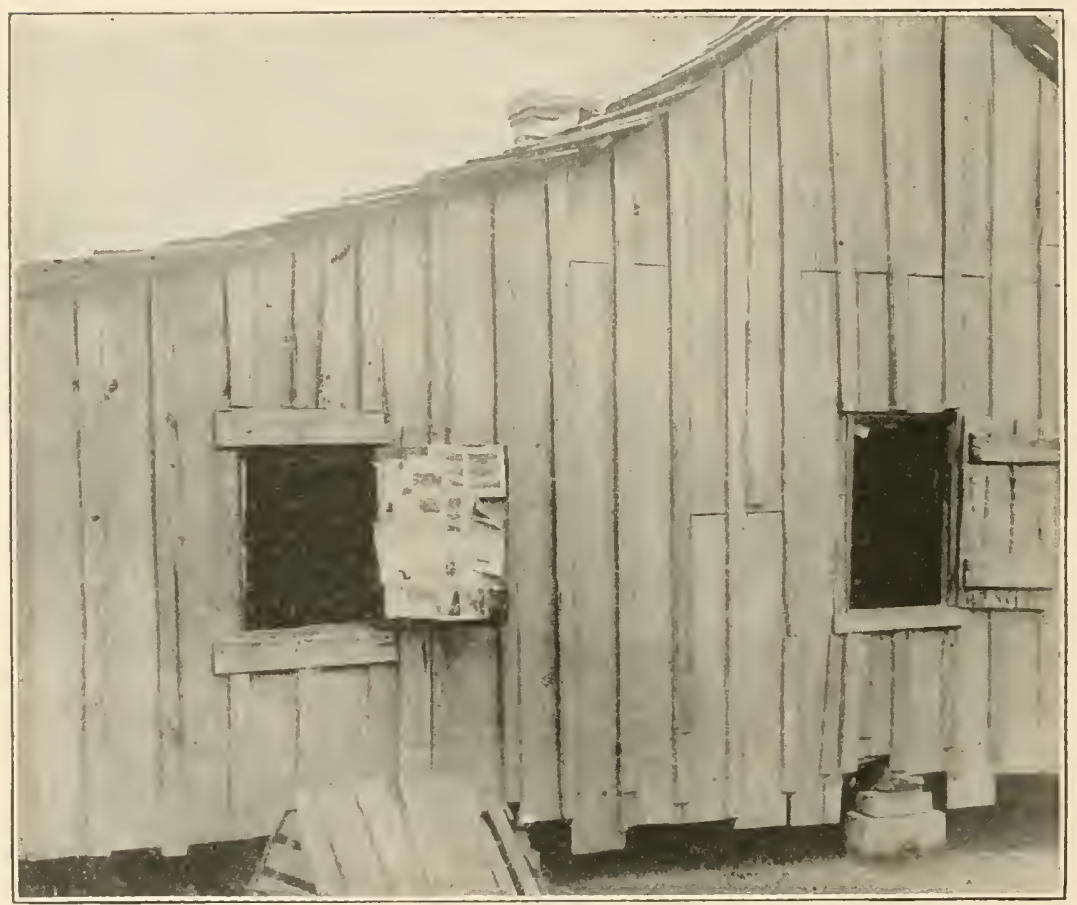

(U. S. Public Health Service)

Fig. 139.-Tenant house in too poor a condition to warrant screening.

too large meshes; and (3) the use of sliding or easily removable screens, which frequently result in their being left open through carelessness or negligence.

Tarbett ${ }^{2}$ reports that inspection of houses in the vicinity of an aviation camp in Arkansas in 1918 revealed that not 10 per cent of the buildings were properly screened. In this same connection, Carter says: "I do not think that 2 per cent of the

${ }_{1}^{1}$ Transactions of the First Annual Conference of Sanitary Engineers, U. S. Public Health Service, 1919. 
sereened houses in the United States are perfeetly sereened. I will say this, that I saw not a single cantomment that was even well sereened."

\section{ESSENTIALS OF GOOD SCREENING}

The first consideration in good screening is to apply it only to houses in a state of repair that justifies screening. Therefore, in starting a screening campaign, the houses should be carefully inspected and divided into three classes: (1) Those already in a satisfactory condition; (2) those that can be put in such condition; and (3) those that cannot be successfully screcned. The last class should not be touched, and the second should not be touched either, until the necessary repairs are made.

A No. 16 mesh eloth is sufficient for Anopheles mosquitoes, but, if protection against all mosquitoes is desired, the eloth should be at least 18 meshes to the inch, as Aedes calopus can pass through a No. 16 mesh. Varying conditions may demand the use of different kinds of sereening material, but, for adequate protection against all mosquitoes, nothing less than 18 meshes to the inch should be considered, or, if a sereening material of less than this be used, it should be painted.

A third essential is that the work be earefully done. This means that certain rules, evolved by experience, should be followed, and that the work should be executed with skill and care.

A fourth essential is that no opportunity for tampering with the screening be afforded. This means that no easily removable screens be used. As already pointed out, if screens of such type are employed, they will be sure to be left open occasionally.

Finally, every opening in the house should be screened. It will not do much good to screen the doors and windows, if the chimneys are left unprotected and open spaces are left elsewhere.

\section{SCREENING OF DOORS}

Since sereening, like the proverbial chain, is only as effective as its reakest point, especial attention should be paid to this weak point, which, in most eases, is the door. This is because it is the one movable seetion most frequently used and, therefore, is most subject to the carelessness of the people who use it.

As mosquitoes are prone to congregate on the sheltered or leeward side of a building, rather than on the windward side, it is 
well, if a door on that side is frequently used, to build a little vestibule of screen material about it. Prolonged observation indicates that mosquitoes are bound to get in most single doors, even though they be opened only for a moment. However, if there is a vestibule in front of the door proper, so that the second screen door is not opened until the first is closed, the chances of entrance by mosquitoes are very much decreased.

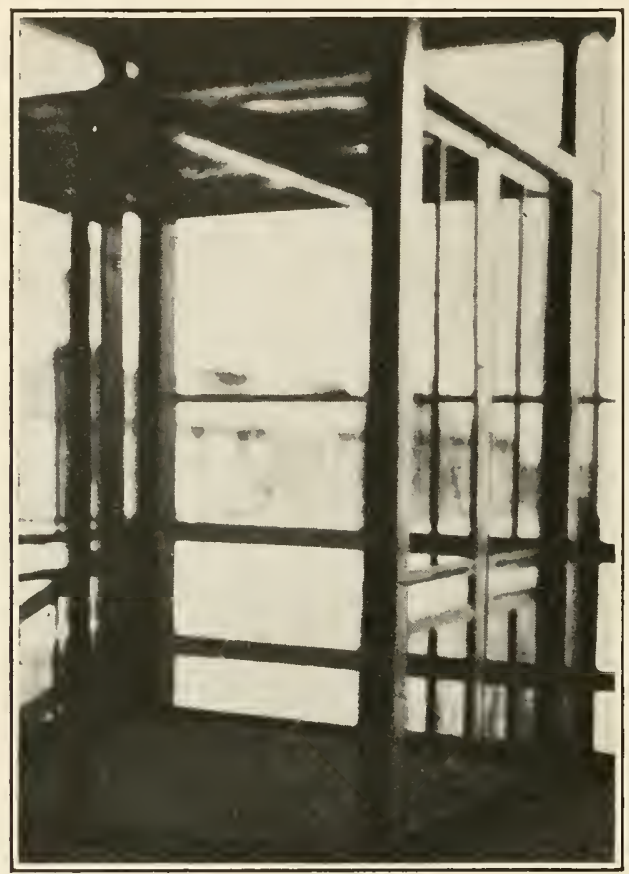

FIG. 140.- Testibule to poreh with double screen doors, shown on right and extreme left, the outer doors being at the left. The screening material does not show up very plainly.

Screen doors should always open outward, else the mosquitoes which settle on them will be driven into the house whenever they are opened, particularly when a person enters the house. This is a point that should be kept in mind at all times.

"When the door of entrance," writes Carter, " is at the top of a flight of steps, no landing intervening, it should be so placed that the edge of the door opposite the hinge comes as near the middle of the " Anti-malarial Measures for Farm-houses and Plantations," U. S. Public Health Service, 1919. 
length of the step as may be. This may be done by having folding doors one best to stay fastened, or by moving the whole single door to the left and fill in the space to the right by screening. The reason is that one always goes up about the middle of the steps, and, if the door opens from the ends of the steps, the person entering, after beginning to open the door, steps down a couple of steps so as to get out of its way, thus opening the door more widely and holding it open longer than advisable."

\section{SOME GENERAL RULES}

The following general rules in regard to construction and installation of screen doors are given by Snidow: ${ }^{1}$

1. "To prevent warping, the frame should be made of substantial, carefully selected, light-weight material, well-braced with iron brackets at the corners. In order to add a double protection against sagging, a wire support should be drawn diagonally across the lower half. This may be accomplished by use of a double wire attached loose, then tightened with a turn-key until the desired tension is reached.

2. "The section of screen wire covering the frame should be cut sufficiently large to allow a lap of $3 / 4$ inch all the way around, and should be tacked on firmly with tacks not more than 3 inches apart. Afterwards, molding strips should be nailed on, eovering edges of wire and tack heads.

3. "The lower half of the door frame should be covered on the inside with a reinforcing section of the so-called hardware-cloth, a coarse, substantial wire screen with about a quarter-inch opening between the meshes. This will protect the bottom panel of the door from kicks and the carelessness of children.

4. "A light strip of wood, about 3 inches broad, should be nailed across the door frame at about the height of a man's shoulders. This is to push against when opening the door.

- 5. "A satisfactory spring should be used to insure the door remaining tightly closed against the battens when not in use.

6. "Two hooks or catches should be provided, one about half-waty up to the top section of the closing side of the frame, and the other near the bottom. The top eatch may be used alone during the day, but at night both should be fastened. This will help to prevent warping.

7. "In fitting screen doors in the door frames, no attempt at elgefitting should be made. The door should be made to fit against a 3 -inch batten all the way around the inside, and sufficient space should be allowed around the edges and the frame for the door to swell in wet weather without scraping at the bottom."

"Transactions of the First Annual Conference of Sanitary Engincers, U. S. Public Health Service, 1919. 
The writer would supplement the provision for reinforcing the lower half of the door (No. 3) by adding a light, wooden "kickboard," similar to the "push-board" mentioned in No. 4, to reecive the kick with which many persons open sereen doors.

Almost any substantial hinge will do. Spring hinges, the springs of which can be adjusted from time to time, have been found advantageous by the writer, as they render unnecessary the separate springs commonly used, which, as a rule, soon weaken if a door is used very much.

\section{SCREENING OF WINDOWS}

Many of the considerations that are mentioned above in comnection with the screening of doors also apply to screening of

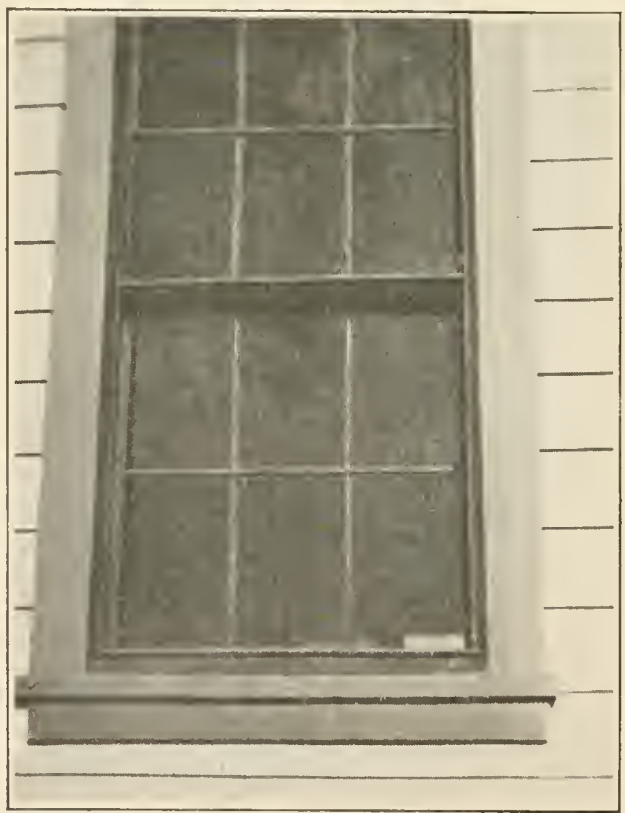

F1G. 141. Close-up view of a window screen. This sereen hangs from the top and is drawn up tightly against the battens on the sides and the sill on the bottom by a hook fitting in a ring attached to the inside of the sill.

windows. Probably the most important of these is that relating to making the frame of the sereen fit tightly up against battens.

Probably the best type of serecning for windows is that in which the top of the frame is hinged to the batten over the window with 
small metallic fasteners. The parts of the fasteners attached to the sereen franne fit into the parts on the window batten. A hook at the botton of the screen frame, connecting with a ring in the window ledge, draws the frame of the sereen tightly against the window battens on the sides and top and the ledge on the bottom.

When there is no suitable batten or when the window frame is in bad shape, as is frequently the ease in negro cottages, it probably is best to tack the sereen material over the whole window.

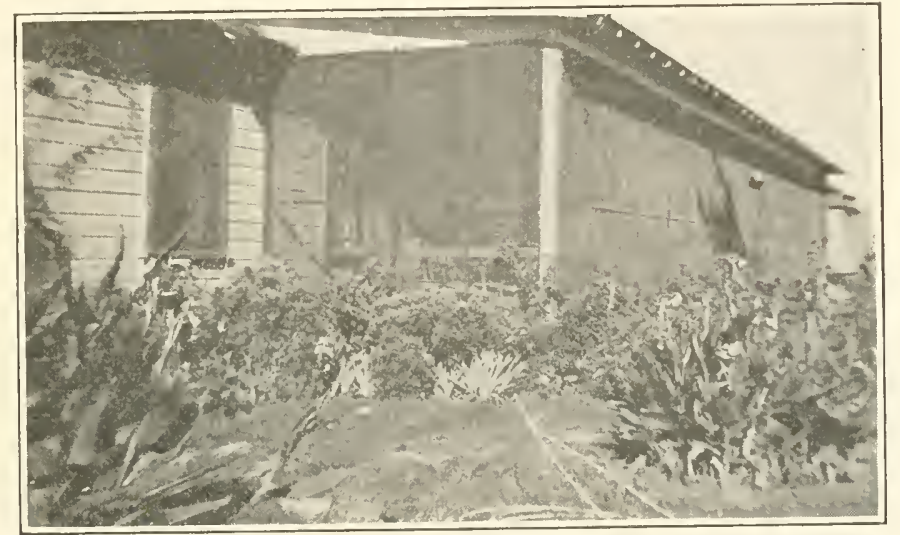

FIG. 142.-Screened porch at cantonment. The sereening, which runs u1' and down, is supported by 2 by 4 timbers. The elges of the sereening are covered with molding strips.

Molding strips then should be nailed over the tack heads around the window opening.

Iron brackets should be used to strengthen the corner's of window sereens as well as of door sereens.

\section{SCREENING OF PORCHES}

This may be done in any way that will result in an effective job. The screening may be put on either horizontally or vertically. In either case, the framing for the sereen should be firm and substantial, the various supports being placed at such intervals that there will be plenty of lap for tacking on the wire. After the screening is firmly in place, the edges should all be covered with molding.

One point that should not be overlooked in porch screening is the importance of not leaving any open spaces where screening 
connects with a sided or weather-boarded surface. The best way of doing this probably is to eut the support to fit the surface. If this is not practicable, the resulting spaces should be filled up with paper pulp, pieces of wood or other material.

Sometimes the nailing of a strip along the outer edges of the porch as a support for the bottom of the screen wire may interfere with the draining off of rain-water that may be blown in on the poreh during storms. One way to provide for this eontingeney is to bore a few holes in the floor just inside the bottom strip and tack small pieces of sereening material over or underneath them.

\section{SCREENING OF CHIMNEYS AND FIRE-PLACES}

When the house is provided with fire-places, screens are required either at the tops of the chimneys or over the openings

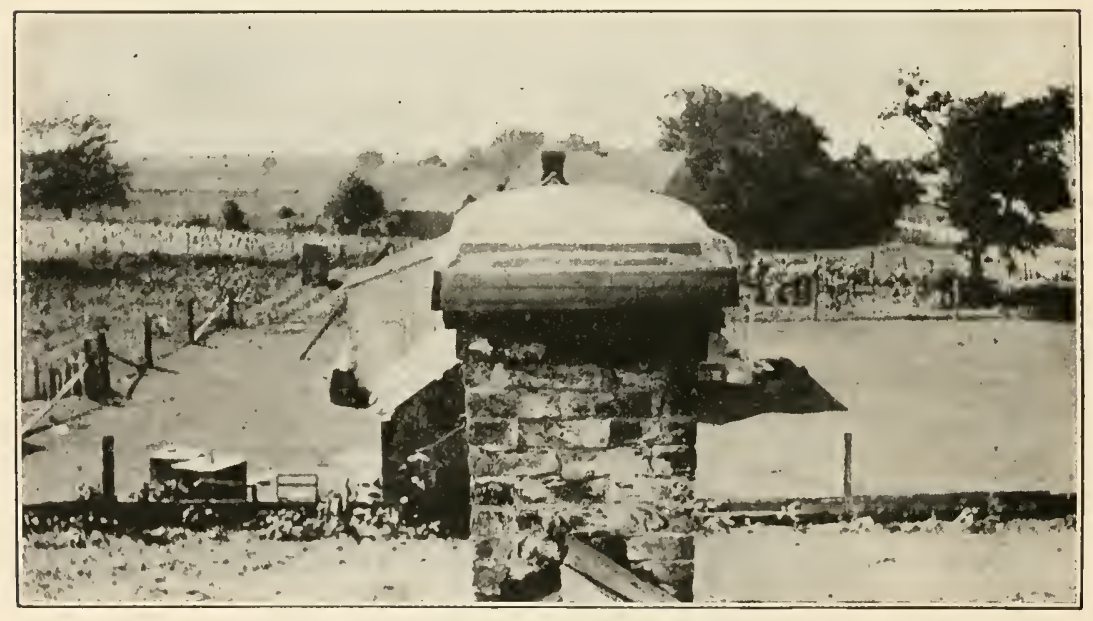

(U. S. Public Health Service)

FIG. 143.-Chimney protection.

of the fire-places. Observations indicate that, unless the ehimney or fire-place is sereened, mosquitoes will deseend into the house by this route in abundanee.

As the fire-places are usually not used much during the mosquito season, it has been found that screening the chimney is often the easiest way of handling this matter. A section of sereen wire is placed over the ehimney and held in position by a tier of bricks around the edge of the top.

As soot soon fills the meshes of the wire, if the chimuey is used, 
it will be found advisable in most cases to remove the sereen from the chimney as soon as cold weather comes.

Should it be desired to sereen the fire-place instead of the chimney, this may be done. Probably the best way of doing this is to make the frame of the sereen fit exactly the fire-place opening. If the fire-place is screened instead of the chimney, all stove-pipe openings in the ehimney should also be elosed.

In some sections, it is customary to bore a hole in the floor to permit the drip from the ice-box to escape through to the ground. In such eases, mosquitoes may enter the house through these holes. The best way to prevent this is either to divert the drip to the sewer by means of a pipe or else to close the hole and put a pan under the ice-box, emptying it whenever necessary.

\section{THE LIFE OF A SCREEN}

The life of a sereen ordinarily depends upon two things - the material of which it is made and the eare it receives.

Probably the best material for sereens for all-round use is bronze or copper. This material will last a life-time, unless tom by aceident. It is so expensive, however, that but little bronze or copper screening is seen today.

The material most commonly used is a galvanized iron. The life of this type of sereen depends upon its care and treatment. Ordiuraly, away from the sea-coast, this type of screening should last several years-from 4 or 5 to 10 or 11 . Carter ${ }^{1}$ states that the screening of the U.S. Marine Hospital at Baltimore-a so-called rustless iron-put on in 1903 did not require renewal until 1914. This sereening was not painted until the fourth year, and then was painted with a very thin coat every second year. The writer has observed galvanized iron sereening, put on in 1917, in very good condition late in 1921 , and it had not been painted at all.

Judicious treatment will undoubtedly greatly prolong the life of a sereen. It is reported that an application of banana oil each season gives very good results. The ordinary treatment, however, is painting, a very thin eoat being applied every second year or so.

Torn wire sereening may be repaired by placing a small piece

I Transactions of the First Annual Conference of Sanitary Engineers, U. S. Public Health Service, 1919. 
of screening over the torn opening and sewing it fast with a strand of thin wire.

\section{SCREENING NEAR THE SEA-SIDE}

The economical sereening of houses close to the sea and exposed to the extreme salt atmosphere of the ocean is a problem. Houses a few hundred yards from the water are not so difficult, but no metal sereen seems to last very long on houses close to the salt water. Painting does not alway appear to help matters, and, in some cases, seems to cause more rapid deterioration.

Ordinary cloth screens are objectionable on account of their interference with ventilation, their sagging and the facility with which they eatch and hold dust, etc. Snidow, ${ }^{1}$ however, recommends a type of cloth screen which has a hard, waxed surface, similar to that of wire.

Carter ${ }^{1}$ reports that at the Chandeleur Islands double bobbinet lasted a full season, while iron sereen material endured only three months.

\section{CONDUCTING A SCREENING CAMPAIGN}

In cases where it has been decided to initiate a sereening campaign in a community, the best practice seems to be more or less as follows:

1. The area should be carefully surveyed, every house being visited and classed, as described earlier in the chapter. Once this is done, some idea of the cost of the eampaign can be obtained.

2. The next step should be to decide upon the best way of doing the work - that is, whether it will be preferable to let each house owner screen his own premises or to have all screening done by the director of the campaign. The writer strongly recommends the latter method, since, in this way, large savings are made possible by consolidated buying and by having a standardized procedure, and the work will be done better and more uniformly.

3. Owners of properties that require repair prior to sereening should be given a certain length of time in which to make the repairs. Those not worth repairing should be ordered vacated, if practicable, and, if not, nothing should be done toward screening them, as the imperfect results would only tend to discredit the work.

4. Once the materials are procured, transportation obtained

1"Transactions of the First Annual Conference of Sanitary Engineers, U. S. Public Health Service, 1910. 
and construction gangs organized, the work should be carried on systematically, street by street, or block by block. Careful cost records should be made.

5. A system of monthly inspection should be organized to see that the screening is maintained in good condition.

\section{VALUE OF SCREENING}

That screening, if properly done, is rery effective in reducing morbidity and amnoyance occasioned by mosquitoes is certain. Shaw reports that at Lake Charles, La., the malaria rate of screened houses, as ascertained by history index, was 50 per cent lower than in unserecned houses.

The St. Louis \& Southwestern Railway in 1917 began sereening the box cars in which its bridge and building gangs sleep. The following table ${ }^{2}$ shows the remarkable falling off in the rate of hospital admissions for malaria following the sereening:

\begin{tabular}{|c|c|c|c|}
\hline & 1915 & 1916 & 1917 \\
\hline Hospital admissions for malaria.... & 87 & 74 & 37 \\
\hline
\end{tabular}

An interesting demonstration involving sereening was carried out on a number of plantations near Lake Village, Ark., in 1916 by the U. S. Public Health Service and the International Health Board. Thirty-three houses were screened at a cost of $\$ 14.59$ per house or $\$ 1.76$ per capita. The incidence of malaria, as revealed in blood examinations in May and December, 1916, both of the sereened group and of a control unsereened group, is shown in the following table. ${ }^{3}$

\begin{tabular}{|c|c|c|}
\hline & May & December \\
\hline Sicreened group, per cent infected........... & 11.97 & 3.52 \\
\hline Unscreened group, per cent infected......... & 21.84 & 19.23 \\
\hline
\end{tabular}

\section{COST OF SCREENING}

While the cost of screening varies, of course, with the size of the house and the number of doors, windows, porches and chim-

1 Transactions of the First Annual Conference of Sanitary Engineers, U. S. Public Health Service, 1919.

2 Transactions of the First Annual Conference of Sanitary Engineers, U. S. Public Health Service, 1919.

" "Malaria Control, A Report of Demonstration Studies," U. S. Public Health Service, 1917. 
neys or fire-places in it, the eost of screening an ordinary fourroom or six-room house should not, as a rule, much exceed $\$ 25$ to $\$ 50$, if ordinary galvanized iron screening material is used.

An itemized table of the cost of screening 31 houses at Kress, Va., in 1918 is given by Snidow. ${ }^{1}$ On this job, Snidow says, it was unnecessary to screen any chimneys. Galvanoid sereen wire, used in the work, cost $\$ 3.50$ per 100 square feet, wholesale. The table follows:

\begin{tabular}{|c|c|c|c|c|c|c|c|c|}
\hline $\begin{array}{c}\text { House } \\
\text { number }\end{array}$ & $\begin{array}{c}\text { Nuumber } \\
\text { porehes }\end{array}$ & $\begin{array}{l}\text { Number } \\
\text { windows }\end{array}$ & $\begin{array}{c}\text { Number } \\
\text { doors }\end{array}$ & $\begin{array}{l}\text { Cost of } \\
\text { wire }\end{array}$ & $\begin{array}{l}\text { Cost of } \\
\text { lumber }\end{array}$ & $\begin{array}{l}\text { Cost of } \\
\text { hardware }\end{array}$ & $\begin{array}{c}\text { Cost of } \\
\text { lahor }\end{array}$ & $\begin{array}{c}\text { Total } \\
\text { cost }\end{array}$ \\
\hline 1 & 1 & 11 & 2 & $\& 15.26$ & 6.00 & $\$ 2.54$ & $8.40 \$$ & $\$ 32.20$ \\
\hline 2 & 1 & 12 & 2 & 17.22 & 6.50 & 2.64 & 8.40 & 34.76 \\
\hline 3 & 1 & 9 & 2 & 15.40 & 5.75 & 2. 29 & 8.40 & 31.84 \\
\hline 4 & 2 & 7 & 2 & 16.34 & 5.80 & 2.14 & 11.20 & 35.48 \\
\hline 5 & 1 & 13 & 2 & 15.89 & 4.50 & 2.64 & 11.20 & 34.23 \\
\hline 6 & . & 5 & 3 & 4.83 & 3. 00 & 2.46 & 5.60 & 15.89 \\
\hline 7 & .. & 4 & 3 & 4.34 & 2.70 & 2.26 & 5. 60 & 14.90 \\
\hline s & . & 4 & 3 & 4.34 & 2.70 & 2.26 & 5.60 & 14.90 \\
\hline 9 & . & 5 & 3 & 4.83 & 3.00 & 2.46 & 5.60 & 15.89 \\
\hline 10 & 1 & 4 & 3 & 11.13 & 3.95 & 2.21 & $7.00^{\prime}$ & 24.29 \\
\hline 11 & 1 & 7 & 3 & 10.57 & 4.10 & 2.31 & 7.00 & 23.98 \\
\hline 12 & 1 & 6 & 2 & 9.62 & 3.85 & 1.99 & 7. 00 & 22.46 \\
\hline 13 & 1 & 6 & 2 & 9.62 & 3.85 & 1.99 & 7.00 & 22.46 \\
\hline 14 & 1 & 6 & 2 & 9.62 & 3.85 & 1.99 & 7.00 & 22.46 \\
\hline 15 & 2 & 12 & 2 & 22.22 & 6.90 & 2.69 & 14.00 & 45.81 \\
\hline 16 & 1 & 12 & 2 & 16.34 & 6.00 & 2.44 & 8. 40 & 33.18 \\
\hline 17 & 2 & 3 & 2 & 21.17 & 5.85 & 1.59 & 11. 20 & 39.81 \\
\hline 18 & 1 & 4 & 3 & 15.40 & 4.35 & 2.46 & 7.00 & 29.21 \\
\hline 19 & 1 & 4 & 3 & 15.40 & 4.35 & 2.46 & 7.00 & 29.21 \\
\hline 20 & 1 & 4 & 3 & 15.40 & 4.35 & 2.46 & 7.00 & 29.21 \\
\hline 21 & 1 & 10 & 3 & 17.64 & 6.80 & 3.01 & 11.20 & 38.65 \\
\hline 22 & .. & 3 & 3 & 3.85 & 1.95 & 2. 21 & 2.80 & 10.81 \\
\hline 23 & .. & 1 & 3 & 0.60 & 0.75 & 1.81 & 2.80 & 5.96 \\
\hline 24 & .. & 7 & 1 & 4.41 & 2.75 & 2.27 & 4.20 & 13.63 \\
\hline 25 & .. & 3 & 1 & 2.97 & 1.40 & 1.27 & 2. 80 & 8.44 \\
\hline 26 & . & 5 & 3 & 3.95 & 1.30 & 1.91 & 2.80 & 9.96 \\
\hline 27 & .. & 5 & 3 & 3.95 & 1.30 & 1.71 & 2.80 & 9.76 \\
\hline 28 & $\ldots$ & 5 & 3 & 3.95 & 1.30 & 1.71 & 2.80 & 9.76 \\
\hline 29 & .. & 2 & 1 & 1.57 & 0.45 & 0.67 & 1.40 & 4. 09 \\
\hline 30 & .. & 2 & 1 & 1.57 & 0.45 & 0.67 & 1.40 & 4.09 \\
\hline 31 & . & 5 & 2 & 4.93 & 2.20 & 1.59 & 5.60 & 14.32 \\
\hline Totals.... & 20 & 186 & 73 & $\$ 304.33 \$$ & $\$ 112.00$ & $\$ 65.11$ & $\$ 200.00 \$$ & $\$ 681.64$ \\
\hline
\end{tabular}

Detailed costs of the screening at Lake Village, Ark., already referred to, with galvanized iron wire, costing $\$ 3.00$ per 100 square feet, are furnished by Derivaux, Taylor and Haas, in a

${ }^{1}$ Transactions of First Annual Conference of Sanitary Engineers, U. S. Public Health Service. 
report, ${ }^{1}$ from which the following table has been eompiled, labor costing from 40 to 50 cents an hour; in this case, the chimneys also were screened.

\begin{tabular}{|c|c|c|c|c|c|c|c|c|}
\hline $\begin{array}{c}\text { House } \\
\text { number }\end{array}$ & $\begin{array}{l}\text { Number } \\
\text { chimneys }\end{array}$ & $\begin{array}{l}\text { Number } \\
\text { windows }\end{array}$ & $\begin{array}{c}\text { Number } \\
\text { doors }\end{array}$ & $\begin{array}{c}\text { Cost of } \\
\text { wire }\end{array}$ & $\begin{array}{l}\text { Cost of } \\
\text { lumber }\end{array}$ & $\begin{array}{c}\text { Cost of } \\
\text { hardware }\end{array}$ & $\begin{array}{l}\text { Cost of } \\
\text { labor }\end{array}$ & $\begin{array}{l}\text { Total } \\
\text { cost }\end{array}$ \\
\hline 1 & 1 & 7 & 3 & 84.52 & $\$ 2.15$ & $\$ 0.90$ & $\mathrm{~s} 11.00 \mathrm{~s}$ & 818.57 \\
\hline 2 & 1 & 7 & 2 & 3.44 & 2.15 & 0.60 & 6.00 & 12.19 \\
\hline 3 & 1 & j & 2 & 2.90 & 2.15 & 0.60 & 8.50 & 14.15 \\
\hline 4 & 1 & 5 & 2 & 2.90 & 2.15 & 0.60 & S. 50 & 14.15 \\
\hline 5 & .. & 2 & 2 & 1.55 & 2.15 & 0.60 & S. 50 & 12.80 \\
\hline 6 & 1 & 2 & 3 & 2.63 & 2.15 & 1.85 & 7.90 & 14.53 \\
\hline 7 & 1 & 1 & 2 & $1.2 \mathrm{~s}$ & 2.65 & 2.10 & 12.00 & 18. 03 \\
\hline 8 & 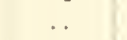 & 2 & 2 & 1.55 & 2.65 & 1. 20 & 14.00 & 19.40 \\
\hline 9 & 1 & 2 & 2 & 2.46 & 2.40 & 0.60 & 7.85 & 13. 31 \\
\hline 10 & 1 & 1 & 3 & 1. 10 & 2.45 & 0.85 & 7.00 & 11.40 \\
\hline 11 & 1 & 5 & 3 & 3.17 & 2. 90 & 0.55 & 9.00 & 1.5. 92 \\
\hline 12 & 1 & 3 & 2 & 1.91 & 2.15 & 0.70 & 4.00 & $8.76 \mathrm{i}$ \\
\hline 13 & 1 & 3 & 2 & 1.91 & 2.15 & 0.70 & 4.00 & 8.76 \\
\hline 14 & 1 & 3 & 2 & 1.91 & 2.15 & 0.70 & 4.00 & 8.76 \\
\hline 15 & 1 & 2 & 2 & 1.66 & 4.90 & 0.60 & 6.90 & 14.06 \\
\hline 16 & 1 & 2 & 4 & 2.66 & 4.90 & 1. 10 & 10.40 & 19.06 \\
\hline 17 & 1 & 2 & 4 & 2.66 & 4.90 & 1. 10 & S. 80 & 17. 46 \\
\hline $1 \mathrm{~s}$ & 1 & 4 & 4 & 3.86 & 4.90 & 1.10 & 9.60 & 19.46 \\
\hline 19 & 1 & 2 & 3 & 2.36 & 1.95 & 0.85 & 6.40 & 11. 56 \\
\hline 20 & 1 & 3 & 2 & 2.09 & 1.20 & 0.60 & 4. 80 & 8. 69 \\
\hline 21 & 1 & 3 & 3 & 2. 36 & 2.40 & 0.85 & 5. 20 & 10.81 \\
\hline 22 & 1 & 3 & 2 & 1.82 & 0.40 & 0.60 & 4.00 & 7.82 \\
\hline 23 & 1 & 4 & 4 & 3.44 & 2.40 & 1. 10 & 7.60 & 14.54 \\
\hline 2.4 & 1 & 4 & 4 & $3.9 \mathrm{~s}$ & 2.79 & 1. 10 & 10.00 & 17.87 \\
\hline 25 & 1 & 2 & 2 & $1 . \$ 2$ & 2.44 & 0.60 & 7.00 & 11. S6 \\
\hline 26 & 1 & 2 & 2 & 1.82 & 3.11 & 1. 10 & S. 50 & 14.53 \\
\hline 27 & 1 & 4 & 4 & 3.99 & 3.90 & 1. 60 & 12.00 & 21.48 \\
\hline 28 & 2 & 4 & 5 & 3.98 & 3. 40 & 1.35 & 12.50 & 21.23 \\
\hline 29 & 1 & 2 & 2 & $1.0 \%$ & 2.40 & 0.60 & 6.50 & 10.55 \\
\hline 30 & 1 & 4 & 4 & 1. 43 & 2.90 & 1.10 & 12.50 & 17.93 \\
\hline 31 & 1 & 2 & 2 & 1.41 & 1. 90 & 0.70 & S. 00 & 12.01 \\
\hline 32 & 1 & 4 & 4 & 3. 16 & 2. 80 & 1.10 & 8.00 & 15.06 \\
\hline 33 & 1 & 7 & 3 & 3. 16 & 1. 90 & 0.85 & 6.80 & 12.71 \\
\hline Totals.... & 32 & $10 \mathrm{~s}$ & 92 & $\$ \$ 1.93$ & $8 \times 8.89$ & $\$ 31.85$ & $\$ 267.75 \mathrm{~s}$ & $\$ 169.42$ \\
\hline
\end{tabular}

\section{DOES SCREENING PAY?}

It has been shown that good sereening will greatly reduce the incidence of the mosquito-borne diseases. Costs of good sereening have also been discussed. The question as to whether or not screening will pay, on a dollar-and-cent hasis alone, may now be taken up.

1 "Malaria Control: A Report of Demonstration studies," U. S. Public Health Service, 1917. 
As a result of the screening demonstration carried on by the U. S. Public Health Service and the International Health Board near Lake Village, Ark., already referred to, it was found that the incidence of malaria, as revealed by blood examination, was reduced from 11.97 to 3.52 per cent for the screened group, but remained virtually unchanged for the unscreened group. Study of the cost of serecning for the screened group and of the losses arising from malaria for both groups gives the interesting results shown in the following table:

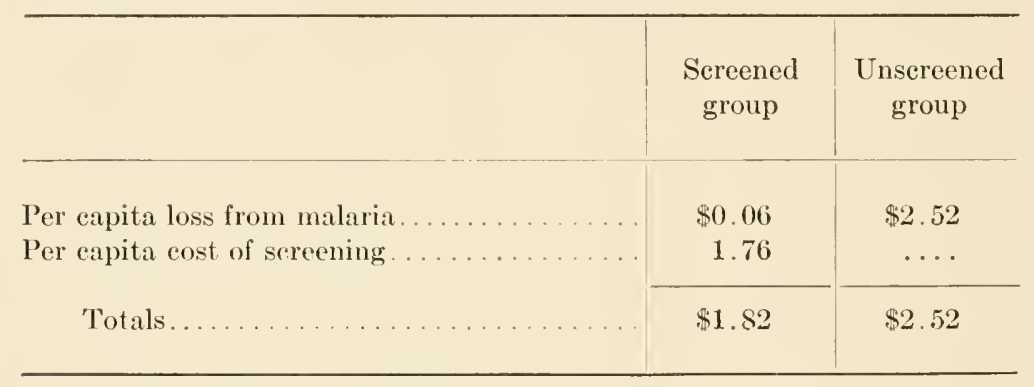

It is apparent from this that screening much more than paid for itself, and this on the assumption that it would last only 2 years. ${ }^{1}$ In addition, there is to be considered the freedom enjoyed by the sereened group from amnoyance by mosquitoes and also from the fly pest and its accompanying dangers of typhoid.

I "Malaria Control: A Report of Demonstration Studies," U. S. Public Health Service, 1917. 


\section{CHAPTER XI}

\section{OTHER MEASURES AND EXPEDIENTS AND POINTS REQUIRING INVESTIGATION}

\section{SCOPE OF THIS CHAPTER}

In previous chapters, the standard methods of mosquito eradication and control have been discussed at some length. In the present chapter, it is intended to outline various auxiliary measures in dealing with mosquitoes-some of demonstrated value; others still under investigation - and to call attention to points that require further study and that may lead to results of importance.

It may be stated here definitely that we do not yet know, by any means, all that is worth knowing about mosquitoes. There are still many important questions that need clearing up, and it is possible that, as they are eleared up, new and valuable methods of procedure in eradicating mosquitoes will be developed. Also, as our knowledge of the mosquito increases, it is not improbable that it may be possible to effect considerable economies in connection with present methods of control.

Despite the present limitations of our knowledge, progress is steadily being made. The problem of the mosquito is being studied from many different angles, and a large number of auxiliary methods of dealing with it have been proposed. In the following sections, a few of these will be discussed.

\section{AUXILIARY METHODS AND EXPEDIENTS IN GENERAL}

It will be noted that the standard offensive methods already described, such as drainage, oiling and fish control, are directed chiefly against the mosquito in its early stages; they are designed either to prevent it from ever coming into existence, as drainage, or to destroy it before it matures, as oiling and fish control. While screening is directed against the adult, it is purely protective, and has no offensive aspects.

While these measures are undoubtedly based on correct prineiples, nevertheless, there is no reason, theoretically, why 
offensive measures against the adult should not be developed as a supplementary procedure. In the plague campaigns against rats and ground-squirrels, direct offensive measures are used against adults with great suecess. The same may be said, to some extent, in regard to flies.

Again, it may be said that there is plenty of scope for further protective measures against adults. There are millions of homes that are not sercened, and many of these cannot be screened effectively. Furthermore, as already pointed out, sereening is protective only in the place that is sereened. For these reasons, other protective measures should be utilized wherever and whenever it appears that they will be of any value.

\section{DIRECT EXTERMINATIVE MEASURES}

The following measures for attacking the adult mosquito appear to have more or less value or to offer possibilities of further development:

1. Direct exterminative measures, preferably by some biological enemy.

2. Indirect methods of harassing and annoying, such as destroying or rendering unattractive its harboring and resting places.

The most practical application of direct exterminative meassures against the adult mosquito would seem to be use of some biological enemy. The use of fish against the earlier stages of the mosquito is an example of the value of this procedure. There remains only to find some animal that is adapted for destruction of the adult mosquito.

\section{THE BAT AS A DESTROYER OF ADULT MOSQUITOES}

Doctor Campbell of San Antonio, Tex., for many years has expounded the view that the domestic bat, Chiroptera, ean be utilized as a means of exterminating adult mosquitoes, and, as a result of his advocacy, San Antonio and other cities have installed bat-roosts for this specific purpose. The idea is to encourage development of enough bats in each community greatly to reduce, if not eliminate, the mosquito pest.

While Doctor Campbell fortifies his arguments with a mass of resolutions and letters of approval, which apparently sustain his conclusions, there seems to be a certain amount of doubt 
in scientific circles as to the general applicability of the scheme. Hoffman ${ }^{1}$ sums up the matter as follows:

"It is eonceivable that bat-roosts may be of advantage in one location, while entirely useless in another. It is possible that bats may exterminate a sufficient number of Anopheles to reduce the mosquito nuisance to a minimum. Conversely, the enormous number of bats required for effective work may constitute an evil in itself not to be tolerated in eivilized communities. The subject has reached the stage where, in my judgment, it is obviously the duty of the several Government departments concerned to institute a thorough investigation and to make a full report."

Chidester ${ }^{2}$ gives the following list of animals, other than fishes, which are recognized as foes of the mosquito in its various stages:

\section{OTHER ANIMAL FOES OF THE MOSQUITO}

PROTOZOA-Spirochaeta culicis, Diplocystis, Nosema stegomyiae, Crithidia fasciculata, Herpetomonous algeriense, Trypanosoma cuticis.

COELENTERATA-IIydra fusea, II. viridis.

PLATYHELMINTHS-Agamodistomum martiranoi.

NEMATHELMINTHS-Agamomermis culicis.

ARTHROPODA-Hydrophilus obtusatus, Dytiscus marginalis, Acilius sulcatus, Nepa, Notonocta, Ranatra fusca, Aeschna, Erythemis simplicicollis, Psorophora ciliata, Megarhinus septentrionalis, Lutzia bigotii, Lesticocampa, Corcthra, Tanypus dyari, Lispa sincnsis, Horpopeza obliterate, Tahydromia macula, Cordilura haemorhoidalis, Monedula signata, Emesa longipes, Salticus, Crangon vulgaris.

AMPHUBIA-Rana pipiens, R. palustris, Discoglossus pictus, Triton cristatus, T. alpestris, Diemyctylus tortosus, Amblystoma opacum.

REPTILIA - Ptychozoon homalccephalum.

AVES-Chordeiles virginianus, Choetura pelagica, Petrochelidon lumfrous, Iridoprocne bicolor, Hirundo erythrogasta, Progne subis, Riparis riparia, Tachycineta thalassina lcpida, Myiochanes virens, Sayornis phocbe, Tyrannus tyrannus, Anas platyrhynchos, Acgilitis semipalmata, Pisobia pusillus.

1 Southern Medical Journal, April, 1921, page 304.

2 "A Biological Study of the More Important of the Fish Enemies of the Salt Marsh Mosquitoes," New Jersey Agrieultural Experiment Stations, 1916. 


\section{MAMMALIA-Eptesicus fuscus.}

Many of these, of course, may turn out to be of no practical value; others may be of value in destroying the earlier stages of the mosquito, like fish: others finally, may be developed into instruments of destruction as against the adult mosquito.

\section{DESTRUCTION OF MOSQUITOES IN DWELLINGS}

"Swat the fly" has long been a slogan in anti-fly eampaigns, in which this procedure has been recognized as a valuable adjunct to other methods of eradication. In anti-mosquito work "swatting" the mosquito is an equally valuable auxiliary measure.

The importance of "swatting" the mosquito was first reeognized in the sanitary work of the Panama Canal Zone, where it was found that daily, systematic killing or eatehing of mosquitoes in the laborers' barracks resulted in a noticeable reduction in the incidence of malaria. The application of this measure there, as an adjunct to screening, was made possible by a standard type of sereened dwelling, a population under one central control and a trained organization to carry out the work. The procedure under these conditions proved effective, and the possibility of its application to other conditions should be more fully investigated.

Repeated surveys show that the favorite hiding-places of mosquitoes in and about homes include "garrets, bed-rooms, on walls, under mosquito-bars, behind pietures, on clothing, behind doors and furniture, in barns, open fire-places, privies, chicken coops, wood and coal sheds, stables, garages, under porches and buildings, in wind-protected corners of porehes, in empty barrels, trash-heaps, wagons, carriages, automobiles and on spider webs." 1

For killing mosquitoes on walls, ete., probably the best device is an ordinary fly-swatter. For attacking them on ceilings the writer has suecessfully used a piece of board about a foot square, covered with several thicknesses of gauze and attached horizontally to the top of a pole 6 or 8 feet long.

Where it is not practicable to reach the mosquitoes with either of these weapons, they may be driven out by burning pyrethrum powder. This powder is not highly efficient in killing mosquitoes,

1 R. H. vov Ezdorf in "Anopheline Surveys" U.S. Public Health Service, 1918. 
unless burned in comparatively large quantities in a tightly closed room for a considerable period. A small amount of the powder, however, will drive them from their hiding-places to points where they ean be reached.

LePrince $^{1}$ sums up the possibilities of systematic destruction of mosquitoes in dwellings as follows:

"I think some very valuable experimental work can be done in this country by applying this matter of destruction of Anopheles to houses, where the house temant is not in any way interested, by using the children to do the catching

\section{HARASSING THE MOSQUITO}

The theory underlying this measure is that mosquitoes will be, to some extent, dispersed and diven away if the enviromment is made unfavorable to them.

It has been observed that, generally speaking, the mosquito, when not secking food, spends its time in some shaded and, preferentially, damp place. It avoids the direct sunlight and, when possible, selects a place where there is a certain amount of moisture. This being so, it is obvious that if we can eliminate these places or render them inaceessible or objectionable to it, the mosquito will either have to get out and seek some new harboring place or, at its peril, remain in an enviromment that has become unfavorable to it.

The favorite harboring places of the mosquito about the average home appear to be bushes, clumps of weeds, high grass, ete, underneath the house, in the cellar, in the garage, under culverts, in stables and other dark places. In each of these, a certain amount of moisture is usually found, due to failure of the sum to penetrate for any extended period.

In carrying out this measure, then, weeds and high grass within a radius of several hundred feet of the dwelling, should be cut and burned; the ground under the house, the cellar, nearby culverts, stables and similar harboring places should be oiled thoroughly from time to time; thick heary foliage should be trimmed out and, if necessary, also oiled or otherwise treated; the lawn or garden hose should be used sparingly, so as not to cause too much dampness about the house.

The writer has tried out this measure for several seasons; and it is surprising what a difference its practice will make-it being

1 Southern Medical Journal, April, 1921, page 291. 
understood that it is of value only in ridding the area of a brood of mosquitoes that has settled there and is useless if new broods are continually emerging from nearby breeding-places. It must, therefore, be used in connection with the other standard methods already described.

\section{FURTHER PROTECTIVE MEASURES}

When the offensive measures against the mosquito fail to bring the desired result, defensive or protective measures may be brought into play. In addition to sereening, there are, as already intimated in a previous section of this chapter, several other more or less valuable protective measures that may be used to repel the mosquito or to avert some of the consequences of its attack.

One of the most interesting and suggestive of these is the use of animals as a living shield between mosquito production areas and human dwelling-places. This measure arose from the observation that mosquitoes frequently are more numerous in stables, etc., than in adjoining dwellings.

Rizzi ${ }^{1}$ records several interesting observations on the subject, made in the vicinity of Trinitapoli, Italy, a well-known center of malaria, which may be summarized as follows:

\section{USE OF ANIMALS AS A PROTECTION AGAINST MOSQUITOES}

1. In a locality usually non-malarious, a stable was found to abound with Anopheles mosquitoes. Careful search led to discovery of the breeding-place, a small basin of water still containing larvae. Rizzi holds that the mosquitoes did not invade surrounding areas, owing to the fact that the single beast in the stable supplied them with sufficient blood.

2. In a village frequently attacked by malaria, only a few mosquitoes were found; they were abundant, however, in two large stables, each about 1,500 feet from the outlying parts of town. No larvae were found in neighboring ponds, although some had been found in the spring. Rizzi believes that in this case, the mosquitoes were attracted to the stables, which, in this way, protected the village from invasion.

${ }_{1}$ Nuovo Indirizzo di Profilassi Anti-malarica, Ann. d'Igiene, Nov. 30, 1919. Compiled from "Public Health Engincering Abstracts," U. S. Public Health Service, July, 2, 1921. 
3. At Trinitapoli itself, Rizzi records, several broods of mosquitoes, hatehed from larvae in nearby ponds, suddenly emerged. Stables in the vicinity of the ponds were first invaded, then stables nearer town and, finally, some outlying houses. Anti-nosquito measures were then pressed, and the invasion was arrested, virtually no mosquitoes entering the town itself. The conclusion seems to be that the stables attraeted the mosquitoes and detained them long enough to enable the anti-mosquito measures to be applied.

Rizzi, however, emphasizes the fact that reliance on the attraetions of stables, ete., is not sufficient in itself. He appears to believe that the use of animals in this way is merely one factor that may be of advantage in connection with the usual anti-mosquito measures, and this view appear's reasonable to the writer. Where stables can be located between the dwelling and a marsh, pond or similar breeding-place, it is believed advantageous so to locate them. Use of land between the dwelling and the breeding-place for a pasture might also be advantageous.

\section{APPLICATION OF SUBSTANCES REPELLENT TO MOSQUITOES}

This measure eannot be relied upon to any great extent, as most of the substances in use at present evaporate within a few hours, and the mosquitoes return.

These substances are generally used at night. 'They are either rubbed on the face and hands or dropped on the pillow or on a towel which is hung over the head of the bed.

Oil of citronella probably is the most efficacious of the mosquito-repelling substances now in use. Others employed inelude spirits of eamphor, oil of peppermint, oil of pemnyroyal, lemonjuice, vinegar and kerosene. Several patented preparationsare also on the market. None of these seem to last until morning, however.

The writer has found bi-weekly or tri-weekly oiling of the floor with kerosene is about as effective as anything else along this line. The odor, of course, is more or less disagreeable to the person oceupying the room, but it is equally as disagreeable to the mosquitoes, and, as a result, they usually keep out.

Another procedure that may conveniently be mentioned here is that of making a smudge. This measure is tolerably effective, as the mosquitoes generally flee from the smoke, but it is almost as objectionable to the oceupants of the room as the mosquitoes 
are. This is a common practice in negro cabins in the malarious districts of the South.

\section{USE OF QUININE FOR MALARIA}

Use of quinine is of value only in eases of malaria; its effect is to destroy the malaria plasmodia, which have been injected into the blood of the malaria patient by infected Anopheline mosquitoes. Quinine, therefore, is of no avail, until the person has been bitten by the mosquito. It is the last measure of defense. Quinine is of no value, however, in the treatment of yellow fever, dengue or filariasis.

The standard treatment for malaria recommended by the National Malaria Committee in the hope that it would be generally adopted by praetieing physicians wherever malaria prevails, is as follows:

"For the acute attack, 10 grains of quinine sulphate by mouth three times a day for a period of at least 3 or 4 days, to be followed by 10 grains every night before retiring for a period of $\delta$ weeks. For infected persons, not having acute symptoms at the time, only the $S$ weeks' treatment is required.

"The proportionate doses for children are: Under 1 year, 1/2 grain; 1 year, 1 grain; 2 years, 2 grains; 3 and 4 years, 4 grains; 5,6 and 7 years, 5 grains; 8,9 and 10 years, 6 grains; $11,12,13$ and 14 years, 8 grains; 15 years or older, 10 grains."

The object of the treatment is not only to relieve the elinical symptoms, but also to disinfect the patient in order to prevent relapses and transmission of the disease to others.

\section{DEMONSTRATIONS OF THE VALUE OF MASS TREATMENT BY QUININE}

Where malaria assumes an epidemic character and very large pereentages of the population are infected, mass treatment by quinine has given excellent results. Prominent among the successful demonstrations of this kind may be mentioned the work in the Panama Canal Zone, the work of the Germans in Africa and the work of the Japanese in Formosa.

In 1920, a very successful demonstration of this kind was earried out in Georgia. In the area in question, there were about 2,900 acres in cultivation and, according to Abercrombie, ${ }^{1}$ the annual loss in this area due to malaria alone was something

${ }^{1}$ Southern Medical Journal, April, 1921, page 286. 
over \$13 an acre. In tabulating the history cards of persons receiving the treatment, it was found that 71 per cent reported having had malaria within the preceding 5 years; 21 per cent reported having had malaria in 1919 ; and 13.5 per cent reported having had malaria some time in 1920 before applying for treatment.

Diseussing the demonstration, Abererombie' says:

"There were 600,000 doses of quinine given . . . The people who took the treatment were 10,339, divided as follows: white people, 6,849 , and colored, 3,490. There were 1,691 families. I think the report shows that out of this total . . . there were something like 27 people who developed chills after completing the treatment. We figured that this cost approximately 50 cents per capita over the county. It cost probably $\$ 1.50$ for each person taking the treatment, but, since it is a county-wide proposition, we are figuring it on a per capita basis in the county."

The campaign was started by interesting the plantation owners and managers from an economic standpoint. Their assistance was obtained in distributing the quinine to their tenants and employes; in addition, 14 free dispensaries were established at various points in the county. In all, about two-fifths of the population of the county was treated.

\section{QUININE VERSUS ANTI-MOSQUITO MEASURES}

While quinine, as has been shown, is very valuable in coping with malaria epiclemies, use of quinine should in no sense be considered as a satisfactory substitute for anti-mosquito measures.

In the first place, quinine is merely a remedy for but one of the effects of mosquito bites. It has no bearing on the annoyance caused by mosquitoes of all speeies and the grave effects of this annoyance upon the health. Moreover, quinine is of no value in coping with those other consequenees of mosquito bites which take the form of yellow fever, dengue and filariasis.

It also seems probable that over a period of years, covering entire populations, adninistration of quinine would frequently prove more costly than execution of anti-mosquito measures.

There is no doubt that quinine has its place in the mosquito problem, but that place is necessarily a limited one.

${ }^{1}$ Southern Medical Journal, April, 1921, page 286. 


\section{POINTS THAT REQUIRE FURTHER INVESTIGATION ${ }^{1}$}

As stated in an earlier part of this chapter, there are still many points in connection with mosquitoes that require further investigation. These investigations may result in improvements in our present methods of dealing with mosquitoes or in the development of entirely new measures of control.

Among the points that may be profitably studied, the following may be mentioned:

1. Hibernation of adult mosquitoes of the various species. What are the natural hibernation places? What relation have shade, shelter, direetion of prevailing winds, proximity of standing water, ete., to the hiberation places? Can any method be devised whereby the mosquito may be successfully attacked during the hibernation period?

2. Survival of larvae over the winter. Can any method of attack be devised that will be of value?

3. Life of the egg. What conditions of dryness will eggs of the various species and genera withstand? How long will eggs of the various species and genera retain their vitality? What circumstances result in depriving the eggs of vitality?

4. Flight distances of the various species and genera, and local conditions influeneing flight, such as moisture, wind, etc.

5. Aquatic plants influeneing mosquito production. What are they, in what manner do they influence production and how can they be utilized in mosquito eontrol work?

6. Factory and chemical wastes which prevent.or favor mosquito-breeding. What are they, and can they be utilized in mosquito control work?

7. How is it that some places, which apparently should, do not produce mosquitoes? What is the connection between the animal and plant life, ehemical and physical properties of the water in such pools and the absence of breeding therein?

8. Some larvicide that does not require replacement as soon as oil and the larvicides now in use. Some larvicide that will be cheaper than those now in use.

These are some of the many points about mosquitoes that more light is desired on. Observation of field workers may result in considerable progress being made.

${ }^{1}$ Adapted from circular of Office of Field Investigations of Malaria, U. S. Public Health Service. 


\section{CHAP'TER XII}

\section{RURAL MOSQUITO AND MALARIA CONTROL}

\section{UNFAVORABLE FACTORS IN RURAL CONTROL}

Mosquitoes and mosquito-borne diseases are, in general, more troublesome in the rural regions than in the cities. Construction of water-supply and sewerage systems eliminates a multiplicity of artificial breeding-places, while city grading and ditching help to provide a means for rain-fall to run off, thus largely obviating the rain-water pool as a breeding-place.

In the rural areas, there are always a number of natural breeding-places. To these must be added the man-made breedingplaces, more or less necessary in the country, but not in the eity, such as cisterns, stock-troughs, stock-ponds, cesspools and a host of others. Furthermore, a certain amount of anti-mosquito work now is being done in most large eities that require it, while in the country, owing to sparsity of population and the large areas involved, community anti-mosquito measures are generally impracticable at present, due to the heary per capita cost. It will be seen, therefore, that at the present time, at least, the problem of mosquito control in rural districts is essentially an individual one.

Towns and villages without modern sanitary conveniences and the unsewered outlying suburbs of the cities are also more difficult to handle than the cities, for the same reasons given above. Anti-mosquito measures in them are, however, somewhat more practicable than in the country itself, because of the greater density of population, which means that the cost will be spread over a much greater number of beneficiaries per unit of area.

\section{FAVORABLE FACTORS IN RURAL CONTROL}

On the other hand, however, it may be saicl that, as a rule, the rural home is better situated, from an anti-mosquito standpoint than many urban homes. Frequently the rural home is situated on fairly high ground, where the wind ean reach it and at a respectful distance from such natural breeding-places as swamps, ete. 
Furthermore, the eleanly and progressive farmer need not suffer from the sloth, ignorance and negligence of his neighbors, as is often the ease with the city or town man. Houses are usually far enough apart to render impossible much annoyance from mosquito-breeding in and about the homes of neighbors. Thus, in order to be free from mosquitoes, the intelligent countryman need only keep his own home in shape.

Sometimes, this is a comparatively easy matter; sometimes it is almost impossible. Much depends upon the topographieal

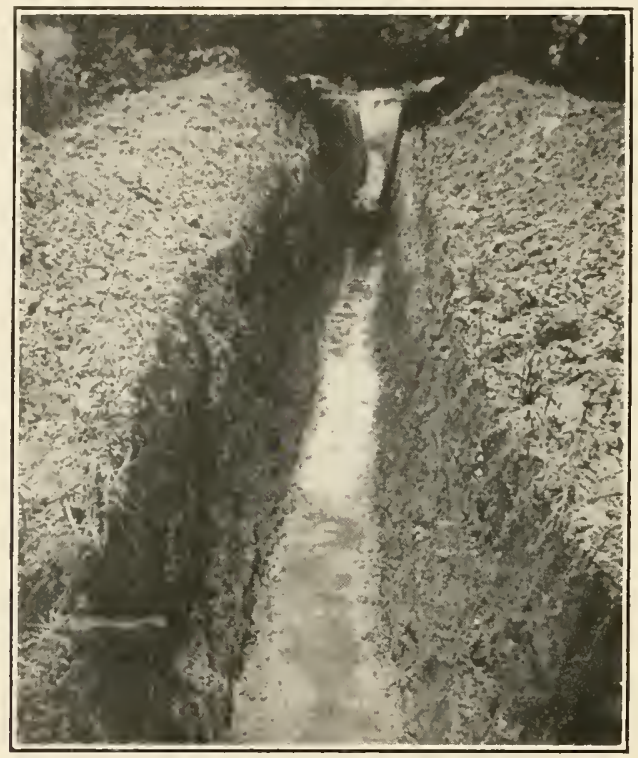

(Photo by E. B. Johnson, C. E.)

FIG. 141.- This ditch, in places 15 feet deep and more than a mile long, was dug by 5 Alabama farmers as a land-improvement project. It drained a swamp of nearly 50 acres.

and meteorological conditions of the district. Thus, in the delta country of the Mississippi, a region of fertile, low-lying soil, interspersed with bayous and slowly-moving streams and having a heavy rain-fall, an individual can do but little. In a well drained section, however, where the home is favorably situated, there is no reason why mosquitoes should cause any annoyance.

\section{NEED FOR A SURVEY}

In undertaking mosquito control measures about the average rural home, probably the first consideration is cost. It would be 
unreasonable to spend more money for mosquito control than such control is worth. The first thing, therefore, is to ascertain what amount is available for the work. This done, it will be possible to determine just what measures will give the most relicf for the money.

Thus, while it may not be possible to eliminate mosquitoes entirely from the home, it may be possible to reduce them greatly at very slight expense. Again, it may be that, while a certain measure, such as tile drainage, for example, might cost too much as an anti-mosquito measure alone, the other benefits that come from it, as improvement of the crop yield, might make the project feasible.

The first essential, then, after determining the amount available for the work is to make a careful survey of the situation from every angle. Doubtless, the survey will show that a considerable amount of breeding can be eliminated at no cost whatsoever, other than a little care and study.

\section{CONTROL MEASURES ABOUT THE AVERAGE HOME}

The first step to take in eliminating mosquito-breeding about the rural home is to stop giving aid and assistance to the enemy. This means that no breeding should be made possible by ignorance or earelessness on the part of the farmer and his family. In other words, cisterns, water-barrels, wells, etc., should either be made mosquito-proof or else should be oiled weekly or stocked with larva-eating fish. The cess-pool should be inspected and, if necessary, made mosquito-tight. Old cans likely to hold water should be hauled away. The roof-gutters should be cleaned out and, if necessary, re-hung. Water-troughs should be cleaned out weekly or stocked with fish. Everypotential breeding-place about the home should be closely watched.

The next step should be sereening. This should be done properly and effectively, along the lines already described. If the house is already screened, any repairs necessary should be made at once. The chimneys should not be forgotten.

These two steps should suffice to prevent any considerable annoyance by mosquitoes in most properly situated homes.

\section{FURTHER MEASURES}

Sometimes, further measures are necessary. It may be that the home is located near borrow-pits or other depressions that 


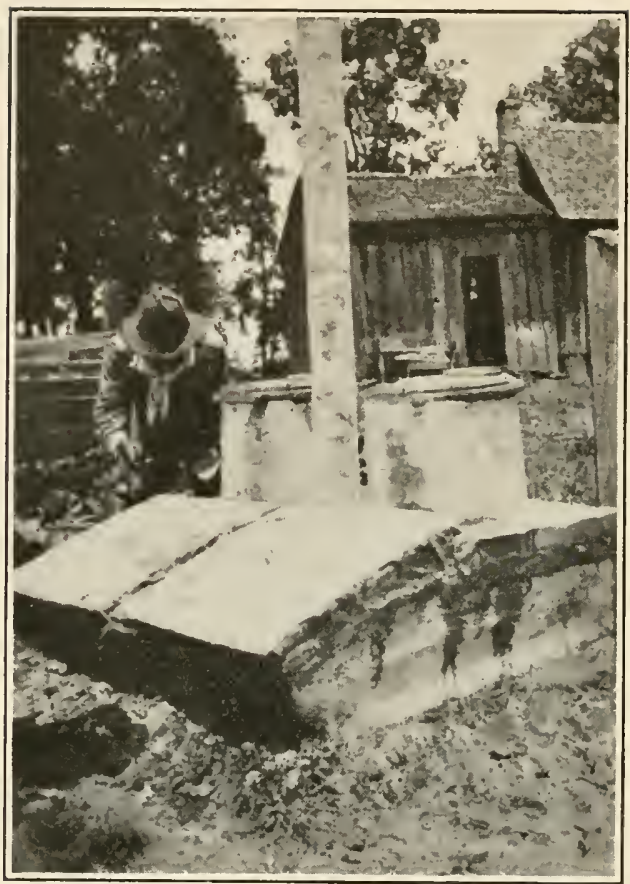

F1G. 145.-Making a concrete privy-vault mosquito-proof. All cracks are plastered over.

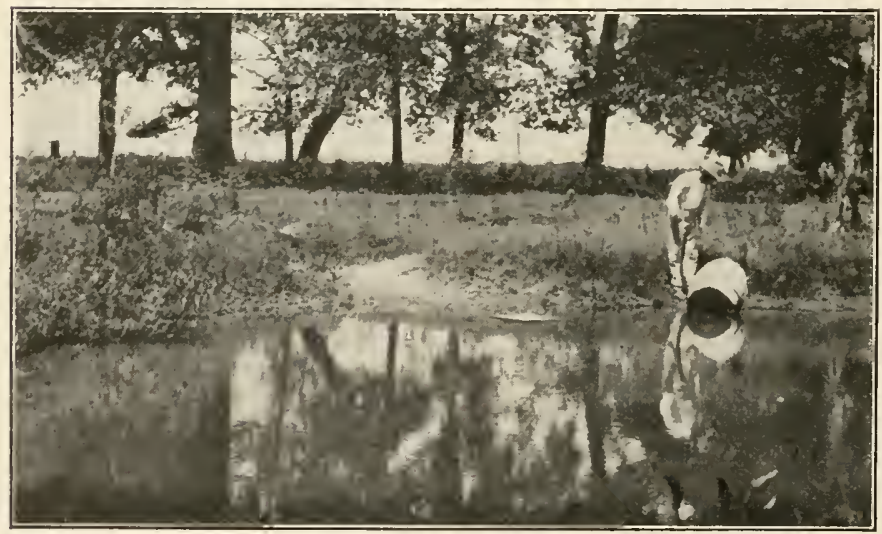

(Photo by E. H. Mfagoon, C. E.)

FIG. 146.- While this pond was free from mosquito larvae, owing to the activities of Gambusia, there was abundant breeding in the barrel which the fish were unable to enter. 
hold water for considerable periods. In this ease, the holes should be filled or drained, in accordance with the suggestions ontlined in a previous chapter.

Should the house be near a flowing stream, fish control probably would be the best method of attack. Even though the edges of the stream were not cleaned periodically, a certain measure of protection would always be assured. Should the stream be one that dries up from time to time, probably the best thing to do would be to oil it, whenever necessary, or, if not too costly, re-channel the stream, so that no water would stand in it for longer than a few days.

\section{PROTECTING HOMES IN SWAMPS, ETC.}

A home situated in or near a swamp woukl give nore trouble. In this case, it probably would pay, in the long rum, if funds were available, to drain the swamp. If this were impracticable, however, for any reason, there are several things that could be done, in addition to sereening and elimination of breeding about the home, that would be of great assistance. Among them are the following:

1. Cut down brush, tall weeds and grass that harbor mosquitoes. Make the yard about the house a shrubless one-open to the sum and wind at all times. High trees may be left.

2. Plant a screen of trees some distance from the house between the breeding-place and the house. This, according to Carter, ${ }^{1}$ serves to hide the lights of the house from the marsh or stops the mosquitoes brought by the breeze from their breeding-places, or both.

3. Stock the swamp or those parts of it adjacent to the house with larva-dlestroying fish.

4. Try starting a bat-roost. While some authorities are doubtful of the efficacy of this procedure, it would cost but little to try it out.

5. Oil nearby portions of the swamp from time to time or install a few submerged drips therein.

6. Build the stables between the house and the swamp, at some distance from the former. If the stables are ahready built elsewhere, or there are none, pasture eattle, hogs or other domestic animals between the house and the swamp.

1 "Anti-malarial Measures for Farm-houses and Plantations." U. S. Public Health Service, 1919. 
7. Make use of some mosquito-repelling substance in the home.

8. Kill all mosquitoes that succeed in penetrating the screens or otherwise entering the house.

9. If symptoms of malaria develop, use quinine, as directed in a previous chapter.

\section{THE RICE-FIELD PROBLEM}

An area within or near a rice-field is the worst possible site for a home from an anti-mosquito point of view.

In the light of our present knowledge, there is no really effective means of protection in such a case. This is due to the methods used in growing rice, which call for flooding of the cultivated area for several months. In the Arkansas rice section, flooding water is first applied when the riee is 3 to 5 inches high; the depth is increased with the growth of the rice until a depth of 4 to 6 inches is reached, and this depth is maintained during the growing season. It will be seen therefore, that rice-fields constitute an idcal breeding-place, since there is quiescent water and dense vegetation.

Some slight measure of success in reducing larvae by means of Gambusia affinis is reported by Tarbett. ${ }^{1}$ He states, however, that they fail generally to penetrate the rice, remaining ehiefly in the more open water along the levees.

Tarbett ${ }^{1}$ also reports that broad-casting oil-soaked saw-dust appeared to give somewhat encouraging results. Dry red-oak saw-dust was used. Thirty gallons of oil, soaked up into 10 bushels of saw-dust, sufficed for one acre. "The results obtained were encouraging," he says, "breeding being controlled for a period of two weeks after application, and this without an appreciable effect upon the rice. In this experiment, fuel oil appeared to give better results than did mixed oil" (mixed with kerosene).

\section{THE RICE-FIELD PROBLEM ABROAD}

According to Gunasekara, ${ }^{2}$ little rice is raised in Ceylon because of the increased incidence of malaria which it gives rise to and of the vigorous methods of combatting the infection carried out there. These include: abandonment or removal of all dwellingplaces within a mile of the rice-fields; destruetion of all harboring

1 Transactions of the First Annual Conference of Sanitary Engincers, U. S. Public Health Service, 1919.

${ }^{2}$ Journal, Ceylon Branch, British Medical Association, 1919. 
places for adults within the same radius; compulsory screening of dwelling-places; exclusion of all outside labor without previous blood-examination; the prophylactic and eurative administration of quinine; and the removal of all infective cases from the area.

Legendre reports that in Madagascar, Cellia squamosa and C. pharoensis, local Anopheline hosts of malaria, manifest a preference for rice-fields as breeding-places as against marshes and swamps. He asserts that malaria is more prevalent in the hill rice-fields than in the lowland fields, and attributes this fact to the greater abundance of fish in the lowland rice-fields. Recommendations made to combat malaria in Madagascar include institution of an anti-larval service, forbidding of irrigation in the vicinity of towns and compulsory culture of fish, wherever practicable.

According to Carter, ${ }^{2}$ attempts to control malaria about the rice-fields of Italy have been given up. He states that cultivation of rice is now forbidden within 2 kilometers of a village.

Carter states that in 1917 it was estimated that about $\$ 40,000,000$ was invested in the production of rice in the United States and that this investment is rapidly increasing.

\section{COMMUNITY MEASURES IN RURAL AREAS}

As has been already indicated, community offensire measures against the mosquito at the present time are rarely carried out in rural sections, due to the sparsity of population per unit of area and the heary consequent per capita cost.

Sometimes, however, considerable valuable anti-mosquito work is done by drainage district organizations, as the result of measures designed primarily as agricultural improvements. While this sort of work is not so effective, from an anti-mosquito standpoint, as work expressly designed to rid the community of mosquitoes, it is, nevertheless, of considerable assistance.

Again, two or more farmers may combine to carry out a tile drainage scheme. This, likewise, has its value, from a health viewpoint.

However, it would appear that the rural population will have to become much denser and land will have to increase greatly in value before it will be practicable to carry out in most rural

${ }_{1}$ Bulletin, Soc. Path. Exot., Feb. 9, 1921.

2 Transactions of the First Annual Conference of Sanitary Engineers, U. S. Public Health Service, 1919. 
communities the direct offensive anti-mosquito campaigns that are being waged in cities, towns and villages today.

Several community protective projects have been successfully carried out, however. These include both sereening and quininetreatment campaigns. Some of these have extended over comparatively wide areas, and have succeeded in greatly reducing the incidenee of malaria.

\section{RURAL COMMUNITY PROTECTIVE DEMONSTRATIONS}

An interesting demonstration of the efficacy of sereening as a community protective measure, carried out on a group of plantations near Lake Village, Ark., is deseribed in the chapter on screening. In this demonstration, no other measure than screening was employed; yet a reduction of 70.6 per eent in the incidence of malaria was obtained at an annual per capita cost of only $\$ 1.76$.

In connection with this same demonstration, an investigation as to the efficacy of quinine treatment was carried out on another group of plantations. Of a total of 306 persons who received treatment, 69 were given sterilizing doses and the remainder, 237, were given immunizing doses. A parasite index taken in May, 1916, at the beginning of the work, and again in Deeember of the same year, showed a reduction of 64.45 per cent. The per capita cost of the work, omitting overhead expenses, was 57 cents. The cost of malaria per capita for a control untreated group was $\$ 2.52$.

In 1918, a demonstration of malaria reduction by quinine treatment of plasmodia carriers was carried out in Sunflower County, Mississippi. The county had a population of about 9,000 , about 1,000 living in the town of Ruleville and the rest on cotton plantations. A survey showed that, of the rural population, 40 per cent had had clinical malaria within 12 months and that, of the remaining 60 per eent, 22 per cent had the parasites in their blood. On one plantation, having a tenant population of 600 , the average annual physicians' bill for the preceding 10 years had been approximately $\$ 4,000$, of which $\$ 3,000$ was attributed to malaria. As a result of the work, there was no transmission of malaria in Ruleville during the year, and the town was free from mosquitoes. In the rural area, the recluetion in the incidence of malaria during the year was estimated at 
80 per cent. The per capita cost of the work in Ruleville was 41 cents and in the rural area, $\$ 1.08$.

In Chapter XI is described another extensive community demonstration of quinine treatment in Cieorgia, which, at a cost of only about $\$ 1.50$ per person taking treatment, resulted in the almost total elimination of malaria symptoms in more than 10,000 persons 
APPENDIX A

\section{TABLE TO DETERMINE SPECIES OF CERTAIN COMMON AMERICAN MOSQUITOES}

The following table, prepared by Weiss and Patterson, is reprinted from Headlee's valuable pamphlet, "The Mosquitoes of New Jersey and 'Their Control," with some abridgment and with certain changes in nomenclature suggested by the work of Howard, Dyar and Knab:

\section{ADULTS}

\section{Series $\mathrm{X}$ in Which the Wings are Spotted}

\section{PALPI UNIFORMLY DARI BROWN}

Wings with two white spots on the front margin; last vein white with black ends, Anopheles punctipennis Say.

Wings with four distinet brown spots; last vein wholly dark brown, Anopheles quadrimaculalus Say.

PAIPI WHITE MARKED A'T BASE OF JOINTS

Last vein white marked with three black spots, Anopheles crucians Wied.

\section{Series $\mathrm{Y}$ in Which the Wings are not Spotted}

\section{A. IN WHICH THE FEET ARE WHITE OR YELLOWISH BANDED}

I. The Beak has a More or Less Distinct White Band or Ring at or Near its Middle.

(a) The abdomen has a yellowish stripe down its middle, and sides of thorax are white below a black edging, Acdes sollicitans Wlk.

(b) The abdomen has no yellowish stripe. Sides of thorax are not white.

1. A large, blackish species with a narrow white band near the tip of the femur; the tibia, white-spotted, Psorophora (Janthinosoma) columbiae D. and K.

2. A large brown species with a lighter band near the tip of the posterior tibia, the latter not spotted, Mansonia perturbans Wlk.

3. A smaller, blackish species, without markings on femur or tibia, Aedes laeniorhynchus Wied.

II. The Beak is Without Band or Ring; Uniforin in Color

(a) The joints of the feet or tarsi are banded or ringed at base only.

1. An extremely large, brownish-black speeies. Legs fringed with ereet black scales, Psorophora ciliata Fabr. 
2. A very large speeies with very sealy wings, the sides of the thorax and bands of the abdomen and feet, white, Aedes grossbecki D. and K.

3. Wings thickly clothed with mixed yellow and brown scales. Thorax with broad, brown central stripe. First tarsal segment of anterior legs not banded, Aedes fitchii Felt.

4. A small, dark speeies with lightly sealed wings; the white bands of the feet narrow; those of the abdomen nearly divided in the center, Acdes rexans Meig.

5. A good-sized brown speeies with the bandings yellowish rather than white; these of the abdominal segments only a little or not at all notehed at the middle, Aedes cartatom Coq.

6. Very like the preceding; but the bands of the abdomen and feet are broader and somewhat lighter. Breeds only in fresh water areas, Aides stimuluns. Walker.

7. Very like the two precediug, but thorax has a central brown stripe, Aedes abfitchii Felt.

(b) The joints of the hind feet at least are white-banded or ringed at both base and tip, while last joint of the hind tarsi is usually entirely white.

1. A good-sized brown species, the thorax without lines or marks; bands of tarsal joints broad, Aedes eanadensis Theob.

2. A small, blackish species with top of thorax covered with gray hair and a dark line down its center; bands on tarsi are white and narrow, Aedes atropalpus Coq.

(e) All of last two tarsal joints and apex of middle joint white.

1. A large or medium-sized speeies, black with deep purple reflections, Psorophora (Janthinosoma) sayi D. and II.

\section{B. IN WHICH THE FEET ARE UNIFORM IN COLOR, NOT IN ANY WAY MARKED OR BANDED}

I. The Thorax is Marked in Some Way With sttripes or Spots, or the Sides are White or Golden Browr.

(a) Species with longitudinal white or blue stripes.

1. There are two white longitudinal stripes; the species is moderate-sized and blackish, Aedes trivittatus Coq.

2. There is a well-defined broad eentral white band, and the top of the head is also white, Aedes atlantieus D. and I.

3. There is a diffuse white eentral stripe, not defined as before; a very small blackish species, Aedes dupreei Coq.

4. There is a eentral bluish stripe, also blue spots. A small, dark-brown species, Uranotaenia sapphirina O. s.

(b) Species in which the thorax is yellowish, white or brown, leaving a blackish central stripe or two, usually not sharply defined; all of moderate size. 
1. The thorax is yellowish; brownish abdomen with narrow white bands, Aedes hirsuteron Theob.

2. The thorax is golden yellow. The abdomen is almost black, with broad, white bands, Aedes abserratus Felt.

3. The thorax is golden brown; the abdomen not banded; the legs are black, Aedes aurifer Coq.

4. The thorax is silvery-white at the sides, not extending much on the upper surface, most of which is black; the abdomen is not banded, Aedes triseriatus Say.

(c) Speeies in which the thorax is white-dotted only.

1. There are two small, white dots on each side of the middle and a U-shaped mark at the base; the abdomen is banded, Culex restuans Theob.

(d) Speeies in which the entire under surface is silvery white or yellowish.

1. A small form, having dorsal surface black; stripes on the thorax are irregular. Wyeomyia smithii Coq.

\section{The Thorax is Withodt Marks or Ornamentation}

(a) The segments of abdomen are narrowly banded at their bases.

1. A small dark-brown species; abdominal bands wider in the middle than at sides exeept on seventh segment, which usually has a narrow band, broad at the sides, Aedes fuseus O. S.

2. A moderate-sized brownish species with the bands of abdomen of moderate width, Culex pipiens Linn.

3. A somewhat darker, longer-legged speeies, with very narrow, regular abdominal bands, Culex salinarius Coq.

(b) The segments of the abdomen are narrowly banded at their apices only.

1. A small, slight, blackish species, Culex territans, Wlk.

(c) The abdomen has no bands or only the merest indieations of them.

1. A uniformly dark-brown speeies of moderate size, Culex melanurus Coq.

2. Species having thorax yellowish-brown, somewhat polished, with a thin, bluish-gray fresting, Anopheles barberi Coq.

\section{LARVAE}

Antennae arising from the sides of the head; antennae not pendant (1).

1. No siphon or breathing-tube on eighth abdominal segment, Anopheles (2).

A siphon or breathing-tube on eighth abdominal segment (3).

2. Antennae yellowish; tracheal gills moderate in size, A. punctipennis, A. quadrimaculatus.

Antennae shorter, brownish; tracheal gills short, A. crucians. 
3. Hair tufts on thorax and abdomen simple, sparse or absent (4).

Thorax and abdomen with star-shaped or stellate hair tufts, Uranotaenia sapphirina.

4. Abdomen with four tracheal gills at tip (5).

Abdomen with two tracheal gills only; a small whitish species, with hearl rounded and thorax subquadrate, Wyeomyia smithii.

5. Antennae arise from sides of anterior part of head (6).

Antennae arise from near middle of sides of head; the mouth brushes form a club at sides of mouth; a very large species, Psorophora eiliata.

6. The scales of the eighth abdominal segment are separate (S).

The scales of the eighth abdominal segment, 5 to $S$ in number, are arranged on a band ( $\bar{i}$ ).

The scales are replaced by a series of chitinous bars, arranged in a single row (22).

7. The anal siphon is very large and stout, dilated centrally; antennae much longer than head, slender with an even outeurve or convexity, Psorophora (Janthinasoma) sayi.

The anal siphon shorter, stout, dilated nearer the base; antennae nearly straight slender and shorter than head, Psorophora (Janthinasoma) columbiae.

8. The scales are not more than 16 in number and form a small patch (9).

The scales number 20 or more and form a large patch (12).

9. Annal siphon of moderate length, three times as long as wide, or longer (10).

Anal siphon short, less than three times as long as wide (11).

10. About 12 elongate scales in a single row; 12-16 siphonal spines, each with one moderate-sized tooth, and sometines a few very small ones below it, Aedes fuseus.

Scales 10-15, in partly double row, tapering apically; siphonal spines, 14-1S, simple or with 2 or 3 teeth, Aedes vexans.

Scales 7-12 in patch; a small, translucent species, feeding at bottom; tracheal gills very long and slender, Aedes dupreei.

Scales 6-7, arranged in a curve; tracheal gills, long, slender, uniformly tapering, Aedes abserratus.

11. A stout, black species; the thorax white-banded; antennal tuft composed of many hairs; tracheal gills very long, Aedes atlantieus.

An elongate, slender, gray species; antennal tuft a single bristle; tracheal gills short, Aedes triseriatus.

A large robust, light species; anal siphon bottle-shaped, outer half linear; anal gills slightly longer than width of ninth segment, Mansonia perturbans.

12. Anal siphon short, not much more than twice as long as broad (13).

Anal siphon moderate, from $2 \frac{1}{2}$ to $3 \frac{1}{2}$ times as long as broad (15).

Anal siphon long, not less than 4 times as long as broad (21).

13. Stout, compact larva; antemnal tuft of several hairs (14).

Long, slender larva; antenual tuft of 1 or 2 hairs; 25-35 scales in patch; 17-21 siphonal spines, with 2 or 3 long teeth at base, Aedes atropalpus. 
14. Seales 14-22, with stont apical and slender lateral spines; 13-18 siphonal spines with 2 or 3 small teeth sometimes simple; fresh water, Aerles trinittatus.

Scales 16-22, with rounded apex and slender lateral spines; 12-16 siphonal spines with 1-4 small teeth on both sides; head maculate; salt marsh, Aedes taeniorhynchus.

Scales 20-40, with stout apical and slender lateral spines; 16-24 siphonal spines with 1-5 small teeth; head generally immaculate; salt marsh, Aedes sollicitans.

15. Seales rather broad (16).

Seales elongate (17).

16. Seales $35-40$, with 3 stout apical and smaller lateral spines; $16-20$ siphonal spines with 1-3 small teeth; head maeulate; salt marsh, Aedes cantator.

Seales $25-50$, with one very stout apical and slender lateral spine; 16-22 siphonal spines, with 1-2 large and 4-6 smaller teeth on basal half; head immaeulate; fresh water form, Aedes stimulans.

17. Only the terminal segment, with a dorsal plate or ring (18).

18. Antennae not specially marked or colored (19).

Antennae prominent, white at base, dark at tip, Aedes aurifer.

19. Moderate-sized species (20).

Very large larva; seales 28-34, with long apical and slender lateral spines; siphonal spines $17-22$, with 4 or 5 large teeth basally, Aedes grossbecki.

20. Seales $25-50$ with short apical and rery short lateral spines; siphonal spines 16-20, with 1-2 teeth at base, one usually very large, Acdes hirsuteron.

Scales 25-50, with small apical and smaller lateral spines; $16-24$ siphonal spines with $4-5$ serrations on basal half; antenna dark at tip, Aedes canadensis.

21. Antennal tuft above the middle.

Anal siphon of moderate length, sides a little inflated; tracheal gills moderately long, Culex pipiens.

Anal siphon very long, rather slender and slightly tapering to tip; head narrower than thorax; tracheal gills short, Culex salinarius.

Anal siphon very long and slender; a little constricted centrally; head as wide as thorax; tracheal gills moderate or long, Culex territans.

Antennal tuft below middle.

Seales 24-30, antenna not arising from an offset, Aedes abfitchii.

Anal siphon of moderate length; tracheal gills rather long, Culex, restuans.

Anal siphon 5 times as long as widest diameter; antennae dark at tip, Aedes fitchii.

22. A bronzed, brown larra, with rather long, moderately stout, black breathing tube, Culex melanurus. 


\section{APPENDIX B}

\section{APPROVED ANTI-MOSQUITO ORDINANCE}

The following ordinance, prepared in connection with the joint, cooperative anti-malaria demonstration work of the U. S. Public Health Service and the International Health Board, has been adopted by a large number of eities, towns and villages in various parts of the United States, and has proven uniformly satisfactory:

ORDINANCE FOR THE PREVENTION OF MOSQUTTO BREEDING IN THE

Section 1.-It shall be unlawful to have, keep, maintain, cause or permit, within the (incorporated) limits of . . . . . . . . . . . . . . . . . . any collection of standing or flowing water in which mosquitoes breed or are likely to breed, unless such collection of water is treated so as effectually to prevent such breeding.

Section 2.-Any collections of water considered by Section 1 of this ordinance shall be held to be those contained in ditches, pools, ponds, excavations, holes, depressions, open cess-pools, privy vaults, fountains, eisterns, tanks, shallow wells, barrels, troughs (except horse troughs in frequent use), urns, cans, boxes, bottles, tubs, buckets, defective house roof gutters, tanks of flush closets or other sinilar water containers.

Section 3.-The method of treatment of any collections of water, that are specified in Section 2, directed toward the prevention of breeding of mosquitoes, shall be approved by the accredited health officer, and may be any one or more of the following:

(a) Screening with wire netting of at least 16 meshes to the inch each way or with any other material which will effectually prevent the ingress or egress of mosquitoes.

(b) Complete emptying every seren ( 7 ) days of unsereened containers, together with their thorough drying or cleaning.

(c) Using a larvicide approved and applied under the direction of the health officer.

(d) Covering completely the surface of the water with kerosene, petroleum or paraffin oil once every seven ( 7 ) days.

(e) Cleaning and keeping suffieiently free of vegetable growth and other obstructions, and stocking with mosquito-destroying fish.

(f) Filling or draining to the satisfaction of the health officer.

(g) Proper disposal, by removal or clestruction, of tin cans, tin boxes, broken or empty bottles and similar articles likely to hold water.

Section 4.-The natural presence of mosquito larvae in standing or running water shall be evidence that mosquitoes are breeding there, and failure to 
prevent such breeding within three (3) days after notice by the health officer shall be deemed a violation of this ordinance.

Section 5.-Should the person or persons responsible for conditions giving rise to the breeding of mosquitoes fail or refuse to take necessary measures to prevent the same, within three (3) days after due notice has been given to them, the health officer is hereby authorized to do so, and all necessary cost incurred by him for this purpose shall be a charge against the propertyowner or other person offending, as the ease may be.

Section 6.-For the purpose of enforeing the provisions of this ordinance, the health officer, or his duly aceredited agent, acting under his authority, may at all reasonable times enter in and upon any premises within his jurisdiction; and any person or persons charged with any of the duties imposed by this ordinance failing, within the time designated by this ordinance, or within the time stated in the notice of the health officer, as the ease may be, to perform such duties, or to earry out the neeessary measures to the satisfaction of the health officer, shall be deemed guilty of a separate violation of this ordinance.

Section 7.-Any person who shall violate any provision of this ordinanee shall on each convietion be subject to a fine of not less than One Dollar (\$1.00) or more than Twenty-five Dollars $(\$ 25.00)$, in the diseretion of the court.

Section 8.-All ordinances or parts of ordinances in eonflict with this ordinance are hereby repealed, and this ordinance shall be in full foree and effect days after its approval.

Adopted this.............. day of.....

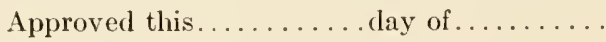




\section{APPENDIX C}

\section{SUGGESTED ANTI-MOSQUITO LEAFLET FOR CAMPAIGN}

\section{EDUCATIONAL WORK}

The experience of the writer has been that only a very small proportion of the inhabitants of the average American municipality have any adecuute idea as to where and in what manner mosquito-breeding takes place about homes, and, consequently, a vast amount of mosquito production ean be eliminated if the citizens are made cognizant of a few simple facts on the subject and persuaded to give their co-operation.

The following matter is not presented as a model essay on the subjeet. It is submitted only to give some idea of the facts which, in the opinion of the writer, ought to be given the people of a town engaging in mosquito control work, in order to obtain their intelligent co-operation. It is believed that the expense of printing and distributing such a leaflet will be more than repaid by the resulting assistance of the informed citizens.

\section{YOUR PAR'T IN THE CITY ${ }^{1}$ AN'TI-MOSQUITO CAMPAIGN}

\section{How to Get Rid of Mosquitoes About The Hone}

Mosquitoes Spread Malaria; Mosquitoes Can Be Eliminated.-In view of the proven fact that mosquitoes are solely responsible for the spread of malaria and other serious diseases and of the further proven fact that mosquitoes ean be done away with in any ordinary community by intelligent effort, the City ${ }^{1}$ authorities have decided this year to initiate an antimosquito eampaign in ........... ${ }^{2}$ and an appropriation has already been made for the purpose.

People Must Lend Their Aid; Your Job and the City's. ' - In order that the eampaign be a success, it is absolutely necessary that every citizen do his part. The eity is prepared to prevent mosquito-breeding in streams, ponds, swamps and other natural breeding-places throughout the City, ${ }^{1}$ as well as in roads, streets, parks and other public places, but the private citizen must prevent mosquito-breeding on his own premises, insofar as such breeding is a result of his own activities or his own negligence. This duty is imposed upon the eitizen by City ${ }^{1}$ ordinanee.

Purpose of This Leaflet Is To Tell You How To Do Your Part.-This leaflet is distributed by the City ${ }^{1}$ with the object of aiding eitizens in doing

1 Substitite Town: or Village, where neeessary.

${ }^{2}$ Insert name of place. 
this duty, by telling them something about the breeding-habits of mosquitoes and about practical and easy ways to prevent such breeding.

It should be fully understood that there is absolutely no doubt that mosquitoes spread malaria and other diseases, nor that mosquitoes can be virtually done away with in any ordinary community. The work on the Panama Canal Zone and in numerous other places has fully demonstrated the truth of these statements.

Some Common Breeding-places about the Average Home.-Mosquitoes breed only in standing or slowly running water. The belief that they breed in grass, bushes or other such places was exploded many years ago. Hence, if we are to do away with mosquitoes, we must either do away with the water or else take steps to prevent them from breeding in it. These other steps include screening, oiling, stocking with mosquito-destroying fish, etc. Which of these measures to take in any particular case depends upon the circumstances, as will be explained direetly.

The usual breeding-places of mosquitoes about homes are: eisterns; harrels, tubs and buekets of water; shallow wells; pools of water from rains, leaky pipes, etc.; tin eans, bottles, ete., that hold water; water-troughs; cess-pools that are not tightly covered; certain types of privies that mosquitoes ean enter; stopped-up roof gutters, ete. In fact, any collection of water that a mosquito can get to is likely to become a breeding-place.

How to Handle the Various Breeding-places.-The best measure to take to stop breeding in any eertain case depends upon the nature of the breedingplace. Thus, where possible, pools of water should be drained; if they cannot be drained, they should be oiled (that is, covered with a visible film of kerosene or other light mineral oil) once a week or else stocked with mosquito-destroying fish, which may be obtained from the City. ${ }^{1}$ Surface eisterms should he screened in such manner that they will be mosquitoproof; underground cisterns should be tightly covered or else stocked with a few nosquito-destroying fish. Barrels, tubs and buckets of water should either be sereened with burlap or netting or else oiled once a week or else emptied and thoroughly dried out onee a week. The best way to handle shallow wells is to stock each with two or three mosquito destroying fish, which will in no way injure the water. Tin cans, bottles, ete., should either be buried or hauled away. Water-troughs should be emptied and then dried out thoroughly once a week. Cess-pools, etc., should be tightly covered and mosquito-breeding privies should be well oiled, after which the lids should be kept elosed down, whenever the privy is not in use. Stoppedup roof gutters should be eleaned out and, where neeessary, re-hung.

Make Inspection of Your Premises Once Every Week.-The City ${ }^{1}$ experts citizens to eliminate or otherwise take eare of any and all of the abovementioned elasses of breeding-places that may be on their premises. One of the best ways of doing this is for each eitizen to make a close inspection of his premises at least once a week, and particularly after heavy rains, emptying all unsereened receptacles containing water or else oiling or otherwise treating them, paying particular attention to tin eans, ete. The reason for making the inspection weekly is that it requires only a little more than a week for the full-fledged mosquito to develop from the egg.

${ }^{1}$ Substitute Toun or Village, where necessary. 
How the City ${ }^{1}$ Helps You To Do Your Part.--An aquarium of mosquitodestroying fish is kept up by the City ${ }^{1}$ anti-mosquito forces for the purposes of supplying all eitizens who may have use for them. These fish are very effeetive for cisterns, shallow wells and more or less permanent pools which it is impracticable to drain. In order for the fish to work effectively, however, it is necessary to keep the pool free from vegetation.

The City ${ }^{1}$ anti-mosquito forces will be glad to help willing citizens in any other manner possible. The director of the campaign will at all times take pleasure in advising such citizens as to the best methods of solving their problems. Citizens who refuse or neglect to keep their premises free from mosquito-breeding will receive seant eonsideration, however. Periodical inspections will be made of every home in the City ${ }^{1}$ and persons who fail to eomply with the law will be prosecuted. The ordinanees provide for a fine of from $\$ 1.00$ to $\$ 25.00$ for each violation.

No Fun Raising Mosquitoes; They Cost City ${ }^{1}$ Real Money.-Howerer, it is the belief of the City ${ }^{1}$ authorities that few, if any, prosecutions will be necessary in .............. There is no pleasure to be derived from raising mosquitoes, and mosquito-farms do not bring any profit; on the contrary, as already stated, mosquitoes spread malaria and other diseases, which yearly cause a vast amount of suffering and expense. It is figured $h y$ health experts that each case of malaria costs from $\$ 15$ to $\$ 20$ in loss of time, loss of efficiency, medicines and physicians' bills. As it is estimated that there were, . . . . eases of malaria in . . . . . . . . . . last year, it will easily be seen that it is to the interest of every eitizen to help eut down this big annual community expense. In addition to the sickness they cause, the amnoyance oecasioned by mosquitoes is well known to every one, and of itself would make it well worth while to do away with the mosquito.

Raising Mosquitoes Almost As Bad As Raising "Conties."-But there is another reason why each eitizen should do his utmost to prevent mosquitobreeding about his home. That is self-respect. A man who raises "cooties" on bis person is regarded as slothful and unclean. The day is not far distant when a man who raises mosnuitoes on his premises will be regarded as equally slothful and unclean.

Director,.........

Anti-mosquito Campaign.

${ }^{1}$ Substitute Toun or V'illage, where necessary.

${ }^{2}$ Insert name of place. 


\section{APPENDIX D}

\section{BIBLIOGRAPHY}

The following publications have been consulted in the preparation of this work:

Transactions of the First Annual Conference of Sanitary Engineers and Other Officers of the Public Health Service Directing Anti-malaria Campaign, Public Health Bulletin No. 104, U. S. Public Health Service, Washington, D. C., 1919.

Transactions of the Second Annual Anti-malaria Conference of Sanitary Engineers and Others Engaged in Malaria Field Investigations and Mosquito Control. Public Health Bulletin No. 155, L'. S. Public Health Service, Washington, D. C., 1921.

Mosquito Control About Cantonments and Ship-yards, by J. A. LE Prixce, Reprint No. 511, U. s. Public Health service, 1919.

Anopheles Crucians Wied. As an Agent in Malaria Transmission, by C. IV. Metz., Reprint No. 536, U. S. Public Health Service, 1919.

Malaria: A Public Health and Economic Problem in the United States, by John W. Trask, Reprint No. 3S2, U. s. Public Health Service, 1917.

Malaria Control: Drainage as an Anti-malarial Measure, by J. A. LEPrince, Reprint No. 25s, U. S. Public Health Service, 1915.

Control of Malaria: Oiling as an Anti-mosquito Measure, by J. A. LePrince, Reprint No. 260, U. S. Public Health Service, 1915.

Filariasis in Southern United States, by Edward Fraxcis, Hygienic Laboratory Bulletin No. 117, U. S. Public Health Service, 1919.

Field Identification of Malaria-carrying Mosquitoes, by Ernest A. Sweet, Supplement No. 32, U. S. Public Health Service, 1918.

Anopheles Crucians: Habits of Larvae and Adults, by C. W. Metz, Reprint No. 495, U. S. Public Health Service, 1919.

Observations on the Food of Anopheles Larrae, by C. W. Metz., Reprint No. 549, U. S. Public Heálth Service, 1919.

The Malaria Problem of the South, by H. R. Carter, Reprint No. 552, U. S. Public Health Service, 1919.

The Relations of the Railroads in the South to the Problem of Malaria and Its Control, by R. C. Derraux, Reprint No. 450, U. S. Public Health Service, 1918.

Use of Dynamite in Anti-malarial Drainage Operations, by J. K. Hoskins and IT. E. Hardenburg, Reprint No. 493, U. S. Public Health Service, 1919.

Malaria: Lessons on Its Cause and Prevention, by H. R. CARTER, Supplement No. 18, U. S. Public Health Service, 1918.

What the Farmer can do to Prevent Malaria, by R. H. Vox Ezdorf, Supplement No. 11, I. S. Public Health Service, 1914.

Demonstrations of Malaria Control, by R. H. Vox Ezdorf, Reprint No. 328 , U. S. Public Health Service, 191s. 
Some Aspects of Malaria Control Through Mosquito Eradication, by C. W. Metz, Reprint No. 500, U. s. Public Health Service, 1919.

Anopheline Surveys: Methods of Conchet and Relation to Anti-malarial Work, by R. H. Von Ezdorf, Reprint No. 272, U. S. Public Health Service, 1918.

Prevention of Malaria: Suggestions on How to Screen the Home to Kieep Out Effectively the Mosquitoes which Spread Disease, by R. H. Vow Ezdorf, Reprint No. 170, U. S. Public Ilealth Service, 1916.

Malaria Control: A Report of Demonstration Studies Conducted in Urban and Rural Sections, by R. C. Derivaux, H. A. TAYlor and T. D. HaAs, Public Health Bulletin No. Ss, U.s. Public Health Service, 1917.

Malaria Control: Results Obtained by a Local Community Following Anti-mosquito Demonstration Studies by the United States Public Health Service in co-operation with the International Health Board, by J. E. Sparks, R. C. Derhyux and H. A. Taylor, Reprint No. 476, U. S. Public Health Service, 191s.

Anti-malarial Measures for Farm-houses and Plantations, by H. R. Carter, Reprint No. 105, ए. S. Public Health Service, 1919.

Fishes in Relation to Mosquito Control in Ponds, by s. F. Hildebrand, Bureau of Fisheries Document No. $87 t$, U. S. Bureau of Fisheries, Washington, D. C., 1919.

Notes on the Life History of the Minnows, Gambusia Affinis and Cyprinodon Variegatus, by S. F. Hildebrand, Bureau of Fisheries Document No. 857, U. S. Bureau of Fisheries, 1917.

Tile Drainage on the Farm, by A. G. Surtu, Farmers' Bulletin No. 524, U. S. Department of Agriculture, 1917.

Trenching Machinery Used for the Construction of Trenches for Tile Drains, by D. L. YARnell, Farmer's' Bulletin No. 698, U. S. Department of Agrieulture, 1915.

The Mosquitoes of New Jersey and Their Control, by Thomas J. Headlee, Bullctin No. 276, New Jersey Agricultural Experiment Stations, New Brunswick, N. J., 1915.

Some Recent Advances in Knowledge of the Natural History and the Control of Mosquitoes, by Thomas J. Headeee, Bulletin No. 306, New Jersey Agricultural Experiment Stations, New Brunswick, N. J., 1916.

A Biological Study of the More Important of the Fish Enemies of the Salt Marsh Mosquitoes, by F. E. Chidester, Bulletin No. 300, New Jersey Agricultural Experiment Stations, New Brunswick, N. J., 1916.

"Field Experiments in Malaria Control," by Wicklfffe Rose, American Medical Association, Chicago, 1919.

The Importance of Malaria from A Public Health and Eeonomic Standpoint, by W. S. Leathers, Southern Mclical Journal, Birmingham, Ala., 1918 .

"Preventive Medicine and Hygiene," by Milton J. Roesnad, D. Appleton \& Co., New York and London, 1918.

"A Plea and a Plan for the Eradication of Malaria Throughout the Western Hemisphere," by Frederick L. Hoffuar, Prudential Insurance Company of America, Newark, N. J., 1917.

"The Use of Explosives in Making Ditches," Institute of Makers of Explosives, New York, 1917. 
"Blasters' Hand-book," E. I. duPont de Nemours \& Company, Wilmington, Del., 1918.

"Myers' Spray Pumps," F. E. Myers \& Bro., Ashland, Ohio.

"Caleo Automatic Drainage Gates," California Corrugated Culvert Company, West Berkeley, Calif.

Other publications on mosquitoes and kindred topics include:

"The Mosquitoes of North and Central America and the West Indies," by L. O. Howard, H. G. DYar and Frederick Kinab, Carnegie Institution, Washington, D. C.

"A Monograph of the Culicidae of the World," by F. V. Theobald, British Museum, London, England.

"Mosquito Control in Panama," by J. A. LePrince and A. J. Orenstein, New York, 1916. 


\section{INDEX}

A

Abercrombie, 216, 217

Abramis chrysolenca, 183

Acilius sulcatus, 211

Aedes calopus, 9, 34

canadensis, 42

cantator, 48

sollicitans, 44

taenierhynchus, 48

vexans, 42

Aegilitis semipalmata, 211

Aeschna, 211

Agamodistomum martiranoi, 211

Agamomermis culicis, 211

Albany, Ga., particulars of antimosquito work at, 61

Alexandria, La., war anti-mosquito work at, 59

Alexandria, Va., war anti-mosquito work at, 59

Algae, $18 s$

Alto, Tex., particulars of antimosquito work at, 64

Amblystoma opacum, 211

Americus, Ga., war anti-mosquito work at, 59

Anas platyrhynches, 211

Animals as protection against mosquitoes, 214

Anniston, Ala., war anti-mosquito work at, 59

Anopheles albimanus, 25

argyritarsis, 25

claviger, 25

costalis, 25

crucians, 25, 29

intermedium, 25

maculipennis, 25

occidentalis, 25,32

pseudomaculipes, 25

pseudopunctipennis, 25

punctipennis, 25, 30
Anopheles albimanus, quadrimaculatus, 25, 28

sinensis, 25

tarsimaculate, 25

Anophelinae, in general, 25

identification of, 25

Anti-mosquito campaign costs, 63

campaign leaflet, 235

ordinance, 233

Applying oil, other methods of, 167

Aquarium, need for, 183

Articles, texts for, 92

Ashburn, 11

Athens, Tex., particulars of antimosquito work at, 64

Atlanta, Ga., war anti-mosquito work at, 59

Augusta, Ga,, war anti-mosquito work at, 59

\section{B}

Bamberg, s. C., particulars of antimesquito work at, 64

Barber and Hayne, 163

Barred killifish the, 176

Bastrop, La., particulars of antimosquito work at, 64

Bat, the, as a mosquito-destroyer, 210

Batesville, Miss., particulars of anti-mosquito work at, 64

Baton Rouge, La., particulars of anti-mosquito work at, 64

Bauxite, Ark., demonstration at, 56

Beginning of mosquito control, the, 51

Bibliography, 238

Biloxi, Miss., anti-mosquito work at, 59

Bishop, 133, 162

Blasting ditches, 113

Boom, to prevent eseape of oil, 192

Breeding-places about homes, 83 
British Guiana, malaria mortality in, 7

British Honduras, malaria mortality in, 7

Brownsville, Tenn., particulars of anti-mosquito work at, 64

Bryan, Tex., particulars of antimosquito work at, 64

\section{C}

Cairo, Ga., particulars of antimosquito work at, 64

Calco gate, the, 153

Calvert, Tex, particulars of antimosquito work at, 64

Cameron, Tex., particulars of antimosquito work at, 64

Campbell, 210

Camphor, spirits of, as a mosquito repellent, 215

Carroll, 153

Carter, 6, 7, 55, 196, 198, 203, 204, 223

Central of Georgia Railway, malaria appropriation, 58

Ceylon, malaria mortality in, 7

methods of mosquito control in, 224

Chandeleur Islands, screening at, 204

Charleston, Miss., particulars of anti-mosquito work at, 64

Charleston, S. C., war anti-mosquito work at, 59

Charlotte, N. C., war anti-mosquito work at, 59

Chattanooga, Tenn., war antimosquito work at, 59

Chester, S. C., particulars of antimosquito work at, 64

Chidester, 183, 211

Chiroptera, 210

Choetura pelagica, 211

Chordeiles virginianus, 211

Citronella, oil of, as a mosquito repellent, 215

Coffeeville, Miss., particulars of anti-mosquito work at, 64
Columbia, S. C., war anti-mosquito work at, 59

Columbus, Ga., war anti-mosquito work at, 59

Columbus, Miss., particulars of anti-mosquito work at, 64

Community measures in rural areas, 225

Complaint bureau, 88

Complaint form, 90

Control measures about the home 221

Co-operation, obtaining, 76, 93

Cordilura haemorhoidalis, 211

Corethra, 211

Corporations, aid anti-mosquito work, 61

Cost records, 95

Costa Rica, malaria mortality in, 7

Costs of blasting ditches, 116

of hand ditehing, 110, 111

of machine ditching, 119, 144

of maintenance, 124

of tile drainage, 131

Craig, 11

Crangon vulgaris, 211

Creosote, as a larvicide, 162

Crithidia fasciculata, 211

Crossett, Ark., demonstration at, 56

Cuba, malaria mortality in, 7

Culex fatigans, 11, 13, 36

pipiens, 39

restuans, 40

salinarius, 49

Culieinae, the, 32

Cyprinodon ealaritanus, 183

variegatus, 180

\section{$\mathrm{D}$}

Dallas, Tex., war anti-mosquito work at, 59

Demopolis, Ala., particulars of antimosquito work at, 64

Dengue, 10, 11, 14

Derivaux, 77, 206.

Dermott, Ark., demonstration at, 56

Diemyetylus tortosus, 211

Dikes, construction of, 145 
Diking, in general, 144

Diplocystis, 211

Discoglossus pietus, 211

Distribution of malaria, 5 of oil, 169

Ditch construction, 106, 140

Ditching by dynamite, 113 by hand, 107, 110, 142 by machinery, 117, 143 costs, 110, 111, 116, 124, 131, 144 required per acre of marsh, 141

Dothan, Ala., particulars of antimosquito work at, 64

Drainage, in general, 99 problems, 102

Drip-cans, 16.5

Duck-weed, 190

Dyar, 32, 43

Dyersburg, Tenn., particulars of anti-mosquito work at, 64

Dytiscus marginalis, 211

$\mathrm{E}$

Eggs, mosquito, 18, 27, 28, 34, 35, 37, $42,43,46$

Eldorado, Ark., particulars of antimosquito work at, 64

Electric Mills, Miss., demonstration at, 55

Emesa longipes, 211

Eptesicus fuscus, 212

Equipment and materials, 82

Erythemis simplicicollis, 211

Estimate of eost, the, 71

Eufala, Ala., particulars of antimosquito work at, 64

Expedients, auxiliary, 209

Expenditures record, the, 96

Exterminative measures, direct, 210

\section{F}

Farmville, N. C., particulars of anti-mosquito work at, 64

Fayetteville, N. C., war anti-

Filariae, 13 mosquito work at, 59

Filariasis, 11, 14

Filling, 13S, 144
Finlay, 51

Fish control, in general, 172 procedure in, 183

Flight, distances of mosquitoes, 17 , $29,36,37,42,44$

Flint, 51

Florence, Ala., war anti-mosquito work at, 59

Foes, animal, of mosquitoes, 211

Fordyee, Ark., particulars of antimosquito work at, 64

Fort Worth, Tex., war anti-mosquito work at, 59

Fresh-water killy, the, 179

Fuchs, 146, 149, 150, 153

Funds, raising, 74

handling of, 75

Fundulus diaphanous, 179

heteroclitus, 176

majalis, 179

notatus, 181

notii, 181

G

Gambusia affinis, 175

Gantt's Quarry, Ala., particulars of anti-mosquito work at, 64

Gies, 148, 156

Girardinus caudimaculatus, 183 poeciloides, 183

Gold-fish, the, 182

Goldsboro, N. C., particulars of anti-mosquito work at, 64

Gorgas, 51, 53

Gornan, 132

Graham, 11

Grecnville, N. C., particulars of anti-mosquito work at, 64

Greenville, S. C., war anti-mosquito work at, 59

Guatemala, yellow fever outbreak suppressed, 53

Gulfport, Miss., war anti-mosquito work at, 59

Gunasekara, 224

Haas, 206 
Hamburg, Ark., demonstration at, 56

Haptoehilus, 183

Harboring-places of the mosquito, 212,213

Harrassing the mosquito, 213

Iartsville, S. C., particulars of antimosquito work at, 64

Hattiesburg, Miss., war antimosquito work at, 59

Havana, freed of yellow fever, 51

Hayne and Barber, 163

Headlee, 15, 19, 21, 24, 43, 46, 140, $141,142,144,146,150$, 151

Hearne, Tex., particulars of antimosquito work at 64 ,

Hematocytozoa, 1

Herpetomonous algeriense, 211

Hildebrand, 173, 181, 183, 184, 187, 185,190

Hirundo ery throgasta, 211

Historical aspects of mosquito control, 50

Hoffinan, 8, 211

Horpopeza obliterate, 211

Houston, 'Tex., war anti-mosquito work at, 59

Hydra fusea, 211

viridis, 211

Hydrochloa carolinensis, $18 \mathrm{~s}$

Hydrophilus obtusatus, 211

I

India, malaria mortality in, 6

Inspection system, 79, 85

Inspector, qualifications of, 81

Inspector's daily report, 75

procedure, 86

Instrument work in drainage, 100

International Health Board, 55, 56, $60,63,69,76,205,20 \mathrm{~s}$

Iridoproene bicolor, 211

Italy, malaria mortality in, 7

rice-field problem, 224

$\mathrm{J}$

Jackson, Miss., war anti-nnosquito work at, 59
Jacksonville, Fla., war anti-mosquito work at, 59

Jacksonville, Tex., particulars of anti-mosquito work at, 64

\section{Ki}

Keltys, Tex., anti-mosquito work at, 57,58

Kierosene, as mosquito repellent, 215 for oiling, 160

Kinab, 25

Kress, Va., sereening work at, 206

\section{L}

Lake Charles, La., war anti-mosquito work at, 59, 205

Lake Village, Ark., demonstration at, $56,205,206,208,226$

Larvae, anatomy of, 24

Larvicide, the Panama, 161

Larvicides, other, 162

Laveran, 50

Leathers, 6

Legendre, 225

Lemon-juice, as a mosquito repel-

Lenert, 123

$$
\text { lent, } 215
$$

LePrince, 59, 60, 62, 64, 81, 93, 125 , $126,134,160,161,162$, $166,170,213$

Lesticocampa, 211

Licker-in wire, 193

Life, of a mosquito, 18 of a screen, 203

Lined ditches, 125

Lispa sinensis, 211

Little Rock, Ark., war anti-mosquito work at, 59

Livingston, Tex., particulars of antimosquito work at, 64

Logs, removal from streams, 136

Lonoke, Ark., war anti-mosquito work at, 59

Louisville, Ky., war anti-mosquito work at, 59

Lucania parvia, 181

Lucius americanus, 183 
Lufkin, Tex., anti-mosquito work at, 57

Lutzia bigotii, 211

\section{M}

Machine ditching, 117, 143

Macon, Ga., war anti-mosquito work at, 57

Macrogametes, 2

Madagascar, mosquito control in, 225

Maintenance costs, $12 t$ of open ditehes, 120

Malaria as a labor problem, 8 census, 68

characteristics of, 1

control in United States, 53

distribution of, 5

economic significance of, 7

history of control at Panama, 52

incidence reports, 67

mortality and morbidity, 6

parasites, 1

transmission of, 1

versus yellow fever control, 10

Malvern, Ark., particulars of antimosquito work at, 64

Mansonia perturbans, 12

Maps, 97

Mast, 179

Materials and equipment, $\$ 2$

Mauritius, malaria mortality in, 7

Measures for attacking adult mosquitoes, 210

exterminative, 210

protective, 214

Megarhinus septentrionalis, 211

Memphis, Tenn., war anti-mosquito work at, 59

Methods, auxiliary, 209

Metz, 30, 103

Microgametocytes, 2

Mignon, Ala., particulars of antimosquito work at, 64

Millington, Tenn., war antimosquito work at, 59

Minnow, the spotted top, 181 the star-headed, 181
Minnow, the top, 17.5

the variegated, 180

Mollinesia latipennia, 1s:3

Monedula siguata, 211

Montgomery, Ala., war antimosquito work at, 59

Monticello, Ark., demonstration at, 56

Mosquito, anatomy of the, 21 as an annoyance, 14

breeding about homes, $\$ 3$

identification of the, 20

in general, 17

life-history of the, 17

repellents, 215

why it bites, 19

Mloss, coon-tail, 1ss

Myiochanes virens, 211

Mvriophyllum, 1ss

\section{N}

Naias flexilis, 190

Nashville, Tenn., war anti-mosquito work at, 59

National Malaria Committee, 216

Navasota, Tex., particulars of antimosquito work at, $6 t$

Negligent citizen, the, $s i$

Nepa, 211

Net for catching fish, 1 s 6

New Orleans yellow fever outhreaks. 52

Newport News, Va., war antimosquito work at, 59

Nicaragua, malaria mortality in, 7

Niter cake as a larvicide, 162

Nosema stegomyia, 211

Notice, form of official, ss

Notonecta, 211

$\mathrm{O}$

Oil, distribution of, 169

kind of, required, 170

storage of, 169

Oiling, costs of, 170

frequency of, 168

place of in anti-mosquito work,

158 
Orange, Tex,, war anti-mosquito work at, 59

\section{P}

Panama Cinal Zone Health Department report, 127

Panama Canal Zone, malaria mortality in, 7

progress in malaria control in, 52

"swatting" the mosquito, 212

Parallel system of clitching, 140

Parham, 86

Pass Christian, Miss., war antimosquito work at, 59

Pennyroyal, oil of as a mosquito repellent, 215

Peppermint, oil of as a mosquito repellent, 215

Personnel, 80

Petersburg, Va., war anti-mosquito work at, 59

Petrochelidon lumfrous, 211

Philippine Islands, malaria mortality in, 7

Physicians, statisties from, 67

Pisobia pusillus, 211

Planning the inspection system, 85

the work, 79

Plants in relation to fish control, 188

Plasmodia, 1

Points requiring investigation, 209. 218

Policy, questions of, 73

Polygonum, 190

Pool-connecting system of ditehing, 140

Porto Rieo, malaria mortality in, 7

Portsmouth, Va., war anti-mosquito work at, 59

Progne subis, 211

Protecting homes in swamps, 223

Psorophora ciliata, 43, 211

Ptyehozoon homalecephalum, 211

Publicity, 91

Pumping, 156

Pupae, 17, 18, 24, 25
Q

Quantieo, Va., war anti-mosquito work at, 59

Quinine, for malaria, 216 treatment demonstrations, 216 versus anti-mosquito measures, 217

\section{$\mathrm{R}$}

Railroads' contributions to malaria hazards, 77

Rain-water fish, 181

Raleigh, N. C., war anti-mosquito work at, 59

Rana palustris, 211

$$
\text { pipiens, } 211
$$

Ranatra fusca, 211

Records, 95

Reports, daily, 93

Rice-field problem, the, 224

Riparis riparia, 211

Rizzi, 214

Roanoke Rapids, N. C., demonstration at, 54

Rock Creek Lumber Company antimosquito work, 64

Rose, 6

Rosenau, 4, 11, 13, 36

Ross, 6, 50

Rural mosquito eontrol, 219 protective demonstrations, 226

Rusk, Tex., partieulars of antimosquito work at, 64

\section{$\mathrm{S}$}

Salt marsh ditches, design of, 140 problem, the, 139

shrinkage, 156

Saltieus, 211

San Antonio, Tex., war anti-mosquito work at, 59

Sayornis phoebe, 211

Schizogony, 2

Screen, life of a, 203

Sereening campaign, conduct of a, 204 
Screening campaign, cost of, 205

of chimneys and fire-places, 202

of doors, 197

of porches, 201

of windows, 200

place of in anti-mosquito work, 195

Searcy, Ark., particulars of antimosquito work at, 64

Seepage outcrops, drainage of, 104

Seine for catching fish, 186

Shaw, 123, 205

Sheffield, Ala., war anti-mosquito work at, 59

Shelby, Ala., particulars of antimosquito work at, 64

Sluice-boxes, 147

Sluices, construction of, 147

specifications for large, 150

Smart-weed, 190

Smith, A. G., 129, 130, 131

Smith, John B., 140

Smudge, to repel mosquitoes, 215

Snidow, 199, 204, 206

Sources of aid, other, $7 \mathrm{~S}$

South Groveton, Tex., particulars of anti-mosquito work at, 64

Spain, malaria mortality in, 7

spartanville, S. C., war antimosquito work in, 59

Spirochaeta culicis, 211

Spirodella polyrrhiza, 190

Sporozoite, 2

Spotted top minnow, the, 181

Sprayers, 163

St. Louis \& Southwestern Railway, $56,60,205$

Stables as an attraction to mosquitoes, 214

Star-headed minnow, the, 181

Statistics, collection of, 66

Straits Settlements, malaria mortality in, 7

Stream re-channeking, 134, 135

Striped killifish, the, 179

Stromquist, 133

Sub-aqueous saw, the, 193

Substances repellent to the mosquito, 215
Sub-surface drainage, 127

Sun-fishes in anti-mosquito work, 182

Sunflower County, Miss., demonstration in, 226

Survey, the, 69, 220

Swamp home, protecting the, 223

Swamps, drainage of, 103, 110

"Swatting" the mosquito, 212

$\mathrm{T}$

Table to determine species of common American mosquitocs, 228

Tachycineta thalassina, 211

Tahydromia macula, 211

Tanypus dyari, 211

Tarbett, 196, 224

Taylor, 206

Texarkana, malaria cases at hospital, 56,57

Texts for articles, 92

Thomasville, Ga., particulars of anti-mosquito work at, 64

Tide-gate, the Calco, 153

Tide-gates, construction of, 149

in general, 147

operation of, 155

other types of, 151

Tile drainage costs, 131

drains, 127

Tiles, placing of, 130

Tools for hand ditching, 107, 142

Top minnows, 175

Topography, need of studying the, 100

Transmission of malaria, 1

of yellow fever, $S$

Trask, 5

Trenching machinery, 117, $11 \mathrm{~s}$

Trinitapoli, Italy, observations at, 211

Trinity, Tex., particulars of antimosquito work at, 64

Triton alpestris, 211

cristatus, 211

Trypanosoma culicis, 211

Tupelo, Miss., particulars of antimosquito work at, 64 
Tuscumbia, Ala., war anti-mosquito work at, 59

Tyler, 'Tex., anti-mosquito work at, 57,58

Tyrannus tyrannus, 211

$\mathrm{U}$

United States anti-mosquito war work, 58,59

Dept. of Agriculture, 8

dengue eases and deaths in, 11

malaria morbidity and mortality in, 6

Marine hospital, screening at, 203

Public Health Service, 7, 11, 53, $54,55,56,57,59,60,61$, $63,69,76,79,168,205$, $20 \mathrm{~s}$

\section{V}

Van Dine, 8, 62

Variations in eggs, larvae and pupae, 18

Variegated minnow, the, 180

Vegetation, removal of for fish control, 186

Venezuela, malaria mortality in, 7
Vertical drainage, 131

Vinegar as a mosquito repellent, 215

Virginia Beach, Va., particulars of anti-mosquito work at, 64

Von Ezdorf, 55, 212

\section{WV}

Wrater gas tar as a larvicide, 162

Water lilies as breeding-places, 189

Wrest Point, Miss., war antimosquito work at, 59

West Point, Va., particulars of antimosquito work at, 64

Williams, 137

Wilmington, N. C., war anti-mosquito work at, 59

Work order, forms, 87

I

Yellow fever, mortality and morbidity, 9

signifieance of, 14

transmission of, 8

versus malaria control, 10

Yarnell, 118, 131

Z

Zygotes, 4 




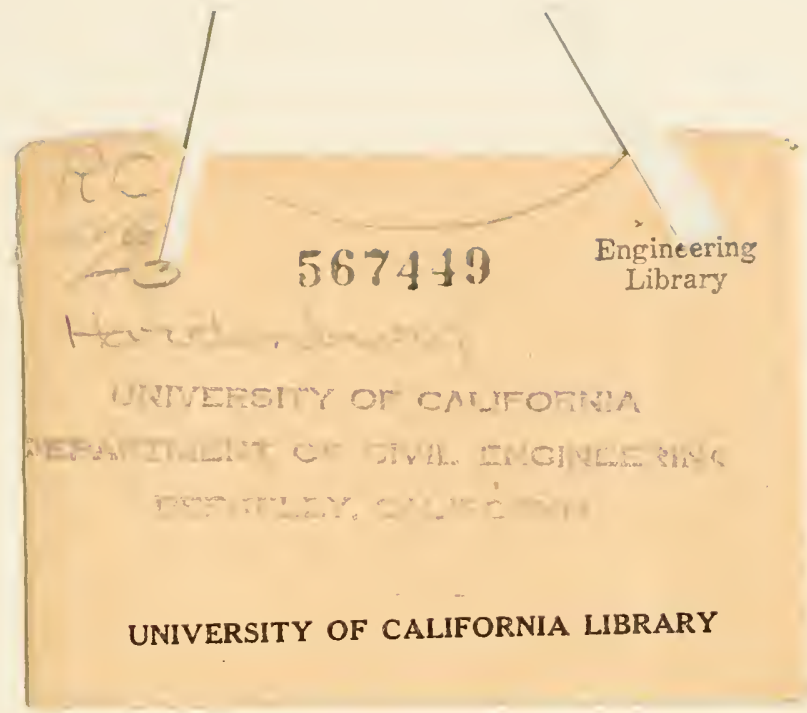


